\title{
NISTIR 88-3860
}

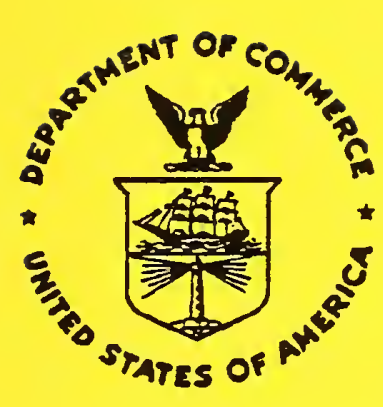

\section{The Interaction of Lighting, Heating and Cooling Systems in Buildings - Interim Report}

Stephen J. Treado and John W. Bean

U.S. DEPARTMENT OF COMMERCE

National Institute of Standards and Technology

(Formerly National Bureau of Standards)

Center for Building Technology

Building Environment Division

Gaithersburg, MD 20899

September 1988

Issued December 1988

Prepared for

U.S. Department of Energy

Office of Buildings and Community Systems

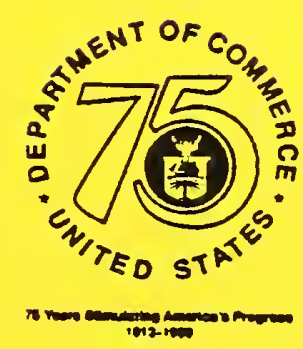




\section{The Interaction of Lighting, Heating and Cooling Systems in Buildings - Interim Report}

Stephen J. Treado and John W. Bean

U.S. DEPARTMENT OF COMMERCE

National Institute of Standards and Technology

(Formerly National Bureau of Standards)

Center for Building Technology

Building Environment Division

Gaithersburg, MD 20899

September 1988

Issued December 1988

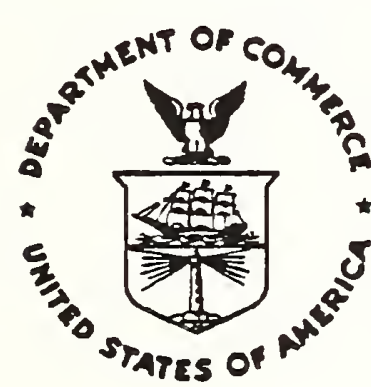

Prepared for

U.S. Department of Energy

Office of Buildings and Community Systems
National Bureau of Standards became the National Institute of Standards and Technology on August 23, 1988, when the Omnibus Trade and Competitiveness Act was signed. NIST retains all NBS functions. Its new programs will encourage improved use of technology by U.S. industry.

\section{U.S. DEPARTMENT OF COMMERCE \\ C. William Verity, Secretary}

NATIONAL INSTITUTE OF STANDARDS

AND TECHNOLOGY

Ernest Ambler, Director 


\section{Abstract}

The effect of interactions between building lighting, heating and cooling systems on the energy performance of the lighting system and cooling loads is examined, based on detailed full-scale measurement and supporting computer simulations. A test facility was designed, constructed and operated to emulate an office space with recessed fluorescent lighting. Special design features simulated adjacent building areas, providing realistic thermal boundary conditions for the test room. The test facility was extensively instrumented to monitor lighting power, cooling load, surface and air temperatures, heat flows and light levels. 398 measured parameters were averaged and recorded every two minutes during testing.

This interim report describes preliminary results from the research effort. The results showed that the lighting system can be constrained to operate at its most efficient level, if the fluorescent lamps are cooled sufficiently.

A two-term exponential relation with four regression coefficients was found to fit the measured data well. An extended set of weighting factors was derived based on the double exponential relation, and values computed from the measurements. Cooling load profiles due to cyclic operation of the lights were computed using the weighting factors. Lighting energy distribution fractions were detennined using a calibrated computer model. Design considerations are discussed.

Keywords: building energy, cooling, heat transfer, lighting, peak loads, weighting factors 
The support of the U.S. Department of Energy and the Electric Power Research of Energy and the Electric Power Research Institute to this research effort is greatfully acknowledged. The useful discussions with Reinhard Radermacher, and Tamami Kusuda are appreciated. The contribution of Ross and Baruzzini and Dubin-Bloome Association in drawing the test facility plans is acknowledged. Thanks to Beth Burdette for typing and editing the manuscript.

\section{Disclamer}

Certain manufacturers and trade names are mentioned in this report for the purpose of describing the testing facility and equipment. This does not constitute an endorsement or recommendation of such equipment, but is provided for informational purposes only. 
Page

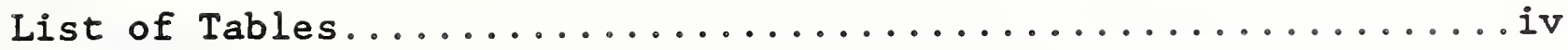

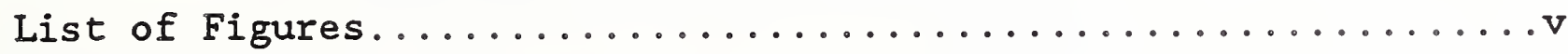

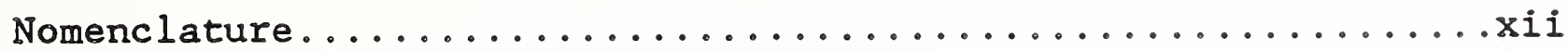

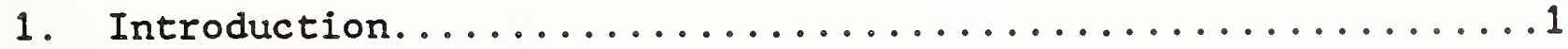

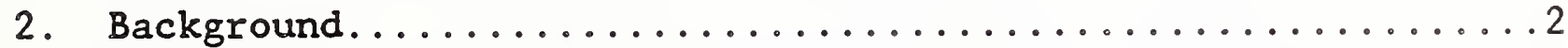

2.1 The Temperature Dependence of Fluorescent Lamps........2

2.2 Energy Distribution from Fluorescent Luminaires.........

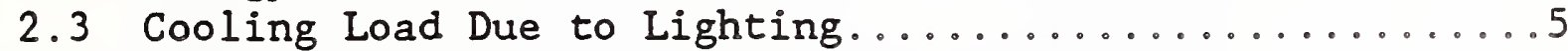

2.4 Weighting Factors and Design Procedures.............6 6

2.5 Building Energy Analysis Computer Programs...........8

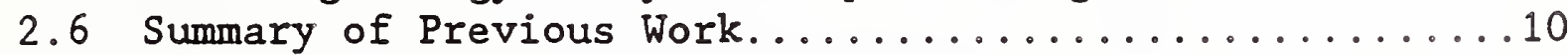

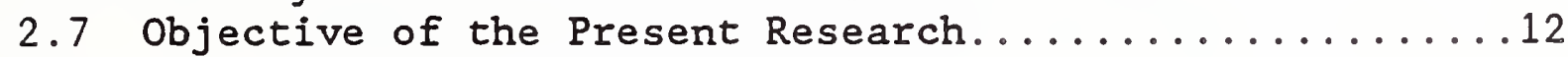

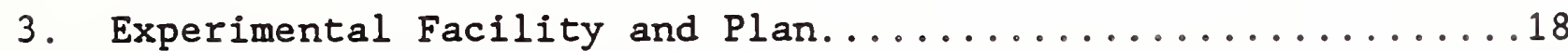

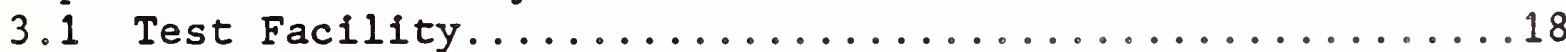

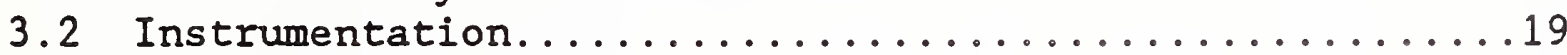

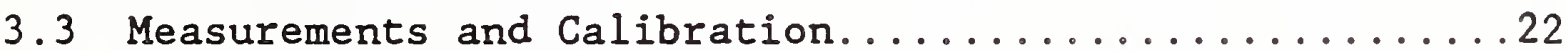

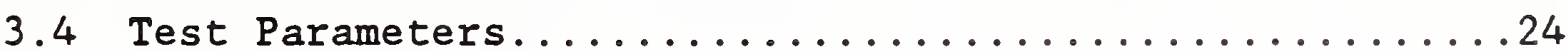

4. Computer Model of Lighting and HVAC Interaction..........38

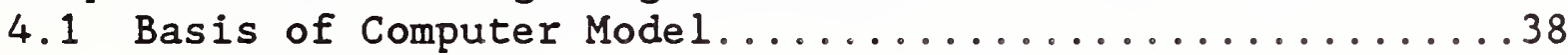

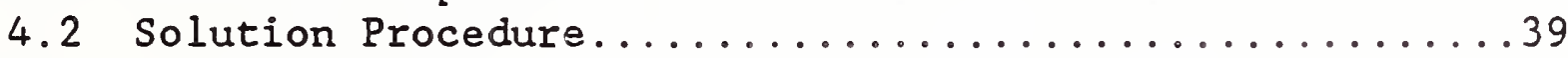

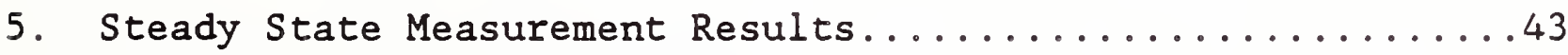

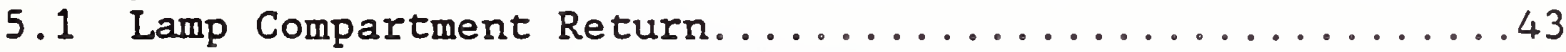

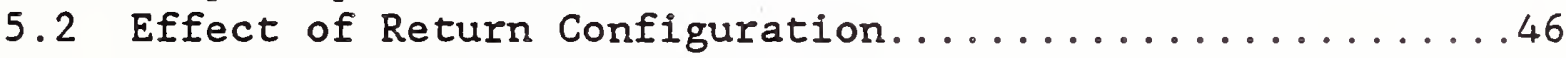

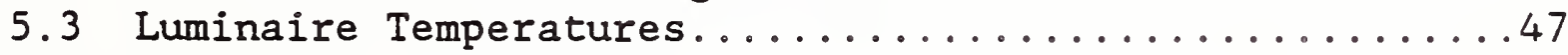

6. Transient Measurement Results....................61

6.1 Cooling Load Profiles and Regression Analysis.........61

6.2 Weighting Factors and Cooling Load Fractions.........67

6.3 Heat Storage in Room Components.................. 70

6.4 Plenum Cooling Load Fraction................... 72

7. Lighting Energy Distribution Fractions...........................

7.1 Calibration and Validation of Computer Model........113

7.2 Computer Simulation Results..................114

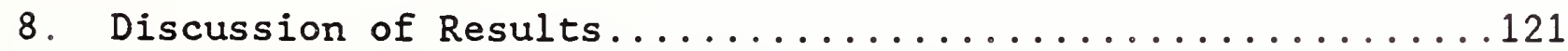

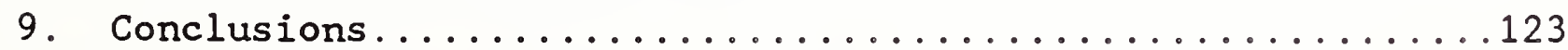

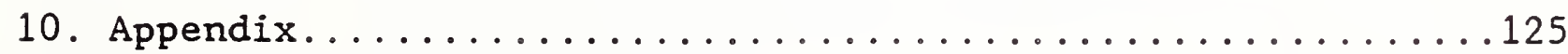

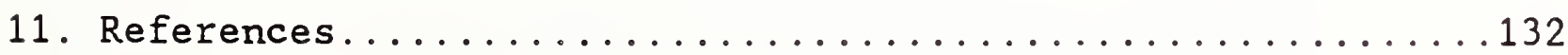




\section{List of Tables}

Table 2.1 Energy Distribution Fractions From Lighting.Systems..4

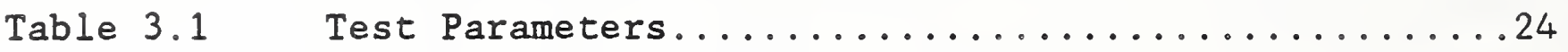

Table 4.1 Nodes for Test Facility Simulation...............38

Table 4.2 Convection Correlations for Simulations..........40

Table 6.1 Regression Coefficients for Sideslot, 200cfm Tests..65

Table 6.2 Average Regression Coefficients for each Test Condition.........................66

Table 6.3 Average Weighting Factors for each Test Condition...67

Table 6.4 Lighting Power and Peak Cooling Load...........68

Table 6.5 ASHRAE-Type Weighting Factors..............69

Table 6.6 Heat Storage Fractions in Room Components.......71

Table 7.1 Lighting Energy Distribution Fractions.........115 
Figure 2.1 Fluorescent Lamp Light Output and Power..........14 Consumption Versus Minimum Lamp Wall Temperature

Figure 2.2 Schematic Diagram of Fluorescent Lamp Components....15

Figure 2.3 Energy Distribution Fractions from Lighting Systems.16.

Figure 2.4 Cooling Load due to Step Change in Lighting........17

Figure 2.5 Cooling Load with Cyclic Operation of Lighting......17 System

Figure 3.1 Cut-away Schematic View of Test Facility.........25

Figure 3.2 Floor and Ceiling Slabs are Supported by Steel.....26 Frame

Figure 3.3 Guard Air Spaces Surrounding Test Room..........27

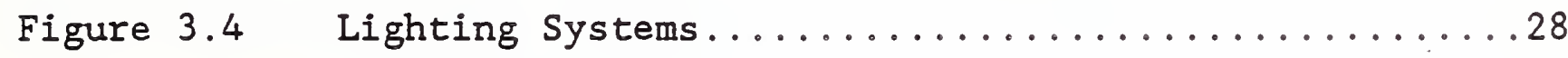

Figure 3.5 Access Doors Allow Entry to Guard Air Spaces.......29

Figure 3.6 Test Room Air Supply and Return Ducts, and Guard....30 Air Ducts

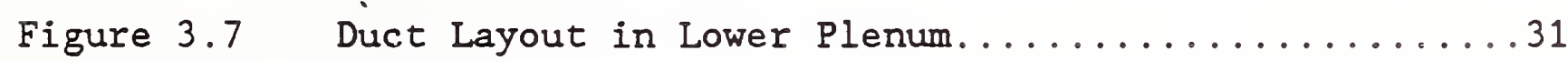

Figure 3.8 Test Room Air Temperature Thermocouple Grid.......32

Figure 3.9 Surface Temperature Measurement Grid...........33

Figure 3.10 Heat Flux Transducer Locations................ 34

Figure 3.11 Wall Guard Air Thermopile Control System Schematic..35

Figure 3.12 Cooling Load Oscillations Due to Excessively High...36 Control Loop Gain Constants

Figure 3.13 Heater Control Signal Oscillations Due to........36 Excessively High Control Loop Gain Constants

Figure 3.14 Outputs From Supply - Return Air Thermopile and....37 Wall Thermopile During Transient Test

Figure 3.15 Wall Thermopile Outputs on Expanded Scale.......37

Figure 5.1 Lighting Power Versus Room Air Temperature and....48 Airflow Rate for Lamp Compartment Return

Figure 5.2 Lighting Power Versus Average Minimum Lamp Wall...48 Temperature 
Figure 5.3

Figure 5.4

Figure 5.5

Figure 5.6

Figure 5.7

Figure 5.8

Figure 5.9

Figure 5.10

Figure 5.11

Figure 5.12

Figure 5.13 Average South Wall Temperature with Lights on......54

Figure 5.14 Average West Wall Temperature with Lights on......54 Versus Room Air Temperature and Airflow Rate

Figure 5.15 Lighting Power Versus Airflow Rate and Path.......55

Figure 5.16 Average Minimum Lamp Temperature Versus Airflow....56 Rate and Path

Figure 5.17 Plenum Air Temperature Versus Airflow Rate and.....56 Path

Figure 5.18 Ceiling Temperatures Versus Airflow Rate and Path...57

Figure 5.19 Floor Temperatures Versus Airflow Rate and Path....57

Figure 5.20 North Wall Temperature Versus Airflow Rate and.....58 Path

Figure 5.21 East Wall Temperature Versus Airflow Rate and Path..58 

Figure 5.22 $\begin{aligned} & \text { South Wall Temperatures Versus Airflow Rate and.....59 } \\ & \text { Path }\end{aligned}$

Figure 5.23 West Wall Temperatures Versus Airflow Rate and.....59 Path

Figure 5.24 Luminaire Temperatures During Lights on Step.....60 Change Test

Figure 5.25 Luminaire Temperatures During Lights off Step......60 Change Test

Figure 6.1 Measured Cooling Load and Lighting Power for......73 Back-to-Back Lights on and Lights off Tests

Figure 6.2 Adjusted Cooling Loads..................73

Figure 6.3 Measured Cooling Load and Lighting Power Versus.... 74 Single Exponential Regression Fit, CG160 On

Figure 6.4 Calculated Minus Measured Cooling Load, CG160 On...74

Figure 6.5 Measured Cooling Load Versus Double Exponential....75 Regression Fit, CG160 On

Figure 6.6 Measured Cooling Load and Lighting Power Versus.... 75 Single Exponential Regression Fit, CG160 off

Figure 6.7 Initial Transient, CG160 off..............76

Figure 6.8 Measured Cooling Load Versus Double Exponential....76 Regression Fit, CG160 off

Figure 6.9 Measured Cooling Load and Lighting Power Versus....77 Single Exponential Regression Fit, CG120 On

Figure 6.10 Measured Cooling Load and Lighting Power Versus.... 77 Double Exponential Regression Fit, CG120 On

Figure 6.11 Measured Cooling Load and Lighting Power Versus....78 Single Exponential Regression Fit, CG200

Figure 6.12 Initial Transient, CG200.................

Figure 6.13 Measured Cooling Load Versus Double Exponential....79 Regression Fit, CG200

Figure 6.14 Measured Cooling Load and Lighting Power Versus....79 Single Exponential Regression Fit, SS120 On

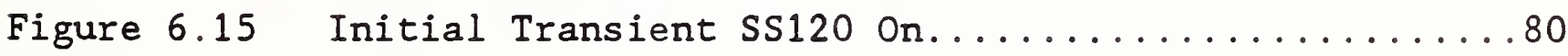

Figure 6.16 Measured Cooling Load Versus Double Exponential....80 Regression Fit, SS120 On 
Figure 6.17 Measured Cooling Load and Lighting Power Versus....81 Single Exponential Regression Fit, SS120 off

Figure 6.18 Initial Transient, ss120 off...............81

Figure 6.19 Measured Cooling Load Versus Double Exponential....82 Regression Fit, SS120 off

Figure 6.20 Measured Cooling Load and Lighting Power Versus.... 82 Single Exponential Regression Fit, SS160 On

Figure 6.21 Initial Transient, ss160 On................83

Figure 6.22 Measured Cooling Load Versus Double Exponential....83 Regression Fit, SS160 On

Figure 6.23 Measured Cooling Load and Lighting Power Versus....84 Single Exponential Regression Fit, SS160 off

Figure 6.24 Initial Transient, ss160 off................84

Figure 6.25 Measured Cooling Load Versus Double Exponential....85 Regression Fit, SS160 Off

Figure 6.26 Measured Cooling Load and Lighting Power Versus....85 Single Exponential Regression Fit, SS200 On

Figure 6.27 Initial Transient, ss200 On................

Figure 6.28 Measured Cooling Load Versus Double Exponential....86 Regression Fit, SS200 On

Figure 6.29 Measured Cooling Load and Lighting Power Versus....87 Single Exponential Regression Fit, SS200 off

Figure 6.30 Initial Transient, ss200 off...............87

Figure 6.31 Measured Cooling Load Versus Double Exponential....88 Regression Fit, SS200 off

Figure 6.32 Measured Cooling Load and Lighting Power Versus....88 Single Exponential Regression Fit, LC120 off

Figure 6.33 Initial Transient, LC120 off...............89

Figure 6.34 Measured Cooling Load Versus Double Exponential....89 Regression Fit, LC120 off

Figure 6.35 Measured Cooling Load and Lighting Power Versus....90 Single Exponential Regression Fit, LC160 On

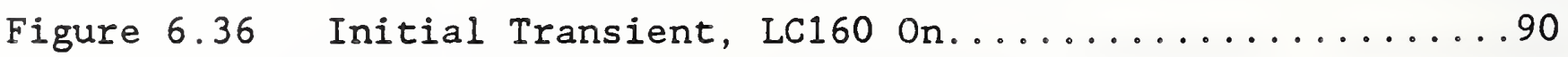

Figure 6.37 Measured Cooling Load Versus Double Exponential....91 Regression Fit, LC160 On 
Figure 6.38 Measured Cooling Load and Lighting Power Versus.....91 Single Exponential Regression Fit, LC160 off

Figure 6.39 Initial Transient, IC160 off.................

Figure 6.40 Measured Cooling Load Versus Double Exponential....92 Regression Fit, LC160 off

Figure 6.41 Measured Cooling Load and Lighting Power Versus....993 Single Exponential Regression Fit, LC200 off

Figure 6.42 Initial Transient, LC200 off...............93

Figure 6.43 Measured Cooling Load Versus Double Exponential.... 94 Regression Fit, LC200 off

Figure 6.44 Comparison of Cooling Load Profiles From.........994 Different Tests with Same Conditions

Figure 6.45 Regression Coefficients Versus Airflow Rate......95

Figure 6.46 Regression Coefficients A, B and C Versus Airflow...95

Figure 6.47 Regression Coefficient A Versus Airflow.........96

Figure 6.48 Regression Coefficient B Versus Airflow.........96

Figure 6.49 Regression Coefficient C Versus Airflow..........97

Figure 6.50 Regression Coefficient D Versus Airflow..........97

Figure 6.51 Cooling Load Profiles for Ceiling Grill Return.....98

Figure 6.52 Cooling Load Profiles for Ceiling Grill Return.....98

Figure 6.53 Cooling Load Profiles for Ceiling Lamp...........99 Compartment Return

Figure 6.54 Cooling Load Profiles for Ceiling $120 \mathrm{cfm}$ Airflow...99

Figure 6.55 Cooling Load Profiles for Ceiling $160 \mathrm{cfm}$ Airflow..100

Figure 6.56 Cooling Load Profiles for Ceiling $200 \mathrm{cfm}$ Airflow..100

Figure 6.57 Cooling Load One Hour After Lights are Energized...101

Figure 6.58 Weighting Factor $a_{0}$, Versus Airflow...........101

Figure 6.59 Weighting Factor a Versus Airflow............102

Figure 6.60 Weighting Factor a2 Versus Airflow............102

Figure 6.61 Weighting Factor b versus Airflow............103 
Figure 6.62 Weighting Factor b Versus Airflow.............103

Figure 6.63 Hourly Cooling Load Fractions for Four Days.......104

Figure 6.64 Hourly Cooling Load Fractions Versus Airflow Rate..104 for Ceiling Grill

Figure 6.65 Hourly Cooling Load Fractions Versus Airflow Rate..105 for Side Slots

Figure 6.66 Hourly Cooling Load Fractions Versus Airflow Rate..105 for Lamp Compartment

Figure 6.67 Hourly Cooling Load Fractions Versus Airflow Rate..106 for Average Conditions

Figure 6.68 Cooling Load Profiles Versus Airflow for Ceiling...106 Grill

Figure 6.69 Cooling Load Profiles Versus Airflow for Side.....107 Slots

Figure 6.70 Cooling Load Profiles Versus Airflow for Lamp.....107 Compartment

Figure 6.71 Cooling Load Fractions with Original and Adjusted..108 Weighting Factors, CG200

Figure 6.72 Cooling Load Fractions with Original and Adjusted..108 Weighting Factors, SS160

Figure 6.73 Cooling Load Fractions with Original and Adjusted..109 Weighting Factors, SS160

Figure 6.74 Total Heat Storage Versus Airflow Rate and........109 Return Configuration

Figure 6.75 Heat Flow Sensor Readings for Floor and Walls.....110 During Back-to-Back Lights on and Lights off Tests

Figure 6.76 Plenum Heat Pickup Fraction Versus Airflow Rate....110 and Return Air Configuration

Eigure 6.77 Plenum Fraction Versus Time for $160 \mathrm{cfm}$, Ceiling...111 Grill Return

Figure 6.78 Plenum Fraction Versus Time for $160 \mathrm{cfm}$, Side.....111 Slot Return

Figure 6.79 Plenum Fraction Versus Iime for $160 \mathrm{cfm}$, Lamp.....112 Compartment Return

Figure 7.1 Comparison of Measured and Simulated Cooling......116 Loads, Ceiling Return, 120 cfm 
Figure 7.2 Comparison of Measured and Simulated Cooling......116 Loads, Ceiling Return, 200 cfin

Figure 7.3 Comparison of Measured and Simulated Cooling......117 Loads, Lamp Compartment Return, $120 \mathrm{cfm}$

Eigure 7.4 Comparison of Measured and Simulated Cooling.

Loads, Lamp Compartment Return $200 \mathrm{cfm}$

Figure 7.5 Iighting Energy Distribution Fractions Versus.....118 Time, Ceiling Return, 120 cfm

Eigure 7.6 Lighting Energy Distribution Fractions Versus.....118 Iime, Lamp Compartuent Return, 120 cfm

Eigure 7.7 Iighting Energy Distribution Eractions Versus.....110 Iime, Ceiling Return, $120 \mathrm{cFm}, 80^{\circ} \mathrm{F}$

Eigure 7.8 Cooling Load Profile for Heavy Therwal Mass.......119 Room, Ceiling Return, $120 \mathrm{cfm}$

Figure 7.9 Iighting Energy Distribution Eractions Versus.....120 Tine, Heavy Thermal Mass Room, Ceiling Rezurn, $120 \mathrm{cfm}$ 


\section{Nomenclature}

$A, B, C, D$ - curve fitting constants

$A F$ - supply and return airflow rate

$A_{i}$ - area of node $i$

$a_{0}, a_{1}, a_{2}, b_{1}, b_{2}$ - weighting factors

$B_{i}$ - radiosity of node $i$

$C, C_{0}$ - tracer gas concentrations

$C_{i}$ - thermal capacitance at node $i$

$\mathrm{CK}_{\mathrm{i}}$ - conduction heat gain at node $\mathrm{i}$

$C_{p}$ - specific heat of air

e - error signal

$E B_{i}$ - black body equivalent thermal radiation power of node $i$ $E M_{i}$ - emittance of node $i$

$F_{1 j}$ - radiation shape factor between nodes $i$ and $j$

G - transfer function

h - convection coefficient

$\mathrm{HC}_{i}$ - convection coefficient at node $i$

Hi - irradiance at node i

I - infiltration rate

$k$ - sample number

$\mathrm{K}_{\mathrm{I}}$ - integral gain constant

$K_{i j}$ - conductance between nodes $i$ and $j$

$\mathrm{K}_{\mathrm{p}}$ - proportional gain constant

m - mass

m - mass flow rate of supply air

Q - cooling load

$\mathrm{QC}_{i}$ - convection heat gain at node $\mathrm{i}$ 
$\mathrm{QRN}_{i}$ - net thermal radiation at node $i$

$\mathrm{QS}_{\text {I }}$ - heat storage at node $\mathrm{i}$

$Q V_{i}$ - visible light watts incident on node $i$

s - Laplace transform variable

$s_{i}$ - fraction of visible light absorbed by node $i$

$t$ - time

$T$ - time increment

$T_{\text {air }}$ - air temperature

TAO - time increment

$T_{i}$ - temperature of node $i$

$T_{M L W}$ - minimum lamp wall temperature

$T_{\text {RET }}$ - return air temperature

$T_{\text {sup }}$ - supply air temperature

VW - light output in watts

W - lighting power

$z$ - z transform variable

$\Delta \mathrm{m}$ - change in control signal

$\Delta T$ - temperature difference

$\sigma$ - Stefan - Boltzmann constant

$\rho$ - density of standard air 
-

$$
\text { . }
$$




\section{Introduction}

Lighting in commercial buildings is the single largest user of electric energy, typically ranging from 25 to 50 percent of total building electrical energy requirements. In $1980,2.8$ (1015) Btu of energy was used for lighting for a total cost of over 40 billion dollars annually[Un85]. An overall increase in lighting efficiency of one percent would produce a savings of 400 million dollars a year.

The performance of the dominant commercial light source, the fluorescent lamp, is strongly dependent on thermal conditions, with both lamp light output and power consumption. varying with minimum lamp wall temperature as much as 20 percent under typically encountered conditions. Proper control of room thermal conditions can ensure that the lamps are operating at their most efficient level.

In addition to the electrical energy purchased and used for lighting itself, heat dissipated from the lighting system adds to the building cooling load in summer, and decreases the heating requirements in winter. Controlling peak cooling loads in summer is of particular interest to electric utilities which have to reduce summer peaks at any cost to control peak electric power demands on hot summer afternoons. Due to finite electric power generation resources, steady electric power demands make most efficient use of electric power generation facilities. The capital cost of expansion of generating capacity has, in turn, led to greater costs to the user in the form of demand charges and ratchet clauses. A demand charge usually takes the form of a higher unit cost for electrical power during periods of heavy system - wide usage. Demand charges frequently are assessed from late morning through early evening.

A ratchet clause ties the unit cost for electric power for the entire year to the maximum electric power demand over a specified interval. The interval might be several hours or longer during periods of heavy usage. With this sort of clause, even a single day of excessive electrical demand could result in significant increases in the total annual cost of lighting energy. Higher peak cooling loads also require larger equipment sizes to maintain comfort conditions, resulting in higher first costs.

Thus, both energy efficiency and cost considerations stand as motivating factors for the conduct of this research project. The objective of this research is to determine energy transfer from lighting systems to building spaces and thermal equipment as influenced by typical operating conditions and equipment configurations, and to develop procedures to promote the design of efficient lighting and HVAC systems, leading to energy and cost savings. A combination of detailed full scale measurements of lighting and HVAC performance and related computer simulations forms the basis of the approach to these issues. This interim report describes the results obtained to date on this ongoing research effort. A final report will be forthcoming following completion of the work. 


\section{Background}

The need to conserve finite energy resources has led to increased efforts to maximize the efficiency of lighting, heating and cooling systems in buildings. A major step in this regard has been the integration of the light sources, or luminaires, with the air distribution system[Be77, Bo77, Fi76, We71, No69]. Using supply or return air to cool a fluorescent luminaire can raise lamp efficacy, defined as the amount of visible light produced per unit of electric energy consumed (and dissipated into the building space). In fact, both the light output and power consumption, and thus efficacy, of a fluorescent lamp vary with lamp wall temperature. Fluorescent luminaires currently dominate the commercial building sector, and are the focus of this study.

There are two major issues associated with the interaction of lighting and HVAC systems in buildings. One issue is the energy performance of the combined system. Energy for lighting will be minimized if the luminaires are operated at their optimum temperature. The total heat gain to the building space from the luminaire would also be minimumized at this condition, meaning minimum cooling loads from lighting. Luminaire temperatures are determined by the total room thermal environment, including air and surface temperatures, and airflow rates.

The second issue relates to the peak cooling loads due to lighting. When a lighting system is switched on, all of the electrical power input does not show up as cooling load immediately, because of heat storage in building components, plenum air (if any) and the luminaires themselves. of course, once the lights are turned off, the stored heat will be dissipated to the room air and eventually appear as cooling load. The result is the same total cooling load, but a lower peak load. Thus, peak cooling loads due to lighting can be controlled by channeling some of the energy dissipated by the luminaire into components such as floor and ceiling slabs, walls and furnishings, thereby redistributing the cooling load due to lighting over a longer period of time.

The capability of storing heat from the lighting system in the room components is a function of luminaire type and location, airflow configuration and thermal storage characteristics of available storage elements. Massive, heavyweight building constructions can store more energy, thereby moderating peak cooling loads to a greater extent.

The key to taking advantage of the thermal interactions between the lighting system, the HVAC system, and the building to control energy usage and peak cooling loads lies in understanding the energy distribution from the lighting both under steady and fluctuating operating conditions. The first step is to examine the temperature dependence of the fluorescent lamps.

\subsection{The Temperature Dependence of Fluorescent Lamps}

The popularity of the fluorescent luminaire can be traced to the relatively high luminous efficacy (approximately 70 lumens/watt) of fluorescent lamps, their large surface area, cool operation, and long life[Lu38]. The fluorescent lamp is an electric discharge source consisting of a glass tube containing mercury vapor at low pressure( 6 - 
$10 \mu \mathrm{m}$ of mercury) and an inert gas, such as argon at a higher pressure $(\sim 2-3 \mathrm{~mm})$ of argon [Mu85]. Light is produced when current flows between electrodes at opposite ends of the tube creating an arc through the mercury and generating ultraviolet radiation, which in turn is transformed into visible radiation by fluorescent materials (phosphors) on the inner tube walls. The primary wavelength of energy generated by a mercury discharge is $253.7 \mathrm{~nm}$. The phosphors are selected to respond most efficiently at that wavelength. Fluorescent lamps must be operated in series with a current limiting device called a ballast, which also provides the required starting and operating lamp voltages.

The performance characteristics of fluorescent lamps are extremely sensitive to temperature conditions, due to the effects on mercury vapor pressure within the lamp. A fluorescent lamp contains more liquid mercury than will become vaporized under typical operating conditions. Any excess mercury tends to condense at the coldest spot on the lamp wall. Thus the mercury vapor pressure varies with the minimum lamp wall temperature. Changes in mercury vapor pressure affect both the light output and power consumption of a fluorescent lamp.

Maximum light output and power consumption occur when the lamp cold spot is approximately $100^{\circ} \mathrm{F}$, although they do not necessarily occur at exactly the same temperature, as shown in figure 2.1. Maximum lamp luminous efficacy also occurs near $100^{\circ} \mathrm{F}$. The exact temperature dependence of different lamps varies somewhat, but all display the same general behavior as shown in figure 2.1[Ie72].1 As lamp wall temperature decreases, light output and power consumption drop due to a suppression of the mercury arc. The result is a one percent decrease in efficacy for each $1.5^{\circ} \mathrm{F}$ decrease in lamp wall temperature. As lamp wall temperature increases above $100^{\circ} \mathrm{F}$, more mercury vaporizes, the mean free path decreases and the proportion of elastic collisions increases. There is also more extinction of radiation. The net effect is a one percent decrease in efficacy for each $2.5^{\circ} \mathrm{F}$ increase in lamp wall temperature [Mu85].

Other factors also influence fluorescent lamp performance including lamp length and diameter, lamp loading and argon pressure. However, these other factors are usually fixed for a particular lamp installation, and not dependent on the thermal conditions. On the other hand, the thermal conditions to which a fluorescent luminaire, that is the lamp and fixture combination, is exposed can significantly alter lamp temperature, and thus, lamp performance. These thermal conditions include air temperatures, airflow conditions near the luminaire and thermal radiation exchange with surrounding surfaces. It is important to note that the thermal environment is somewhat under the control of the building designer, allowing it to be tailored to promote efficient luminaire operating conditions.

\subsection{Energy Distribution From Fluorescent Luminaires}

All of the power input to the lighting system eventually is dissipated into the building space. About 15 percent of the power input to the chapter.

${ }^{1}$ The figures for each chapter are located at the end of each 
luminaire is consumed by the ballast before reaching the lamp. The balance of input power goes to the lamps. Under typical steady state conditions, about 21 percent of the input power to a fluorescent lamp is radiated as visible light, while 37 percent is infrared radiation and 42 percent convective exchange with the air surrounding the luminaire [Ie72]. The exact values of these energy distribution fractions vary with the thermal conditions.

When the lighting system is initially energized, some of the input energy is stored in the luminaire. A fluorescent luminaire consists of four main components, as shown in figure 2.2. In addition to the lamps and ballast, these are the metal housing and the lens or diffuser. A luminaire lens is usually fabricated from acrylic plastic with a prismatic textured design to distribute the light from the lamps. In contrast, a diffuser is an open framework of metal or plastic, frequently with large parabolic cells to direct the light from the lamps. A luminaire with an acrylic lens creates an enclosed lamp compartment, while a parabolic diffuser allows air to circulate freely between the lamp compartment and the surrounding environment.

As mentioned earlier, the light output from the lamps is a function of minimum lamp wall temperature. Once steady luminaire temperatures are achieved, which may take several hours, the remaining input power is dissipated to the surroundings by infrared radiation exchange and convective or conductive heat transfer. The convective fraction is dependent on airflow conditions at the luminaire. In some cases, the ventilation system is utilized to circulate air through the lamp compartment, or through slots at the perimeter of the luminaire, to help cool the lamps by increasing the convective heat transfer [Be77, Bo77, Mu62]. Thus the airflow rate and configuration affect the radiant and convective heat dissipation fractions.

Frequently, lighting systems in commercial buildings are in a recessed mounting above a suspended ceiling, in a plenum space. In that configuration, energy transfer can occur to both the room below the suspended ceiling, and the plenum above. The plenum may also be used to channel return air from the room to the circulation fan duct inlet. Table 2.1 summarizes the various energy transfer fractions from a lighting system to the surrounding environment, including the room, ceiling and plenum.

\section{Table 2.1 Energy Distribution Fractions from Lighting System}

1. Visible light to room

2. Visible light to plenum

3. Convection to room air

4. Convection to plenum air

5. Convection to return air

6. IR radiation to room

7. IR radiation to plenum

8. Conduction to suspended ceiling

9. Stored in luminaire

Figure 2.3 displays these energy distribution fractions schematically. The values of each of the fractions influences the cooling load profiles due to transient or cyclic operation of the lighting system. Knowledge 
of these fractions is necessary to accurately determine cooling loads for equipment design purposes. As will be described later in this chapter, building energy analysis computer programs require the values of these fractions as input parameters.

\subsection{Cooling Load Due to Lighting}

There are several factors which influence the cooling load due to lighting. The luminous efficacy of the lighting system determines the amount of heat dissipated into the building space to provide the required light levels. Less efficient lighting systems use more energy to provide the same. light levels; consequently, more heat must be removed from the building space to maintain comfort conditions. Cooling load profiles due to cyclic operation of the lights are also dependent on the thermal storage characteristics of the room and plenum.

It has been observed that the cooling load due to a step change in lighting power can be approximated by an exponential relation[Ki68]. If the lighting system is suddenly energized in a room at thermal equilibrium, the cooling load $Q$ is related to lighting power $W$ according to:

$$
\frac{Q(t)}{W}=1-A e^{-B t}
$$

where: $\quad t=$ time

$A, B=$ curve fitting constants

Figure 2.4 displays this relation graphically. The values of $A$. and $B$ can be determined from measurements, or detailed calculations. Equation 2.1 approximates the cooling load when the lights are initially turned on by assuming an instantaneous cooling load equal to 1-A. This represents heat dissipation from the lighting system directly into the return air. In actuality, the initial rise in cooling load is steep but requires a finite time interval to reach the value of $1-\mathrm{A}$.

If the lighting system is operated on a cyclic (i.e. daily) schedule and the room has any appreciable thermal mass, the cooling load due to lighting will not yet equal the total lighting power when the lights are turned off. All or part of the heat from the lights which had been stored in the room components will be discharged to the room air, thus contributing to cooling load, as long as the circulation fan and cooling system are in operation. This general effect is shown in figure 2.5. For an interior office space in which no heat is lost through the exterior envelope, the total daily cooling load is the same whether or not any heat storage occurs. Peak cooling loads, however, can vary significantly depending on the heat storage characteristics of the room and plenum. In most buildings, all of the heat stored in the thermal mass of the building space will not be reclaimed during the period in which the lights are turned off. Thus when the lights are turned back on the next day, less storage capacity is available, and cooling loads are higher. Eventually, after a number of cycles, the cooling load profile reaches a steady periodic condition, and the actual peak cooling load is determined. 


\section{4 Weighting Factors and Design Procedures}

Building designers need to be able to predict cooling loads in order to determine equipment sizes, both for fans and cooling equipment. There are many heat sources which contribute to cooling loads in buildings, including lighting, equipment, solar gains and envelope heat gain. The usual approach to determining total peak cooling loads has been to determine the cooling load profile due to each source separately, and then to combine them to determine the peak concurrent cooling load. One of the most widely used methods of achieving this involves weighting factors.

Weighting factor techniques result from the application of $z$-transform procedures to transient heat transfer phenomena. The $z$-transform is, of course, useful for describing processes which are evaluated at discrete time intervals, such as sampled-data systems. In this application, cooling load is usually calculated at intervals of one hour. In this manner, a continuous cooling load profile, such as that given in equation (2.1) is transformed into a sequence of hourly values. The cooling load response due to a series of lighting step changes, either off or on, can be calculated once the weighting factors are known.

An exponential relation of the type given in equation (2.1) (i.e. 1 - A $\exp$ (- Bt) leads to a discrete time series relating cooling load to the time history of cooling load and lighting power, according to the following derivation.

Equation 2.1 represents the output (cooling load) response to a step change in input lighting power. Thus, in $z$ space

$$
Q(z)=G(z) W(z)
$$

where: $\quad G(z)=z$-transfer function

$$
\begin{aligned}
& z=e^{T s} \\
& \mathrm{~T}=\text { time increment } \\
& s=\text { Laplace variable }
\end{aligned}
$$

$G(z)$ is simply the function which relates input to output. A unit step change in lighting has a $z$-transform of

$$
W(z)=\frac{z}{z-1}
$$

while the $z$-transform of the output is

$$
Q(z)=\frac{z}{z-1}-\frac{A z}{z-e^{-B T}}
$$

Solving for $G(z)$ we obtain:

$$
G(z)=\frac{Q(z)}{W(z)}=1-\frac{A z^{2}-A z}{z^{2}-z e^{-B T}}
$$


Combining terms, equation 2.5 leads to

$$
G(z)=\frac{(1-A) z^{0}+\left(A-e^{-B T}\right) z^{-1}}{1-\left(e^{-B T}\right) z^{-1}}
$$

The weighting factors are defined by the coefficient of the $z$ terms in equation 2.6 , as follows:

$$
\begin{aligned}
& a_{0}=1-A \\
& a_{1}=A-e^{-B T} \\
& b_{1}=e^{-B T}
\end{aligned}
$$

Thus equation 2.6 can be written

$$
G(z)=\frac{Q(z)}{W(z)}=\frac{a_{0} z^{0}+a_{1} z^{-1}}{1-b_{1} z^{-1}}
$$

Finally, transforming equation 2.8 back into the time domain produces:

$$
Q(t)=a_{0} W(t)+a_{1} W(t-T)+b_{1} Q(t-T)
$$

Equation 2.9 allows the calculation of cooling load at any time step based on the current lighting power and the lighting power and cooling load from the previous time step.

While equation 2.9 corresponds exactly to equation 2.1 , in reality equation 2.1 does not accurately reflect cooling load during the first two or three hours of a step response test[Mi74]. This is due to the presence of other short term transients. According to equation 2.9, an instantaneous cooling load occurs, equal to $1-\mathrm{A}$, as soon as the lights are energized. This overestimates cooling load during the initial time steps. One technique to improve the accuracy of the cooling load prediction is to drop the $a_{0}$ term in equation 2.9 and replace it with an a2 term [Mi74]. While the resulting relation no longer corresponds exactly to equation 2.1 , it was judged to be more representative of the actual cooling load profile. The adjusted relation is:

$$
Q(t)=a_{1} W(t-T)+a_{2} W(t-2 T)+b_{1} Q(t-T)
$$

The values of the weighting factors for equation 2.10 are as follows:

$$
\begin{aligned}
& \mathrm{a}_{1}=\mathrm{Q}(1) / \mathrm{W}(1)=1-\mathrm{Ae}^{-\mathrm{B}(1)} \\
& \mathrm{a}_{2}=1-\overline{a_{1}}-\mathrm{b}_{1} \\
& \mathrm{~b}_{1}=\mathrm{e}^{-\mathrm{B}(1)}
\end{aligned}
$$


where: the substitution $t=1$ has been made

The value of $a_{2}$ results from the fact that at $t=\infty$, cooling load equals lighting power.

Equations 2.10 and 2.11 are the basis for the cooling load due to lighting calculation procedures found in the ASHRAE Handbook of Fundamentals [As77]. Values for the weighting factors are listed for various room constructions, lighting system types and airflow rates. Also, cooling load factors (CLF's) are listed in tabular form for various lighting daily cycles (i.e. $8,10,12$ hours on). These were determined directly from the weighting factors.

The weighting factors themselves were determined from measurements and analytical procedures. A series of measurements were carried out at the National Research Council Canada [Mi71, Mi73, Mi74], along with some transient thermal modeling [Mi78, Mi83]. The basic measurements consisted of monitoring the cooling load due to a step change in lighting in a room size calorimeter. The values of the weighting factors were determined from the values of $A$ and $B$ in equation 2.1. The $A$ and $B$ values can be determined as follows. For a lights - on test:

$$
\begin{aligned}
& \frac{Q}{W}=1-A e^{-B t} \\
& \ln \left[1-\frac{Q}{W}\right]=\ln A-B t
\end{aligned}
$$

For a lights - off test:

$$
\begin{aligned}
& \frac{Q}{W}=A e^{-B t} \\
& \ln \left(\frac{Q}{W}\right)=\ln A-B t
\end{aligned}
$$

Equations 2.13 and 2.15 enable the determination of $A$ and $B$ using least squares linear regression, where:

$$
Y=a+b t
$$

and

$$
\begin{aligned}
& Y=\ln \left(1-\frac{Q}{W}\right) \text { or } \ln \left(\frac{Q}{W}\right) \\
& a=\ln A, A=e^{a} \\
& b=-B, B=-b
\end{aligned}
$$

\subsection{Building Energy Analysis Computer Programs}

With the advent of modern digital computers, building designers have added new tools to their arsenal of techniques for evaluating building performance. In particular, computer programs have been developed to calculate building energy usage for hourly or other periodic time 
increments. These programs calculate cooling, heating and lighting loads for transient heat storage, and heat gains due to building envelope heat transfer, internal equipment and occupancy factors. Two of the more widely utilized programs are BLAST (Building Loads Analysis and System Thermodynamics) [Hi79] and DoE-2 [Do79].

These two programs fall into two general categories according to their basic solution procedure. BLAST, and other similar programs, are based on heat balance calculations. Following this technique, the building space is divided into elements which can communicate by conduction, convection, or radiation. The sum of all heat transfer to each element is computed for each time step. Any net heat gain results in an increase in temperature of the element, or a cooling load if the nodal temperature is held constant. A net heat loss causes a heating load.

Computer programs like DoE-2 use weighting factors to determine building energy usage. Separate weighting factors are used for each heat source, such as lighting, electric equipment, solar heat gain and exterior thermal heat transfer. Tables of weighting factors are stored for various constructions or custom weighting factors can be computed when needed.

For either type of computer program, the simulation of lighting system performance and related heat gains is accomplished by using user input values. Constant values are input by the program user regarding maximum lighting power and the lighting energy distribution fractions, such as percentages of lighting input power which reach the room as visible radiation, infrared radiation or convection, or enter the return air directly. These values are treated as constants for the duration of a simulation. A lighting schedule is also specified which determines the fraction of the lighting power which is energized for each hour. This accounts for switching of the lights due to occupancy patterns.

The use of constant values for the lighting energy distribution fractions may be adequate for many applications of BLAST and DoE- 2 . However, there are some drawbacks to this approach which may prove to be substantial in many instances. First, the selection of the appropriate values for the fractions is difficult since the fractions are dependent on the thermal conditions and room configuration. Thus, they are dependent variables. Limited data are available to assist the selection of the fraction values. Second, the lighting energy fractions are not constants, but vary with the thermal conditions, especially airflow rates and temperature. The use of constant fractions means that the distribution of lighting energy is assumed to be fixed regardless of operation of the HVAC system. Third, maximum lighting power is assumed to be constant, disregarding the lamp temperature dependence. As a result, the calculation of cooling load due to lighting is subject to a uncertainty of five to fifteen percent at best, and even greater uncertainty if inappropriate lighting energy fraction values are used as input parameters.

The lack of sensitivity of BLAST and DoE-2 to lighting and HVAC interaction effects minimizes the usefulness of these programs for evaluating and comparing different lighting and HVAC system design alternatives. One approach to alleviating this deficiency would be to change the lighting energy fractions from constant values to variables 
which are functions of other simulation variables. The most logical variables would be room air temperature, mean room surface temperature and airflow rate.

\subsection{Summary of Previous Work}

Lighting system performance and its relation to room thermal conditions has been a subject which has attracted attention since the development of fluorescent lamps. The initial emphasis was on ensuring adequate light levels at the expected operating conditions. With the advent of mechanical cooling, the determination of cooling loads due to lighting became a subject of interest. More recently, increasing energy costs and limited electrical power generating capacity have led to increased interest in the development of efficient lighting systems and the control of peak cooling loads due to lighting.

One of the earliest references to removing the heat from lighting [Ei33] dealt with combination incandescent and mercury lamps, which dissipated more than $15 \mathrm{w} / \mathrm{ft}^{2}$ of floor area. The lamps were enclosed in a heatabsorbing glass cylinder and mechanically ventilated to the exterior at an air flow rate of $600 \mathrm{ft}^{3} / \mathrm{min}$ in warm weather. The exhaust air was recirculated to the building during the heating season. The lighting power density of $15 \mathrm{w} / \mathrm{ft}^{2}$ was very high by modern standards.

With the introduction of the fluorescent lamp in the late $1930^{\prime} \mathrm{s}$ and early 1940's, much lower lighting power densities were capable of providing the same light levels [Lu38]. The effects of fluorescent lamps on cooling and comfort were addressed in [Da40] and design factors for lighting and air conditioning were published in [He41]. Lighting was identified to account for an average of 18 percent of total cooling load, and to range from 2 to 47 percent for different installations. Recommendations for fluorescent lighting practice were published in [Ed39]. These papers and reports were based on limited measurement data and basic theoretical calculations, and were not validated for a wide range of conditions. However, they did indicate an appreciation for the thermal effects of lighting even at the early stage of fluorescent lighting system development.

The recommended procedures for designing fluorescent lighting systems and estimating cooling loads due to lighting changed very little through the 1950's. The Illuminating Engineering Society published a guide to lighting and air conditioning [Ie56] which recommended assuming 100 percent of lighting power becomes an instantaneous cooling load. This recommendation was justified by lack of data on heat storage effects, and represents a conservative cooling load estimate leading to oversizing of the cooling equipment.

The lack of data on the thermal performance of fluorescent lighting systems led to several research efforts in the early 1960's. The use of small calorimeters to measure the heat pickups by air circulated through a luminaire became popular. Several researchers used this approach to estimate the energy distribution characteristics of various types of luminaires [Mu62, Ba63, Ba64, Ba65, Sy64, Fi75, Ne71]. Typically, the calorimeters consisted of large insulated boxes, with the Iuminaire mounted on the bottom face. An external fan attached to a duct allowed air to be drawn through the luminaire into the box and then exhausted 
from the box, which served as a plenum. The boxes were usually instrumented with temperature sensors, and luminaire light output and power consumption were measured, along with ventilation air flow rate. These luminaire calorimeters provided much needed information regarding the thermal performance of lighting systems. The temperature dependence of lamp light output and power consumption was demonstrated.

In spite of the usefulness of luminaire calorimeters, they had several weaknesses which did not allow them to address all of the lighting thermal performance issues. The primary element lacking from the luminaire calorimeter was the room in which the luminaire would be installed. Because the luminaire calorimeter did not emulate a room with a plenum, the thermal conditions surrounding the luminaire were not representative of a typical room environment. Heat transfer by radiation, and heat storage in the room and plenum could not be evaluated. Also, convective heat exchange would likely be different in an actual installation than in a small calorimeter. However, design and analysis techniques were published based on calorimeter data [Me63, Me64, Qu62, He66]. Also, field studies were undertaken to demonstrate the application of design procedures [Du64a, Du64b, Fi66].

The Illuminating Engineering Society developed an approved method for the photometric and thermal testing of fluorescent luminaires [Ie68]. This described a calibrated calorimeter and specified a testing and data analysis procedure. This method has been widely utilized.

Progress in the characterization of the thermal performance of lighting systems continued with full scale room tests of fluorescent luminaires [Bo66a, Bo67, Bo68a, Bo68b, No69]. The first four of these references were primarily concerned with comparing steady state temperature and airflow conditions with different air handling systems. The latter reference was concerned with heat transfer from the luminaire to the room and plenum under steady state conditions. None of the studies addressed the transient lighting thermal performance or heat storage issues.

The first transient full scale room lighting thermal performance study was conducted at the National Research Council Canada. Following an initial analytical study [Ki68], a full size room calorimeter was constructed and instrumented [Mi71, Mi74]. The test facility consisted of a test room with floor and ceiling slabs, with a plenum and lighting system in the room and below the floor. The test room walls were foilcovered foam insulation, and the entire structure was enclosed by an insulated shell. Room temperature air was circulated between the room walls and the exterior shell. The temperature of the top of the ceiling slab was controlled by a pond of water at the same temperature as the floor surface. All of the fans and heating and cooling equipment were located in the test room. Cooling load due to the lighting system was determined through an energy balance relation using the temperature rise of the cooling coil water and the measured heat addition and fan power. The return air temperature was held constant by varying the amount of heat addition from an electric heater.

The NRC test facility was used to measure cooling load profiles for a variety of configurations, including various supply and return air locations, with and without furnishings and carpet. Weighting factors 
were calculated as described earlier. The availability of these data represented a great stride forward for the calculation of cooling loads due to lighting, and the weighting factors were incorporated into the ASHRAE handbook of fundamentals [As77]. Additional weighting factors were computed analytically [Mi73]. Methods for utilizing the weighting factors are described in [Mi72, Mi78, Mi83].

The other aspect of previous lighting thermal performance research relates to computer simulation of lighting systems in building spaces. Due to.the limitations in the number of configurations which can be measured, computer models are useful for extending the generality of the results. Two major lighting system modeling efforts have been published. The first computer model focussed on steady state performance using network analysis [So72, So73, So74], drawing on the measurement results from [No69]. The main emphasis was on temperature distributions, comfort conditions and the fractions of lighting energy transferred to the room and plenum. The effect of different return airflow rates and luminaire conditions was also simulated. No transient simulations were performed.

More recently, a detailed transient lighting thermal performance model was been developed [Ba83a]. This model was based on heat balance calculation procedures in an explicit transient finite difference formulation. Cooling load profiles were calculated and compared to some of the results from [Mi73]. The model used empirical correlations for determining convection coefficients, and accounted for the temperature dependence of light output and power consumption. Based on a series of simulations, weighting factors were derived and published [Ba83b].

To summarize the current state of the art, cooling load profiles are computed using ASHRAE-type weighting factors based on a limited set of measurements and simulations. Very little information is available regarding the lighting energy distribution fractions which are needed as input parameters for building energy analysis computer simulations. No data are available regarding heat storage in room components due to cyclic operation of the lighting system.

\subsection{Objective of the Present Research}

The objective of the research reported here is to increase the understanding of the interactions between lighting and HVAC systems in commercial - type buildings. Specifically, the thermal performance of fluorescent luminaires under typical office conditions will be evaluated based on detailed full - scale measurements and related computer simulations. The primary elements of the research are as follows:

- Measure cooling load profiles due to lighting for various room temperatures, airflow rates and airflow configurations.

- Determine ASHRAE - type weighting factors from measured cooling load profiles.

- Investigate the possibility of using another time function to fit calculated cooling loads to measured loads more exactly than the single exponential relation which forms the basis of the ASHRAE weighting factors. 
- Determine extenảed weighting factors to correspond to improved cooling load profile function.

- Examine heat transfer processes from lighting and determine lighting energy distribution fractions.

- Examine heat storage in room and plenum components.

- Examine air and surface temperature conditions.

- Evaluate effect of room air temperature; airflow rate and airflow configuration on lighting and HVAC system performance.

- Develop, calibrate and validate a detailed computer model of the lighting and HVAC interaction test facility.

- Suggest design and operation strategies to control peak cooling loads due to lighting and total energy for lighting and cooling. 


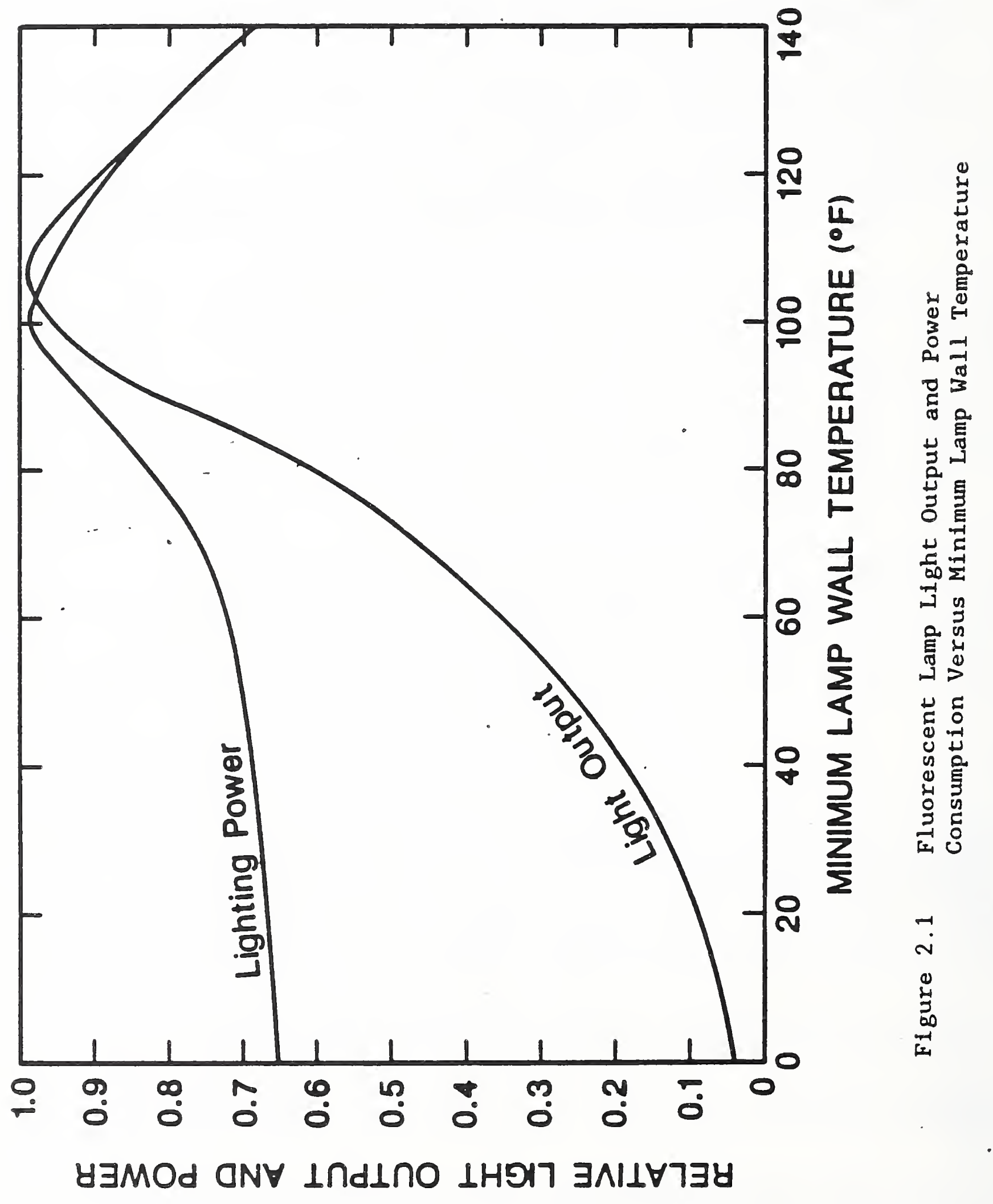




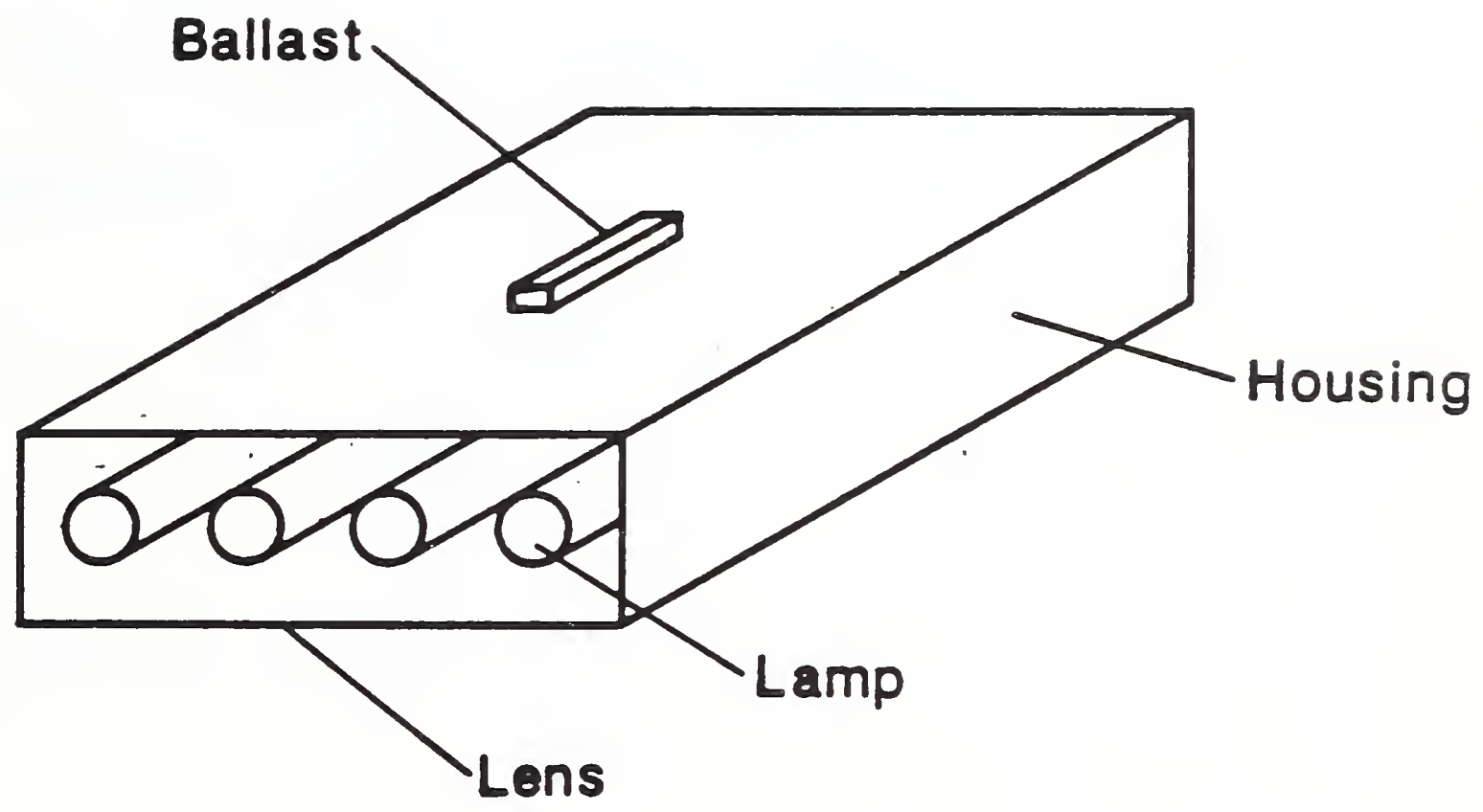

Figure 2.2 Schematic Diagram of Fluorescent Lamp Components 


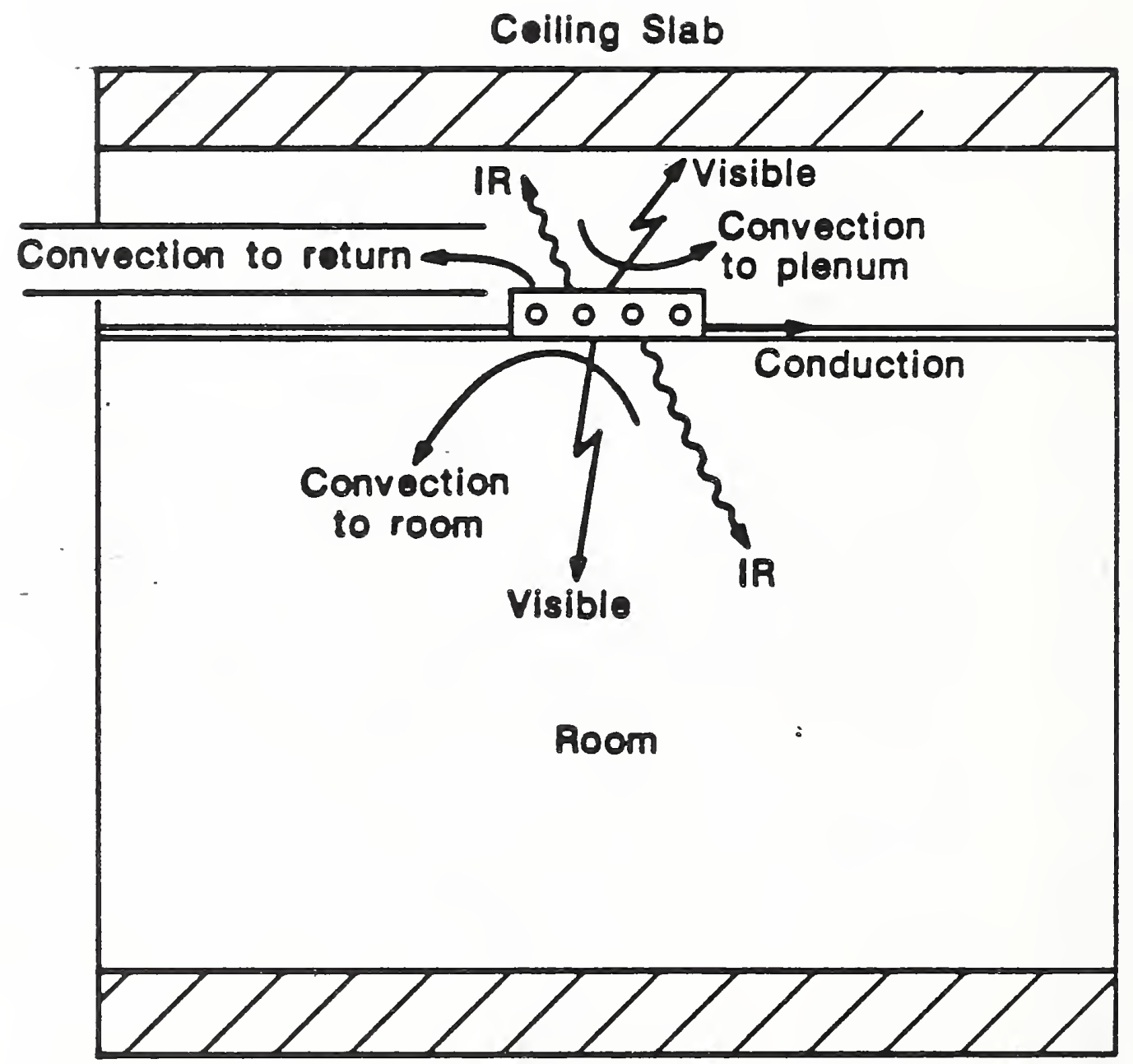

Floor Slab

Figure 2.3 Energy Distribution Fractions from Lighting Systems 
Figure 2.4 Cooling Load due to step Change in Lighting
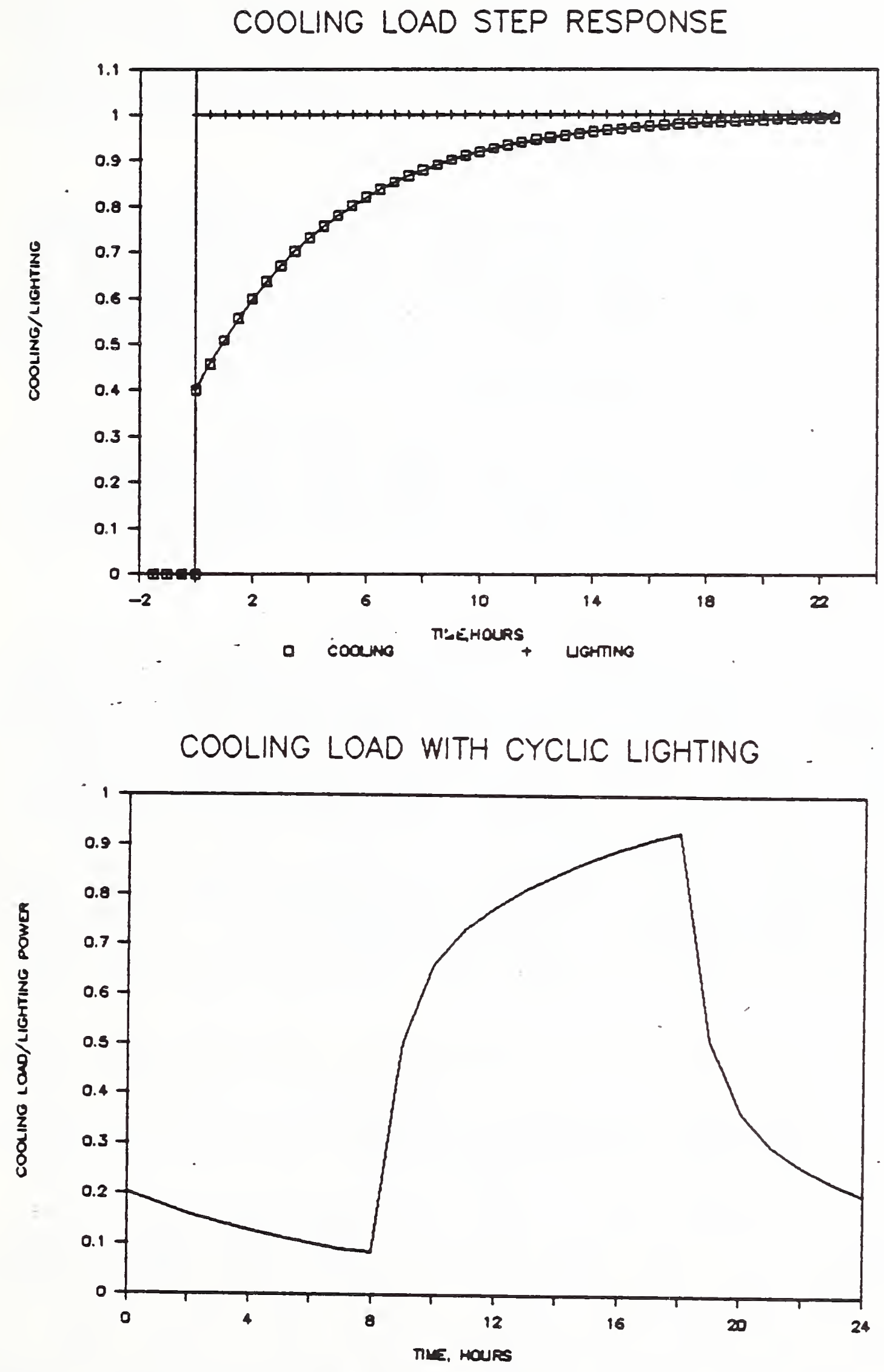

Figure 2.5 Cooling Load with Cyclic Operation of Lighting System 
The lighting and HVAC interaction test facility was designed and constructed to emulate an office space using standard materials and construction techniques. The test facility is extensively instrumented to allow the measurement of cooling load, lighting power, airflow, surface and air temperatures, heat flows and light levels. Three air handling units service seven individually controlled zones, including the test room and surrounding spaces. Data collection and control are accomplished using a computer-controlled system.

The test facility is designed to allow testing configurations to be changed easily. Airflow rate, air return path and room temperature are three of the primary testing parameters. The unique features of the test facility are the guard air spaces, which simulate adjacent building spaces, and the lower plenum with duplicate lighting and HVAC system beneath the test room floor. The air circulation system for the test room emulates a typical building design.

Additional measurement parameters to be evaluated include various luminaire types, number of lamps, the effect of carpet, different wall types, the effect of variable supply air volume and the impact of an exterior condition adjacent to a perimeter wall.

\subsection{Test Facility}

The test facility is constructed on a slab $30 \mathrm{ft}$. 6 in. by $21 \mathrm{ft}$. 4 in. within the large NBS environmental chamber. The facility is divided into two sections, a large insulated shell enclosing the test room area, and a smaller attached control room for housing instrumentation. The overall height is $20 \mathrm{ft}$. 10 1/2in., while the control room ceiling height is $13 \mathrm{ft} .21 / 2$ in. The test room floor slab is elevated to accommodate a lower plenum beneath the floor, and all other room surfaces are adjacent to temperature - controlled guard air spaces. Duplicate lighting and HVAC systems are installed in both the test room plenum and the lower plenum. Figure 3.1 shows a cut - away schematic view of the test facility. The majority of the ductwork is not shown in this figure.

The test room floor and ceiling slabs are $21 / 2$ inch thick concrete built on steel decks supported by a structural steel framework, as shown in figure 3.2. The test room walls are constructed of gypsum drywall on steel studs. The initial test configuration is four interior walls. The guard air spaces are shown in figure 3.3 .

The lighting system locations in the test room and lower plenum are shown in figure 3.4. The edges of the floor slabs extend slightly beyond the walls, while the ceiling slab separates the side guard air spaces from the upper guard air space. Small access doors allow entry into the guard air spaces, as shown in figure 3.5. Also shown is a large double door which opens from the north guard air space. Another door connects the test room/guard air portion of the test facility with steps leading to the floor of the control room. 
Chilled water for cooling, and electrical power are drawn from environmental chamber supplies. The temperature of the chamber is maintained at approximately $75^{\circ} \mathrm{F}$.

During and following construction, the test room, guard air spaces and ducts were sealed and insulated where appropriate to minimize unwanted heat and air flows. All doors were gasketed and joints sealed. All conduits through the test room walls are made of plastic to reduce heat flow.

Each air handling system consists of a fan and chilled water coil, with separate electric duct heaters for each supply duct. The output of each of the electric duct heaters is controlled by a separate 4 to $20 \mathrm{~mA}$ control signal, allowing independent temperature control for each of the seven supply air systems. The test room air system is dedicated to the test room only. Return air is taken from the plenum near one corner of the room, through a variable speed fan, over a cooling coil, past an electric duct heater and supplied through diffusers at suspended ceiling height. All ductwork is insulated. The air temperature leaving the cooling coil is controlled to set point by an automatic valve which varies chilled water flow. Room air temperature is controlled by varying the electric power to the duct heater. Figure 3.6 shows the test room ducts.

The second air handling system services the east, south, west and upper guard air spaces. Chilled water flow is adjusted manually to keep air temperature after the cooling coil below the minimum required for testing, so that control is maintained by modulating the control of the heater. Figure 3.6 shows the east, south and north guard air duct systems. Supply air is introduced at the top of the vertical guard air spaces, and extracted at the bottom. In the upper guard air space, air is supplied at the center and extracted around the edges.

The third air handling system services the lower plenum and north guard air space. The north guard air space is designed to function as either an interior or exterior condition, although was only used as a interior space during these tests. The lower plenum supply duct is identical to the test room, while the return air inlet is in the opposite corner. Figure 3.7 shows the duct layout in the lower plenum, and air handling unit number three.

The electrical system design is standard, except for sub-metering of the lighting, auxiliary electric power, fan power and test room heater power. The seven electric duct heaters and variable speed fan drive are individually controlled by the computer system, as will be described later. Identical lighting systems are installed in the test room and lower plenum.

\subsection{Instrumentation}

The operation of the test facility, data collection and control of measurements is by a personal computer based data acquisition and control system. The system consists of an IBM AT and three Keithley Series 500 units. The computer collects data and controls the heaters and fan and other measurement parameters under the control of a 
specialized computer program written in SOFT500, an extended version of BASIC. A total of 398 parameters are recorded at two minute intervals.

All channels except the surface temperatures are sampled every 12 seconds, and then values averaged over two minutes. The 12 second readings for the photometers are an average of 100 samples to negate the effects of flicker from the fluorescent lamps.

One day's worth of data takes 2.2 mbyte of storage. Following a test, which may last several days, data is stored on a cartridge storage device and transferred to another IBM AT computer for analysis. The raw data is first loaded into a database system called RBASE and then subsets of the data are exported to LOTUS for processing, plotting and analysis.

The raw data is also analyzed by a program which computes average values for 30 minute intervals. Computed averages include floor and ceiling temperatures, wall temperatures, air temperatures, light levels and heat flows.

The primary measurement parameters are lighting power, cooling load, return airflow rate and room temperature. Additional measurements of air and surface temperatures, heat flows and light levels are intended to supply supporting information. Some of the measurements also serve as feedback signals for the control loops, such as the floor and wall thermopiles.

Lighting power is measured using a solid state transducer with a current output proportional to power consumption. This sensor was calibrated at NBS and found to have an uncertainty of less than 0.1 percent.

The sensible cooling load is derived from the temperature difference of the air from the room supply to return, and the airflow rate. The return airflow rate is measured using an array of four hot wire anemometers in the return air duct. These sensors measure mass velocity and do not need to be corrected for density. The airflow rate in cfm (AF) is given by:

$$
A F=(V e l) \frac{f t}{m i n} \text { (duct area) } f t^{2} \text { (conversion factor) }
$$

The conversion factor is necessary to account for the true volume flow corresponding to the measured velocities. Since airflow velocity varies through the duct cross - section, the measured velocity may differ from the average. The conversion factor was determined by comparison to the airflow measured with a detailed traversing of the return air duct. The duct area is $0.92 \mathrm{ft}^{2}$. The airflow velocity uncertainty is 3 percent. 
The cooling load for the test room is given by:

$$
Q=\dot{m} C_{p} \Delta T=(A F)(\rho)(C p)\left(T_{R E T}-T_{S U P}\right)
$$

where: $\rho=$ density of standard air

$C p=$ specific heat of air

$\mathrm{T}_{\mathrm{RET}}=$ return air temperature

$\mathrm{T}_{\text {SUP }}=$ supply air temperature

The cooling load in watts is:

$$
\begin{aligned}
\mathrm{Q} \text { (watts) } & =(\mathrm{AF}) \frac{\mathrm{ft}^{3}}{\min }(\rho) \frac{\mathrm{lb}}{\mathrm{ft}^{3}}(\mathrm{Cp}) \frac{\mathrm{Btu}}{\mathrm{lb} \cdot \mathrm{F}}(\Delta \mathrm{T}) \mathrm{F} \frac{60 \mathrm{~min}}{1 \mathrm{hr}} \frac{1 \mathrm{w}}{3.413} \frac{\mathrm{Btu}}{\mathrm{hr}} \\
& =(\mathrm{AF}) \frac{\mathrm{ft}}{\min }(0.08056) \frac{\mathrm{lb}}{\mathrm{ft}^{3}}(0.240) \frac{\mathrm{Btu}}{1 \mathrm{~b} \cdot \mathrm{F}}(\Delta \mathrm{T}) \mathrm{F}(17.580) \\
& =(0.33990)(\mathrm{AF})(\Delta \mathrm{T})
\end{aligned}
$$

The supply to return air temperature difference is measured using a type $T$ thermopile with 42 pairs of junctions. At $23 \mu \mathrm{v}$ per ${ }^{\circ} \mathrm{F}$ per pair of junctions, this thermopile generates $1 \mathrm{mv}$ per ${ }^{\circ} \mathrm{F}$ temperature difference. Although slightly non - linear in response, throughout the range of testing the non - linearity is less than a one half percent effect, and uncertainty is approximately $0.1^{\circ} \mathrm{F}$.

The test room air temperature is measured with an array of 64 thermocouples, in a four by four by four grid, as shown in figure 3.8. The upper 16 thermocouples are in the plenum, while the average of the 48 thermocouples below the suspended ceiling is used as the room temperature control point. Temperature measurement uncertainty is $0.75^{\circ} \mathrm{F}$.

Surface temperatures are measured throughout the test room, primarily on the north, east and south walls, floor and ceiling, as shown in figure 3.9. Two of the luminaires have 16 thermocouples each, while the other two luminaires have 8 thermocouples each.

Heat flux transducers are mounted on each room surface, at the center and around the perimeter, as shown in figure 3.10. The center transducers are one square foot in area, producing a milivolt signal proportional to heat flow through the surface. The other heat flow sensors are smaller disks or squares. The heat flow meters were calibrated using the NBS Guarded Hot Plate. Uncertainty is approximately 5 percent

Thermopiles are used extensively to control the test room boundary conditions. The most typical boundary condition is to simulate a test room surrounded by similar spaces. Thus, wall temperature conditions would be symmetric about the center plane of each test room wall, and the surface temperature would remain equal on both sides of the wall. The average temperature difference across each wall is measured using Type $T$ thermopiles with 30 pairs of junctions. The control system 
attempts to keep the thermopile readings equal to zero by varying the power supplied to each electric duct heater. When the lights are switched on, the interior of the test room walls begin to heat up, causing an imbalance in surface temperatures across the walls which is sensed by the thermopile which, in turn, causes the control signal to the appropriate heater to increase. In this manner, heat can be stored in the gypsum board walls, but no net heat flow through the wall will occur. Figure 3.11 demonstrates the wall thermopile system schematically.

The control of the lower plenum and upper guard air space is also accomplished using thermopiles. The intent is to maintain the temperature at the top of the ceiling equal to the top of the floor, and the bottom of the floor equal to the bottom of the ceiling. Net heat flow will occur through the floor and ceiling, but should be equal in magnitude and direction. The temperature distribution will vary across the floor and ceiling slabs due to the presence of the lighting system. Duplicate lighting systems below the floor and ceiling provide equivalent temperature distributions, while the thermopiles control average temperatures to equivalent levels. One 36 pair junction thermopile is attached to the top of the ceiling and floor slabs and another is attached to the bottom of the two slabs. Power to the electric duct heaters is varied to maintain equal surface temperatures.

The control loops operate on a 12 second sampling interval. A digital proportional and integral control algorithm is implemented to vary electric heater power as required in response to the thermopile readings. The change in controller output, $m$, is related to the error signal, e, according to [Ra78]:

$$
\Delta \mathrm{m}=\mathrm{m}(\mathrm{K})-\mathrm{m}(\mathrm{K}-1)=\mathrm{K}_{\mathrm{p}}[\mathrm{e}(\mathrm{K})-\mathrm{e}(\mathrm{K}-1)]+\mathrm{K}_{\mathrm{I}} \mathrm{Te}(\mathrm{K})
$$

where: $\quad K=$ sample

$\mathrm{T}=$ sampling interval

$\mathrm{K}_{\mathrm{p}}=$ proportional gain constant

$\mathrm{K}_{\mathrm{I}}=$ integral gain constant

At the start of a test, the heaters are all off and are gradually increased automatically to achieve and maintain the desired condition. Values for $K_{p}$ and $K_{I}$ were determined by trial and error.

Light levels in the test room are monitored continuously at the center of each surface using silicon photovoltaic cells corrected for eye response. Also, periodically detailed light distribution measurements are made using an array of photocells. The photocells were calibrated using an NBS reference source, and have an uncertainty of less than one percent.

In addition to the sensors described above, numerous other air and surface temperatures are measured in the guard air spaces and air handling systems to help monitor test facility performance.

\subsection{Measurements and Calibration}

Both steady state and transient tests can be run in the test facility. steady state tests involve establishing a test configuration and 
allowing conditions to stabilize. The transient tests involve the response of cooling load due to sudden switching of the lighting system. Thus, the test facility goes from one steady state condition, either lights on or off, to the other steady state condition.

The initial tests were used to calibrate the test facility, tune the digital control loops and verify the proper operation of the equipment and sensors. The test facility has two natural calibration conditions, that with the lights off (zero cooling load), and with the lights on (cooling load equal to lighting power). Initial steady state measurements indicated excessive heat gains to the test room with no lights on. Additional insulating and sealing of the test room envelope alleviated this problem.

The air supply rates for the guard air spaces, and chilled water flows, were adjusted to enable their proper temperature control. Air must be supplied to the guard air spaces at the range of temperatures required to match surface temperatures with the test room. Thus the air temperatures after the cooling coils must be below that needed for the guard air spaces, so that the guard air supply temperature can be controlled through the addition of heat by the electric duct heater. The airflow rate to each of the guard air spaces must be great enough to control the surface temperature, but low enough to match the room surface temperatures when they are heated by the lighting system. These rates were adjusted by trial and error.

Test room air leakage was measured using sulfur - hexafluoride tracer gas decay. Natural infiltration was found to be 0.017 air changes per hour. Sulfur hexafluoride was injected into the test room with fans off and ducts sealed. The decay in $\mathrm{SF}_{6}$ concentration was monitored over time and the air infiltration (I) calculated from:

$$
I=-\frac{1}{t} \ln \left(\frac{C}{C o}\right)
$$

where: $t=$ time interval

$\mathrm{C}_{0}=$ initial $\mathrm{SF}_{6}$ concentration

$\mathrm{C}=$ final $\mathrm{SF}_{6}$ concentration

Sulfur hexafluoride concentration was determined using an electron capture detector.

The values for the gain constants for the digital control systems were determined by monitoring heater operation and cooling load in response to a step change in lighting. Initially, $K_{p}$ and $K_{I}$ were set to unity. Excessive oscillations in cooling load and heater operation were observed, as shown in figure 3.12 and 3.13. The gains were successively reduced until oscillations were minimized, while sufficiently fast response was maintained. Gain values of 0.1 were found to be most effective.

One of the key indicators of the performance of the control systems is the thermopile output values during a transient test. The thermopiles should read zero if the control systems are operating properly. Figure 3.14 shows the outputs from the supply return air thermopile and one wall thermopile. The lights were switched on at hour seven, causing the supply to return air temperature difference to increase as cooling load 
picks up. The wall thermopile, however, maintains an average zero reading, with some small, rapid fluctuations due to air turbulence and controller operation. The other thermopile outputs are shown in figure 3.15 for the same test, on an expanded scale. The average temperature difference as measured by the thermopiles is within $0.03^{\circ} \mathrm{F}$ of zero for each sensor. The rapid temperature difference fluctuation are generally less than $0.2^{\circ} \mathrm{F}$. This performance was also observed for other tests.

\subsection{Test Parameters}

The primary testing parameters evaluated in this report are airflow configuration, airflow rate and room temperature, and the testing is aimed towards evaluating the effects of these parameters on the transient and steady state performance of the lighting and HVAC system. A series of tests was executed for 27 basic configurations, for three variations of each of the primary parameters. The testing parameter variations are summarized in table 3.1. This table also lists the code for each parameter option. These codes appear throughout the figures for identification purposes. Additional test parameters and room configurations are scheduled for future testing. These are also listed in table 3.1 and labeled with *.

Table 3.1 Test Parameters

$$
\begin{aligned}
\text { Airflow return } & \text { - ceiling grill (code CG) } \\
& - \text { luminaire side slots (code SS) } \\
& - \text { lamp compartment (code LC) }
\end{aligned}
$$

$\begin{aligned} \text { Airflow rate } & -30 \mathrm{cfm} \text { per luminaire, } 120 \mathrm{cfm} \text { total (code 120) } \\ & -40 \mathrm{cfm} \text { per luminaire, } 160 \mathrm{cfm} \text { total (code 160) } \\ & -50 \mathrm{cfm} \text { per luminaire, } 200 \mathrm{cfm} \text { total (code 200) }\end{aligned}$

Room air temperature $-70^{\circ} \mathrm{F}, 75^{\circ} \mathrm{F}, 80^{\circ} \mathrm{F}$

Luminaire type - parabolic diffuser, prismatic lens

Number of lamps per luminaire - 2*, 4

With/without carpet*

Wall type - 4 interior walls

- 3 interior walls, 1 exterior curtain wall*

- 3 interior walls, 1 exterior block wall*

Constant or Variable* supply air volume

Night - setback*

The luminaires tested were four, four-tube units with parabolic diffusers. Each luminaire had two ballasts and four standard 40 watt lamps. Return air could be directed either through the lamp compartment, through slots on the sides of the luminaire, or through the ceiling grill return. Additional tests will be performed using fourtube luminaires with prismatic lenses, and two-tube luminaires with parabolic and prismatic diffusers. 


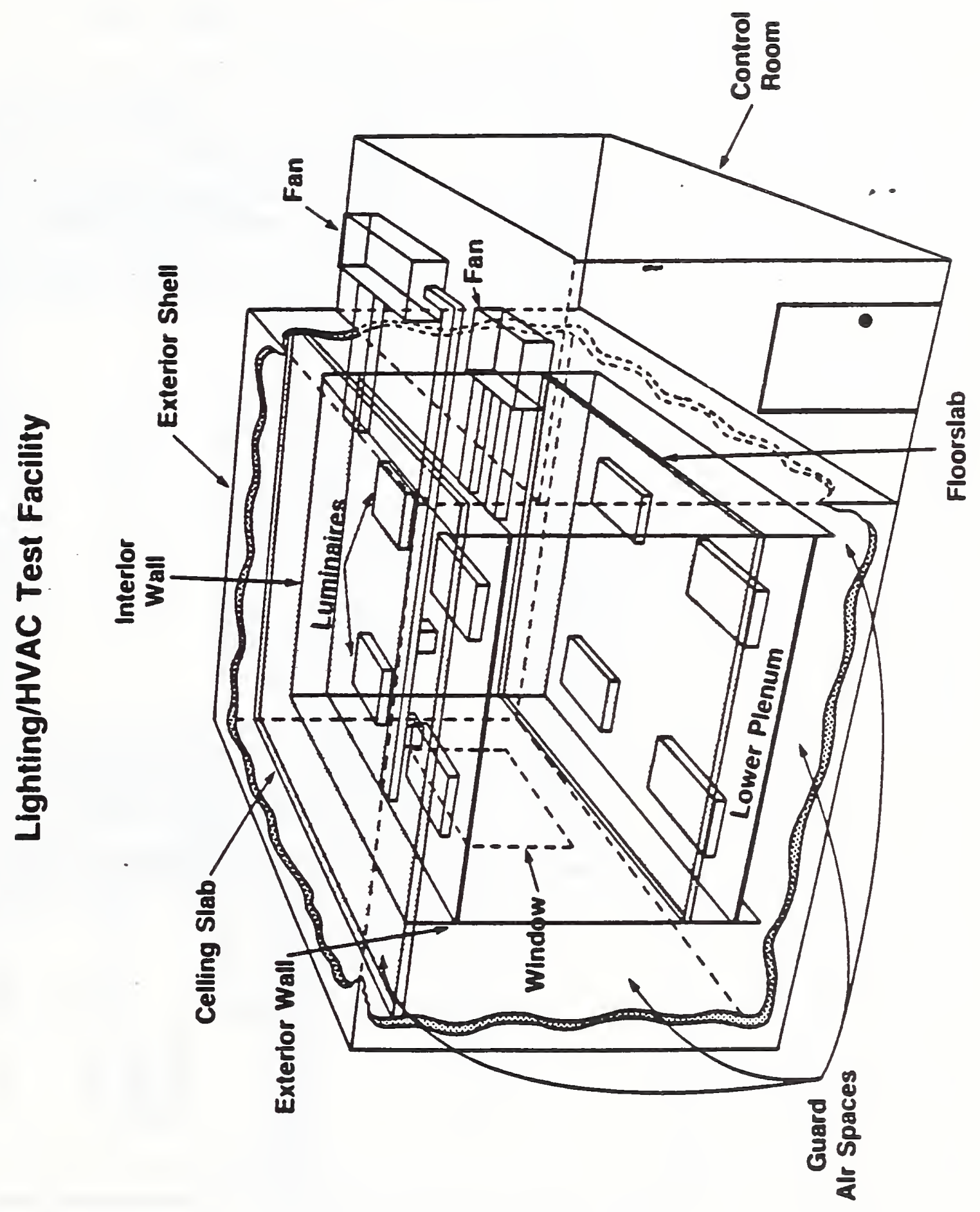

Figure 3.1 Cut-away Schematic View of Test Facility 


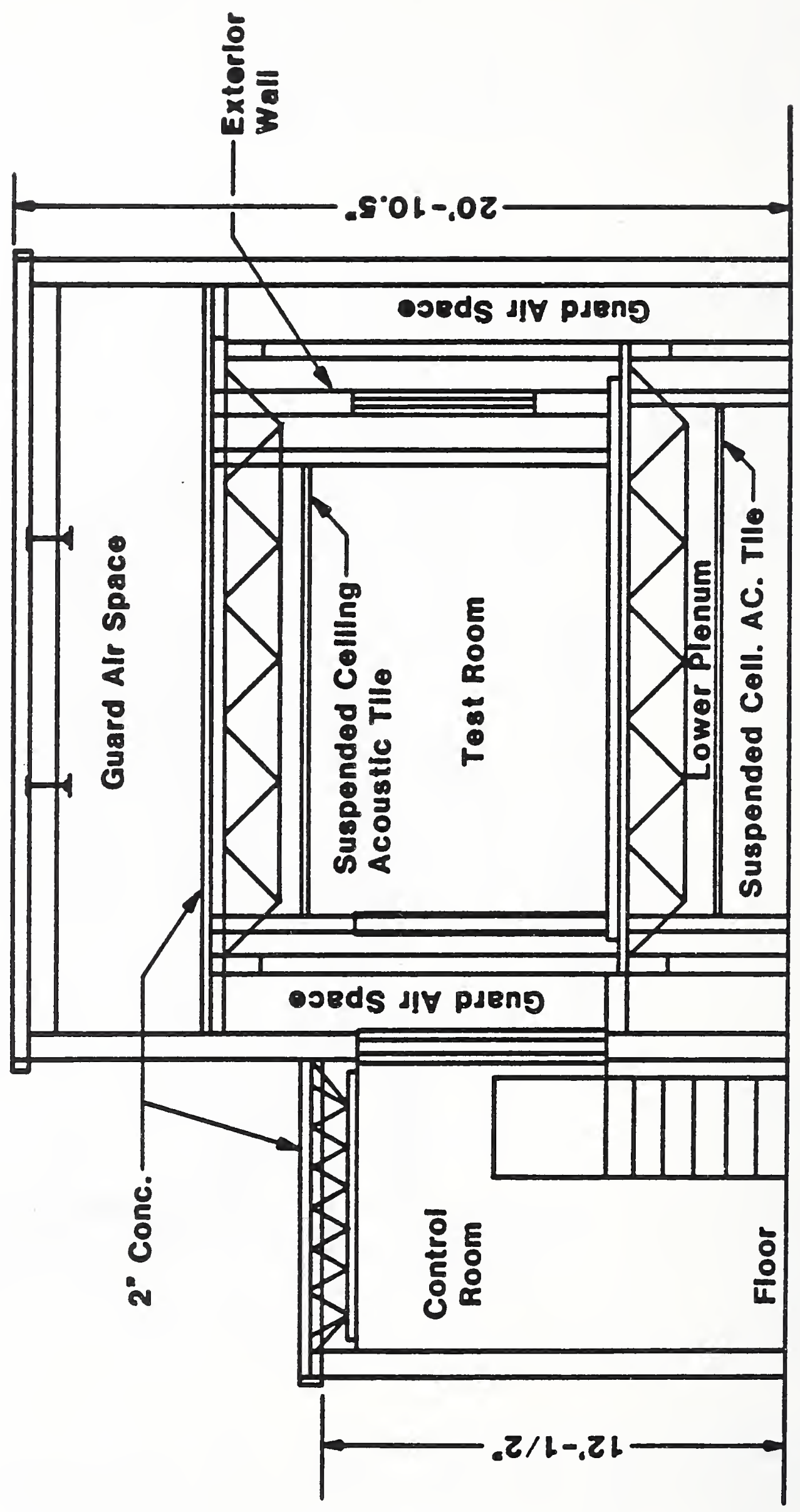

Figure 3.2 Floor and Ceiling Slabs are Supported by Steel Frame 


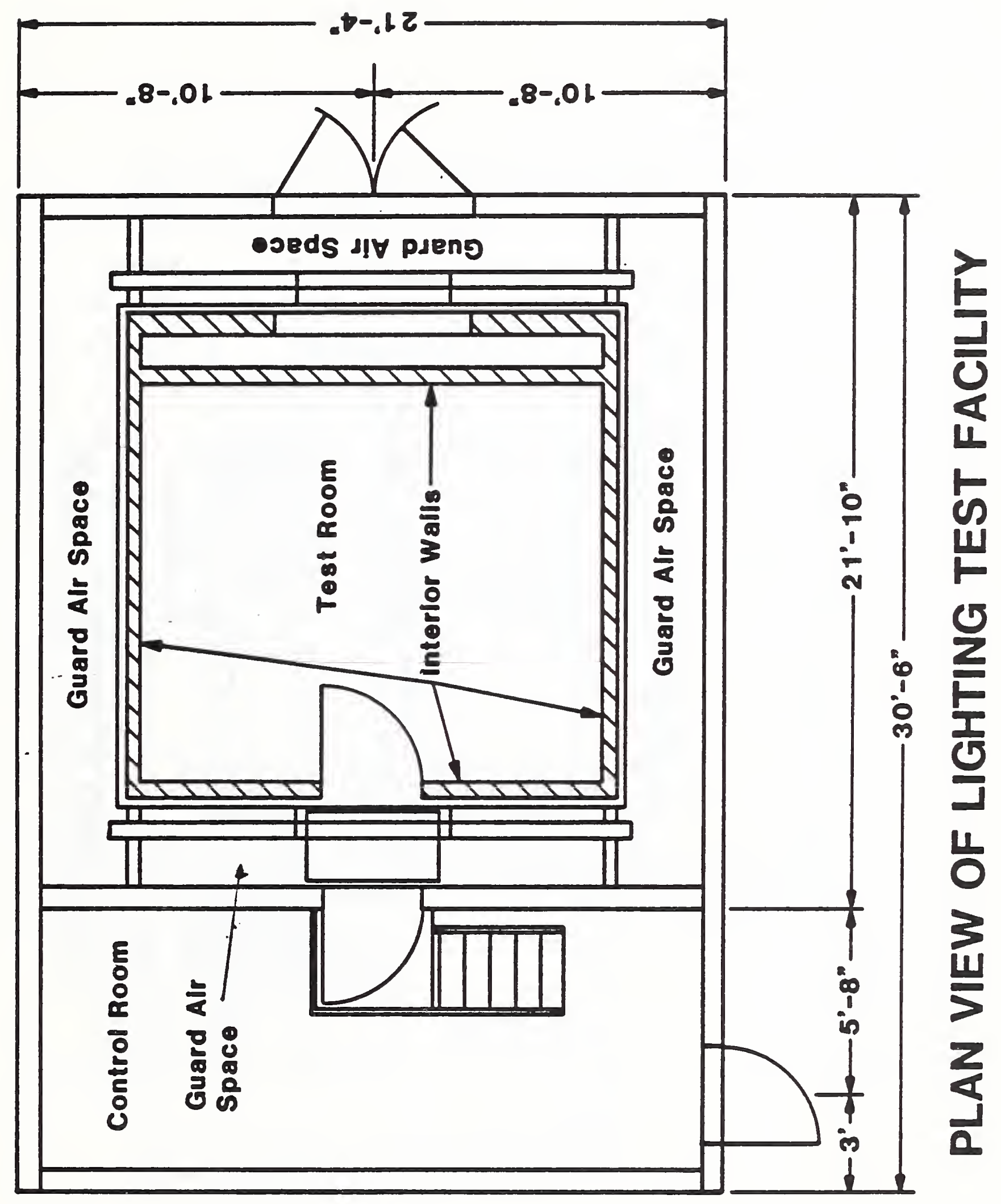

Figure 3.3 Guard Air Spaces Surrounding Test Room 


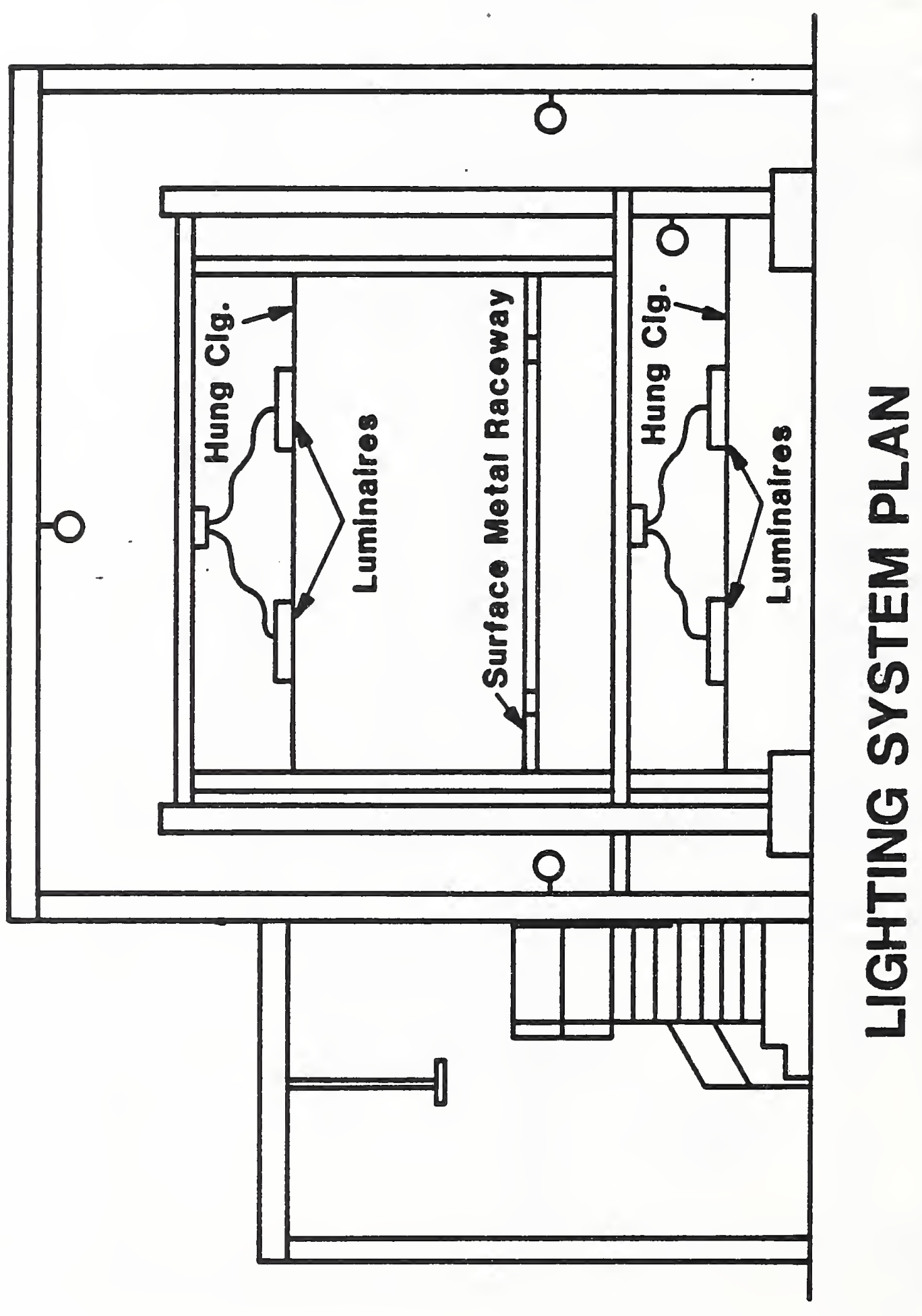

Figure 3.4 Lighting Systems 


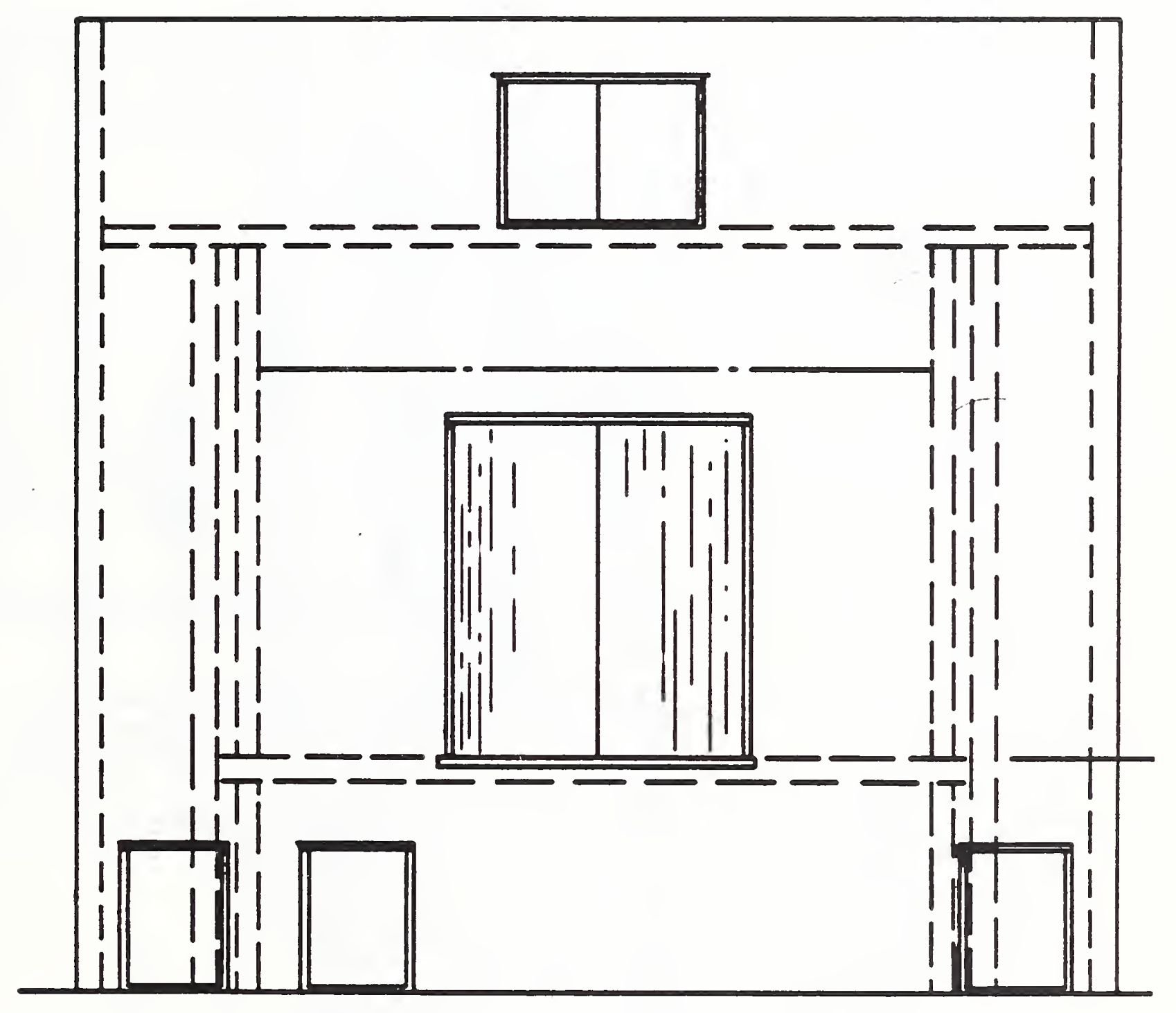

Figure 3.5 Access Doors Allow Entry to Guard Air Spaces 


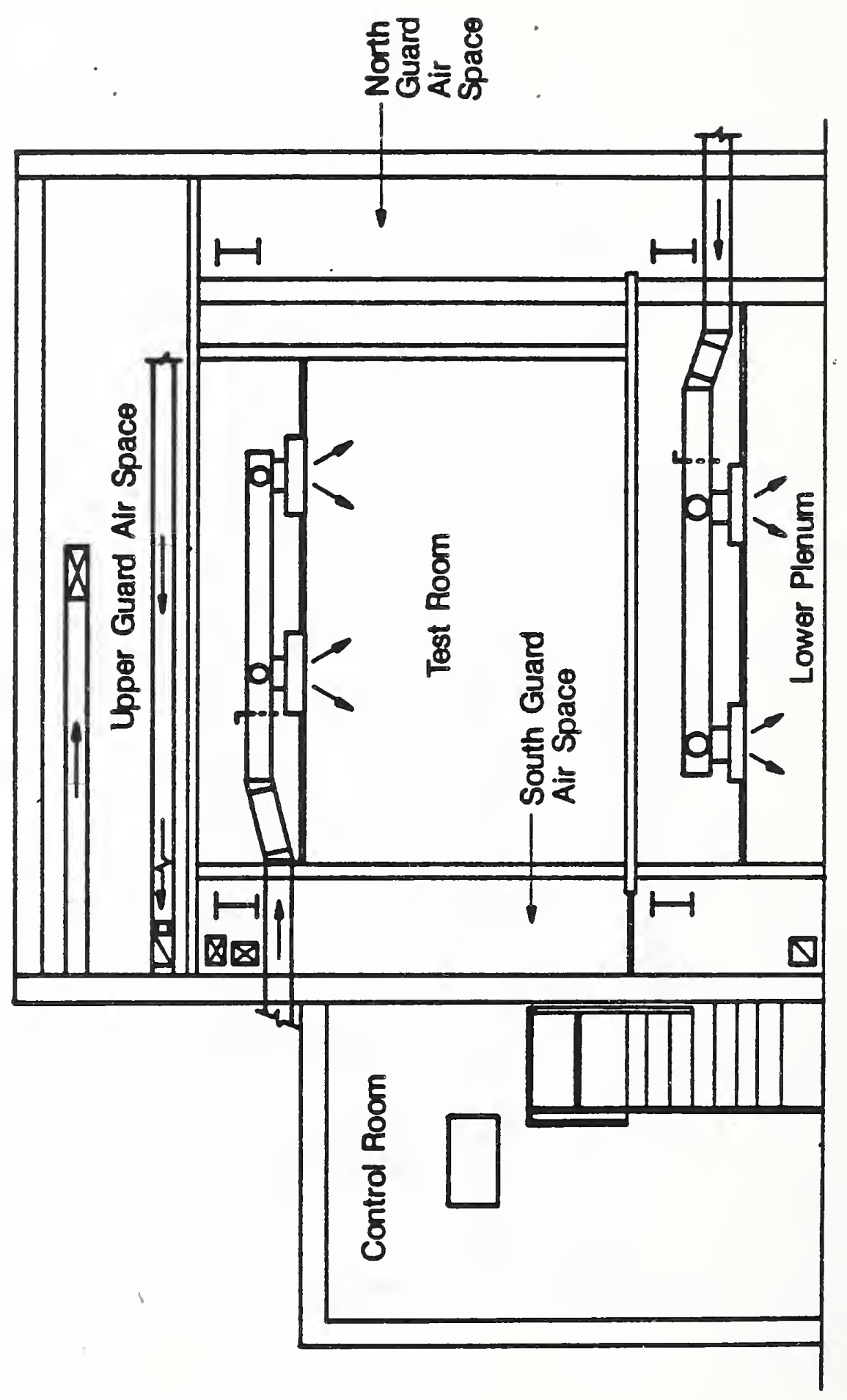

Figure 3.6 Test Room Air Supply and Return Ducts, and Guard Air Ducts 


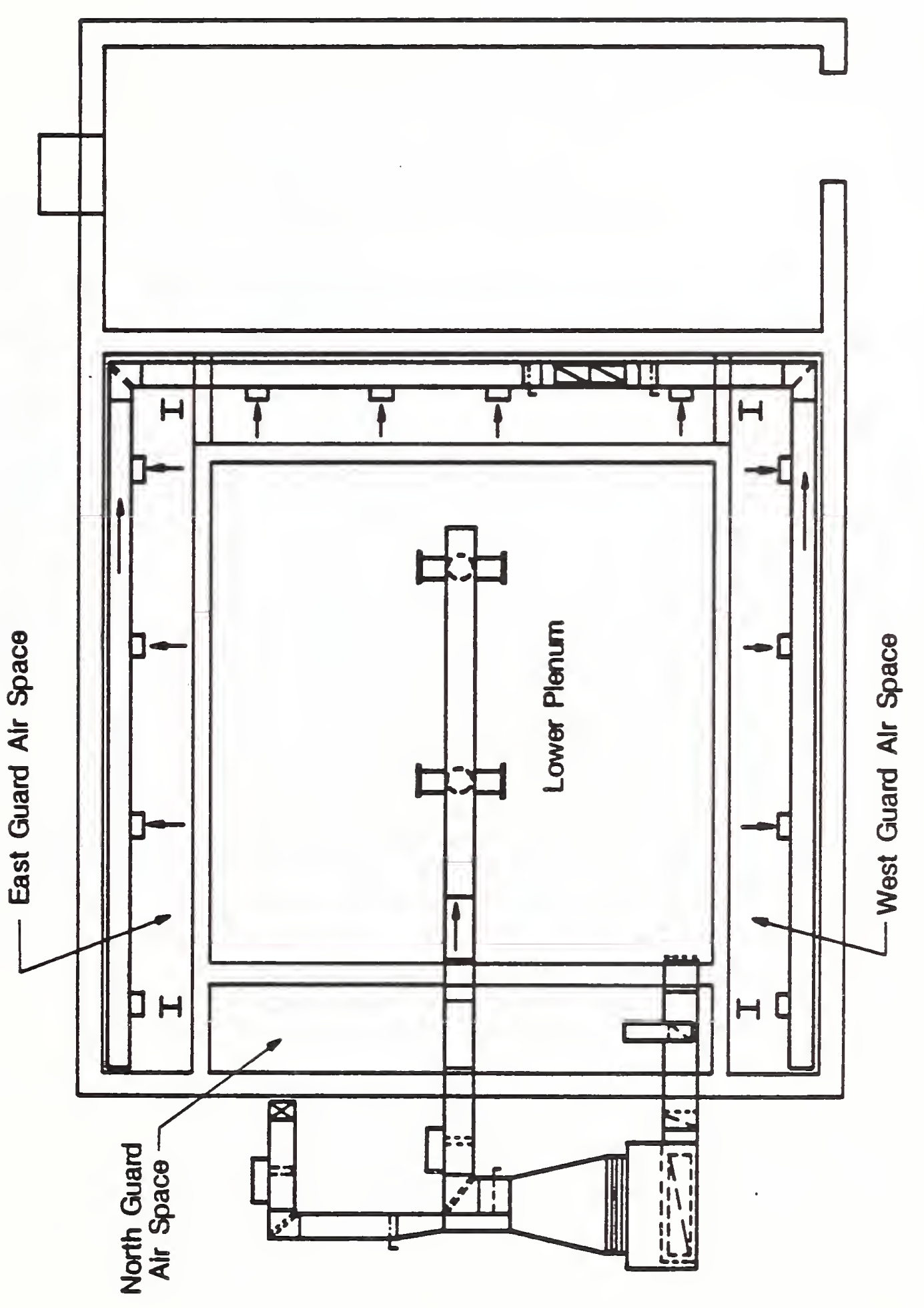

Figure 3.7 Duct Layout in Lower Plenum 


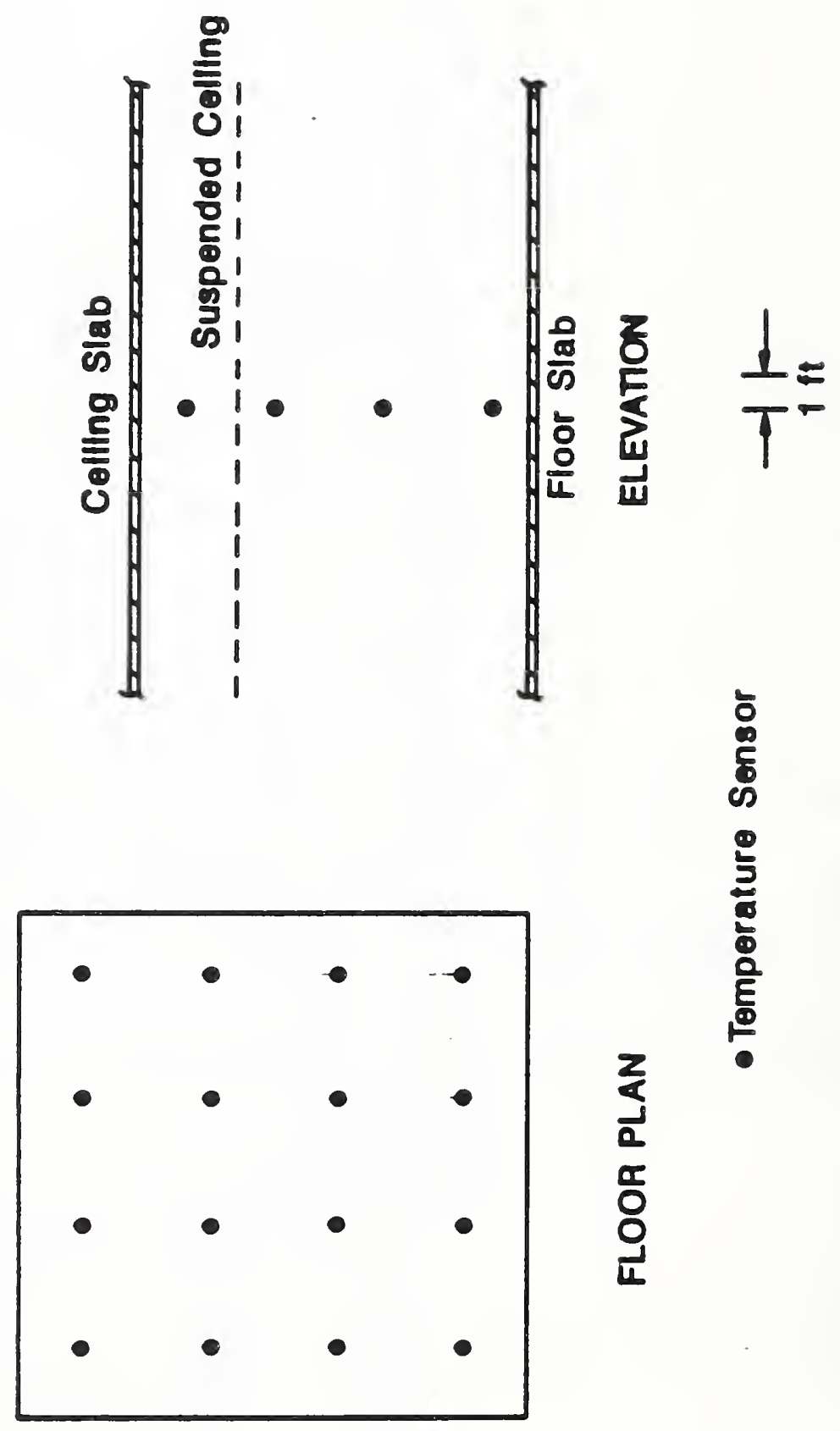

Figure 3.8 Test Room Air Temperature Thermocouple Grid 


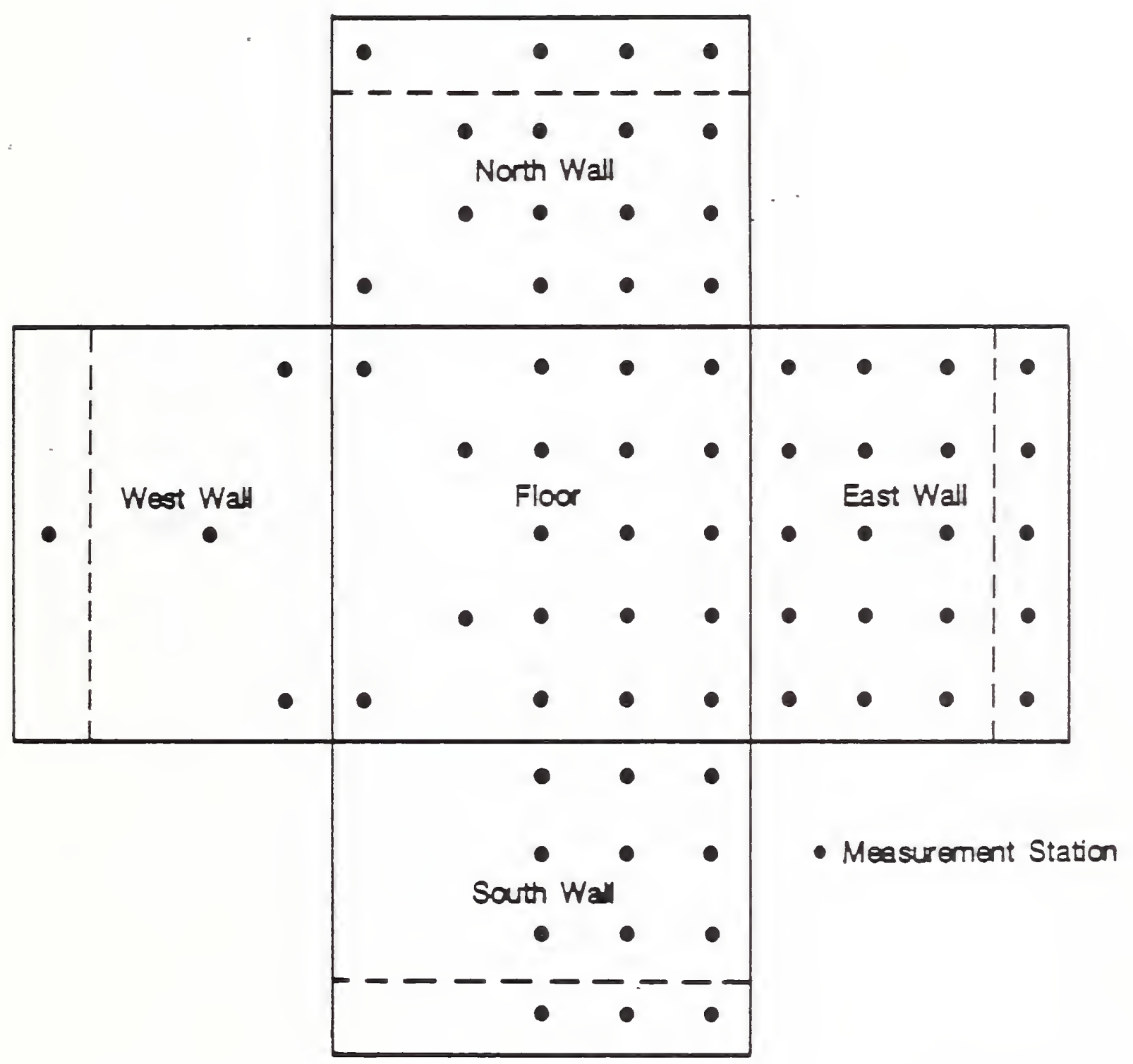

Figure 3.9 Surface Temperature Measurement Grid 


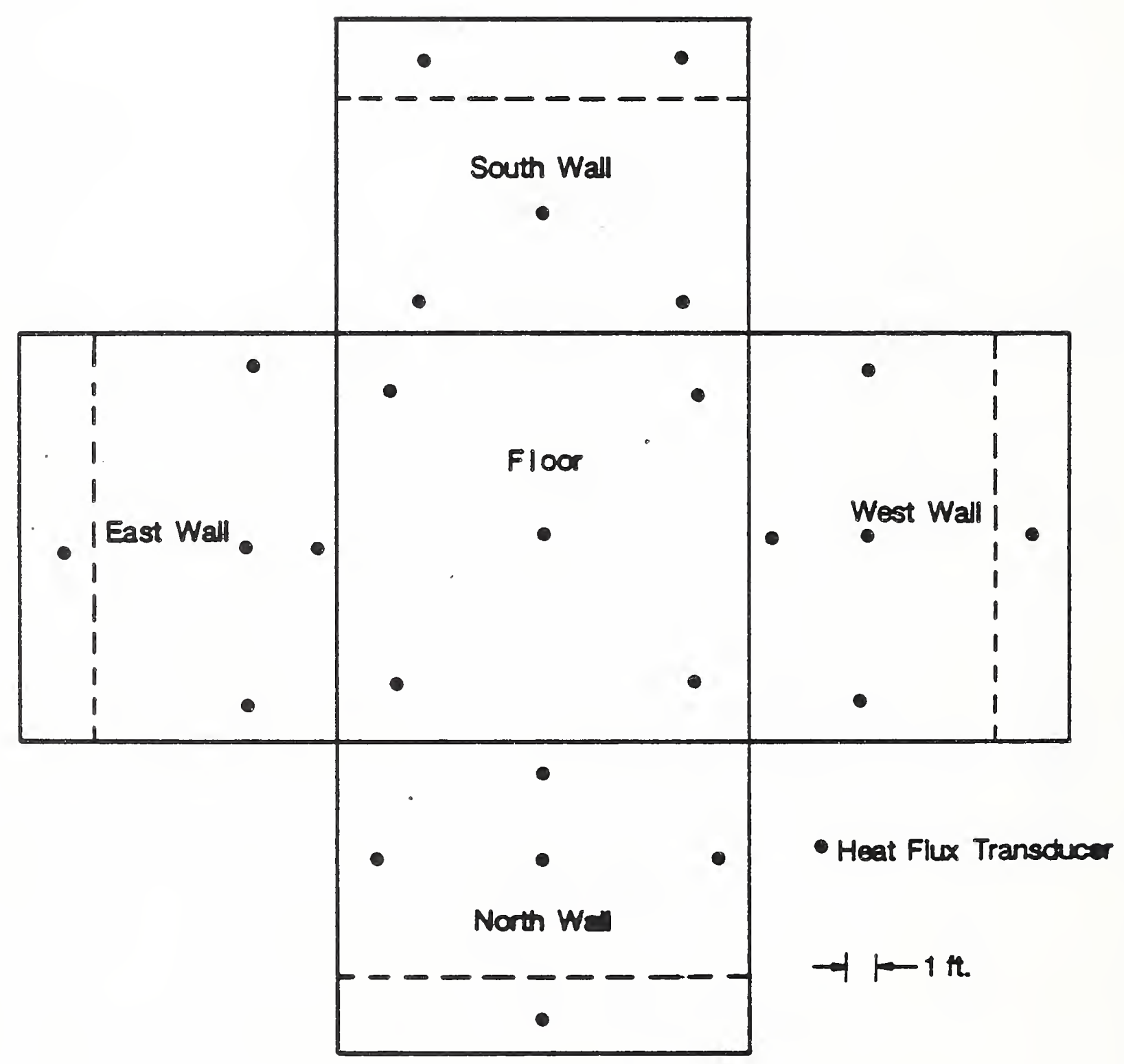

Figure 3.10 Heat Flux Transducer Locations 


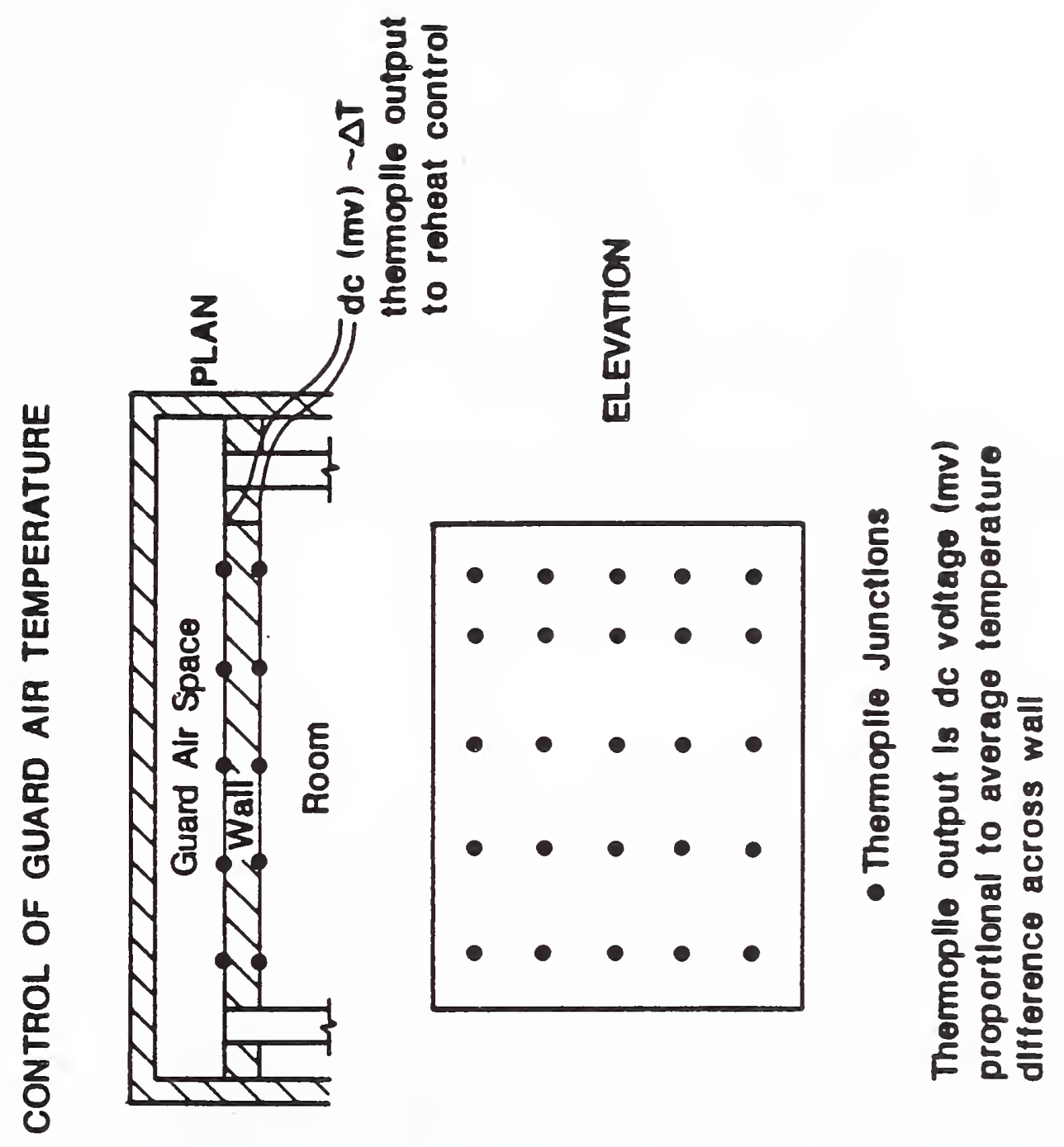

Figure 3.11 Wall Guard Air Thermopile Control System Schematic 
Figure 3.12 Cooling Load Oscillations Due to Excessively High Control Loop Gain Constants

\section{$c \nmid 2318$}
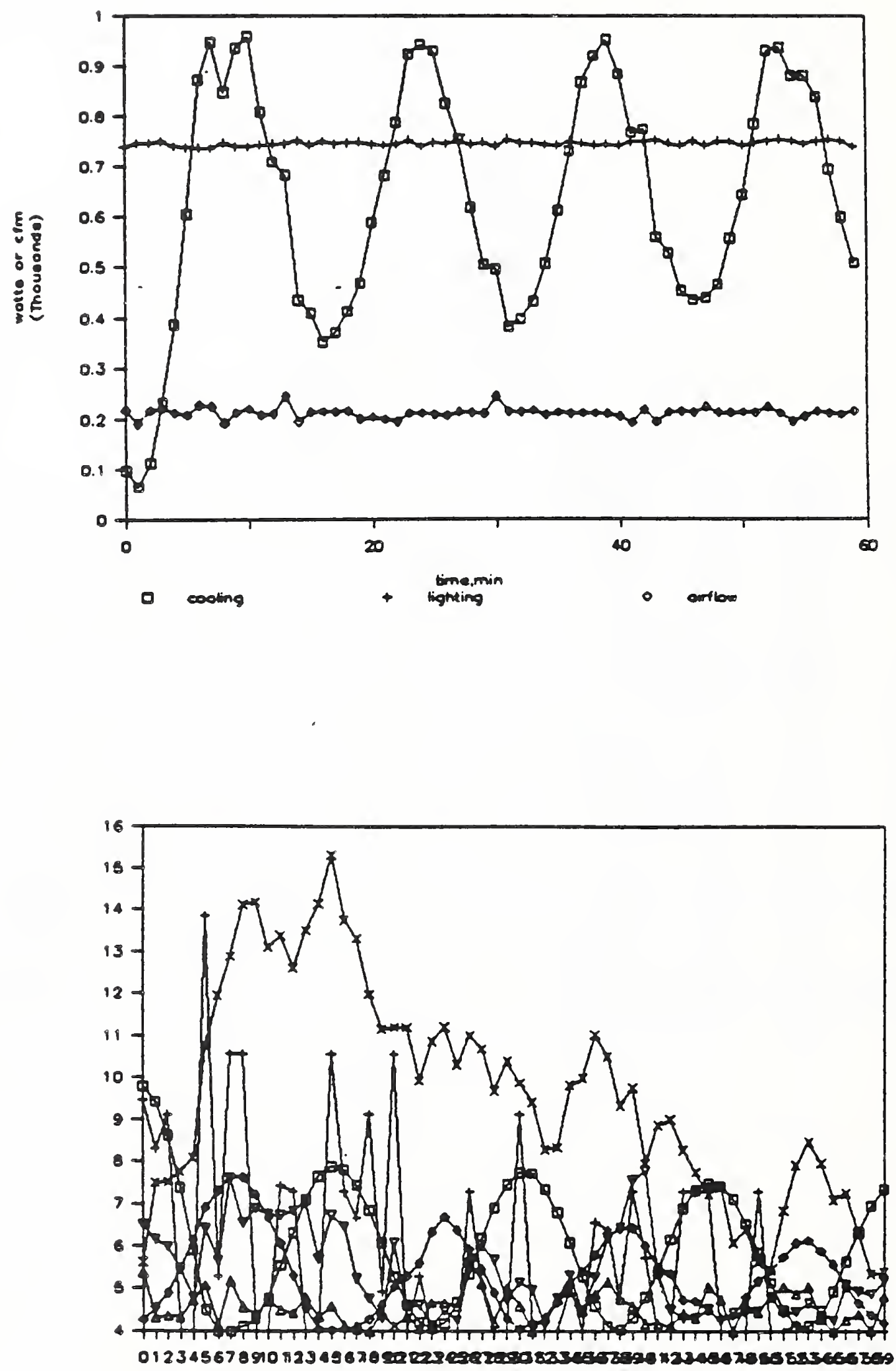

$0 \quad+20 \quad 20 \times 30 \quad 0 \quad 4$

Figure 3.13 Heater Control Signal Oscillations Due to Excessively High Control Loop Gain Constants 

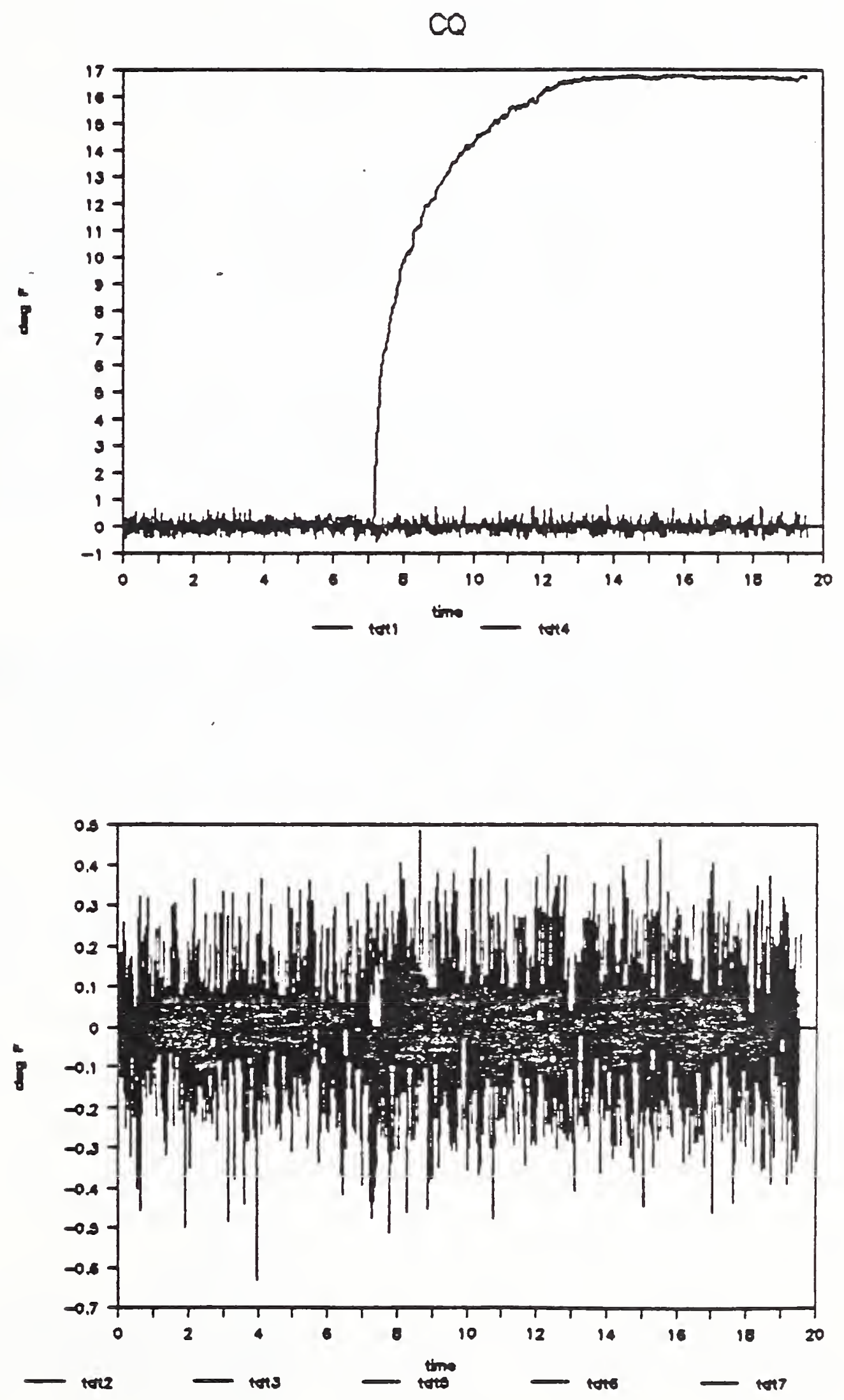

Figure 3.15 Wall Thermopile Outputs on Expanded Scale 
4. Computer Model of Lighting and HVAC Interaction

One of the objectives of this research is to determine the energy distribution fractions from fluorescent luminaires under typical operating conditions. Most of these fractions cannot be measured directly. For example, while the distribution and amount of visible light from the luminaires can be measured with photometers, heat transfer from the luminaires by convection and infrared radiation cannot. As a result, another method for determining the distribution fractions is needed, which can be validated by the measurements.

The method chosen to determine the lighting energy distribution fractions is a computer implementation of an analytical model. By modeling the test facility, including the lighting system and room components, the lighting energy fractions can be computed. Calibration of the computer model with the measured data verifies the accuracy of the computed fractions.

One additional benefit of the computer model is that simulations can be executed for more lighting and room configurations than can be tested, due to limitations in time and physical constraints. Thus, the computer model is useful for extending the measurement results to a larger collection of configurations.

\subsection{Basis of Computer Model}

The computer model is a transient finite-difference formulation using an explicit solution procedure. Heat balance equations are solved for each node, with each node representing a major component of the room or lighting system. The net heat transfer by conduction, convection, infrared radiation and visible radiation is determined for each node. Any net heat gain represents heat storage and causes an increase in node temperature.

The test facility is modeled using 25 nodes. While this is an approximation of the actual facility, the results, as will be shown in section 7, compare favorably to the measurements. Table 4.1 lists the nodes used in the model.

Table 4.1 Nodes for Test Facility Simulation

$\frac{\text { Node }}{1}$
2
3
4
5
6
7
8
9
10
11
12
13
14

Location
Room Air
Plenum Air
Luminaire Air
Lamp
Ballast
Luminaire Housing
Luminaire Diffuser
Floor Surface
Floor Middle
Floor Bottom
Ceiling Bottom
Ceiling Middle
Ceiling Top
Suspended Ceiling Top 
The major simplifications related to the definition of the nodes involve the luminaire and the room and plenum air. The four luminaires of the test room are simulated as a single luminaire with four times the power input, light output and area of a single luminaire. The luminaire itself consists of six nodes, namely, ballast, housing, lamp, diffuser top and bottom, and air. A comprehensive modeling of the luminaire would involve detailed three dimensional conduction and convection, and is beyond the scope of the present research effort. However, the six node model of the luminaire proved to be useful for analyzing the interaction of the lighting and HVAC systems, by allowing for sufficient detail to provide sensitivity to the parameters being varied during the testing.

The room air is assumed to be fully mixed and held at a constant temperature. This is a widely utilized assumption, since a more vigorous treatment would significantly complicate the problem, because three dimensional air circulation calculations would be required. Given the nature of the test facility being modeled, the expected increase in simulation accuracy would be much less than the increase in model complexity.

The plenum air is also assumed to be fully mixed, but the temperature is allowed to vary as heat is stored or reclaimed. Again, for the purpose of evaluating energy transfer from lighting, this assumption can be justified.

\subsection{Solution Procedure}

Initially, all node temperatures are set equal to the room air temperature, which is held constant throughout the simulation. Heat transfer between nodes by conduction, radiation and convection is computed for each time step. The net heat gain to each node is used to calculate new temperatures for each node, or cooling load.

The simulation is initialized with values for nodal properties, including surface areas, volumes, thermal capacitances, surface emittances and radiation shape factors between nodal pairs. The radiation shape factors were precomputed, assuming diffusely reflecting surfaces, using the procedure from [Wa86]. Also specified as input parameters are the fractions of the visible light output from the luminaires which are absorbed by each node. These fractions are constant and were determined from measurement using photometers on a two foot grid across all surfaces. The luminous efficacy of the visible light output must also be specified. This is not the system luminous 
efficacy, but rather the lumens contained in each watt of visible light from the luminaire.

All nodal temperatures are initially set equal to the room air temperature set point. The lamp temperature determines the relative light output, in lumens and power consumption, in watts. The form of these temperature dependent functions is described later. The watts of visible light output (VW) are determined by dividing the lumen output by the luminous efficacy:

$$
\mathrm{VW}=\frac{\text { lumen output }}{\text { luminous efficacy of light output }}
$$

The heat source at the lamp is determined by subtracting the watts of visible light and the ballast losses from the lighting power. A constant ballast fraction of 0.15 was assumed, in the absence of any data on ballast temperature dependence.

The black body equivalent thermal radiation power (EB) from each node (i) was computed from:

$$
E B_{i}=\sigma T_{i}^{4}
$$

where: $\sigma=$ Stefan - Boltzmann constant

$\mathrm{T}_{\mathrm{i}}=$ absolute temperature of node $i$ (or)

The visible light watts incident on each node $\left(Q V_{i}\right)$ were determined from:

$$
\mathrm{QV}_{\mathrm{i}}=\mathrm{S}_{\mathrm{i}} \mathrm{VW}
$$

where: $\quad S_{i}=$ fraction of visible light absorbed by node $i$

(determined from measurements)

The convection coefficients between air and surface nodes are computed from free or forced convection correlations, adjusted as appropriate [As77]. Table 4.2 lists the correlation used for each node.

\section{Table 4.2 Convection Correlations for Simulations}

Lamp, Housing

Vertical Surfaces

Horizontal Surfaces

$$
\Delta \mathrm{T}=\text { temperature difference, }{ }^{\circ} \mathrm{F}
$$

The calibration of the computer model is accomplished primarily through the adjustment of the convection coefficients, since these have the most uncertainty and least link to fundamental heat transfer theory. The calibration procedure is described in chapter 7 . 
The rate of heat transfer between nodes by thermal radiation is determined by solving for the radiosity of each node. Nodal radiosity $\left(B_{i}\right)$ is composed of emitted and reflected radiation, according to:

$$
B_{i}=\left\{\left[E F_{i} \cdot E B_{i}\right]+\sum_{j} \underline{E}_{1} F_{i j} \cdot B_{j}\right\}\left(\frac{1}{1+E F_{i}}\right)
$$

where: $\quad E F_{i}=E M_{i} /\left(1-E M_{i}\right)$

$$
\begin{array}{ll}
E M_{i}= & \text { emittance of node } i \\
F_{i j}= & \text { radiation shape for factor between nodes } i \text { and } j
\end{array}
$$

Application of equation 4.4 to all the surface nodes leads to a set of simultaneous equations for $B$. These are solved using Gauss-Seidel iteration.

The net radiation at each node $\left(Q R N_{i}\right)$ is computed by subtracting radiosity from irradiance, where irradiance (Hi) at node (i) is given by:

$$
H_{i}=\sum_{j=1}^{N} F_{i j} \cdot B_{j}
$$

Thus :

$$
\mathrm{QRN}_{i}=\left(\mathrm{H}_{i}-\mathrm{B}_{i}\right) \mathrm{A}_{i}
$$

where: $\quad A_{i}=$ surface area of node $i$

Heat transfer by convection is determined for each surface node using the convection coefficients and the surface and adjacent air temperatures.

$$
\mathrm{QC}_{i}=\mathrm{HC}_{i} \cdot\left(\mathrm{T}_{\mathrm{air}}-\mathrm{T}_{\mathrm{i}}\right) \mathrm{A}_{\mathrm{i}}
$$

where: $\quad Q C_{i}=$ convective heat gain for node $i$

$\mathrm{HC}_{i}=$ convection coefficient for node $i$

$\mathrm{T}_{\mathrm{air}}=$ temperature of adjacent air

Similarly, heat transfer by conduction $\left(\mathrm{CK}_{i}\right)$ is computed from:

$$
C K_{i}=\sum_{j}^{N} K_{i j}\left(T_{j}-T_{i}\right) A_{i}
$$

where: $\quad k_{i j}=$ conductance between nodes $i$ and $j$

The heat storage in each node $\left(Q_{i}\right)$ is determined from:

$$
\mathrm{QS}_{i}=\left(\mathrm{QRN}_{i}+\mathrm{QC}_{i}+\mathrm{QV}_{i}+\mathrm{QK}\right)_{i}
$$

The lamp and ballast have additional storage amounts due to source heat, as mentioned earlier. 
The last step in the process is to compute new node temperature, according to:

$$
\text { new } \mathrm{T}_{i}=\mathrm{T}_{i}+\frac{\mathrm{QS}}{\mathrm{C}_{\mathrm{i}}}
$$

where: $\quad C_{i}=$ thermal capacitance of node $i$

$$
=\left(\mathrm{mC}_{\mathrm{p}}\right)_{i}
$$

$m=$ mass of node $i$

$c_{p}=$ specific heat of node $i$

Since room air temperature is held constant, the computed heat storage in the room air is actually the cooling load. The plenum air heat balance also includes heat transfer due to mass flow of the return air through the plenum. This term is:

$$
\text { Plenum heat }=\dot{\mathrm{m} C p}\left(\mathrm{~T}_{\text {room air }}-\mathrm{T}_{\text {plenum air }}\right) \text { TAO }
$$

where: $\quad$ TAO = time increment

Once the new temperatures are computed, the entire cycle is repeated for each time step until steady conditions are achieved, thus simulating a step response test. 


\section{Steady State Measurement Results}

Steady state measurements of lighting system performance are useful because, as will be shown later, the lighting system may be operating at equilibrium with its thermal environment for long periods of time. Thus, the lighting and HVAC system should be designed and operated so that the lighting system is at its peak efficiency, meaning that the lamps are between $100-104^{\circ} \mathrm{F}$.

When the lighting system is initially switched on, the luminaire temperature increases until equilibrium conditions are achieved. This may take several hours. The equilibrium temperatures, and related energy flows are dependent on the room thermal environment. For the lighting system, two of the most important room thermal parameters are room air temperature and a return airflow rate. The return airflow configuration also can exert a strong influence.

The effects of room air temperature, airflow rate and return air configuration on the thermal conditions of the lighting system and room components were examined through a series of steady state tests. The lighting system was left on while the various parameters were changed, and data collected until steady state conditions were observed for each measurement configuration. At least four hours of steady conditions were required to ensure equilibrium had occurred.

\subsection{Lamp Compartment Return}

The effects of different room air temperatures and airflow rates will be greater for lamp compartment return than for side slots or ceiling grill returns, because the return air circulates directly over the lamps. The airflow rate was varied from 120 to 160 to $200 \mathrm{cfm}$, or 30 to 40 to 50 cfm per luminaire. Room air temperature was set at 70,75 or $80^{\circ} \mathrm{F}$. Lighting power, light output, average air and surface temperatures, and minimum lamp temperatures were determined from measurements for each configuration.

The effect of airflow rate and room air temperature on lighting power consumption is shown in figure 5.1. The numbers next to the data points are the actual room air temperatures. The trends are as would be expected, with cooler air temperatures and higher air flow rates causing greater power usage. It should be noted that light output also increases along with power consumption as does luminous efficacy, and thereby, lighting system efficiency. The difference between the greatest lighting power, 767 watts $\left(4.56\right.$ watts/ft ${ }^{2}$ ) and the least, 730 watts ( 4.35 watts $/ \mathrm{ft}^{2}$ ) is five percent. By comparison, with the test room fan off, the average minimum lamp wall temperature was $133^{\circ} \mathrm{F}$, and the lighting power consumption was 671 watts, only 87 percent of maximum.

The variation in lighting power is tied directly to the minimum lamp wall temperature, as shown in figure 5.2. The lighting power density is plotted versus the average minimum lamp wall temperature. This is the average of the individual lamp temperature minima for each luminaire. The range in average minimum lamp temperatures is not great, spanning less than ten degrees $F$. This indicated that even the $80^{\circ} \mathrm{F}$ room temperature and $120 \mathrm{cfm}$ airflow condition cool the lamps to some extent, 
with an average minimum lamp wall temperature of less than $111^{\circ} \mathrm{F}$. According to the formula from [Mu85], a ten degree $F$ difference in minimum lamp temperature would correspond to a four percent change in luminous efficacy. Least - squares linear regression was used to correlate lighting power with minimum lamp wall temperature for use in the computer model simulations. Relative lighting power, that is the ratio of actual to maximum lighting power, was found to be related to average minimum lamp wall temperature ( $\mathrm{T}_{\mathrm{MLW}}$ ) by:

$$
\begin{aligned}
& \text { Relative } \\
& \text { Lighting }=1.3089-0.00323 \mathrm{~T}_{\mathrm{MLW}}\left({ }^{\circ} \mathrm{F}\right) \\
& \text { Power }
\end{aligned}
$$$$
\text { for } \mathrm{T}_{\mathrm{MLW}} \geq 95.6^{\circ} \mathrm{F}
$$

Lighting system light output varied with room air temperature and airflow rate in a manner similar to lighting power consumption, as shown in figure 5.3. The difference between the greatest light output, and the least is four percent. The relationship between light output and average minimum lamp wall temperature is shown in figure 5.4. Using linear regression relative light output was found to vary with minimum lamp wall temperature according to:

$$
\begin{aligned}
& \text { Relative } \\
& \text { Light }=1.2960-0.00297 \mathrm{~T}_{\mathrm{MLW}}\left({ }^{\circ} \mathrm{F}\right) \\
& \text { Output }
\end{aligned}
$$

\section{for $T_{M L W} \geq 99.7^{\circ} \mathrm{F}$}

The conditions in this series of tests found the average minimum lamp wall temperatures to be at or above the temperature corresponding to maximum power consumption and light output. Thus, cooling the lamps by lowering the air temperature or increasing air flow always caused an increase in light output and power consumption. With lower lighting power densities, it is likely that lamp temperatures would be below the temperatures corresponding to maximum light. output and power consumption, under some conditions.

The relationship between lighting system luminous efficacy and average minimum lamp wall temperature is displayed in figure 5.5. Considerable scatter in the data is apparent, due to uncertainty in the lighting power and light output values which make up the luminous efficacy ratio. Due to the scatter and limited data available, no correlation was derived for luminous efficacy. However, it appears that luminous efficacy peaks near $104^{\circ} \mathrm{F}$, with a minimum value, for the lowest average lamp wall temperature $\left(\sim 98^{\circ} \mathrm{F}\right)$, two percent lower than the maximum. This low lamp temperature occurred for an extra data point collected at a room temperature of $65^{\circ} \mathrm{F}$. A decrease in luminous efficacy is also seen at the hotter lamp temperatures.

Average minimum lamp wall temperature as a function of airflow rate and room air temperature is shown in figure 5.6. A five degree change in room air temperature causes a correspondingly smaller change in minimum lamp temperature, about four degrees at the high airflow rate, and three degrees at the low airflow rate. Changing airflow rate has the greatest effect at the $70^{\circ} \mathrm{F}$ air temperature, with an increase in airflow from 30 
to $50 \mathrm{cfm}$ per luminaire causing a $3^{\circ} \mathrm{F}$ drop in minimum lamp temperature. The same airflow change caused only a $1^{\circ} \mathrm{F}$ drop in minimum lamp temperature for the $80^{\circ} \mathrm{F}$ room air temperature. This is probably due to the stronger effects of convection when the room and lamp temperature. differences are greater.

While the room air is being held constant at the set - point, the plenum air can heat up due to energy from the lights. Figure 5.7 shows average plenum air temperature, computed from the average of 16 thermocouples, as a function of airflow rate and room air temperature. At the lowest airflow rate, plenum air temperature increased by between 5 and 6 degrees $F$ over room air temperature. At the highest airflow rate, plenum air temperature exceeded room air temperature by 4 to 5 degrees F.

Figure 5.8 shows the average floor temperatures for both the tops of the floor slab and ceiling slab. Very close agreement is seen between the average temperatures of the top surfaces of both slabs. Average floor surface temperature is about two to three degrees $F$ warmer than room air temperature, with the extreme range in airflow rates causing less than a one degree change in floor temperature, for a constant room air temperature.

Similar results are shown for the ceiling in figure 5.9, which shows data for both the bottoms of the ceiling and floor slabs. The match in temperatures is not as good as the floor temperatures. This is partly due to the high conductivity steel decks, which make surface temperature measurements difficult, partly due to the small number of thermocouples under the floor slab, and partly due to control system performance. The lower steel deck is typically measuring one degree wartuer than the upper steel deck. The upper steel deck (room ceiling) is about two degrees above room air temperature.

The average temperature of all the walls was determined individually and as a group, both for above and below the suspended ceiling. Figure 5.10 shows the results for the average temperature of all of the walls together. Below the plenum, the room walls do not show much increase in temperature due to operation of the lighting system. The walls in the plenum do heat up noticeably.

Some temperatures are at or slightly below the room air temperature setpoint. It is possible that the wall temperatures could be slightly below the average room air temperature due to non -uniform room air temperatures. The walls above the plenum heat up about two or three degrees above room air temperature. The full range of airflow rates have about a one degree effect, with the highest airflow rate keeping the plenum air about one degree cooler than the lowest airflow rate.

Average temperatures were also determined for each wall individually. The results are shown for the north wall in figure 5.11, east wall in figure 5.12, south wall in figure 5.13 and west wall in figure 5.14. The west wall is not instrumented with as many thermocouples as the east wall, and the north and south walls have detailed thermocouple grids over only one half of their widths. The individual wall temperatures are similar to the average wall temperatures, although the north and east walls are shown to be slightly warmer than the south and west 
walls. In all cases the plenum walls are about three degrees $F$ warmer than the corresponding room walls. Also, a five degree change in room air temperature produces nearly a five degree change in average wall temperatures, for all conditions.

\subsection{Effect of Return Configuration}

A series of steady state tests was run with different airflow rates and return air configurations, for a room temperature of $75^{\circ} \mathrm{F}$, with the lights on. Figure 5.15 presents lighting power as a function of airflow rate and return path. The letters next to the points identify the return air path by its initials. Lighting power with the lamp compartment return is substantially greater than either the side slot or ceiling grill return. This is due to the increased cooling of the lamps with the lamp compartment return. The lighting power results are very similar for the side slots and ceiling grill returns. Lighting power increases with airflow for all return configurations.

The variations in lighting power are a direct result of the minimum lamp temperatures, as shown in figure 5.16. Minimum lamp wall temperature decreases with increasing airflow rates, with lamp compartment return keeping the lamps about 7 of cooler than either the side slots or ceiling grill. The range of airflow rates caused minimum lamp wall temperature to vary by $3^{\circ} \mathrm{F}$ for each return configuration.

Figure 5.17 presents average plenum air temperature versus airflow rate and return path. Plenum air temperatures decrease with higher airflow rates, particularly for the lamp compartment return. Plenum air temperatures span about $2{ }^{\circ} \mathrm{F}$ for the range of conditions, and are greatest for the lamp compartment return. This is due to the heat pickup from the luminaires. Plenum air temperatures for the ceiling grill return are affected the least by airflow rate.

The ceiling and floor temperatures are shown in figures 5.18 and 5.19 , respectively, versus airflow rate and path. The scales are magnified on these plots. Both the floor and ceiling heat up the most for the ceiling grill return at $200 \mathrm{cfm}$, and the lamp compartment return at 120 cfm. These two opposite conditions have similar effects because low airflow with the lamp compartment return allows the slabs to heat up, while the high airflow with the ceiling grill increases convective heat transfer to the slabs from the warm plenum air. The slab temperatures exceed room air temperature by two to four degrees $F$ for the range of conditions tested.

Figures $5.20,5.21,5.22$ and 5.23 present the temperature results for the north wall, east wall, south wall and west wall, respectively, both for the room and plenum portions of the wall. The patterns are very similar for each of the walls, with the plenum walls being about $3{ }^{\circ}$ warmer than the room walls. The low temperatures indicated for the south and west walls are due to the limited number of temperature sensors located on these surfaces. The return air path has very little effect on the wall temperatures. Increasing the airflow rate causes plenum wall temperatures to decrease, but has little effect on room wall temperatures. This indicates that heat transfer by forced convection at the room walls is a minor effect. 


\section{3 Luminaire Temperatures}

Luminaire temperatures were measured using thermocouples distributed on the luminaire surfaces. As was mentioned earlier, luminaire temperatures reach equilibrium relatively quickly after the lights are switched on or off. Figure 5.24 shows the rapid rise in luminaire temperature after the lights are switched on. Room air temperature is $70^{\circ} \mathrm{F}$, and airflow equal to $200 \mathrm{cfm}$ with ceiling grill return for this test. The two warmest temperatures are the tops of the lamps, which are above $52^{\circ} \mathrm{C}$ or $126^{\circ} \mathrm{F}$. The bottom of the lamp end is $46.5^{\circ} \mathrm{C}$, or $116^{\circ} \mathrm{F}$. At the center of one lamp, the top temperature is $52.4^{\circ} \mathrm{C}\left(126^{\circ} \mathrm{F}\right)$ and the bottom $43.5^{\circ} \mathrm{C}\left(109^{\circ} \mathrm{F}\right)$. For the second lamp, temperatures at the same locations are $43.2^{\circ} \mathrm{C}\left(110^{\circ} \mathrm{F}\right)$ and $37.0^{\circ} \mathrm{C}\left(99^{\circ} \mathrm{F}\right)$. This demonstrates the cooling effect at the bottom of the lamps, and the trapping of heat near the lamp tops. The top of the luminaire housing, facing the plenum, is at $39^{\circ} \mathrm{C}$, or $102 \mathrm{~F}$, and the diffuser is nearly at room air temperature, $21.6^{\circ} \mathrm{C}$ or $71^{\circ} \mathrm{F}$.

Similar data are presented in figure 5.25 for side slot air return, 200 cfm and $70^{\circ} \mathrm{F}$ test condition in a lights off test. The two warmest temperatures are again the lamp tops, at $52^{\circ} \mathrm{C}$ or $126^{\circ} \mathrm{F}$. The ballast housing interface is $47.7^{\circ} \mathrm{C}$ or $118^{\circ} \mathrm{F}$. The bottom of the lamp center is $43^{\circ} \mathrm{C}\left(110^{\circ} \mathrm{F}\right)$, while the housing bottom is approximately $36^{\circ} \mathrm{C}\left(97^{\circ} \mathrm{F}\right)$. All of the temperatures return to room temperature in less than two hours, except for the ballast which requires about four hours.

Similar luminaire temperature distributions were observed for other test configurations. Fluorescent lamp temperatures varied substantially from top to bottom, and end to center, and from lamp to lamp. These temperature variations are due to localized differences in airflow patterns and rates. As a result, the entire lighting system, including 16 lamps, is operating with each lamp drawing a different amount of power as a result of its individual minimum lamp wall temperature. The variations in lighting power and light output observed were for the lighting system as an ensemble. 
Figure 5.1 Lighting Power Versus Room Air Temperature and Airflow Rate for Lamp Compartment Return
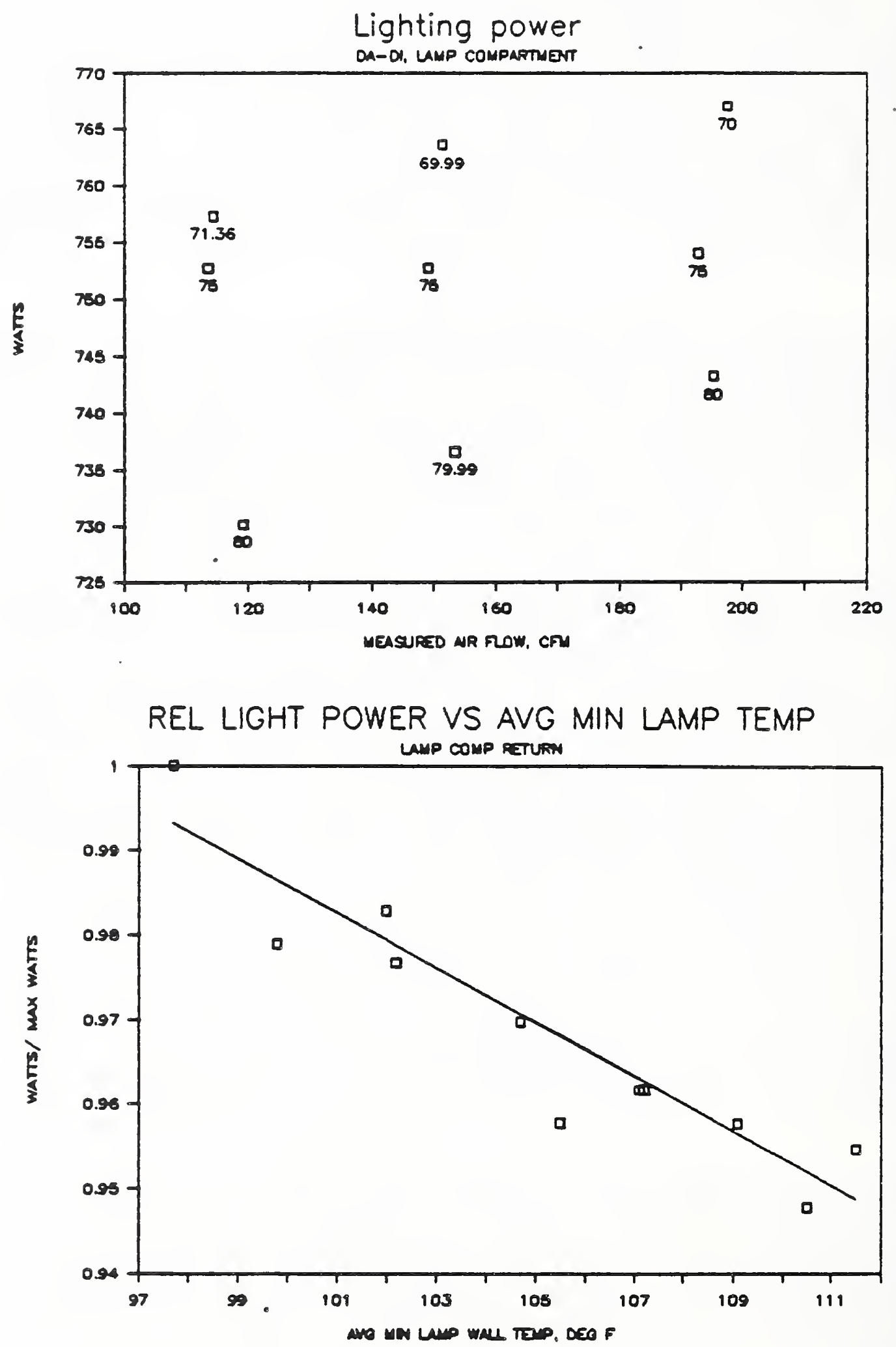

Figure 5.2 Lighting Power Versus Average Minimum Lamp Wall Temperature 
Figure 5.3 Light Output Versus Room Air Temperature and Airflow Rate
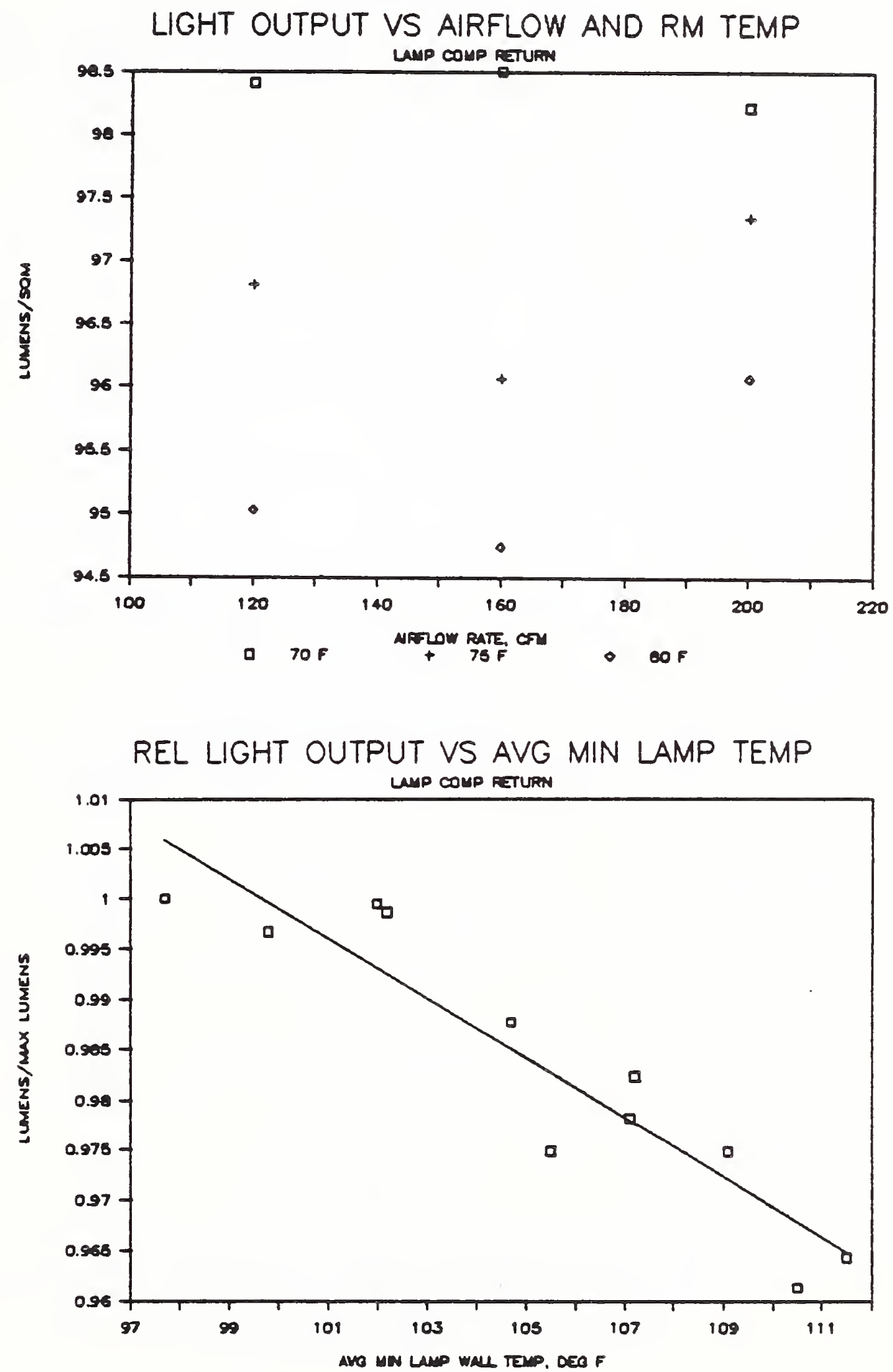

Figure 5.4 Light Output Versus Average Minimum Lamp Wall Temperature 
Figure 5.5 Lighting System Luminous Efficacy Versus Average Minimum Lamp Wall Temperature
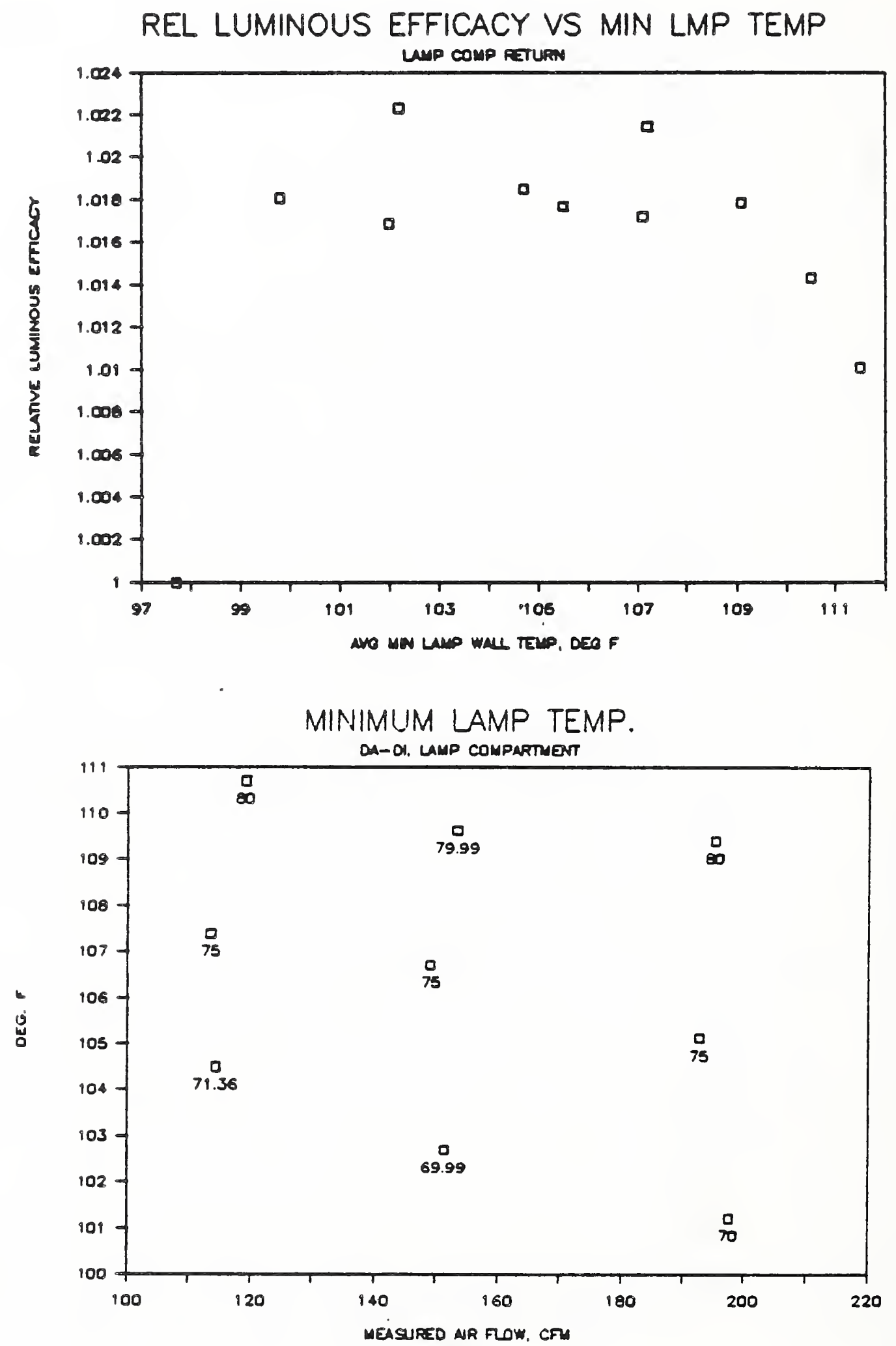

Figure 5.6 Average Minimum Lamp Wall Temperature Versus Room Air Temperature and Airflow Rate 
Figure 5.7 Average Plenum Air Temperature with Lights on Versus Room Air Temperature and Airflow Rate
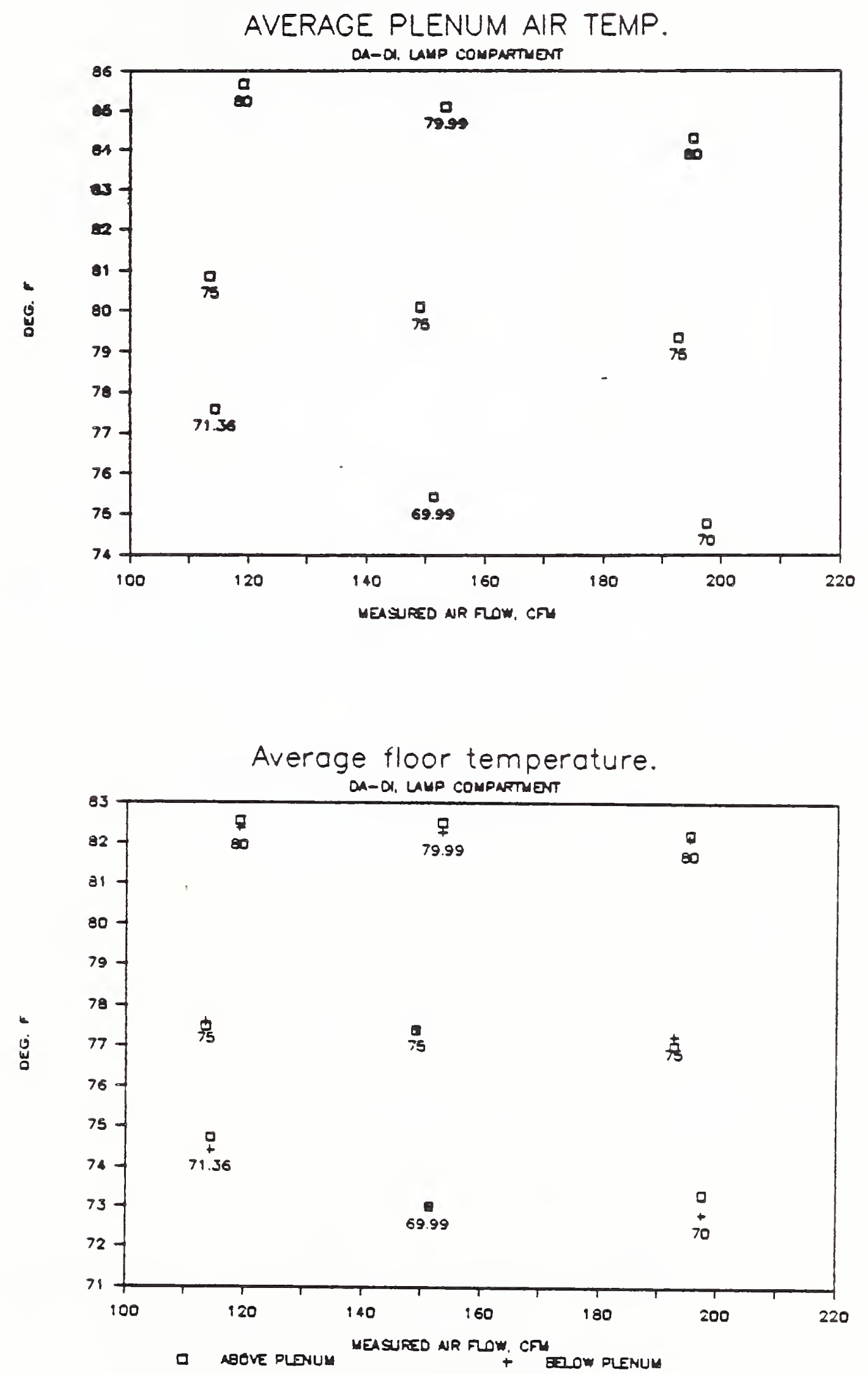

Figure 5.8 Average Floor Temperature with Lights on Versus Room Air Temperature and Airflow Rate 
Figure 5.9 Average Ceiling Temperature with Lights on Versus Room Air Temperature and Airflow Rate

Average ceiling temperature

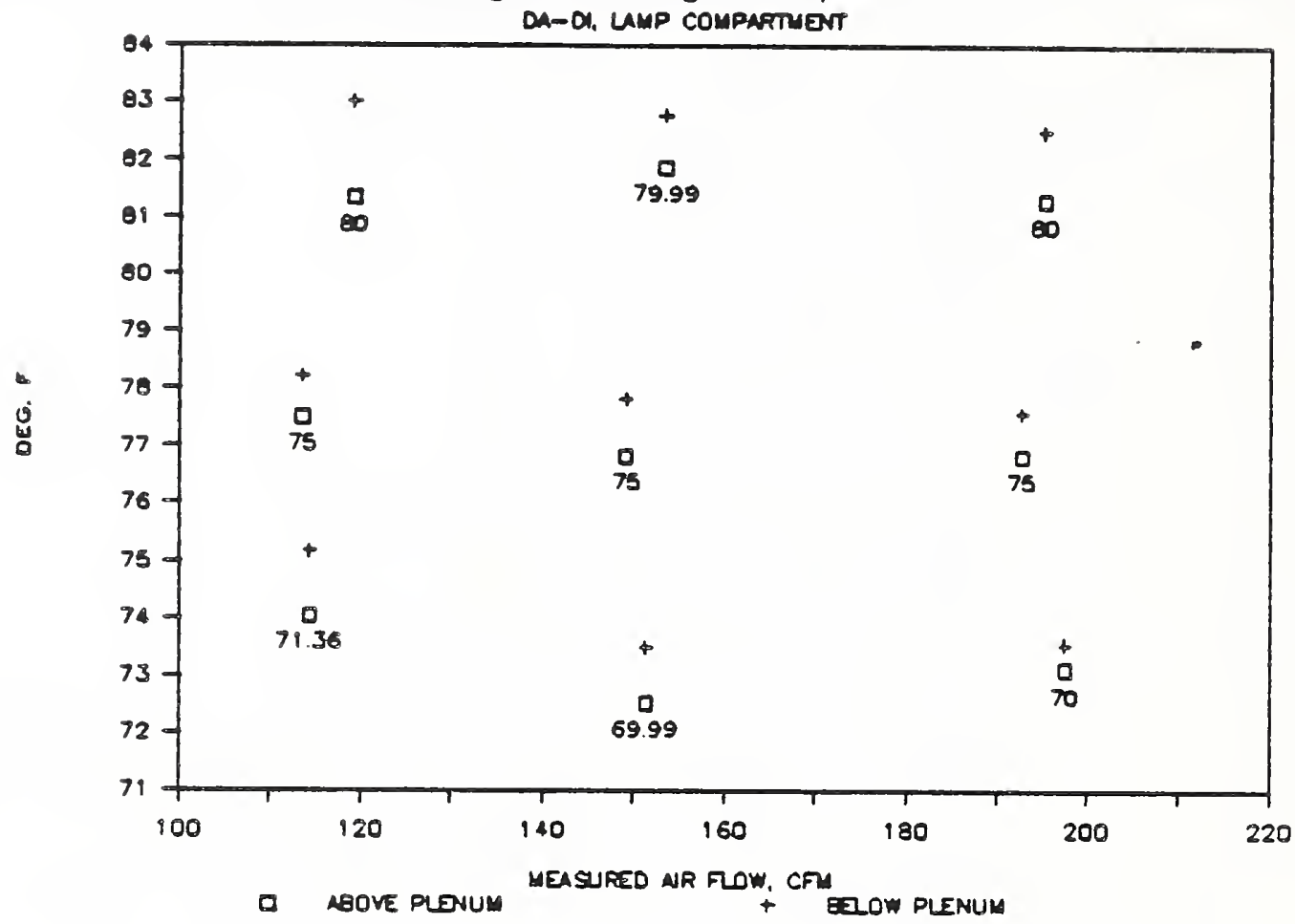

Average wall temperature

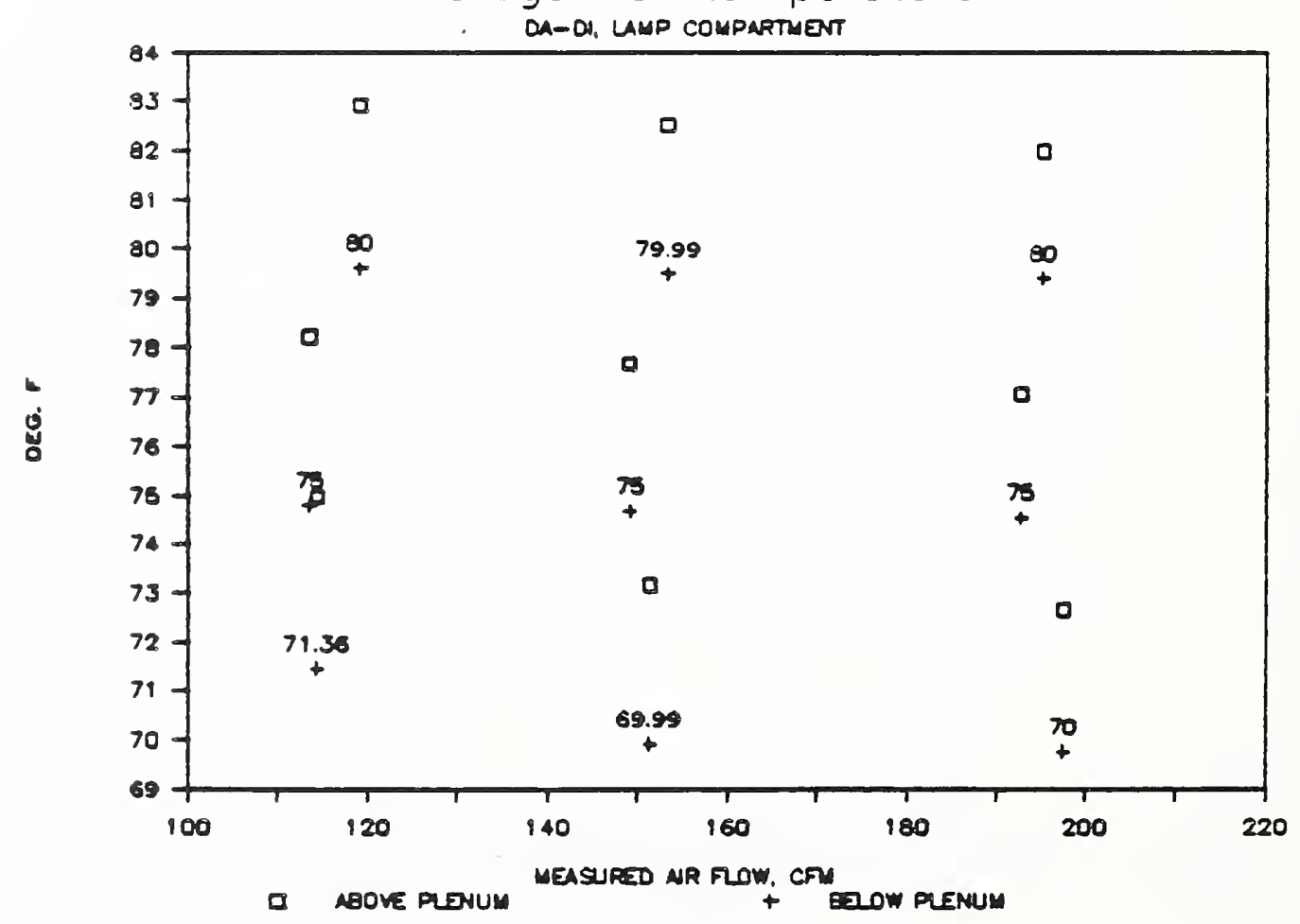

Figure 5.10 Average Wall Temperature with Lights on Versus Room Air Temperature and Airflow Rate 
Figure 5.11 Average North Wall Temperature with Lights on Versus Room Air Temperature and Airflow Rate
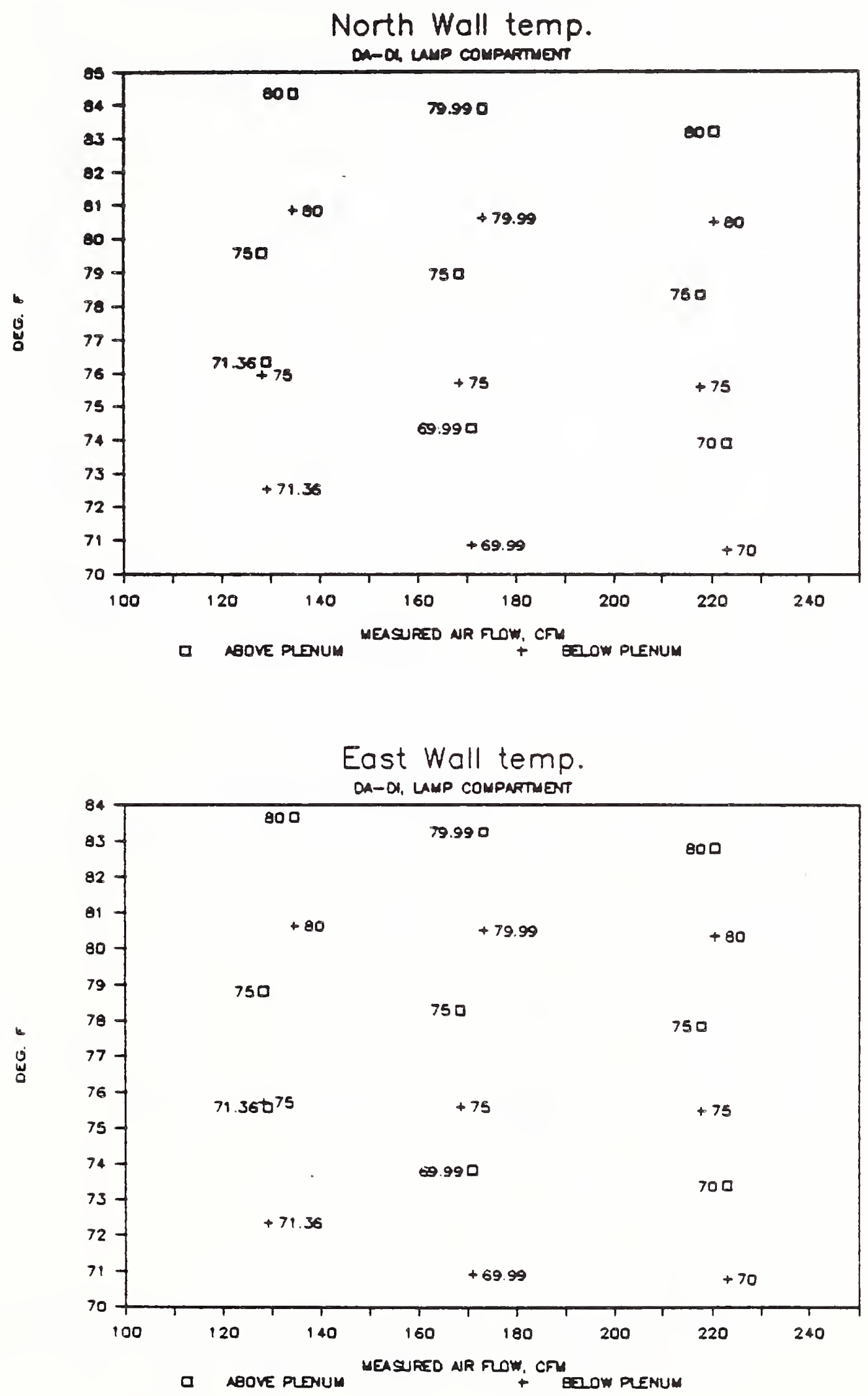

Figure 5.12 Average East Wall Temperature with Lights on Versus Room Air Temperature and Airflow Rate 
Figure 5.13 Average South Wall Temperature with Lights on Versus Room Air Temperature and Airflow Rate
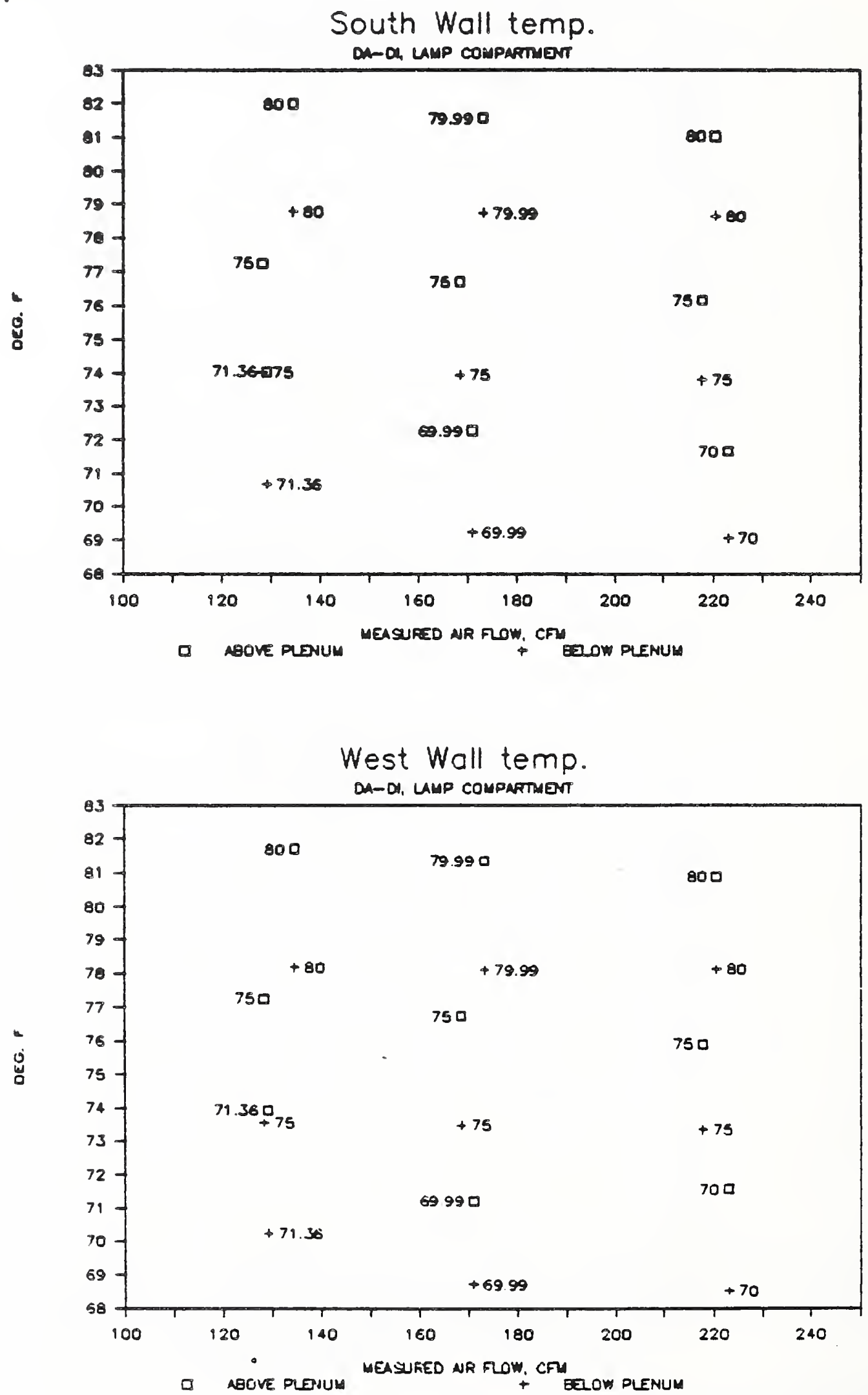

Figure 5.14 Average West Wall Temperature with Lights on Versus Room Air Temperature and Airflow Rate 


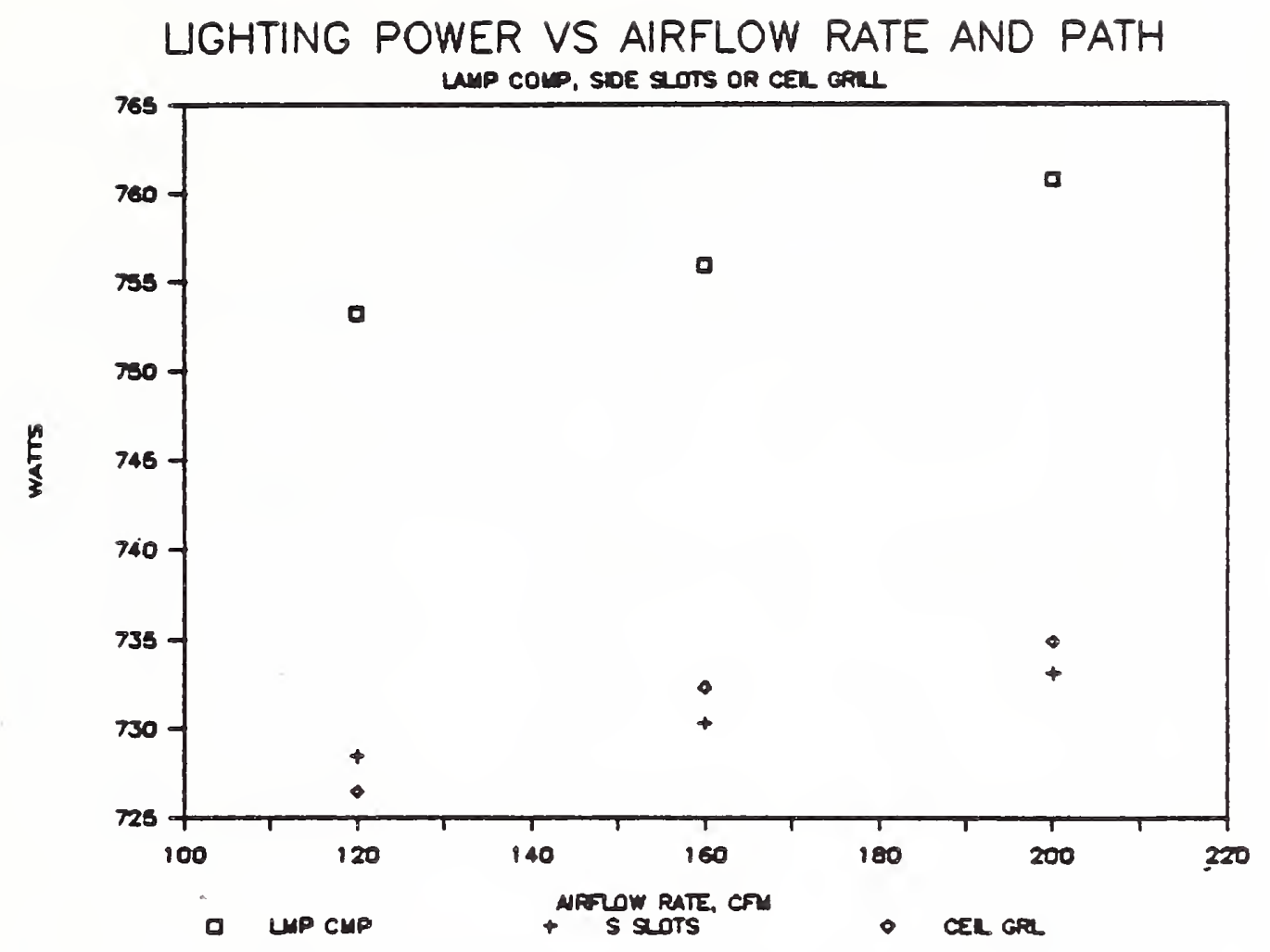

Figure 5.15 Lighting Power Versus Airflow Rate and Path 
Figure 5.16 Average Minimum Lamp Temperature Versus Alrflow Rate and Path

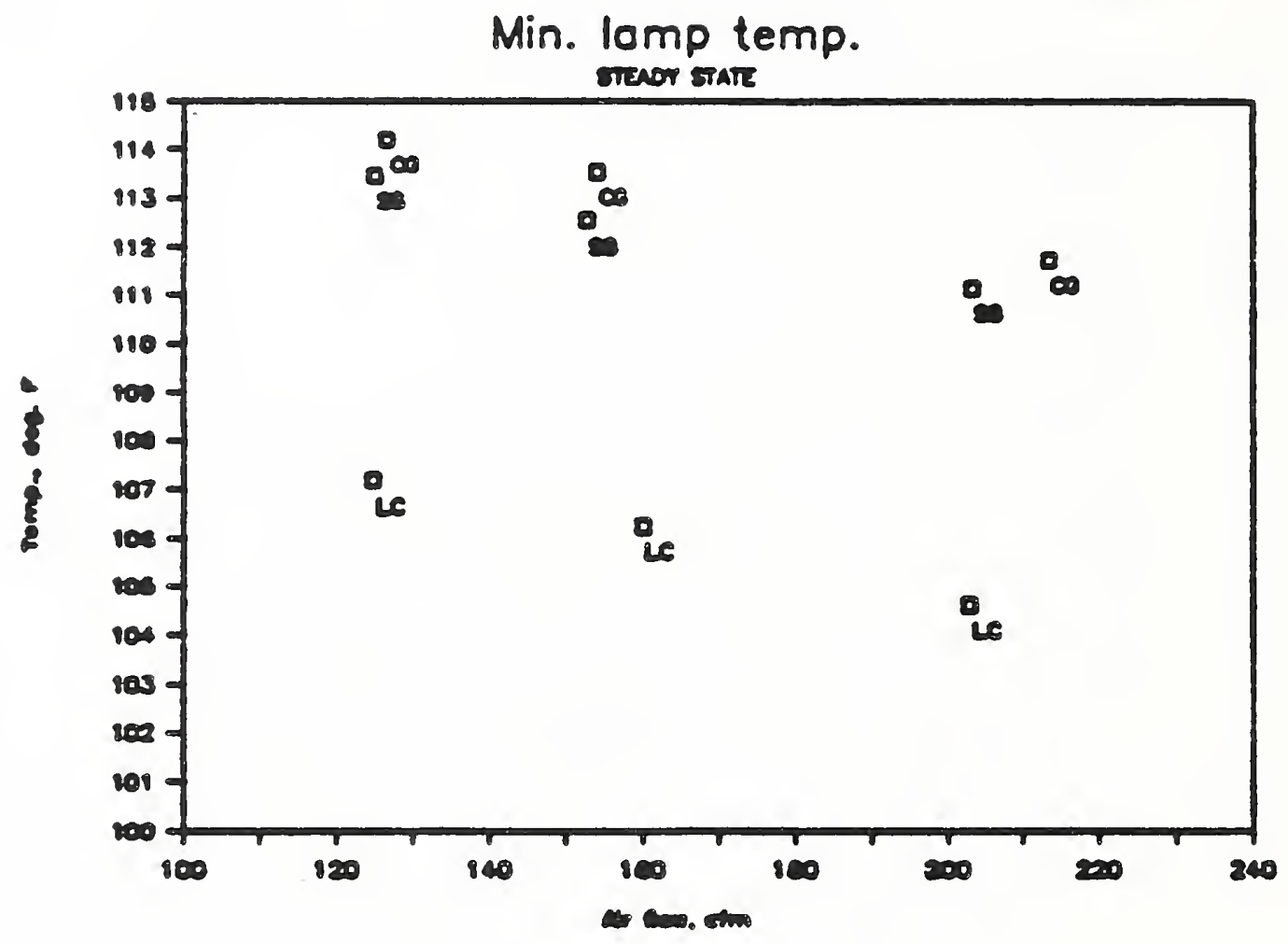

Plenum oir temp.

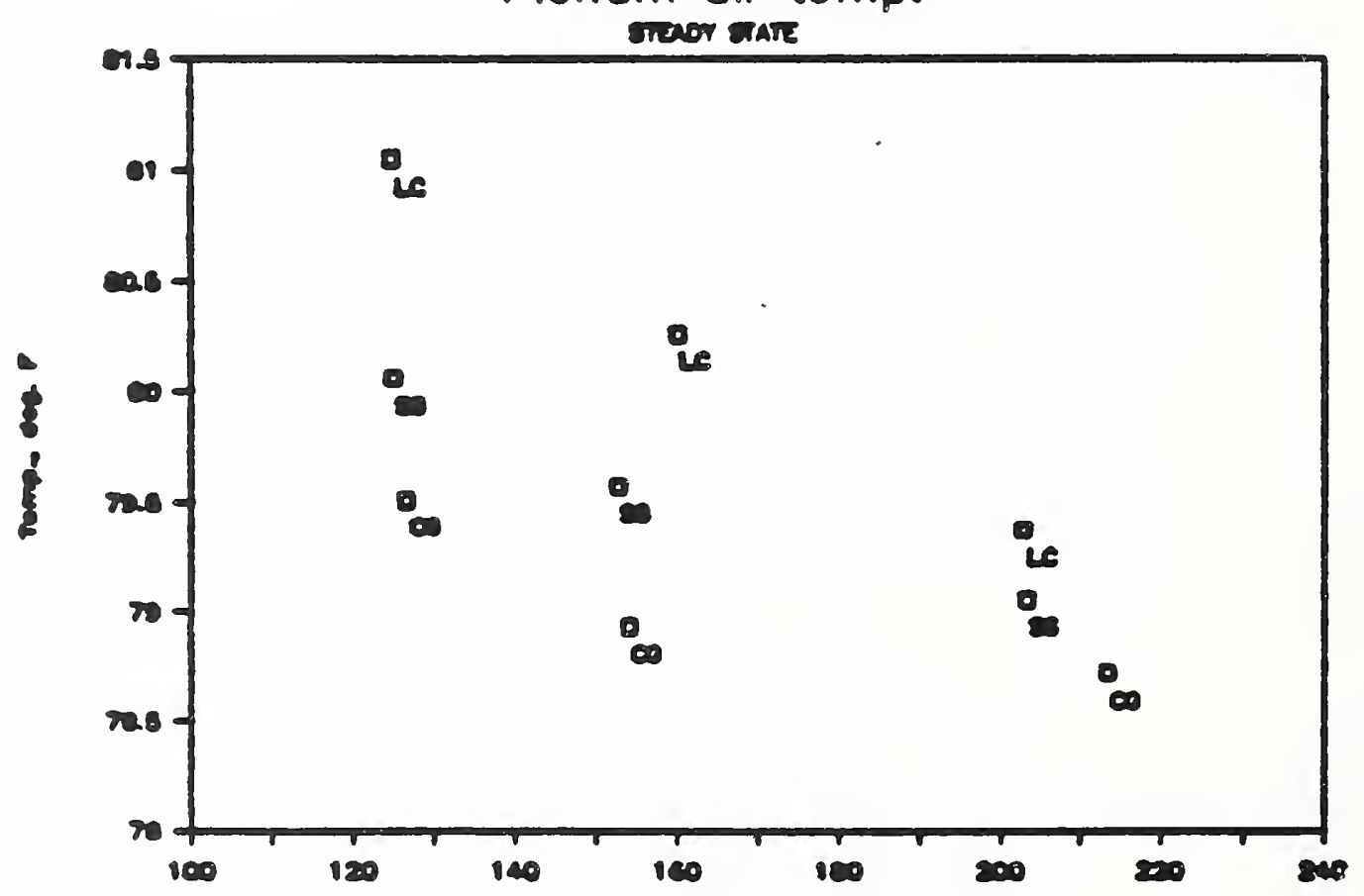

Figure 5.17 Plenum Air Temperature Versus Airflow Rate and Path 
Figure 5.18 Ceiling Temperatures Versus Airflow Rate and Path

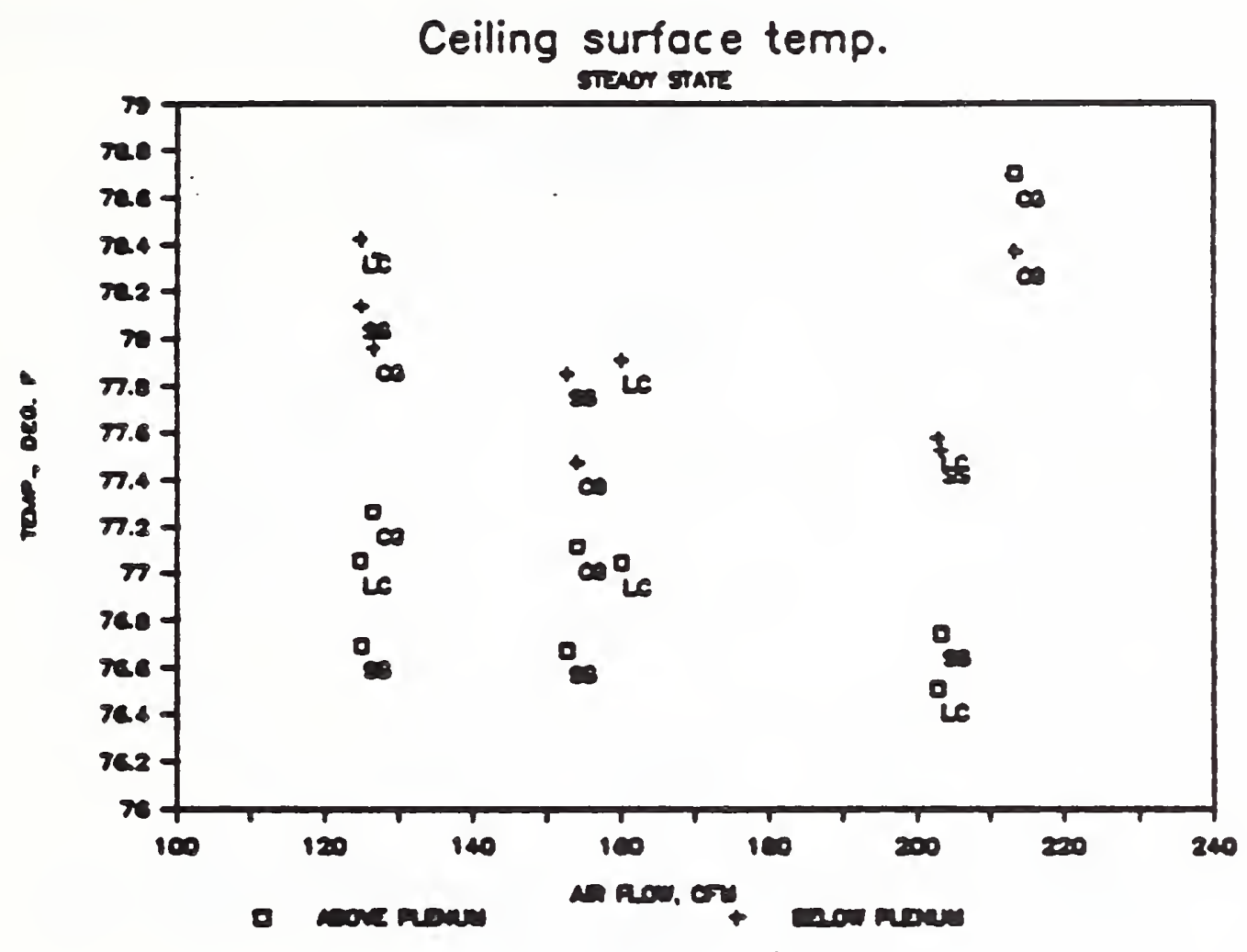

Floor surfoce temp.

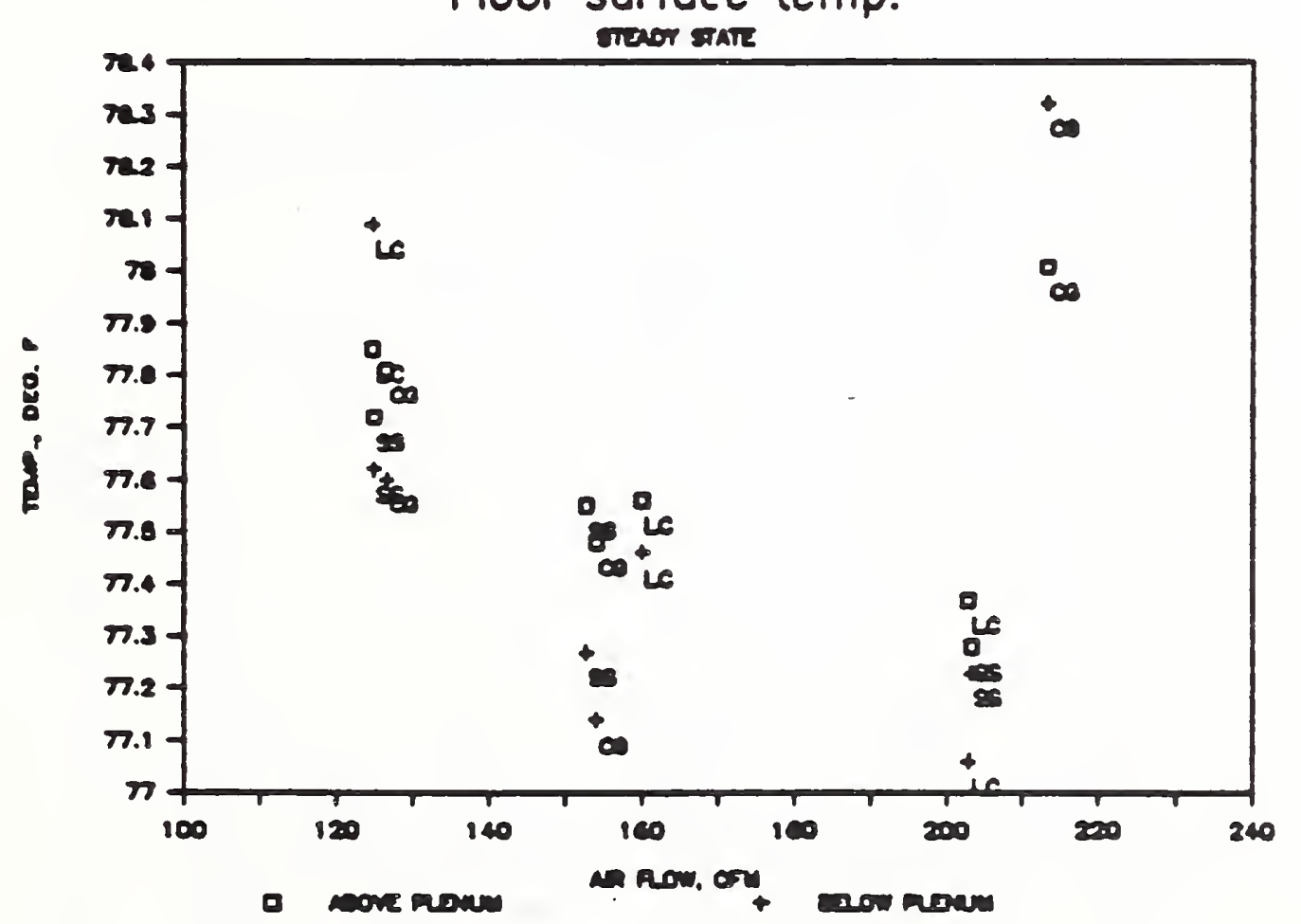

Figure 5.19 Floor Temperatures Versus Airflow Rate and Path 
Figure 5.20 North Wall Temperature Versus Airflow Rate and Path

North Wall surface temp.

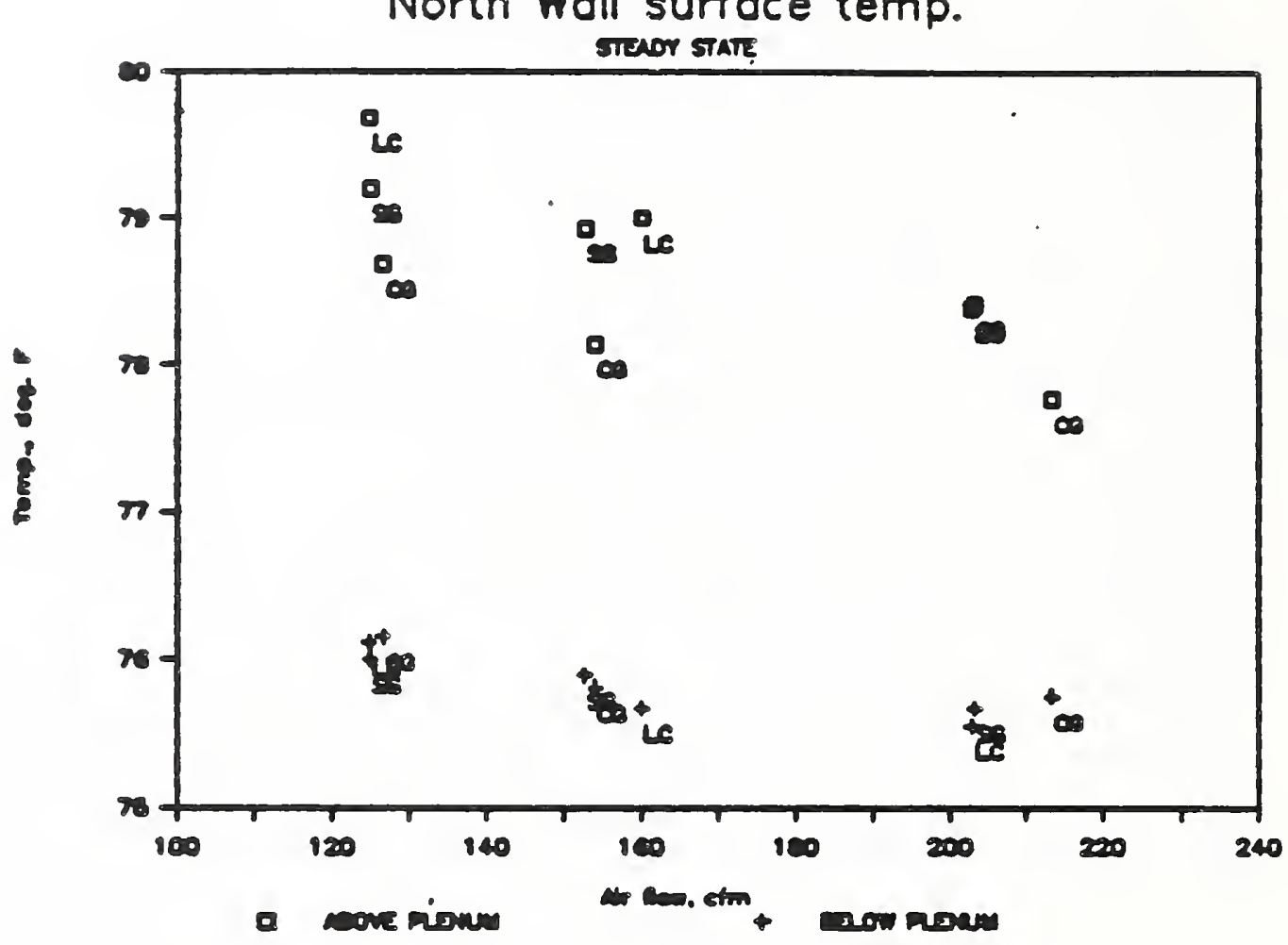

Eost Wall surface temp.

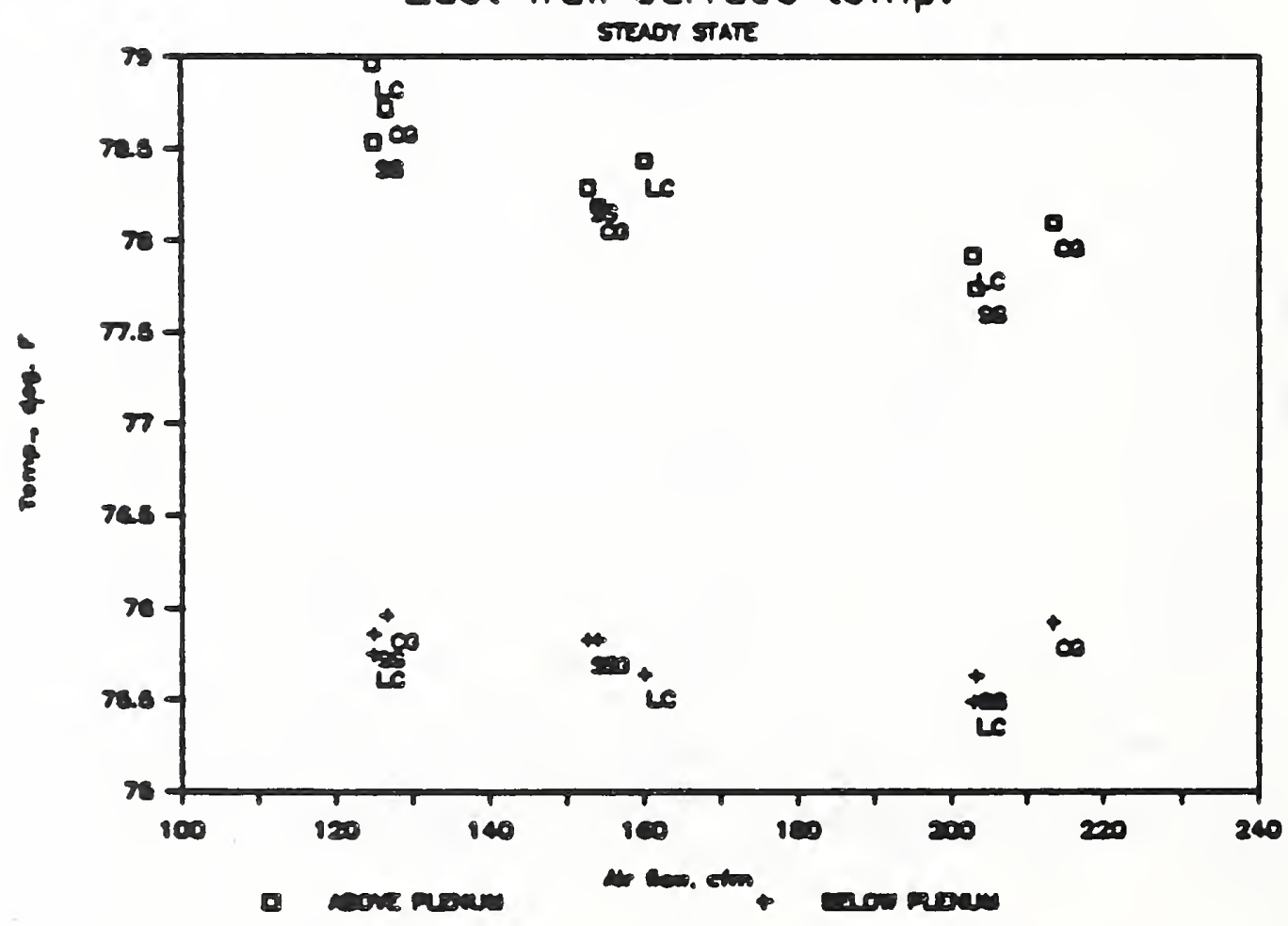

Figure 5.21 East Wall Temperature Versus Airflow Rate and Path 
Figure 5.22 South Wall Temperatures Versus Airflow Rate and Path

South Woll surfoce temp.

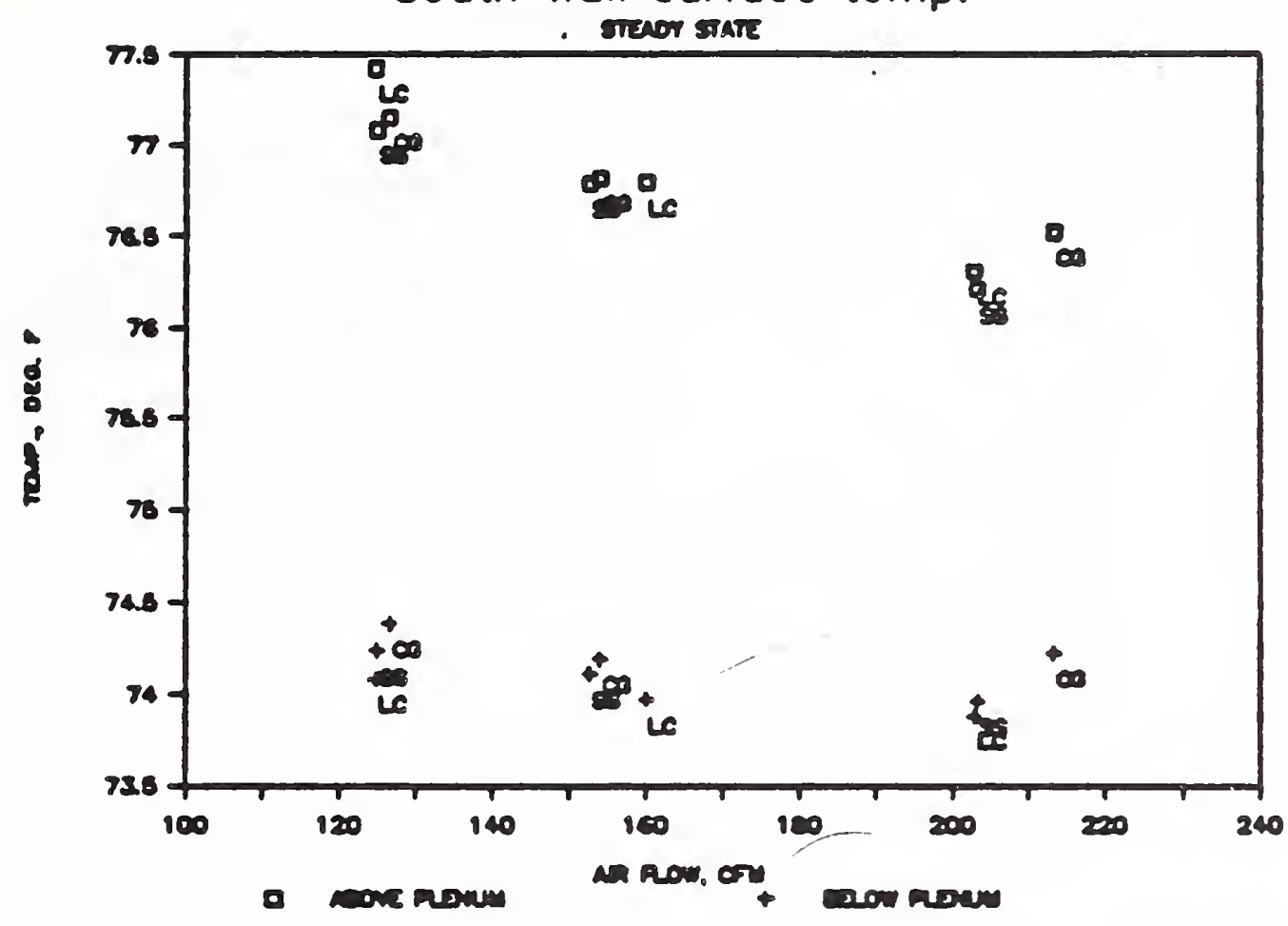

West Wall surfoce temp.

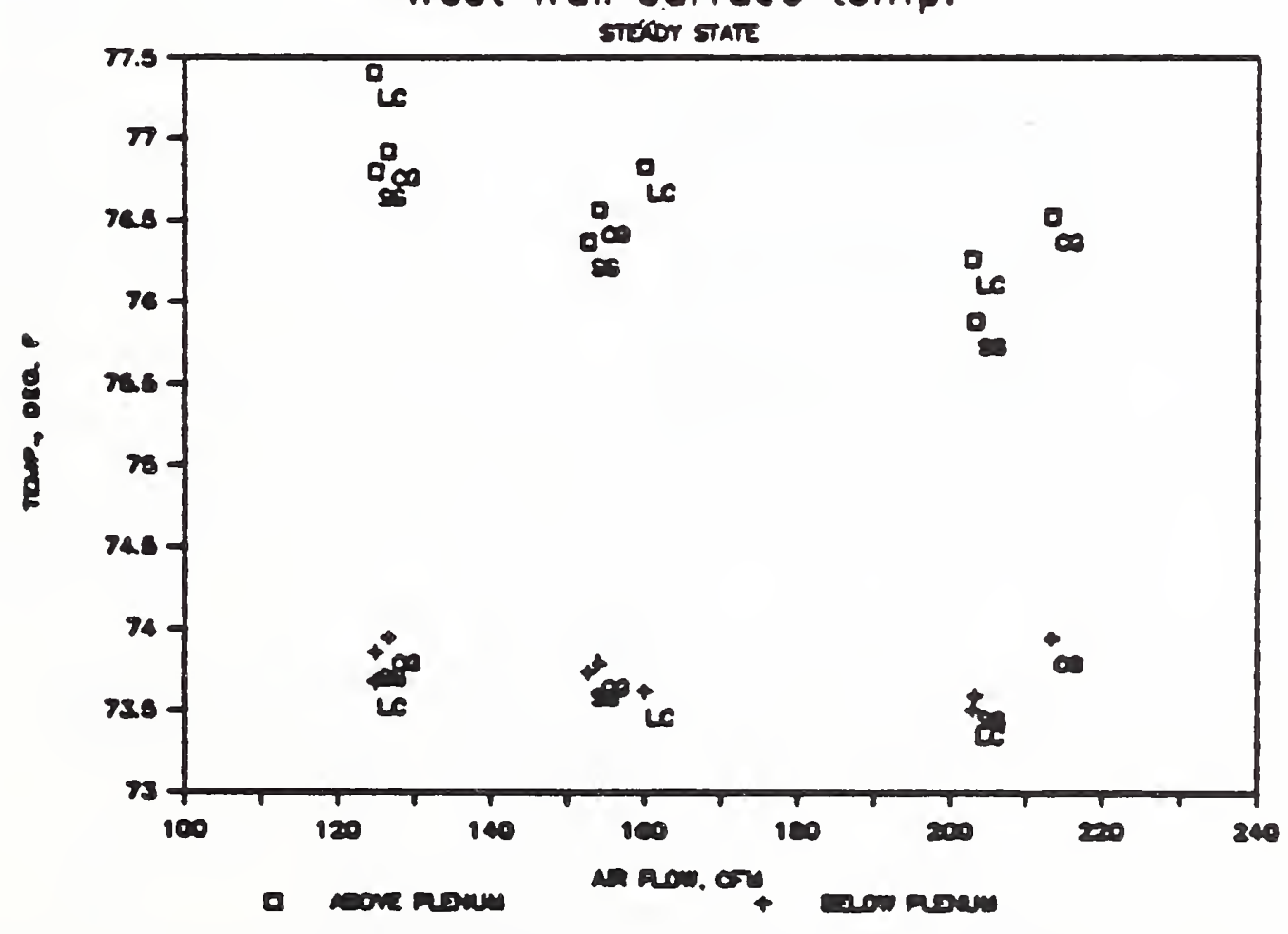

Figure 5.23 West Wall Temperatures Versus Airflow Rate and Path 
Figure 5.24 Luminaire Temperatures During Lights on Step Change Test
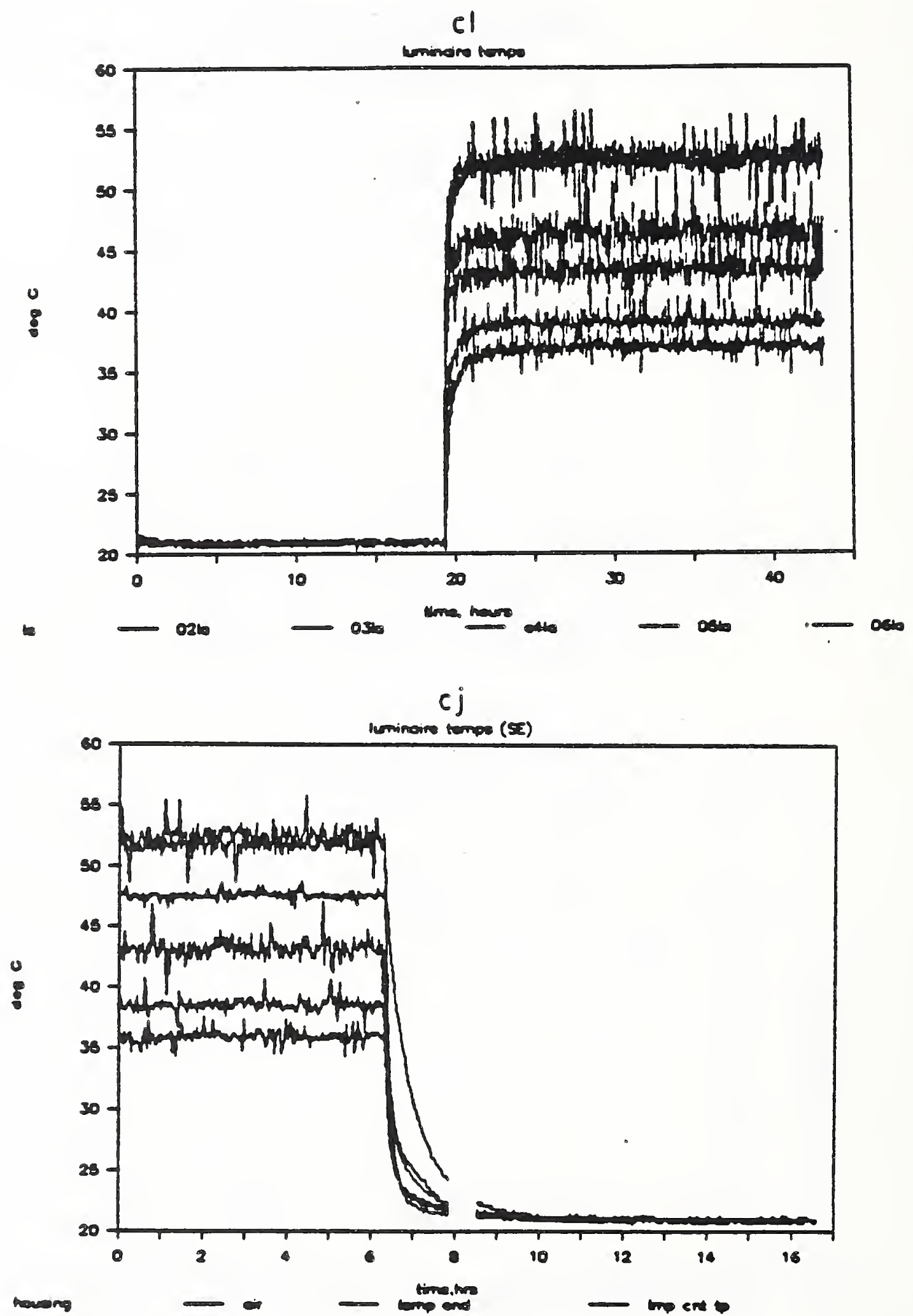

Figure 5.25 Luminalre Temperatures During Lights off Step Change Test 


\section{Transient Measurements}

Transient tests were run to determine the response of cooling load to a step change in lighting. Starting from a steady state condition with lights on or off, the lighting was switched and the cooling load monitored until equilibrium conditions were attained. Usually, back-toback tests were run, first a lights-on test, followed by a lights-off test. The lighting system is the only planned heat source in the test room. Under ideal conditions, the measured cooling load with the test room at equilibrium and the lights off would be zero. At equilibrium with the lights on, cooling load would equal lighting power. In reality, small heat gains to the test room caused slight cooling loads with the lights off. This zero offset was assumed to be constant for the duration of a test, and the measured cooling loads were adjusted accordingly. The typical zero offset was less than 20 watts, compared to a lighting power of 750 watts.

After adjusting for the zero offset, the measured cooling load at equilibrium with the lights on did not precisely match the measured lighting power. This offset was assumed to be due to variations in the conversion factor used to compute return airflow volume from the measured average velocity and heat loss induced by the lights-on condition. The measured cooling loads were adjusted so cooling load equaled measured lighting power with the lights on and the test room at equilibrium. This correction factor was usually less than four percent, and varied with airflow rate, increasing slightly as airflow increased.

Figure 6.1 shows the measured cooling load and lighting power for a lights-on test followed by a lights-off test. The lighting power follows the square wave pattern, and the resulting cooling load an exponential pattern. The spikes in the cooling load before the lights were turned on occurred during routine maintenance and are of no consequence to the test. Slight cooling loads are seen when the lights are off, both before the initial switching of the lights and after the lights were turned off. Measured cooling load was less than measured lighting power with the lights on. After adjusting for the zero and full scale offsets, the cooling load appears as in figure 6.2. This adjustment procedure was followed for all of the test results.

The figure labels sometimes include a two character code, such as EM. This is simply a test identification code, and is not important. The label PARA refers to parabolic diffuser type luminaire. The code in the figure captions relates to the airflow rate and return configuration, according to:

CG - $\quad$ ceiling grill return
SS - $\quad$ side slot return
LC - $\quad$ lamp compartment return
$120 \quad-\quad 120$ cfm airflow
$160-\quad 160$ cfm airflow
$200-\quad 200$ cfm airflow

\subsection{Cooling Load Profiles and Regression Analysis}

Preliminary analysis of the initial transient tests indicated that a single exponential relation was not sufficient to represent cooling load 
due to lighting during the first several hours after the lighting system had been switched on or off. This fact was noted by other researchers, as mentioned earlier. This effect is demonstrated in figure 6.3, which shows measured cooling load and lighting power and calculated cooling load using a single exponential, as in equation 2.1. The test conditions are ceiling grill return, room air temperature of $75^{\circ} \mathrm{F}$ and return airflow rate of $160 \mathrm{cfm}$. The calculated cooling load overestimates the measured cooling load for the first two or three hours. The regression coefficients for this test were $A=0.46464$ and $B$ $=0.16534$.

The difference between the calculated and measured cooling loads is plotted in figure 6.4. This initial transient is due to heat storage in the luminaires and heat absorption by. the light-weight room components, such as the walls and suspended ceiling. The shape of this plot suggested the addition of a second exponential relation to match the initial transient response. Thus, cooling load due to lighting would be given by:

$$
\frac{Q(t)}{W}=1-A e^{-B t}-C e^{-D t}
$$

The values of $C$ and $D$ can be determined from linear regression, according to:

$$
\ln \left[1-A e^{-B t}-\frac{Q(t)}{W}\right]=\ln C-D t
$$

Values for $C$ and $D$ were computed for this test, and the resulting calculated cooling load plotted versus measured cooling load in figure 6.5. The agreement between measured and calculated cooling loads is quite good. The regression coefficients were $C=0.41984$ and $D=$ 1.21765 .

Before continuing with the results from other transient test, the derivation of the weighting factors corresponding to equation 6.1 is warranted. Equation 6.1 is the output (cooling load $=Q(t)$ ) of the system to a step lighting input $(W)$. In the discrete case:

$$
Q(z)=G(z) \frac{z}{z-1}=\frac{z}{z-1}-\frac{A z}{z-e^{-B T}}-\frac{C z}{z-e^{-D T}}
$$

The transfer function $G(z)$ is needed to determine the weighting factors, so that the response of cooling load to arbitrary lighting power input patterns can be computed. Thus,:

$$
\begin{aligned}
& G(z)=1-\frac{A z(z-1)}{z\left(z-e^{-B T}\right)}-\frac{C z(z-1)}{z\left(z-e^{-D T}\right)} \\
& =\frac{\left(z^{2}-z e^{-B T}\right)\left(z^{2}-z e^{-D T}\right)-\left(A z^{2}-A z\right)\left(z^{2}-z e^{-D T}\right)-\left(C z^{2}-C z\right)\left(z^{2}-z e^{-B T}\right)}{\left(z^{2}-z e^{-B T}\right)\left(z^{2}-z e^{-D T}\right)}
\end{aligned}
$$




$$
\begin{aligned}
G(z) & =\frac{(1-A-C) z^{\circ}+\left(A e^{-D T}+A+C e^{-B T}+C-e^{-D T}-e^{-B F} z^{-1}+\left(e^{-(B+D) T}-A e^{-D T}-C e^{-B T}\right) z^{-2}\right.}{1-\left(e^{-D T}+e^{-B T}\right) z^{-1}+\left(e^{-(B+D) T}\right) z^{-2}} \\
& =\frac{a_{0} z^{0}+a_{1} z^{-1}+a_{2} z^{-2}}{1-b_{1} z^{-1}+b_{2} z^{-2}}
\end{aligned}
$$

where: $a_{0}=(1-A-C)$

$$
\begin{aligned}
& a_{0}=\left(1-e^{-D T}+A+C e^{-B T}+C-e^{-D T}-e^{-B T}\right) \\
& a_{1}=\left(A e^{-(B+D) T}-A e^{-D T}-C e^{-B T}\right) \\
& a_{2}=\left(e^{-(D T}\right) \\
& b_{1}=\left(e^{-D T_{+}}-B e^{-B T}\right) \\
& b_{2}=\left(e^{-(B+D) T}\right)
\end{aligned}
$$

Inverting back to the time domain, the cooling load due to lighting is given by:

$Q(t)=a_{0} W(t)+a_{1} W(t-T)+a_{2} W(t-2 T)+b_{1} Q(t-T)-b_{2} Q(t-2 T)$

The quantities $a_{0}, a_{1}, a_{2}, b_{1}$, and $b_{2}$ are the weighting factors corresponding to equation 6.1 . The addition of the second exponential introduces two additional terms, namely the lighting power and cooling load from two hours before the current time step. The five weighting factors are not all independent, since they are derived from only four coefficients. The values of the weighting factors are determined, however, strictly from the regression coefficients A, B, C and D, and choice of a time step increment. A one-hour time increment is frequently employed for building energy analysis, although any time step can be used.

The values for $A$ and $B$ are, of course, the same for the single and double exponential relations for computing cooling load due to lighting. Thus, after the initial transient has dissipated, the cooling loads due to a step change in lighting are equivalent. The traditional ASHRAEtype weighting factors can be computed from $A$ and $B$.

Returning to the transient test results, a lights-off test was run with identical conditions to the first test described above. The two tests were run back-to-back. Figure 6.6 displays measured cooling load and lighting power, and cooling load calculated by a single exponential regression fit. The regression coefficients were $A=0.62233$ and $B=$ 0.20377 . Cooling load is underestimated for several hours following the turning off of the lights. In the case of the double exponential fit for the lights-off test, cooling load is given by:

$$
Q(t)=A e^{-B T}+C e^{-D T}
$$

The regression coefficients can be determined as before. After subtracting the first exponential, the initial transient was plotted, as in figure 6.7. Performing a second regression analysis, the value of $C$ was found to be 0.38232 and $D$ was found to be 2.24065 . The double exponential regression fit is plotted in figure 6.8. The initial transient decayed slightly faster during the lights-off test. However, measurement uncertainty and non-perfect control system performance, 
however good, combine to obscure the significance of this difference. Although the regression coefficients from the two tests are not identical, the cooling load profiles they represent are very similar, as will be shown later.

Similar tests were run with ceiling grill return, but with various airflow rates. Figure 6.9 displays measured and calculated cooling loads for a lights-on test at $120 \mathrm{cfm}$, for the single exponential. The initial transient is of a very short duration. The double exponential fit is shown in figure 6.10. The value of $D=4.250$ was the largest for all the transient test runs. The values of the other coefficients were $A=0.72791, B=0.24514$ and $C=0.14638$. For the ceiling grill return, 200 cfm test, the measured and single exponential calculated cooling loads are plotted in figure 6.11. The regression coefficients are A.= 0.56150 , and $B=0.18567$. The initial transient is shown in figure 6.12 , and the double exponential fit is plotted in figure 6.13. The agreement between the measured and calculated cooling loads is very good. The value of $C$ was 0.39523 and $D$ was 2.04771 .

A similar series of tests was run with side slot and lamp compartment returns, for the same three airflow rates. The regression coefficients are summarized following the description of the figures. Figure 6.14 shows the measured cooling load and single exponential fit for the lights-on the test with side slot return at $120 \mathrm{cfm}$. Figure 6.15 shows the initial transient, and 6.16 displays the double exponential fit. For the same condition, lights-off test, the measured and single exponential cooling loads are plotted in figure 6.17. The initial transient is shown in figure 6.18, and the double exponential fit in figure 6.19 .

For this test, and almost all of the others, the initial transient decays faster during the lights-on test than the lights-off test. This is partly due to the sharp peak in lighting power when the lights are initially energized. No equivalent "negative peak" occurs when the lights are extinguished. It is also possible that some physical mechanism inhibits heat storage when the lights are initially turned on, and retards the discharge of stored heat when the lights are turned off. A third possibility would be some artifact of the control system. A precise pinpointing of the cause of this difference was not forthcoming, however, the impact on the average cooling load profiles was small, as will be demonstrated later.

Figure 6.20 shows the measured cooling load and single exponential fit for the side slot return at $160 \mathrm{cfm}$, lights-on test. Figure 6.21 displays the initial transient, and 6.22 plots the double exponential fit. The same three plots for the lights-off test are shown in figures $6.23,6.24$ and 6.25 .

The results for the side slot tests with $200 \mathrm{cfm}$ airflow are shown is figures $6.26,6.27$ and 6.28 for the lights-on test and $6.29,6.30$ and 6.31 for the lights-off test.

Similar data for the lamp compartment return are displayed in figures $6.32,6.33$ and 6.34 for $120 \mathrm{cfm}$, lights-off test. The test had the poorest match between the measured cooling loads and the double 
exponential fit. The cooling load profile is characterized by a rapid initial change, followed by a prolonged, slow settling to zero.

Figures $6.35,6.36$ and 6.35 present the data for the $160 \mathrm{cfm}$, lights-on test, and figures $6.38,6.39$ and 6.40 show the results from the $160 \mathrm{cfm}$, lights-off test. Finally, figures $6.41,6.42$ and 6.43 display the results for the $200 \mathrm{cfm}$, lights-off test. In all cases, the agreement between the measured cooling load and double exponential fit was very good.

Since, in most cases, more than one test was run for each configuration, suitable average regression coefficients needed to be determined to represent each condition. Simple arithmetic averaging of multiple values of each regression coefficient was found to be sufficient for this purpose. A demonstration of this also addresses the issue of the significance of different regression coefficient values from different tests with identical configurations, and explores the repeatability of the measurements.

A series of four tests were run in succession with identical test configuration of side slot return and $200 \mathrm{cfm}$ airflow. Two of the tests were lights-on and two were lights-off. The test identification codes and regression coefficients are listed in Table 6.1.

Table 6.1 Regression Coefficients for Side Slot 200 cfm Tests

\begin{tabular}{lllll} 
ID Code & $\frac{\mathrm{A}}{n}$ & $\frac{\mathrm{B}}{\mathrm{B}}$ & $\frac{\mathrm{C}}{\mathrm{D}}$ & \\
\cline { 2 - 2 } & 0.58987 & 0.21513 & 0.31755 & 1.76135 \\
ES Off & 0.64542 & 0.23799 & 0.35654 & 2.70828 \\
ET On & 0.642139 & 0.23166 & 0.25832 & 2.69113 \\
ET Off & 0.57479 & 0.21544 & 0.3558 & 1.88319
\end{tabular}

While the regression coefficients vary for the four tests, the cooling load profiles they represent are very similar. Figure 6.44 shows the cooling loads for each of the four tests, plotted as symbols, and the cooling load plotted from the average regression coefficients, plotted as a solid line. Very good agreement is apparent between the tests, and the cooling load profile calculated from the average coefficients represents the average of all the cooling load profiles. This figure indicates good measurement repeatability.

Average regression coefficients were determined for each test configuration. These values are summarized in table 6.2, along with overall average values for each regression coefficient. 
Table 6.2 Average Regression Coefficients for Each Test Condition

\begin{tabular}{llllll} 
Return & Airflow & A & B & C & \multicolumn{1}{l}{ D } \\
CG & 120 & 0.72791 & 0.24514 & 0.14638 & 4.250 \\
CG & 160 & .53937 & .18183 & .39826 & 1.71436 \\
CG & 200 & .57391 & .20444 & .45193 & 2.47985 \\
& & & & & \\
SS & 120 & .68507 & .21748 & .37771 & 3.1224 \\
SS & 160 & .68603 & .22321 & .40393 & 4.010 \\
SS & 200 & .61305 & .22506 & .32205 & 2.2610 \\
& 120 & .47603 & .11463 & .52696 & 1.21763 \\
LC & 160 & .60498 & .18701 & .34944 & 1.9729 \\
LC & 100 & .63085 & .22480 & .34122 & 2.93645 \\
LC & 200 & & & & \\
& & .615311 & 0.202622 & 0.368653 & 2.662736
\end{tabular}

CG - Ceiling Grill/SS - Side Slots/LC - Lamp Compartment

The effect of the airflow rate and return air configuration on the regression coefficients was examined in a series of plots. Figure 6.45 shows all the regression coefficients plotted versus airflow rate. All return air paths are included in this figure. The variability and magnitude of the $D$ coefficients tends to obscure the differences between the other coefficients. The variability of the $D$ values is least for the $200 \mathrm{cfm}$ airflow. Figure 6.46 displays the values of A, B and C for all tests. In general, these coefficients bunch together at the highest airflow rate also.

The effect of airflow rate and return air path on the individual regression coefficients is shown in figures 6.47 for $A, 6.48$ for $B, 6.59$ for $C$ and 6.50 for $D$. No clear pattern is apparent relating the values of these coefficients to airflow rate. The $A$ values tend to increase with airflow rate for the lamp compartment return, and decrease for the side slots and ceiling grill returns. The $B$ values vary the least. The value of $B$ is dependent on the long - term heat storage characteristics of the room, which are only weakly influenced by airflow rate of the path. The value of $\mathrm{C}$ increases with airflow rate for the ceiling grill return, and decreases for lamp compartment return. The opposite is true for the $D$ values.

In order to compare the cooling load profiles represented by the regression coefficients, cooling load responses to a unit step change in lighting were computed and plotted for each test configuration. Figure 6.51 shows the cooling load profiles for the ceiling grill return, figure 6.52 for the side slots and figure 6.53 for the lamp compartment return. The effect of airflow rate is minor, except for the lamp compartment return. The cooling load profile for the $120 \mathrm{cfm}$ airflow rate is consistently less than the other airflow rates, but not by a large margin.

A second series of plots compares the effects of return air path for constant airflow rate. Figure 6.54 is for $120 \mathrm{cfm}, 6.55$ for $160 \mathrm{cfm}$ and 6.56 for $200 \mathrm{cfm}$. Only the lamp compartment return, $120 \mathrm{cfm}$ cooling 
load profile stands out, being noticeably lower than the side slots or ceiling grill return.

One general indicator of short term cooling load performance is to look at the cooling load for one hour after the lights are energized. Figure 6.57 shows cooling load after one hour versus airflow rate and return air path. The effect of airflow rate is quite strong and apparent, with increasing airflow rate causing a greater cooling load after one hour. The difference between the extreme values is approximately 20 percent. The side slot return has the lowest cooling load at each airflow rate. The ceiling grill return produces the greatest one hour cooling load at 120 and $160 \mathrm{cfm}$, while the lamp compartment is greatest at $200 \mathrm{cfm}$.

\subsection{Weighting Factors and Cooling Load Fractions}

Weighting factors were computed for each of the test configurations using equation 6.7 , based on the average values for the regression coefficients. These weighting factor values are listed in table 6.3.

Table 6.3 Average Weighting Factors For Each Test Condition

$\begin{array}{lccccc} & \mathrm{a}_{0} & \mathrm{a}_{1} & \mathrm{a}_{2} & \mathrm{~b}_{1} & \mathrm{~b}_{2} \\ \text { CG120 } & 0.12571 & 0.20237 & -0.11377 & 0.796859 & 0.011163 \\ \text { CG160 } & 0.06237 & 0.35298 & -0.27903 & 1.013821 & 0.150139 \\ \text { CG200 } & -0.02584 & 0.54342 & -0.34816 & 0.898859 & 0.068269 \\ & & & & & \\ \text { SS120 } & -0.06338 & 0.54887 & -0.29864 & 0.848593 & 0.035439 \\ \text { SS160 } & -0.08996 & 0.60744 & -0.32105 & 0.818080 & 0.014505 \\ \text { SS200 } & 0.0649 & 0.35344 & -0.23781 & 0.902714 & 0.083237 \\ \text { LC120 } & 0.00299 & 0.42612 & -0.34687 & 1.187626 & 0.263880 \\ \text { LC160 } & 0.04558 & 0.35989 & -0.25862 & 0.968488 & 0.115335 \\ \text { LC200 } & 0.02793 & 0.42633 & -0.26362 & 0.851729 & 0.042372 \\ \text { AVG } & 0.016035 & 0.44158 & -0.28699 & 0.886343 & 0.056962\end{array}$

CG-Ceiling Grill/SS-Side Slots/LC-Lamp Compartment

The effect of airflow rate and return air configuration on the weighting factor values was examined in a series of plots. Figure 6.58 shows $a_{0}$ versus airflow for all return air paths. The $a_{0}$ values are small, and bunch together at the $200 \mathrm{cfm}$ airflow rate. The three negative values are not consistent with the physical system, but result from the extremely steep initial slope of the cooling load. Based on observation of these $a_{0}$ values, the substitution of an $a_{2}$ term for an $a_{0}$ term utilized in [Mi74] does not seem unreasonable.

The values of $a_{1}$ are shown in figure 6.59. Again, the values converge somewhat at $200 \mathrm{cfm}$. The values of $a_{2}, b_{1}$ and $b_{2}$ are displayed in figures $6.60,6.61$ and 6.62 , respectively. No general correlations are apparent, although the trend for values to converge at the $200 \mathrm{cfm}$ airflow rate continues to be seen. The $b_{1}$ and $b_{2}$ values exhibit $a$ similar pattern, due to their interdependence. 
In order to evaluate the effect of the airflow rate and configuration on cooling load due to cyclic operation of the lights, cooling load fractions were computed from the weighting factors for a ten hour on daily lighting cycle. Figure 6.63 shows the hourly cooling load fractions, that is the ratio of cooling load to lighting power, for four successive daily cycles. The data repeat after the second day. This plot is for one test configuration. What is of interest is the steady periodic cooling load, which occurs in this plot from the second day on. Peak cooling load fraction does not reach 1.0, and some cooling load is present at all times, even when the lights are off.

Figures $6.64,6.65$ and 6.66 show the steady periodic cooling load fractions versus airflow rate for ceiling grill, side slots and lamp compartment, respectively. The most notable aspects of the cooling load fraction profiles is their similarity. With the exception of a few points at the lights on and lights off instants, and the $120 \mathrm{cfm}$, lamp compartment return configuration, the cooling load fraction profiles are very similar. "The exceptional points occur due to the negative $a_{0}$ values. This issue is addressed below.

Figure 6.67 shows the cooling load fraction profile for the average set of weighting factors. This is the average profile for all test configurations.

While the previous cooling load fractions were based on unit lighting power, the actual cooling load profiles will vary due to differences in lighting power for each test configuration. To examine this effect, the cooling load fractions for each configuration were scaled by the average measured lighting power. These results are shown in figures $6.68,6.69$ and 6.70 , for ceiling grill return, side slots and lamp compartment return, respectively.

The scaling by actual lighting power has a slight (approximately 5 percent maximum) effect which is difficult to discern from the figure. However, it is important that this factor be considered when estimating peak cooling loads, since the cooling load fractions only determine the shape of the cooling load profiles, not the magnitudes. The lighting powers and peak cooling loads for each test configuration are listed in table 6.4 .

Table 6.4 Lighting Power and Peak Cooling Load

Return Airflow (cfm) Power (watts)

\author{
Peak \\ Cooling (watts)
}

$\begin{array}{llll}\text { Ceiling Grill } & 120 & 726.5 & 670.0 \\ \text { Ceiling Grill } & 160 & 732.6 & 660.8 \\ \text { Ceiling Grill } & 200 & 734.9 & 671.3 \\ \text { Side Slots } & 120 & 728.4 & 660.9 \\ \text { Side Slots } & 160 & 730.3 & 665.8 \\ \text { Side Slots } & 200 & 733.3 & 676.3 \\ & & & 686.3 \\ \text { Lamp Comp. } & 120 & 753.2 & 676.2 \\ \text { Lamp Comp. } & 160 & 755.9 & 701.3 \\ \text { Lamp Comp. } & 200 & 762.5 & \end{array}$


Peak cooling load varies over six percent for the range of test conditions, primarily due to variations in lighting power. The maximum peak cooling load occurred for the $200 \mathrm{cfm}$, lamp compartment return, which had the greatest lighting power. Of course, light output would be high for this condition also.

In order to alleviate the problems due to negative $a_{0}$ values, the offending values were replaced with zeros, and the other coefficients adjusted to compensate. The $a_{0}$ values were close to zero anyway. Compensation with $a_{1}$ and $a_{2}$ were both tried. The sum of the "a" coefficients must remain the same after adjustments. Figure 6.71 shows the original cooling load fraction profile, and two new profiles corresponding to compensating with $a_{1}$ and $a_{2}$, for the ceiling grill, 200 cfm test condition. The al compensation is seen to alleviate the problem points while matching the original profile test. The adjusted profiles for side slots $120 \mathrm{cfm}$ and $160 \mathrm{cfm}$ are shown in figures 6.72 and 6.73 , respectively. While the new profiles are slightly different than the originals, the elimination of the problem points outweighs this aspect.

A better way to alleviate the problem of negative $a_{0}$ values would be to force the cooling load regression fit through zero. This would correspond to having $A$ plus $C$ equal to one, thus $a_{0}$ would equal zero. This approach will be investigated for future test results.

ASHRAE - type weighting factors were calculated from the regression coefficients in table 6.2, using equation 2.11. Only the values of $A$ and $B$ are required for this calculation. Table 6.5 lists the ASHRAEtype weighting factors for each of the test conditions.

$\begin{array}{ccccc} & \text { Table 6.5 ASHRAE } & - & \text { Type Weighting } & \text { Factors } \\ \text { Return } & \text { Airflow } & { }^{1} & \mathrm{a}_{1} & \mathrm{~b}_{1} \\ \text { CG } & 120 & 0.430 & -0.213 & 0.783 \\ \text { CG } & 160 & 0.550 & -0.384 & 0.834 \\ \text { CG } & 200 & 0.532 & -0.347 & 0.815 \\ & & & & \\ \text { SS } & 120 & 0.449 & -0.254 & 0.805 \\ \text { SS } & 160 & 0.451 & -0.251 & 0.800 \\ \text { SS } & 200 & 0.510 & -0.308 & 0.798 \\ & & & & \\ \text { LC } & 120 & 0.576 & -0.468 & 0.892 \\ \text { LC } & 160 & 0.498 & -0.327 & 0.829 \\ \text { LC } & 200 & 0.496 & -0.295 & 0.799 \\ \text { Average } & & 0.498 & -0.315 & 0.817\end{array}$

CG-Ceiling Grill/SS-Side Slots/LC-Lamp Compartment

The $b_{1}$ values cluster above 0.8 , similar to the lightweight room values from [Mi74]. Increasing airflow rate causes a to increase for the ceiling grill and side slot configurations, but to decrease for the lamp compartment return. This may be attributed to the relatively stagnant air conditions in the test room with the lamp compartment return at the low airflow rate. The initial heat pickup is greater, but the progress toward equilibrium is slower, as the heat from the lights is absorbed by the massive elements of the test room. The $a_{1}$ values are similar to [Mi74]. 


\subsection{Heat Storage in Room Components}

The heat stored in the test room components during a step response test can be determined in several ways. The total heat stored can be calculated from the difference between lighting power and cooling load. The heat stored in each component can be measured using heat flow sensors, or calculated from the measured temperature rise of each component. While the test facility is instrumented with heat flow sensors, there are not enough sensors to enable to measurement of all the heat storage. thus, the first and third methods were utilized. The heat flow sensors are useful, however, for giving a qualitative indication of heat storage processes, at the attached surface.

The total heat stored in a lights-on test is:

$$
\begin{aligned}
\text { Total Heat Stored } & =\int_{0}^{\infty}\left(A e^{-B t}+C e^{-D t}\right) d t \\
& =\frac{A}{B}+\frac{C}{D}
\end{aligned}
$$

The heat reclaimed in a lights - off test is also given by equation 6.10. The units of the heat storage determined in this manner are energy per unit power. In this case, that is watt-hours per watt of lighting power. Figure 6.74 shows total heat stored versus airflow rate and return configuration. Airflow rate has a strong effect on heat stored with the lamp compartment return, with lower airflows causing greater heat storage. Airflow rate has little effect on total heat storage with side slots or ceiling grill. These effects are probably due to the shifting of heat storage from the room to the plenum as airflow increases. There is a slight decrease in total heat stored with decreasing airflow rate for the side slot return, but a slight increase for the ceiling grill return.

The heat flow sensor readings provide a view of the dynamic heat flow into the room surfaces. Figure 6.75 shows the heat flow into the floor and the north, east and west walls for back-to-back lights on and lights off tests. The slight negative readings at the beginning of the tests correspond to heat flow from the surface to the room air. These heat flow sensors are at the center of each of the respective surfaces. Some localized heat flow may occur, as the control thermopile is attempting to prevent any net heat flow through the wall as a whole.

Once the lights are turned on, heat flows into all of the surfaces at a decreasing rate until equilibrium conditions are attained. The heat flow into the walls is much less than into the floor slab, and the walls reach equilibrium within several hours. The initial heat flow into the floor is very large, over 7 watts per square meter, and over 20 hours are required for stable floor heat flow. Heat is initially stored in the floor, from the test room and the lower plenum, until the floor temperatures increases and heat begins to flow back into the room, eventually at a steady rate. This net heat gain through the floor is matched by a heat loss through the ceiling. When the lights are turned off, heat flows back into the room as the floor cools. The amount of heat dissipated from the floor to the room is greater than the amount stored, since the lower plenum supplies heat to the floor also. Again, conservation of energy is maintained by an identical loss through the ceiling slab. 
Heat storage in the individual room components was determined from the measured average temperature rise between the lights-off and lights-on condition, times the component mass and specific heat. The average of the floor and ceiling slab temperature rises was used to compute the slab storage, which actually includes heat stored in the ceiling and floor slabs from the test room, but not the lower plenum or upper guard air space. The plenum and room portions of each wall are listed separately, since they attain different temperatures.

Table 6.6 presents the heat storage fractions in the room components for all the test conditions. These are defined as the fraction of the total heat stored in all the room components which is stored in an individual component, such as the walls or slab.

Table 6.6 Heat Storage Fractions in Room Components Ceiling Grill Side Slots Lamp Comp.

\begin{tabular}{|c|c|c|c|c|c|c|c|c|c|c|}
\hline Component & 120 & 160 & 200. & 120 & 160 & 200 & 120 & 160 & 200 & \\
\hline Plenum Air. & $=.0060$ & .0065 & .0058 & .0064 & .0065 & .0062 & .0080 & .0079 & .0066 & \\
\hline Slabs & .6218 & .5731 & .6055 & .6224 & .6126 & .6138 & .5899 & .5766 & .6279 & \\
\hline $\begin{array}{l}\text { North Rm. } \\
\text { Wall }\end{array}$ & .0189 & .0186 & .0170 & .0162 & .0167 & .0171 & .0185 & .0155 & .0143 & \\
\hline $\begin{array}{l}\text { North } \\
\text { Plenum Wall }\end{array}$ & $i^{0135}$ & .0144 & .0125 & .0150 & .0153 & .0141 & .0166 & .0164 & .0147 & \\
\hline $\begin{array}{l}\text { East Room . } \\
\text { Wall }\end{array}$ & .0197 & .0226 & .0210 & .0189 & .0197 & .0215 & .0170 & .0206 & .0177 & \\
\hline $\begin{array}{l}\text { East } \\
\text { Plenum Wali }\end{array}$ & $i^{0139}$ & .0150 & .0134 & .0128 & .0136 & .0130 & .0138 & .0148 & .0135 & \\
\hline $\begin{array}{l}\text { South } \\
\text { Room Wall }\end{array}$ & .0435 & .0471 & .0445 & .0403 & .0410 & .0431 & .0382 & .0433 & .0395 & \\
\hline $\begin{array}{l}\text { South } \\
\text { Plenum Wall }\end{array}$ & $i^{0284}$ & .0329 & .0299 & .0292 & .0286 & .0300 & .0317 & .0316 & .0282 & \\
\hline $\begin{array}{l}\text { West Room . } \\
\text { Wall }\end{array}$ & .0158 & .0174 & .0191 & .0128 & .0149 & .0152 & .0159 & .0178 & .0146 & \\
\hline $\begin{array}{l}\text { West } \\
\text { Plenum Wall }\end{array}$ & $i^{0128}$ & .0154 & .0141 & .0126 & .0114 & .0122 & .0147 & .0163 & .0130 & \\
\hline $\begin{array}{l}\text { Lumin- } \\
\text { aires }\end{array}$ & .0792 & .0999 & .0939 & .0770 & .0816 & .0842 & .0669 & .0725 & .0696 & \\
\hline $\begin{array}{l}\text { Struct- } \\
\text { ural steel }\end{array}$ & .1167 & .1266 & .1138 & .1258 & .1275 & .1206 & .1558 & .1538 & .1295 & \\
\hline $\begin{array}{l}\text { Suspended } \\
\text { Ceiling }\end{array}$ & .0098 & .0106 & .0095 & .0105 & .0107 & .0101 & .0130 & .0129 & . 01 & 08 \\
\hline
\end{tabular}


As would be expected, most of the heat storage occurs in the slabs, typically about 60 percent. The room walls combined account for only ten percent, while the steel supports in the plenum store twelve percent, the luminaires eight percent, and the plenum walls seven percent. The suspended ceiling accounts for only one percent of the heat storage, and the plenum air one half of one percent.

\subsection{Plenum Cooling Load Fraction}

Designers frequently want to know the amount of cooling load due to heat picked up in the room versus the plenum. Heat picked up in the plenum does not affect room comfort conditions. The less heat which enters the room, the lower the airflow rates and higher the air temperatures can be to maintain comfort.

The plenum heat pickup fractions were determined from the ratio of the temperature rise in the air entering the plenum to the return air leaving the room, to the temperature rise from the supply to return.

That is:

$$
\text { Plenum Fraction }=\frac{\mathrm{T}_{\text {Return }}-\mathrm{T}_{\text {Room }}}{\mathrm{T}_{\text {Return }}-\mathrm{T}_{\text {Supply }}}
$$

These temperatures were measured with thermocouples, leading to some scatter in the data. The room air temperature was used as the temperature of the air leaving the room and entering the plenum. This is a reasonable assumption, since the air in the test room is well mixed with the fan on. In addition, for the side slot and lamp compartment returns, return air enters the plenum at many distributed locations, making it difficult to measure.

Figure 6.76 shows the plenum heat pick up fraction versus airflow rate and return air configuration. The values are the average of the plenum fractions for each of the test conditions, excluding the first several hours after the lights were turned on, when the scatter in the data is most prevalent. With the exception of the lamp compartment return, 200 cfm airflow rate condition, the average plenum fraction values ranged from 0.55 to 0.59 . The high plenum fraction at the $200 \mathrm{cfm}$, lamp compartment condition is due to the large heat pickup by the return air being drawn through the lamp compartment at a high flow rate. In general, the plenum fraction values increased with airflow rate, except for the ceiling grill return. The plenum fraction with the side slots increased moderately with airflow rate.

The plenum fraction values from the individual test conditions are plotted in figure $6.77,6.78$ and 6.79 for the ceiling grill, side slot and lamp compartment configurations, respectively, all for an airflow rate of $160 \mathrm{cfm}$. After the lights are turned on, the plenum fraction rises quickly, then gradually decreases for about four hours. This may be due to the gradual heating up of the plenum space. As the plenum temperatures rise, more heat is lost through the ceiling slab, and transferred to the room through the suspended ceiling. 
Figure 6.1 Measured Cooling Load and Lighting Power for Back-to-Back Lights on and Lights off Tests

EM, PARA, 160 CFM, 75 F, LAMP COMP

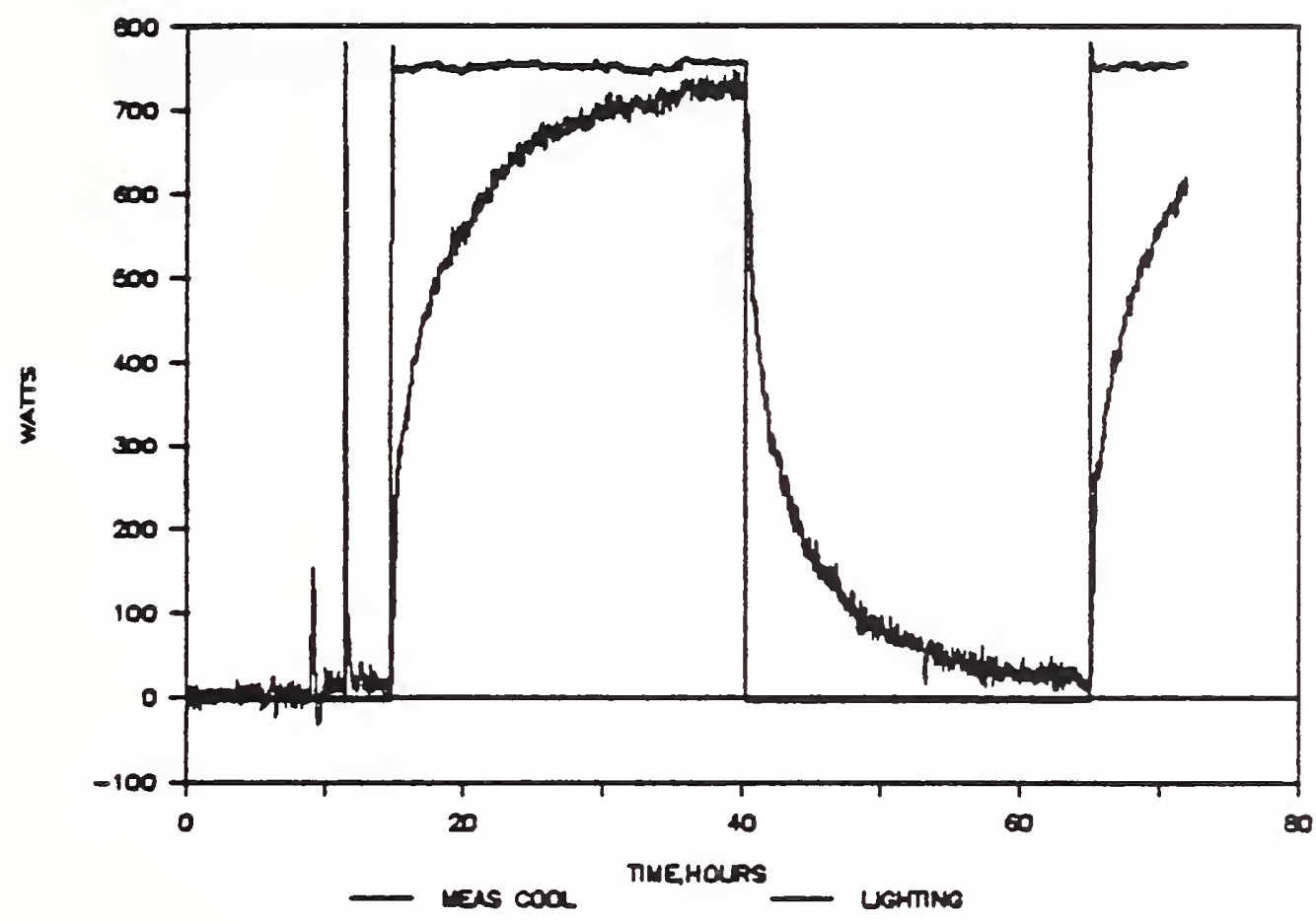

EM, PARA, 160 CFM, 75 F, LAMP COMP

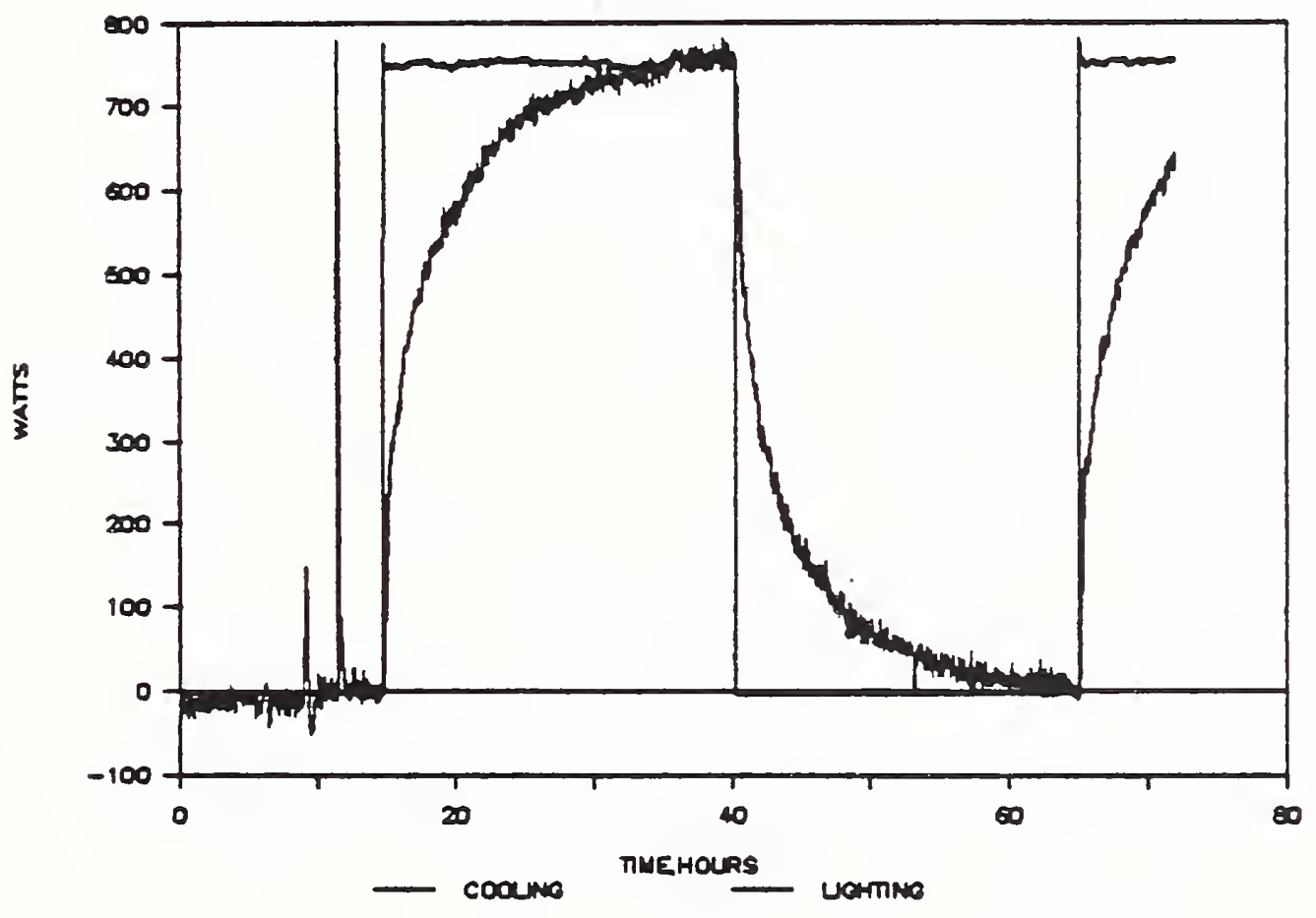

Figure 6.2 Adjusted Cooling Loads 
Figure 6.3 Measured Cooling Load and Lighting Power Versus Single Exponential Regression Fit, CG160 On
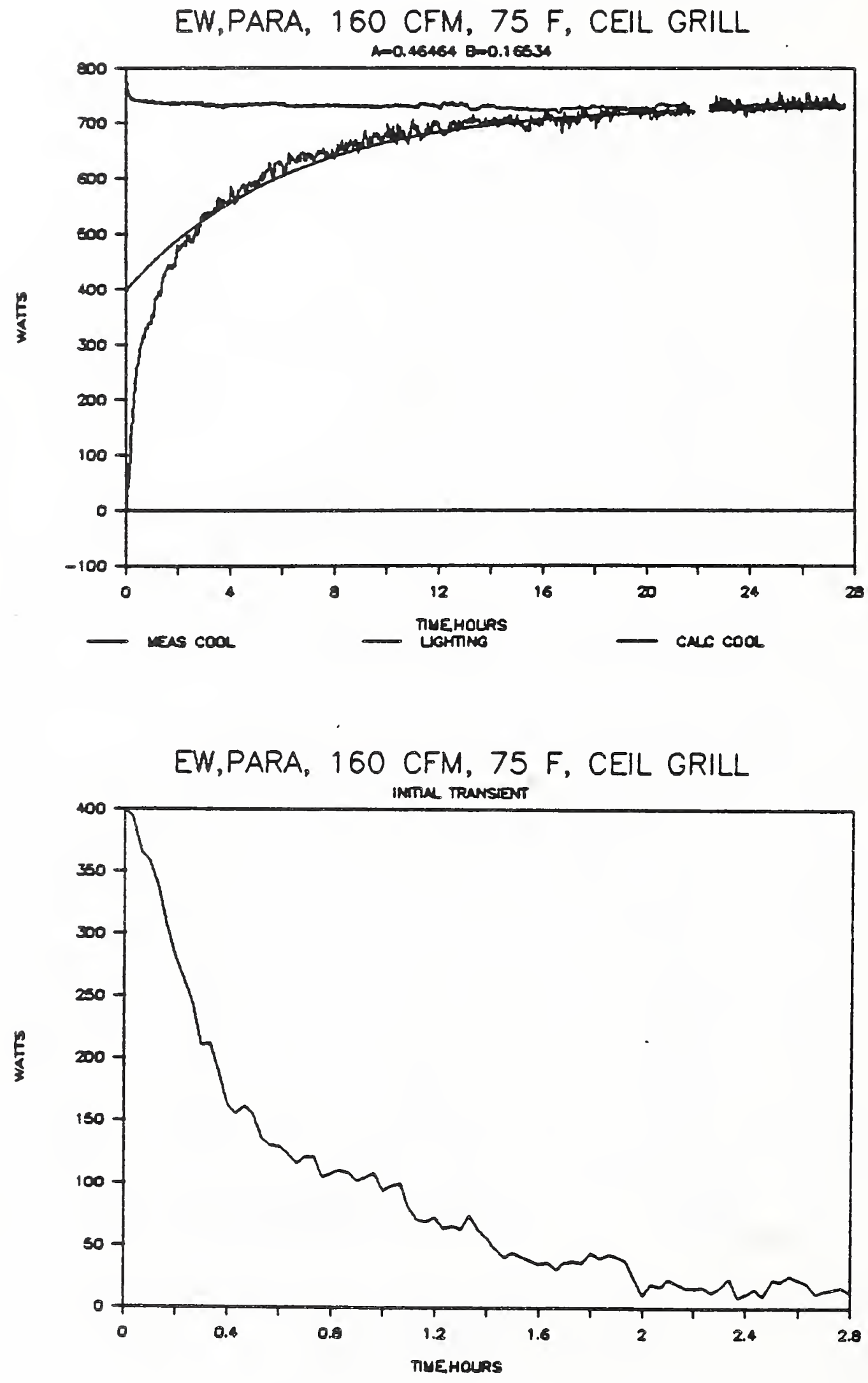

Figure 6.4 Calculated Minus Measured Cooling Load, CG160 On 
Figure 6.5 Measured Cooling Load Versus Double Exponential Regression Fit, CG160 On
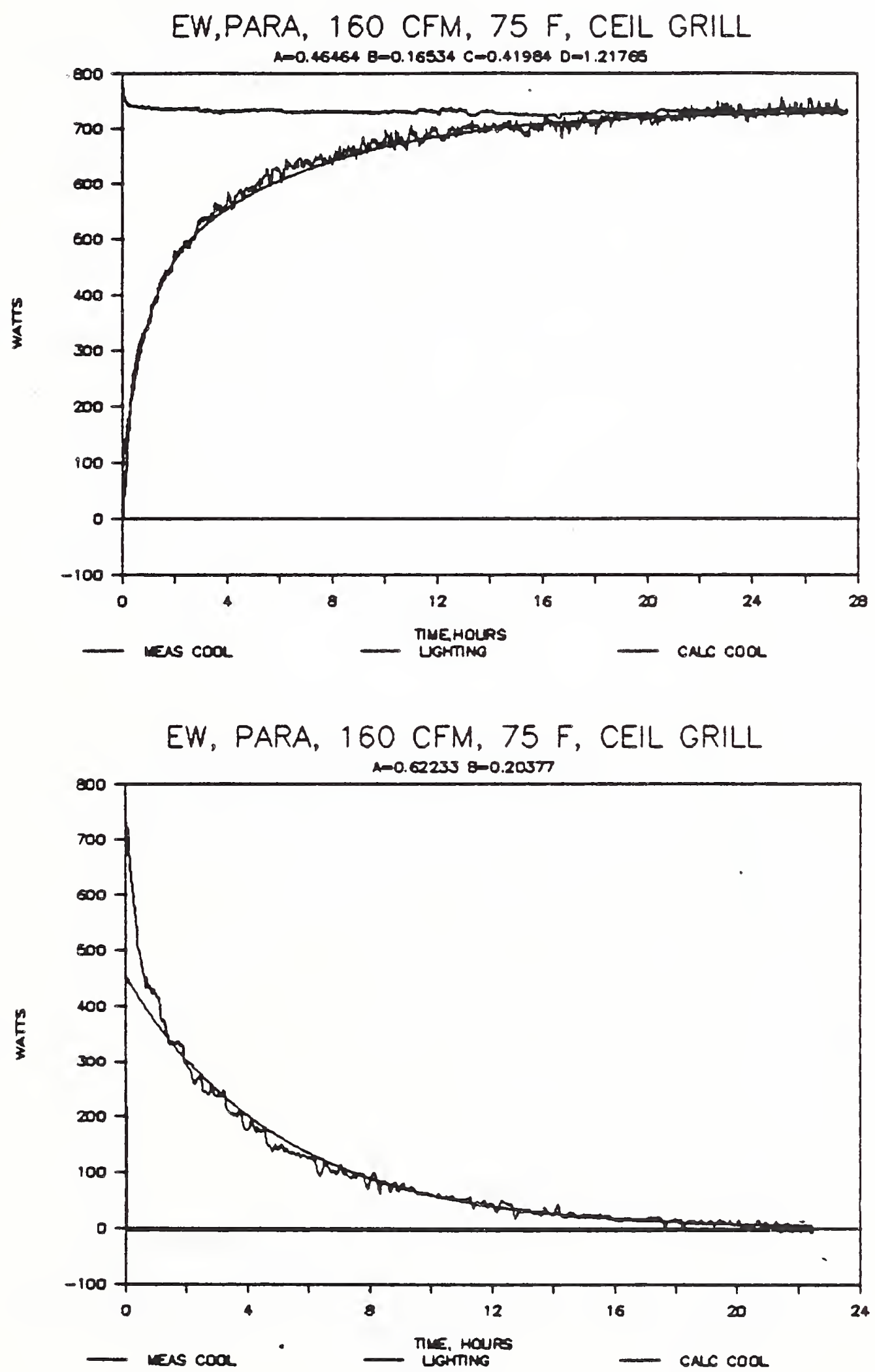

Figure 6.6 Measured Cooling Load and Lighting Power Versus Single Exponential Regression Fit, CG160 off 
Figure 6.7 Initial Transient, CG160 off
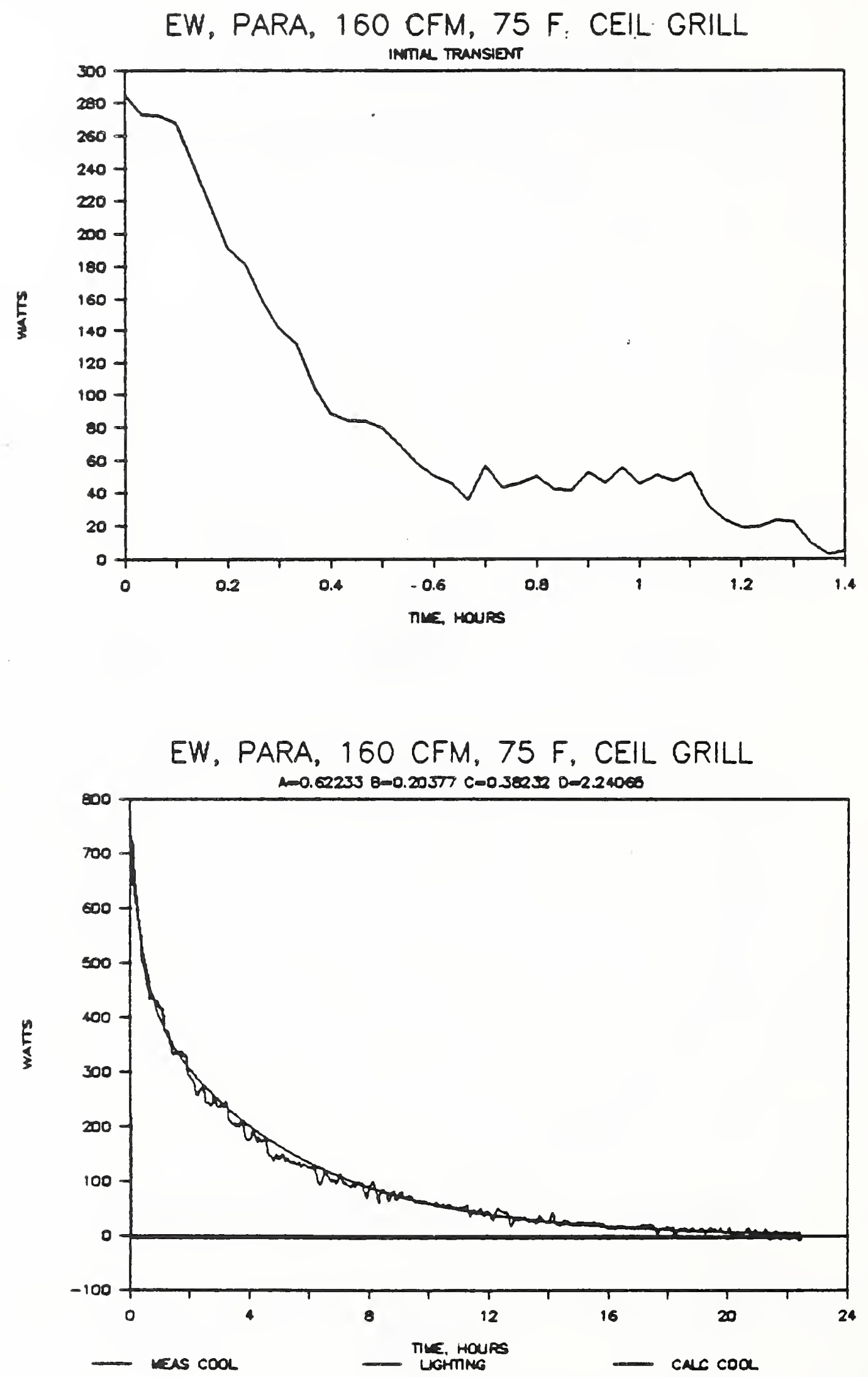

Figure 6.8 Measured Cooling Load Versus Double Exponential Regression Fit, CG160 off 
Figure 6.9 Measured Cooling Load and Lighting Power Versus Single Exponential Regression Fit, CG120 On
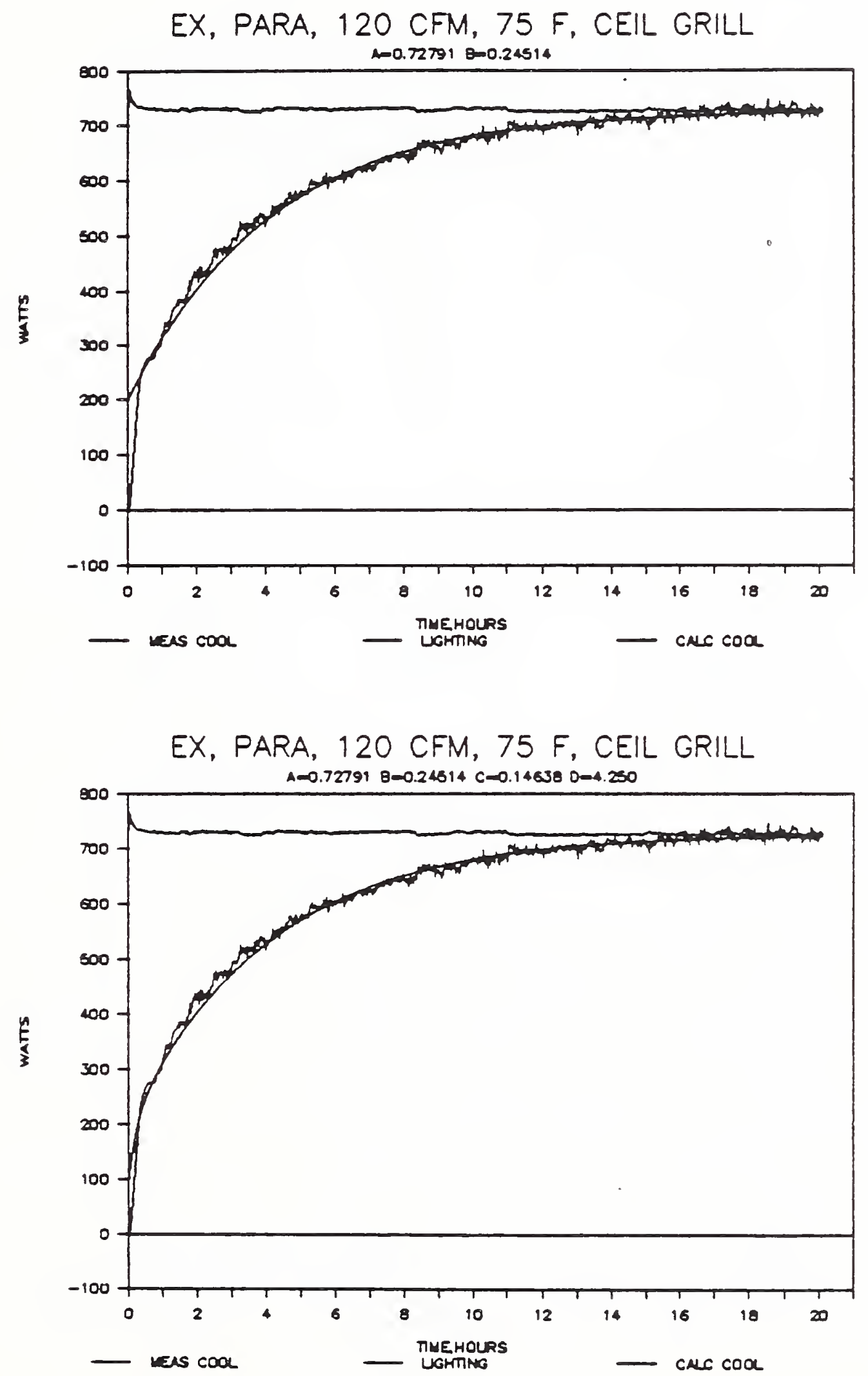

Figure 6.10 Measured Cooling Load and Lighting Power Versus Double Exponential Regression Fit, CG120 On 
Figure 6.11 Measured Cooling Load and Lighting Power Versus Single Exponential Regression Fit, CG200
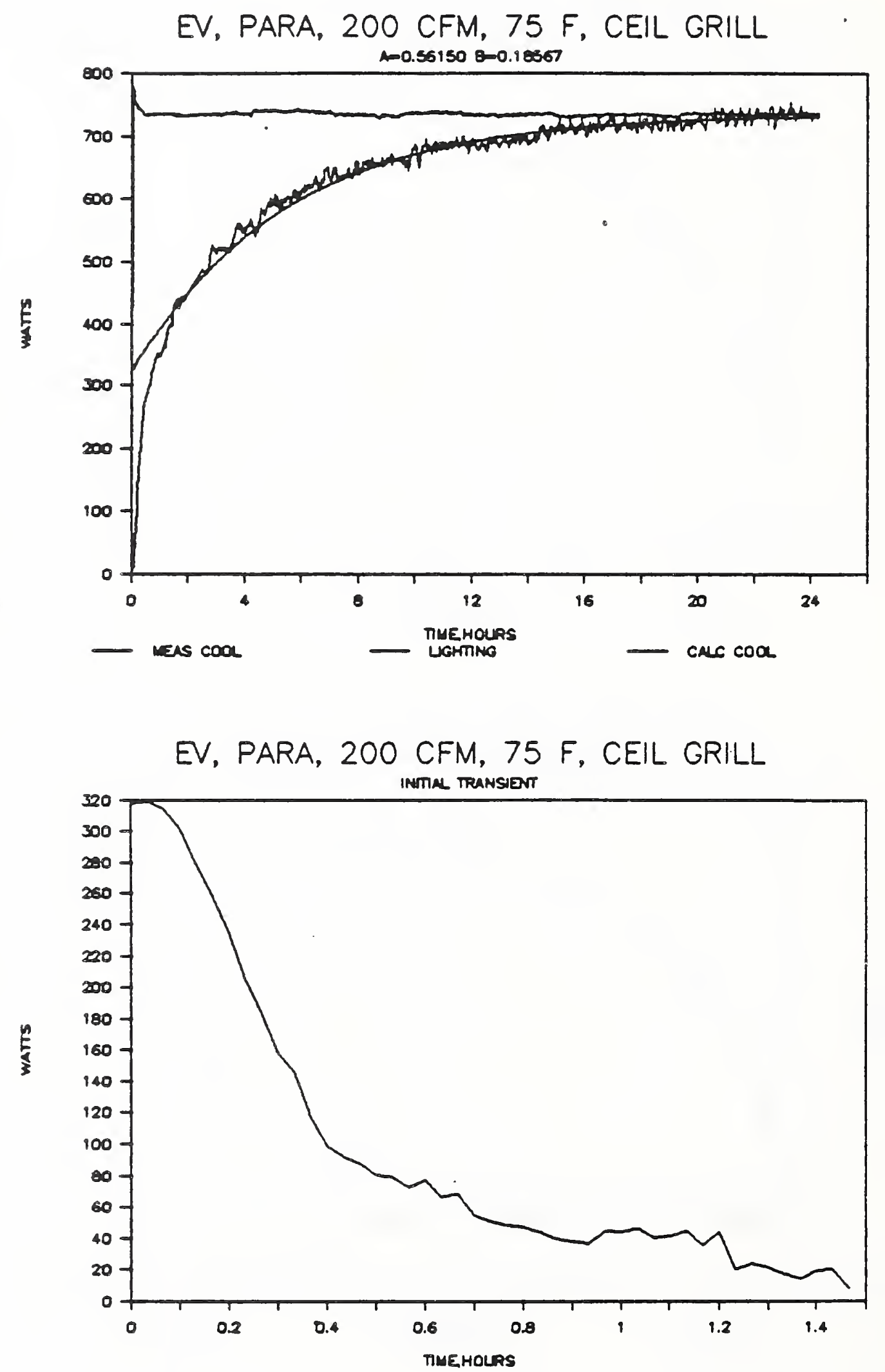

Figure 6.12 Initial Transient, CG200 
Figure 6.13 Measured Cooling Load Versus Double Exponential Regression Fit, CG200
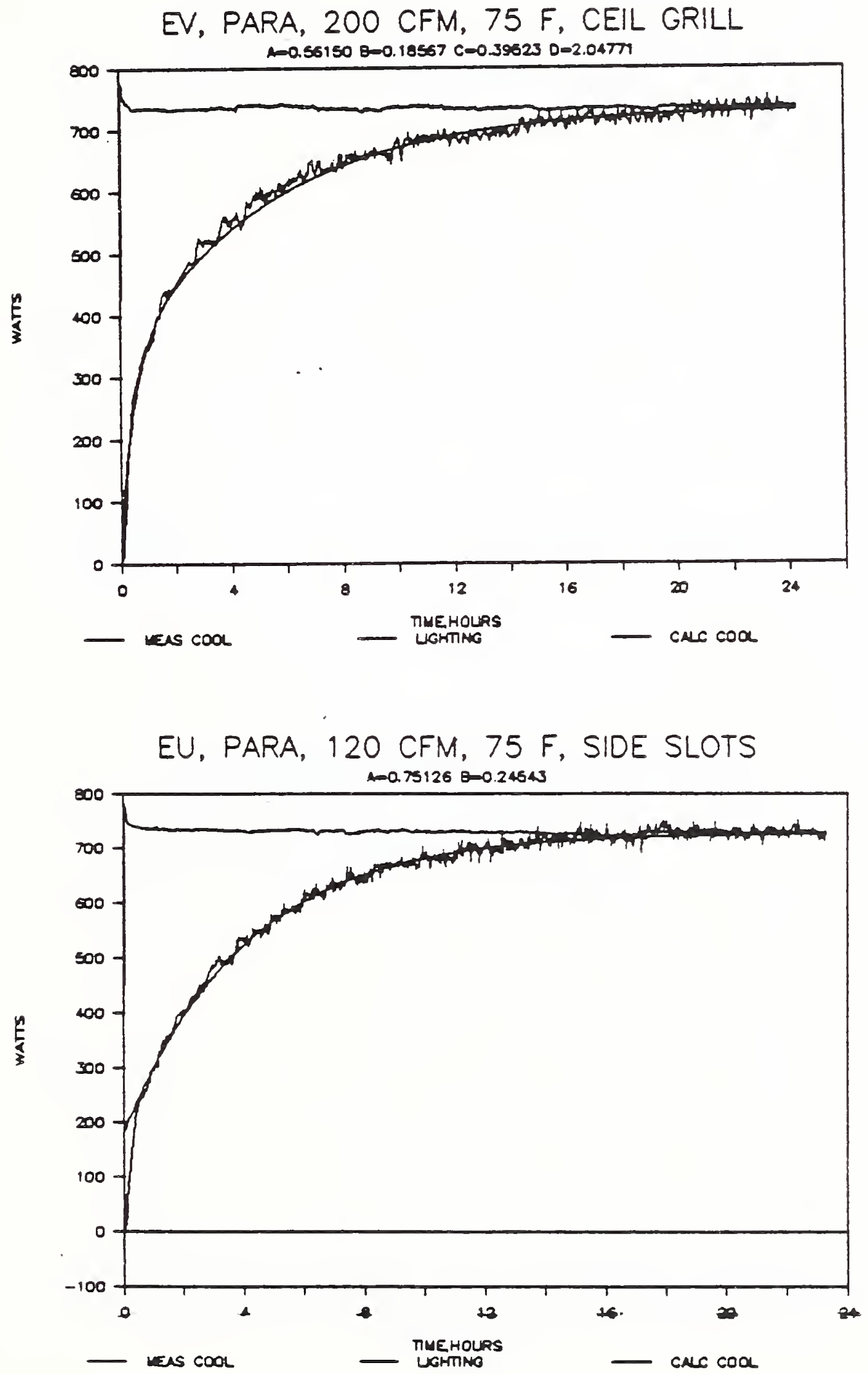

Figure 6.14 Measured Cooling Load and Lighting Power Versus Single Exponential Regression Fit, SS120 On 
Figure 6.15 Initial Transient ss120 On
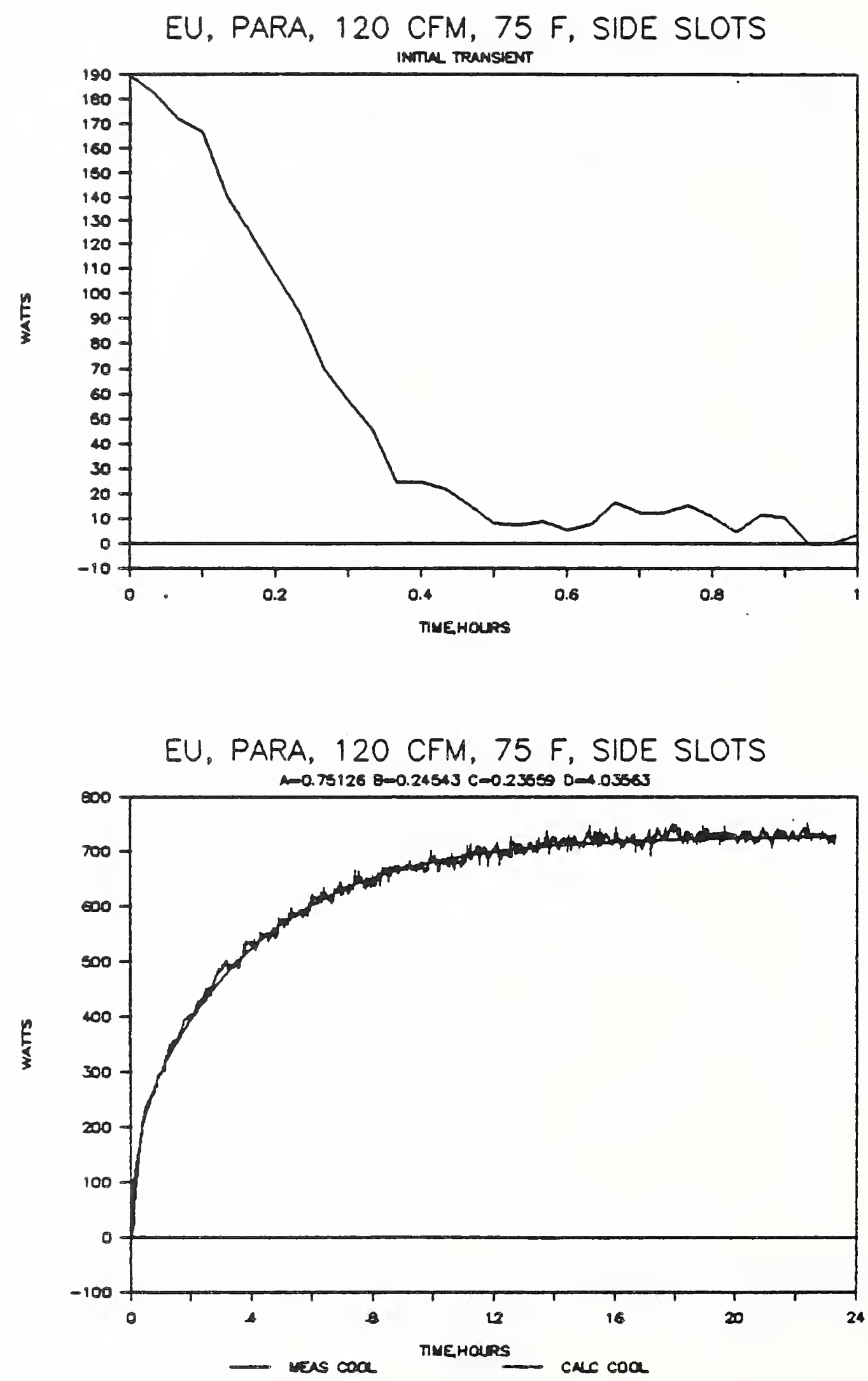

Figure 6.16 Measured Cooling Load Versus Double Exponential Regression Fit, ssi20 on 
Figure 6.17 Measured Cooling Load and Lighting Power Versus Single Exponential Regression Fit, SS120 off
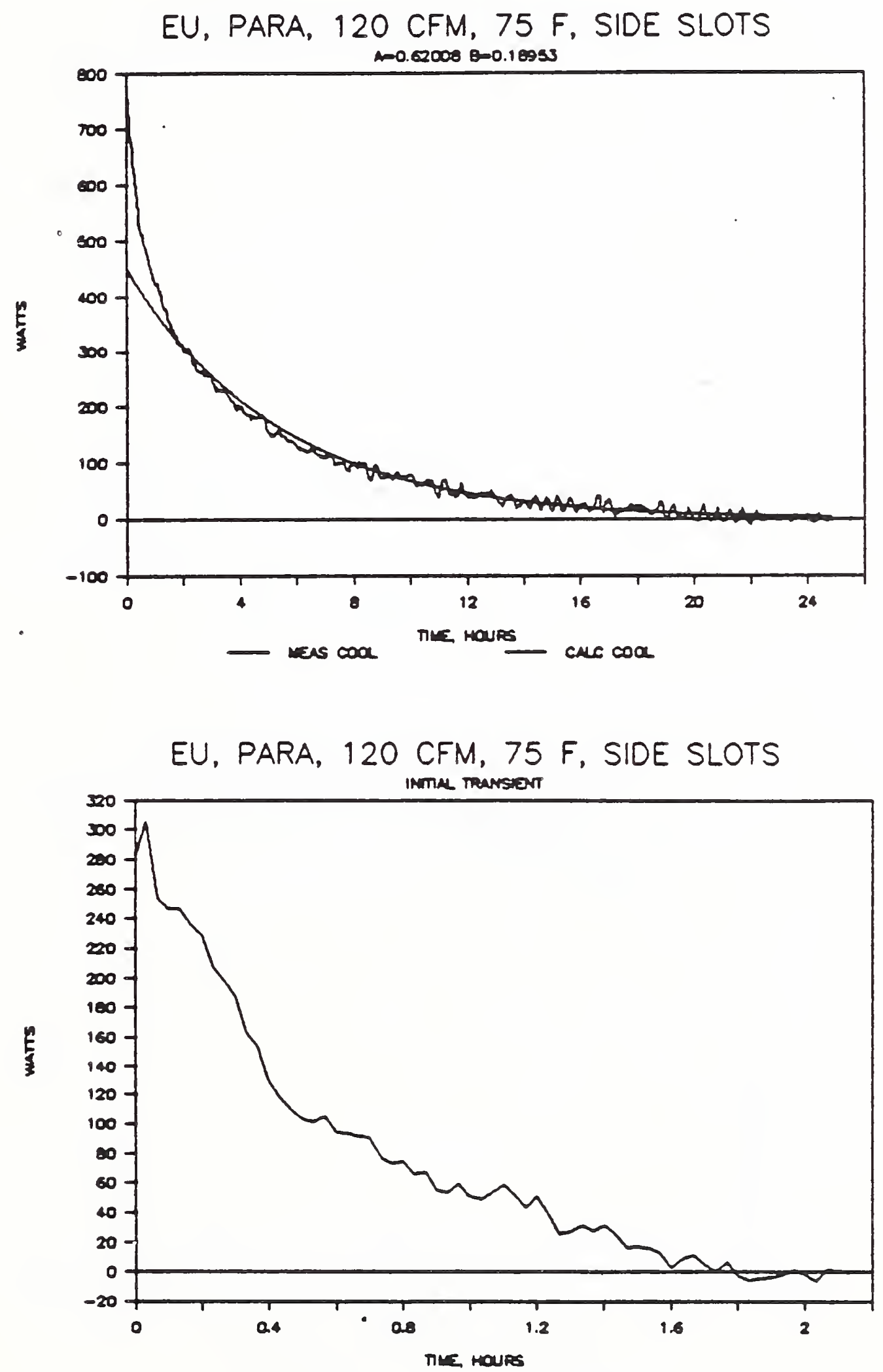

Figure 6.18 Initial Transient, sS120 off 
Figure 6.19 Measured Cooling Load Versus Double Exponential Regression Fit, SS120 off
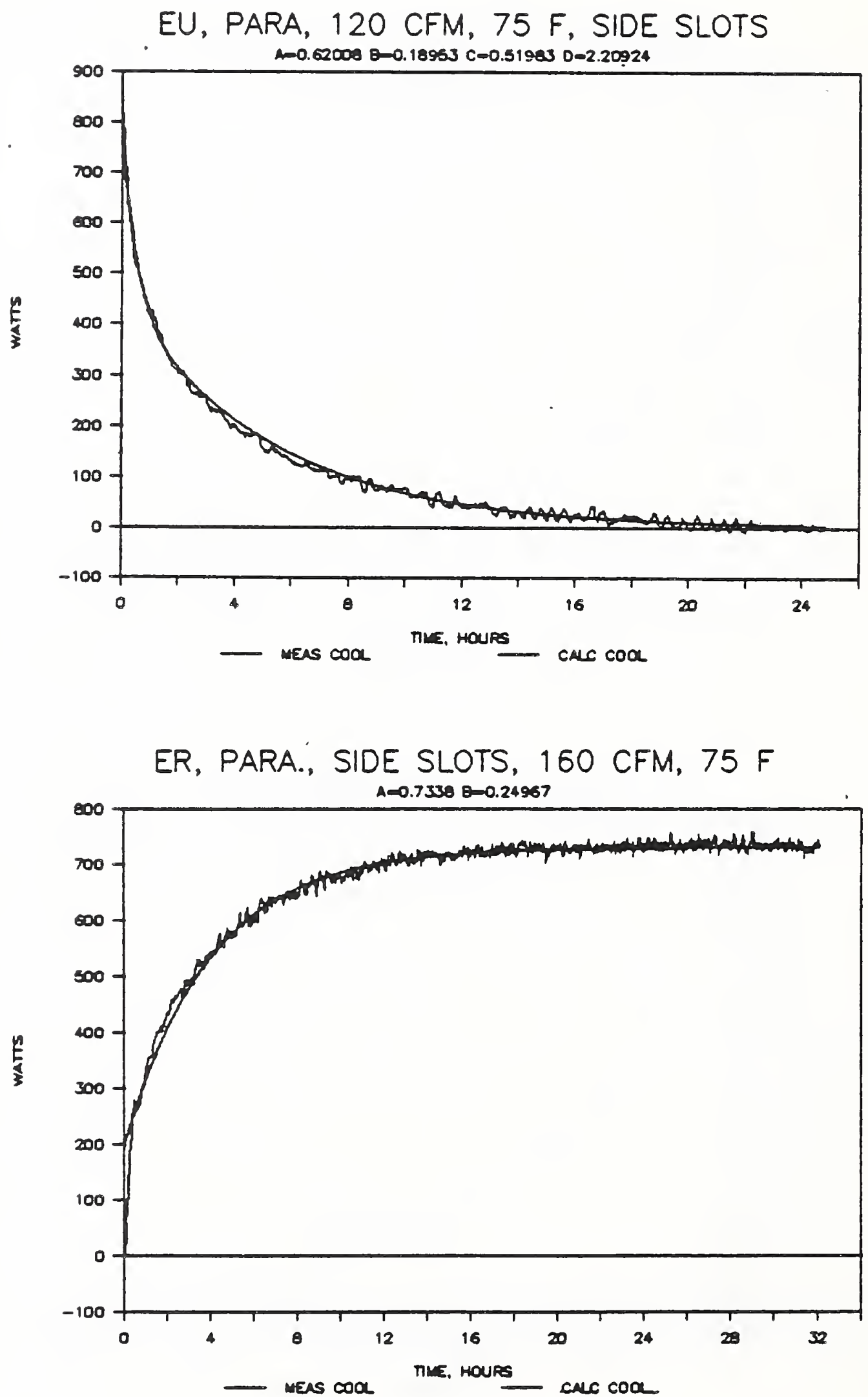

Figure 6.20 Measured Cooling Load and Lighting Power Versus Single Exponential Regression Fit, SS160 On 
Figure 6.21 Initial Transient, SS160 On
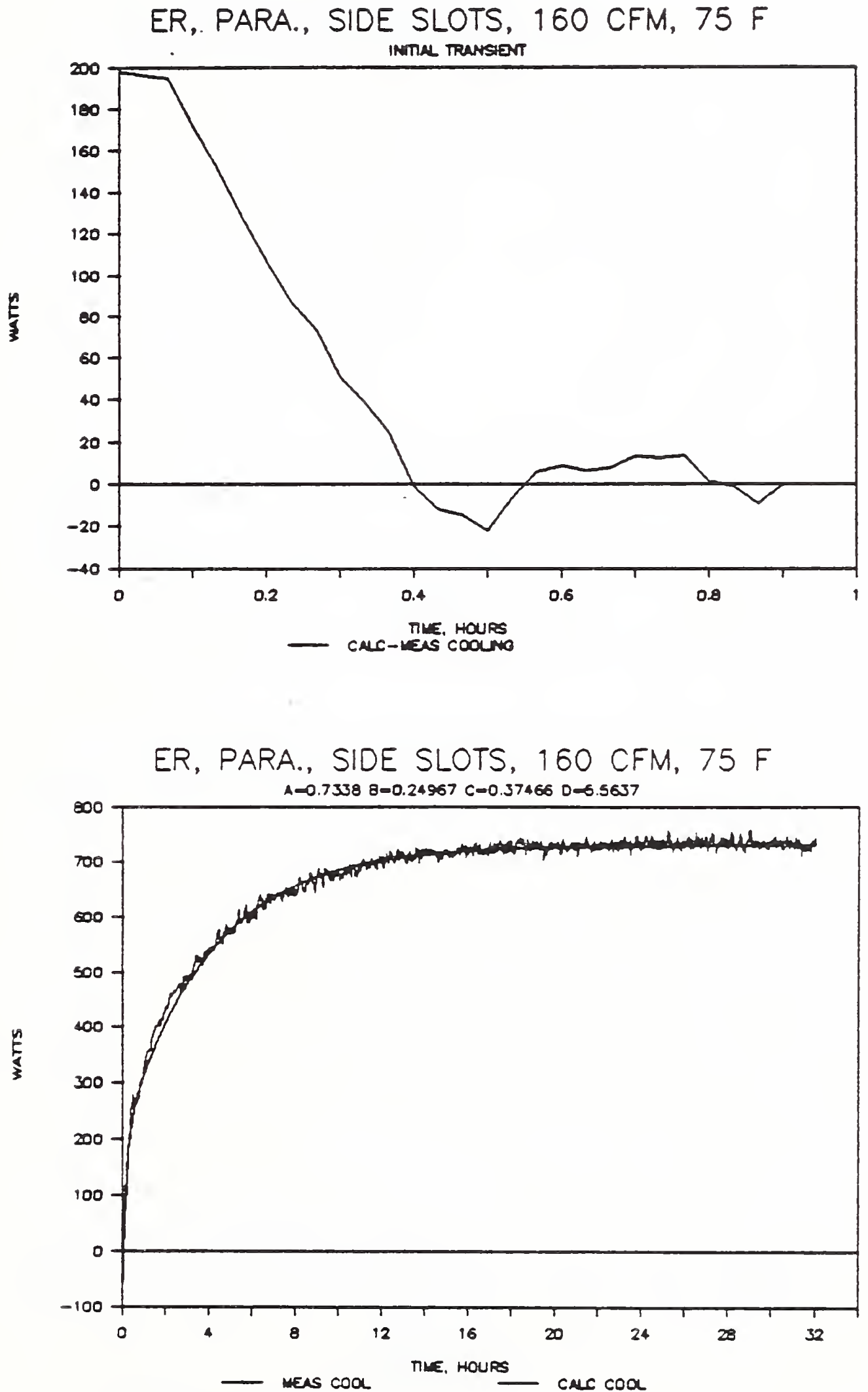

Figure 6.22 Measured Cooling Load Versus Double Exponential Regression Fit, SS160 On 
Figure 6.23 Measured Cooling Load and Lighting Power Versus Single Exponential Regression Fit, SS160 off
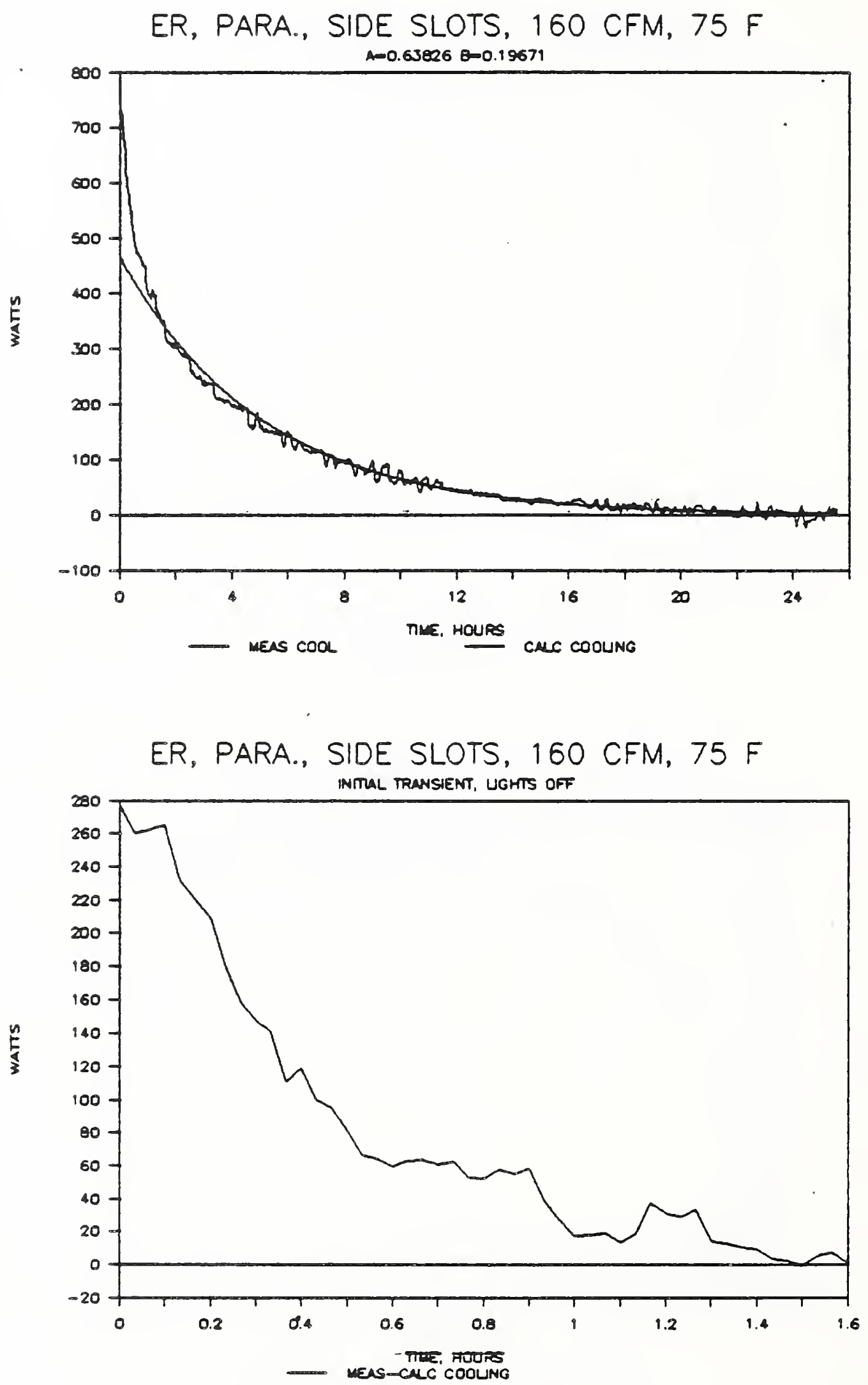

Figure 6.24 Initial Transient, SS160 off 
Figure 6.25 Measured Cooling Load Versus Double Exponential Regression Fit, SS160 off
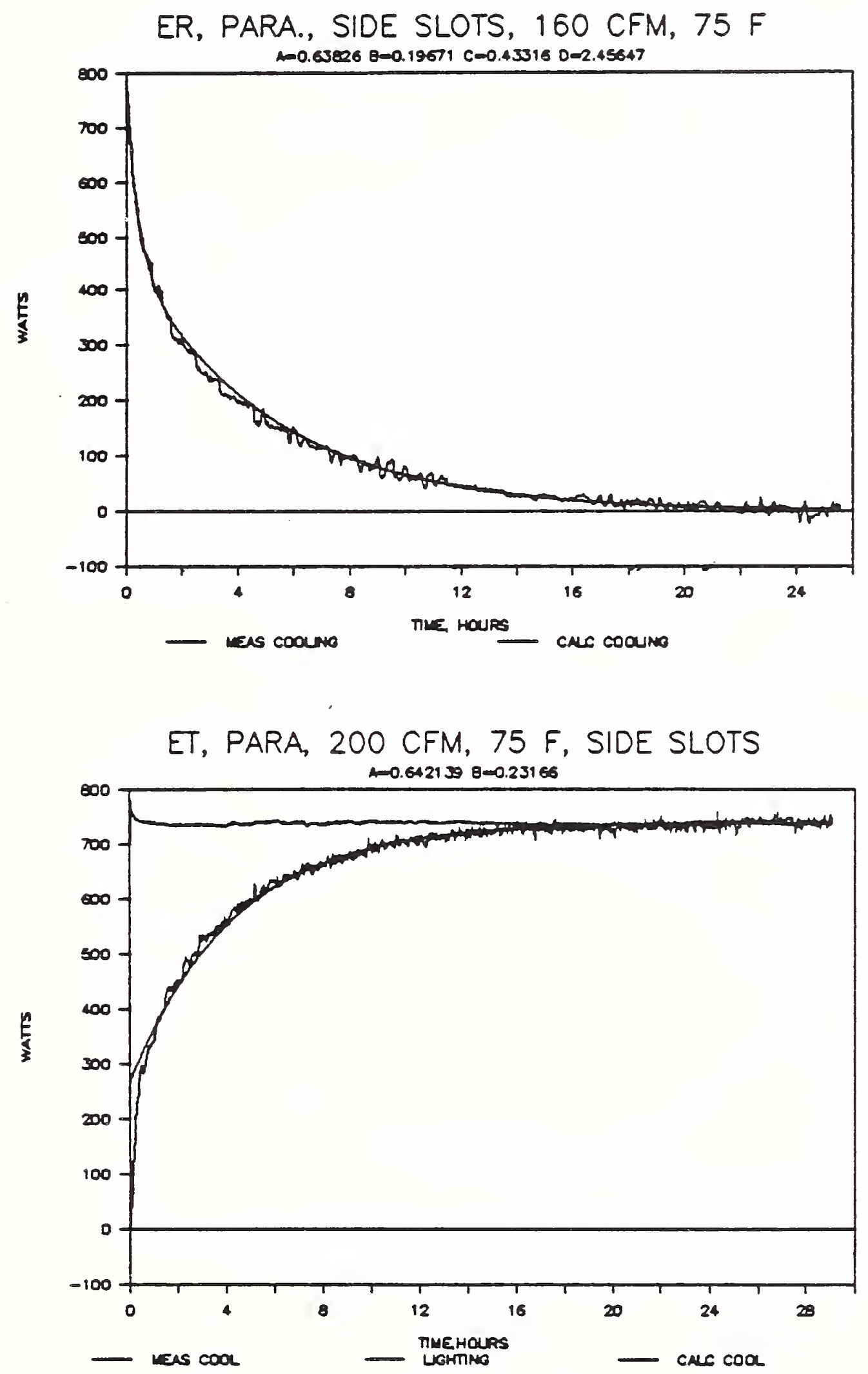

Figure 6.26 Measured Cooling Load and Lighting Power Versus Single Exponential Regression Fit, SS200 On 
Figure 6.27 Initial Transient, ss200 On

ET, PARA, 200 CFM, 75 F, SIDE SLOTS IATRL Transiant
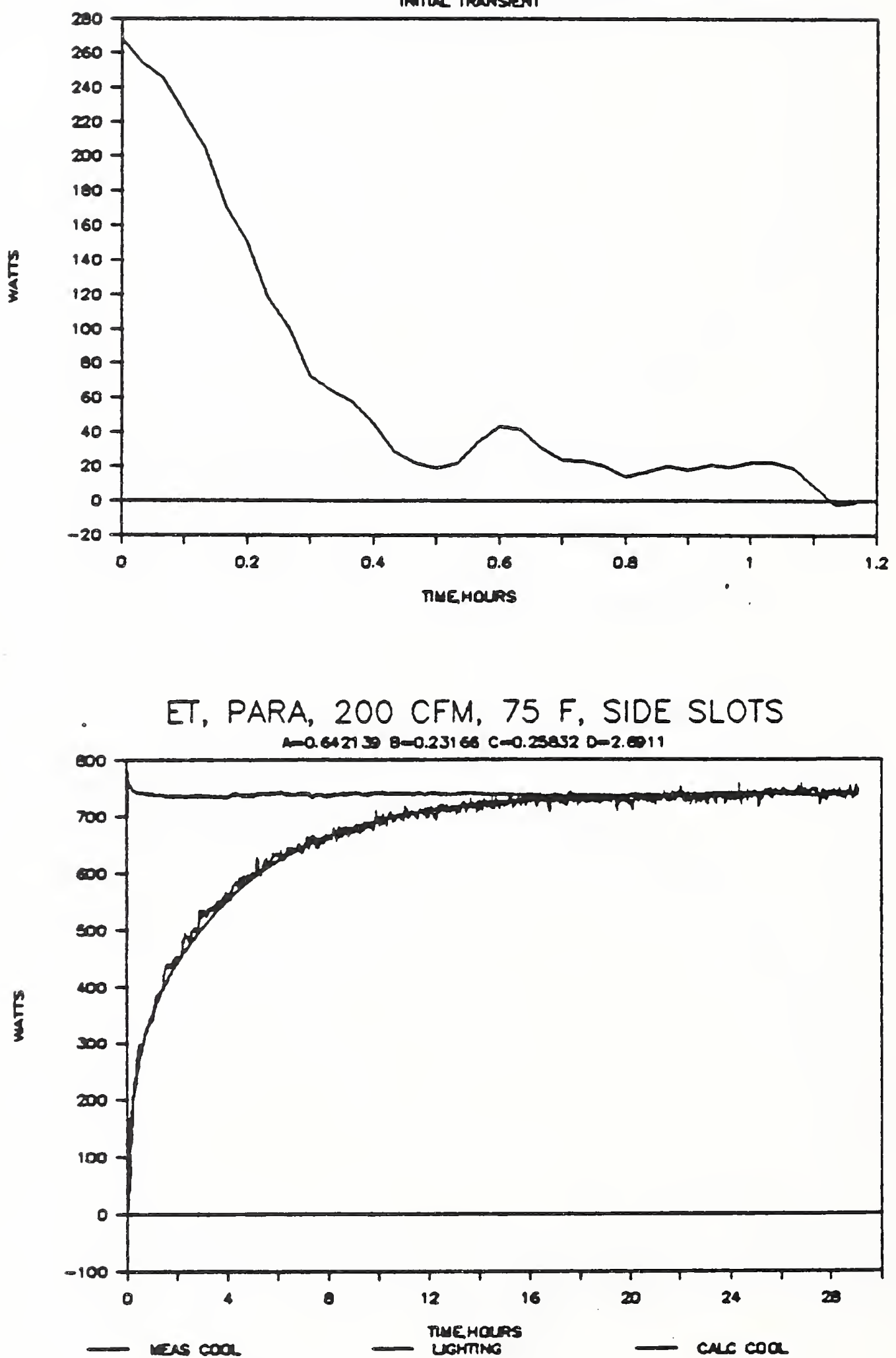

Figure 6.28 Measured Cooling Load Versus Double Exponential Regression Fit, SS200 On 
Figure 6.29 Measured Cooling Load and Lighting Power Versus Single Exponential Regression Fit, SS200 off

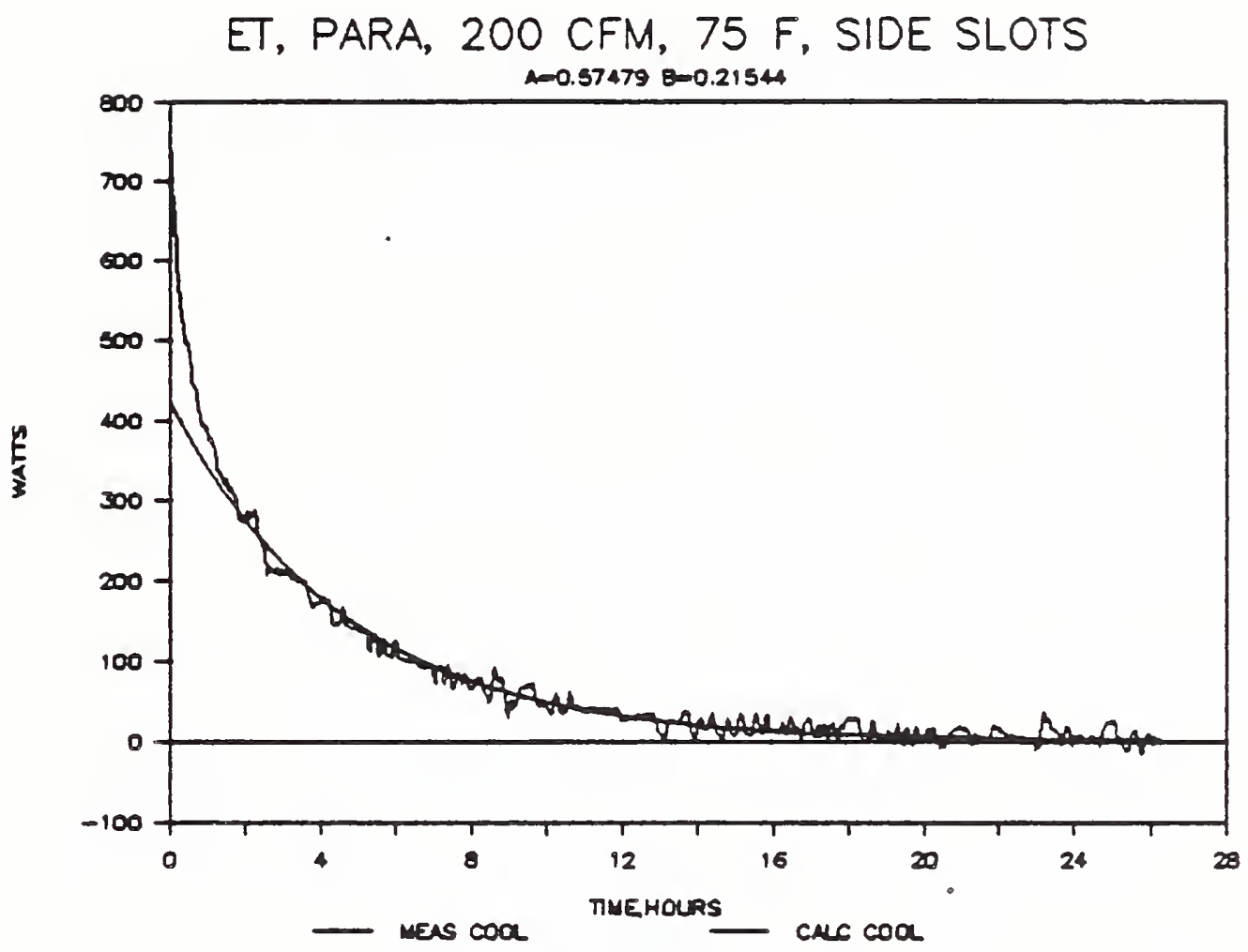

ET, PARA, 200 CFM, 75 F, SIDE SLOTS

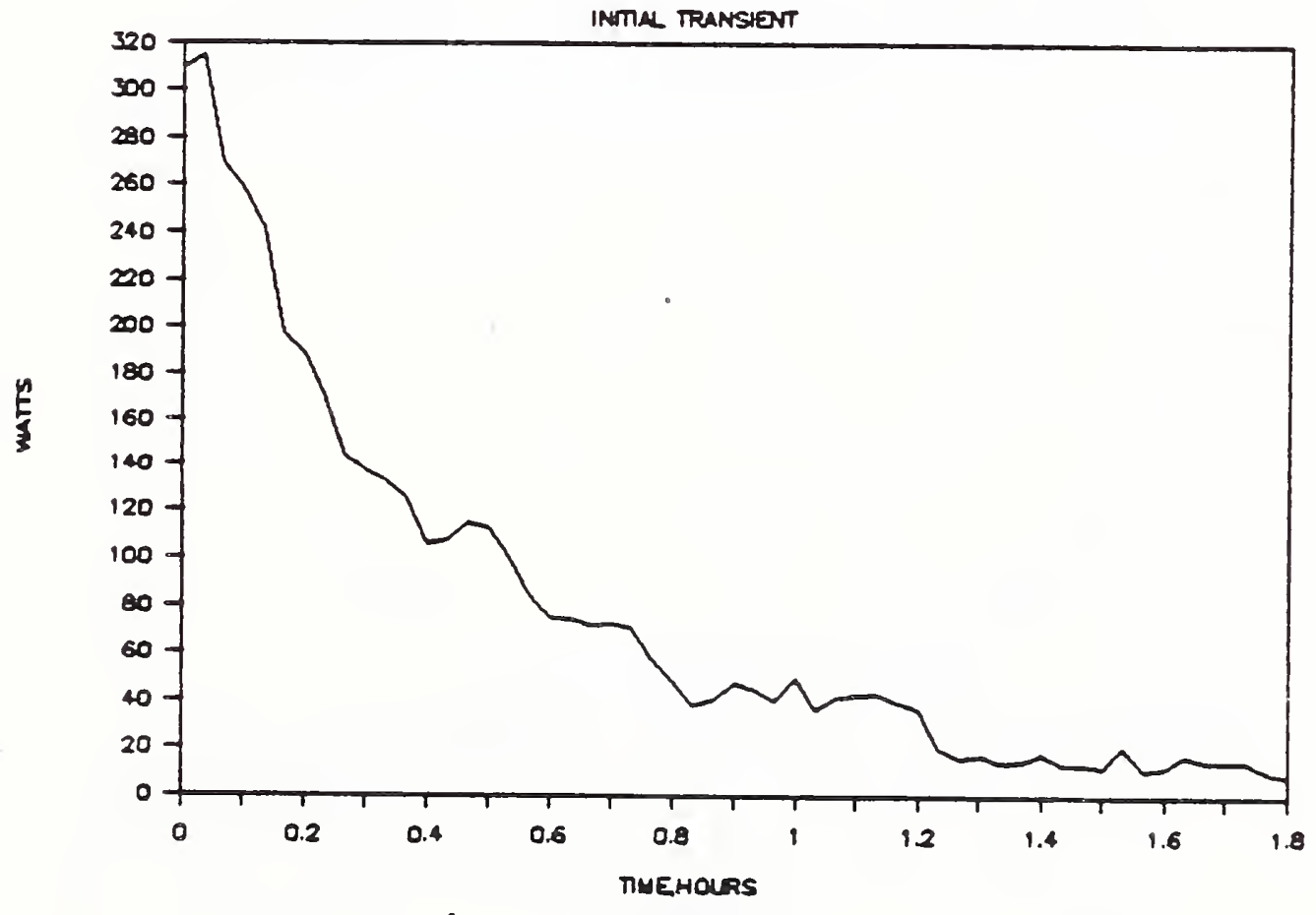

Figure 6.30 Initial Transient, SS200 off 
Figure 6.31 Measured Cooling Load Versus Double Exponential Regression Fit, SS200 off

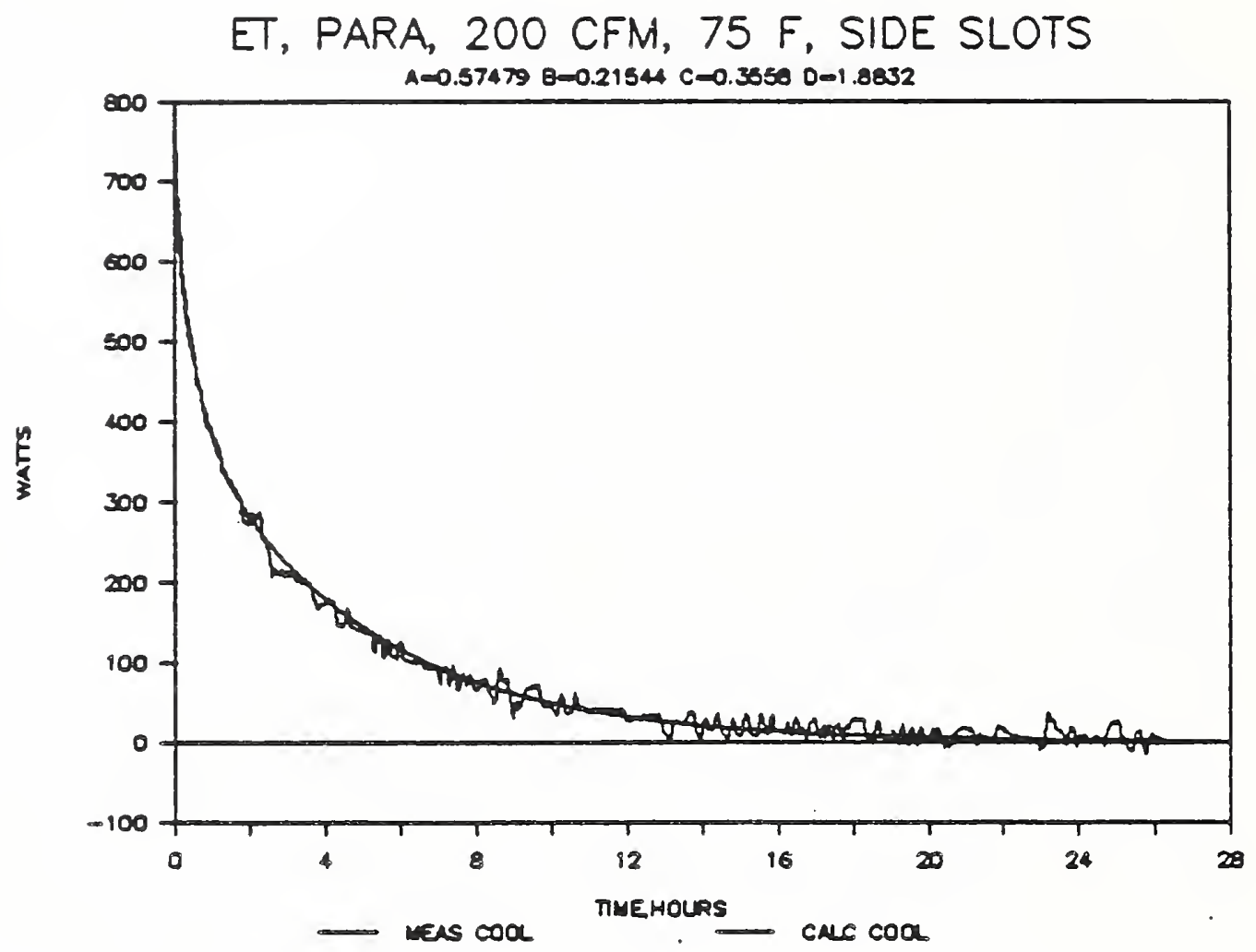

EJ, PARA, 120 CFM, 75 F, LAMP COMP

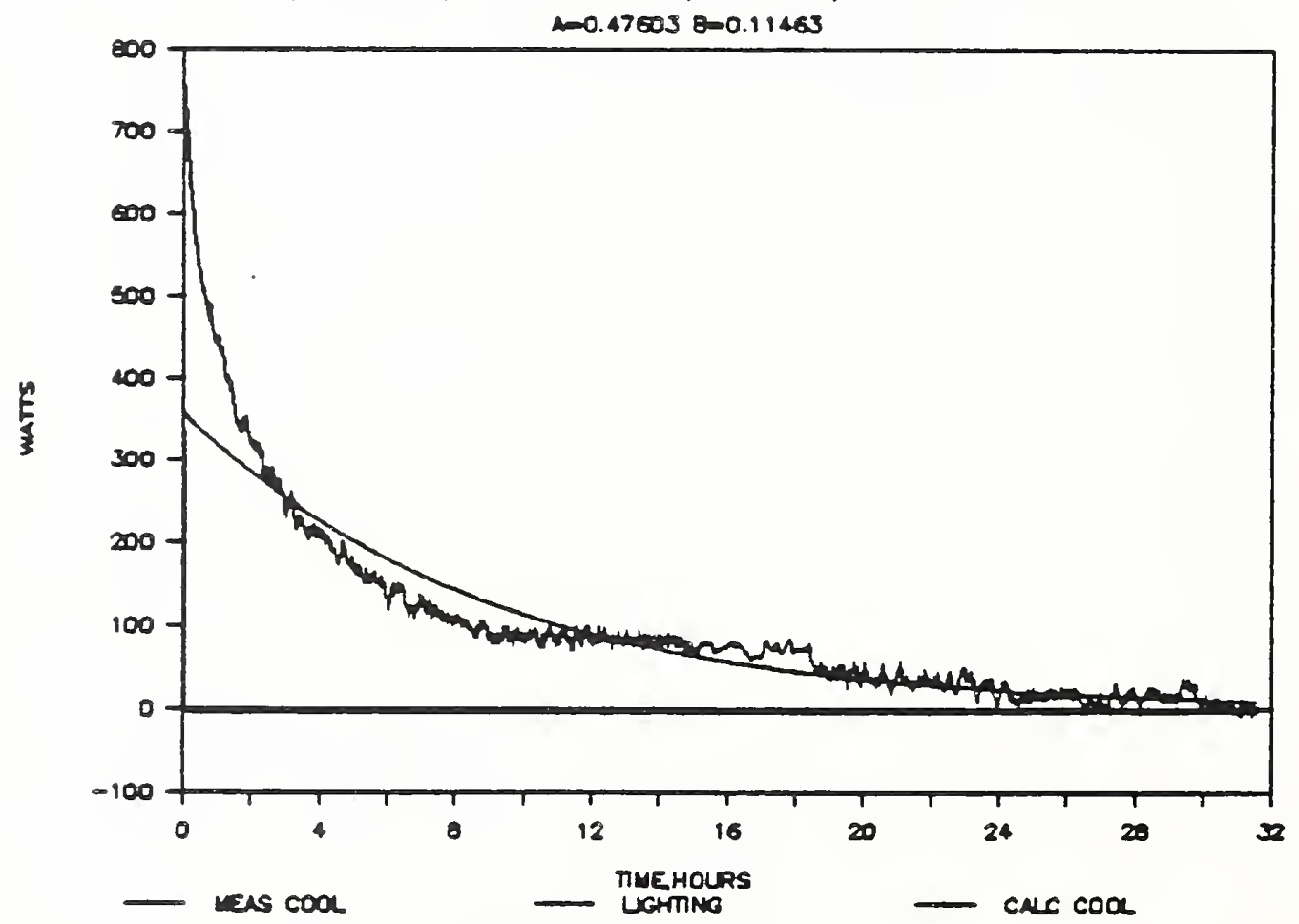

Figure 6.32 Measured Cooling Load and Lighting Power Versus Single Exponential Regression Fit, LC120 Off 
Figure 6.33 Initial Transient, LC120 off
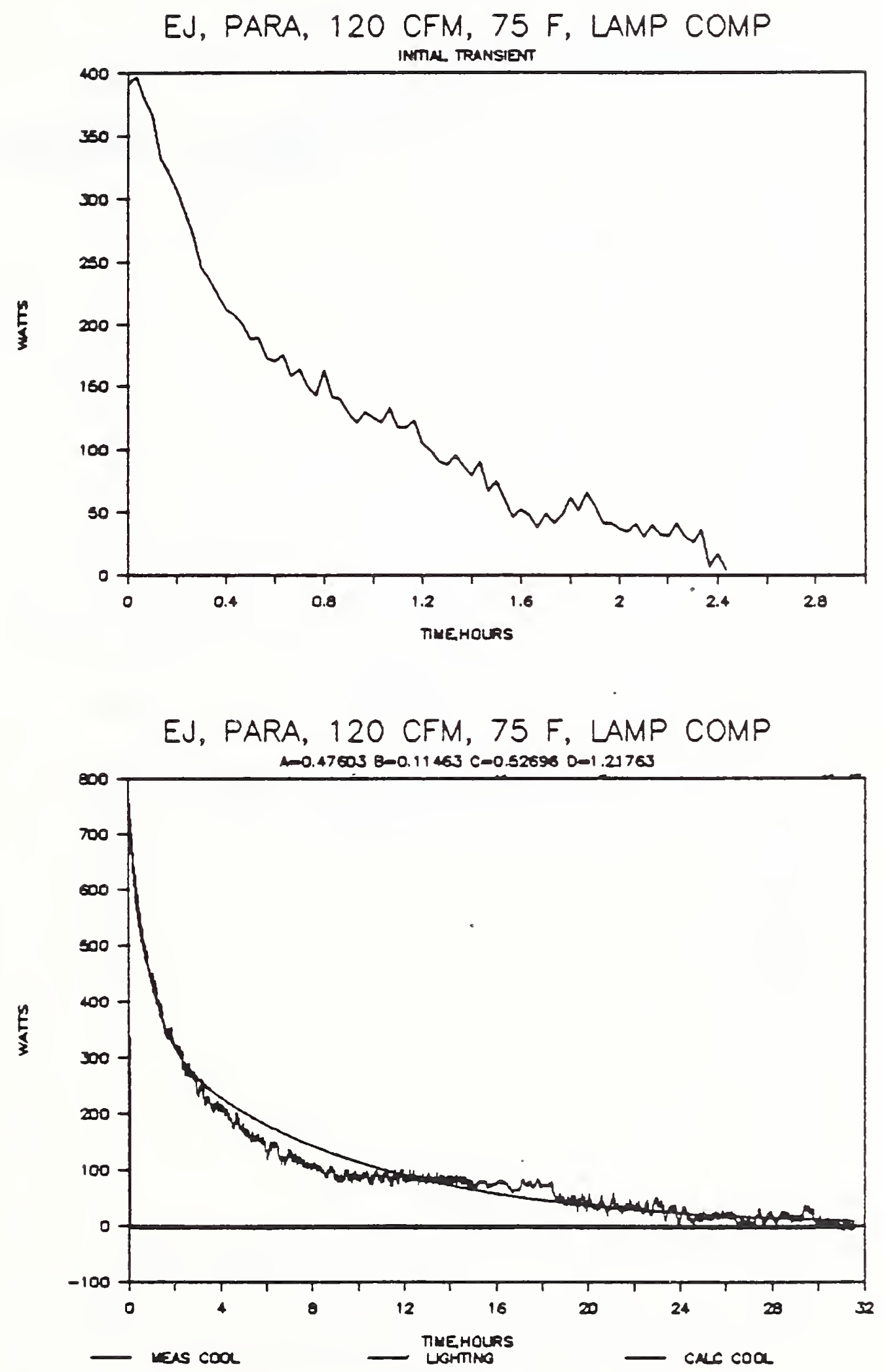

Figure 6.34 Measured Cooling Load Versus Double Exponential Regression Fit, LC120 off 
Figure 6.35 Measured Cooling Load and Lighting Power Versus Single Exponential Regression Fit, LC160 On
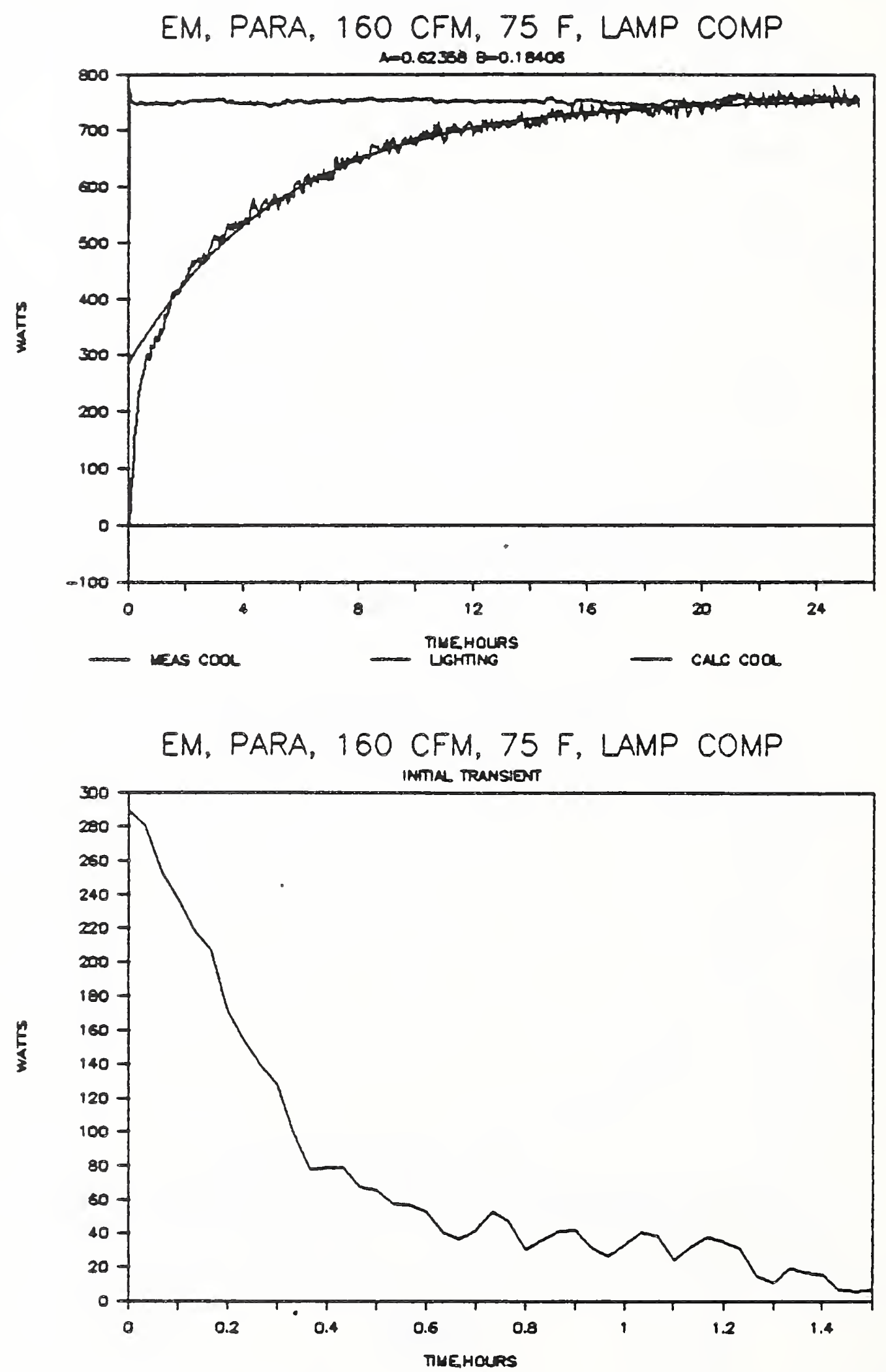

Figure 6.36 Initial Transient, LC160 on 
Figure 6.37 Measured Cooling Load Versus Double Exponential Regression Fit, LC160 On
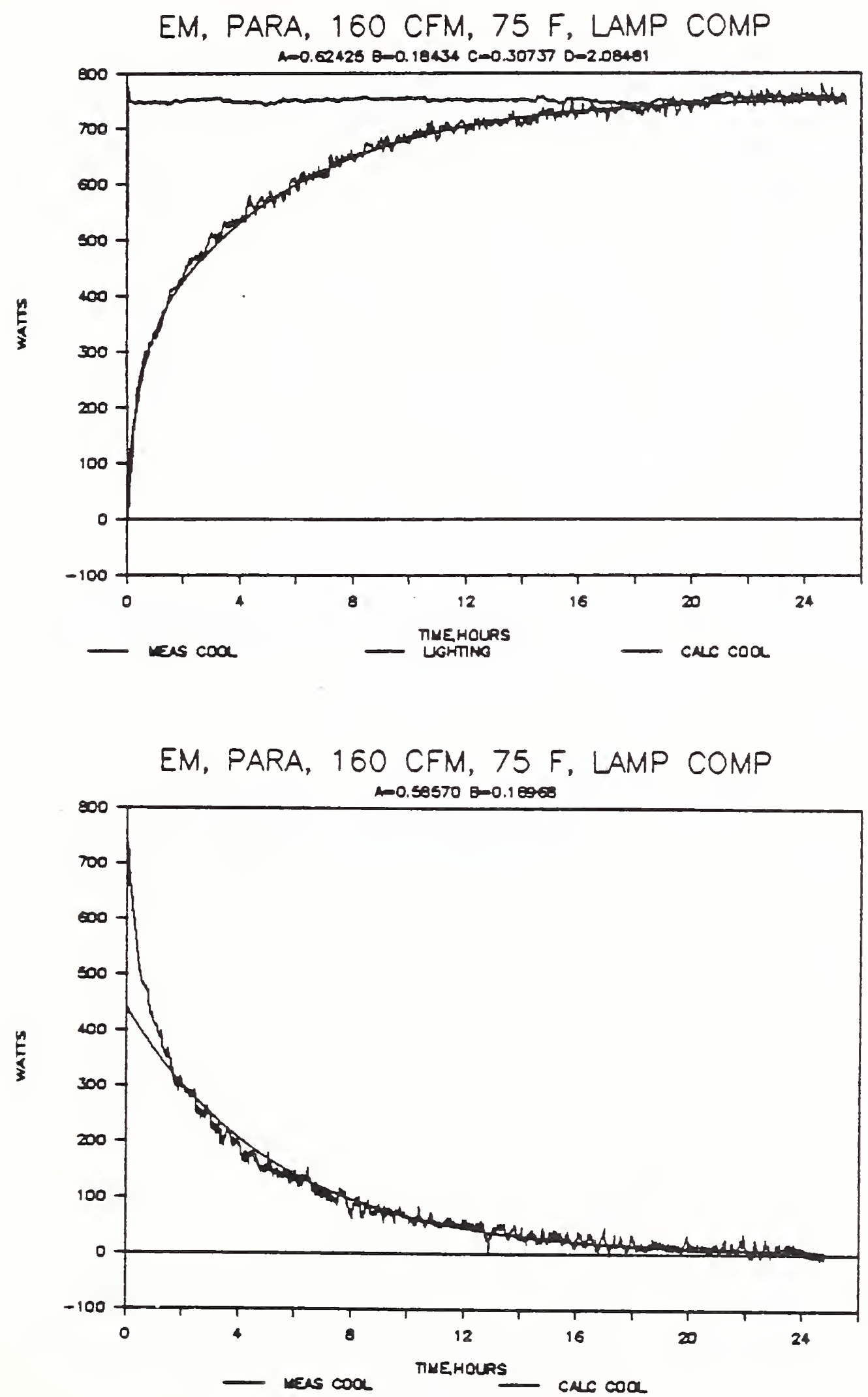

Figure 6.38 Measured Cooling Load and Lighting Power Versus Single Exponential Regression Fit, LC160 off 
Figure 6.39 Initial Transient, LC160 off
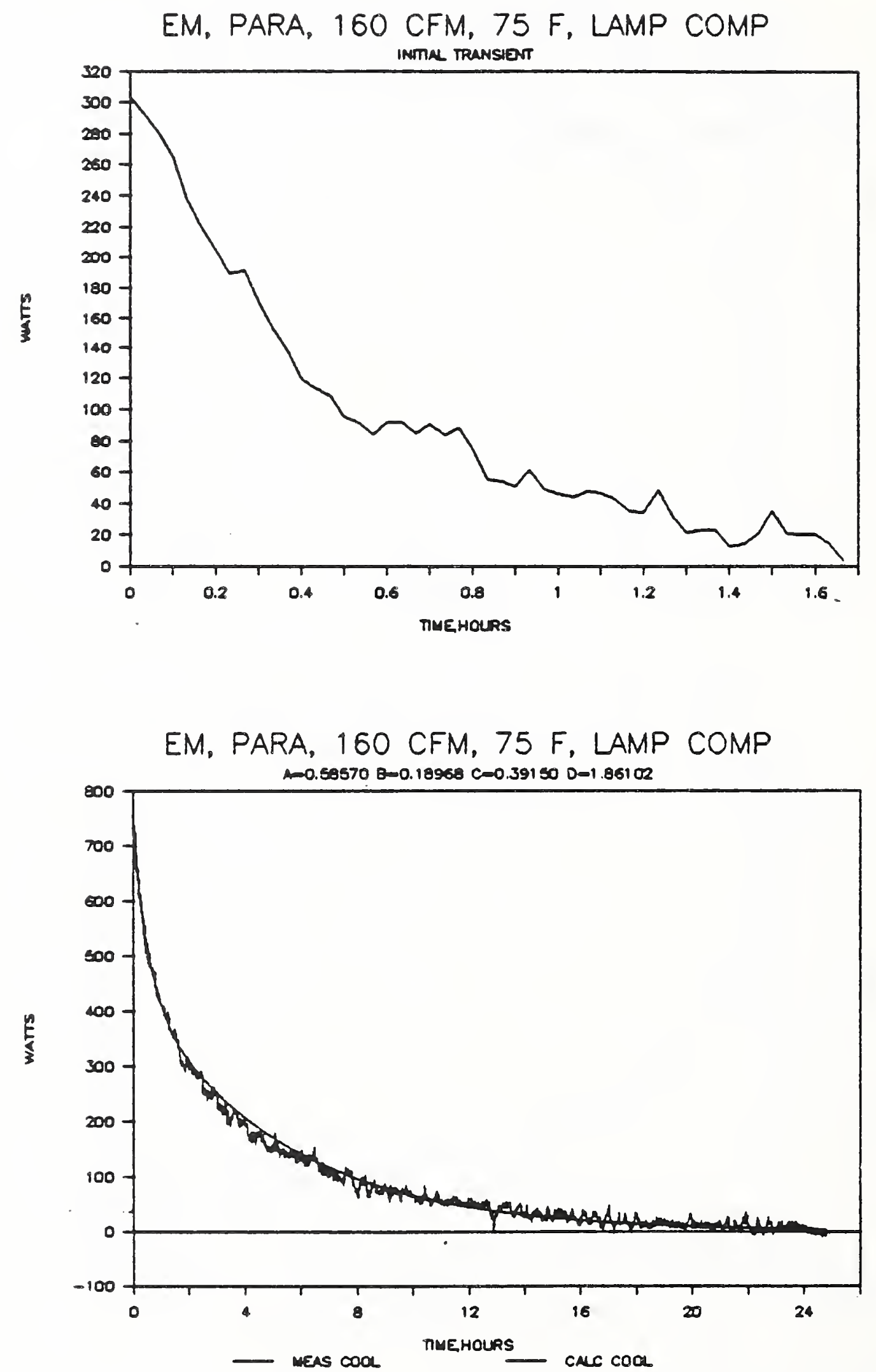

Figure 6.40 Measured Cooling Load Versus Double Exponential Regression Fit, LC160 off 
Figure 6.41 Measured Cooling Load and Lighting Power Versus Single Exponential Regression Fit, LC200 off

EN, PARA, 200 CFM, 75 F, LAMP COMP

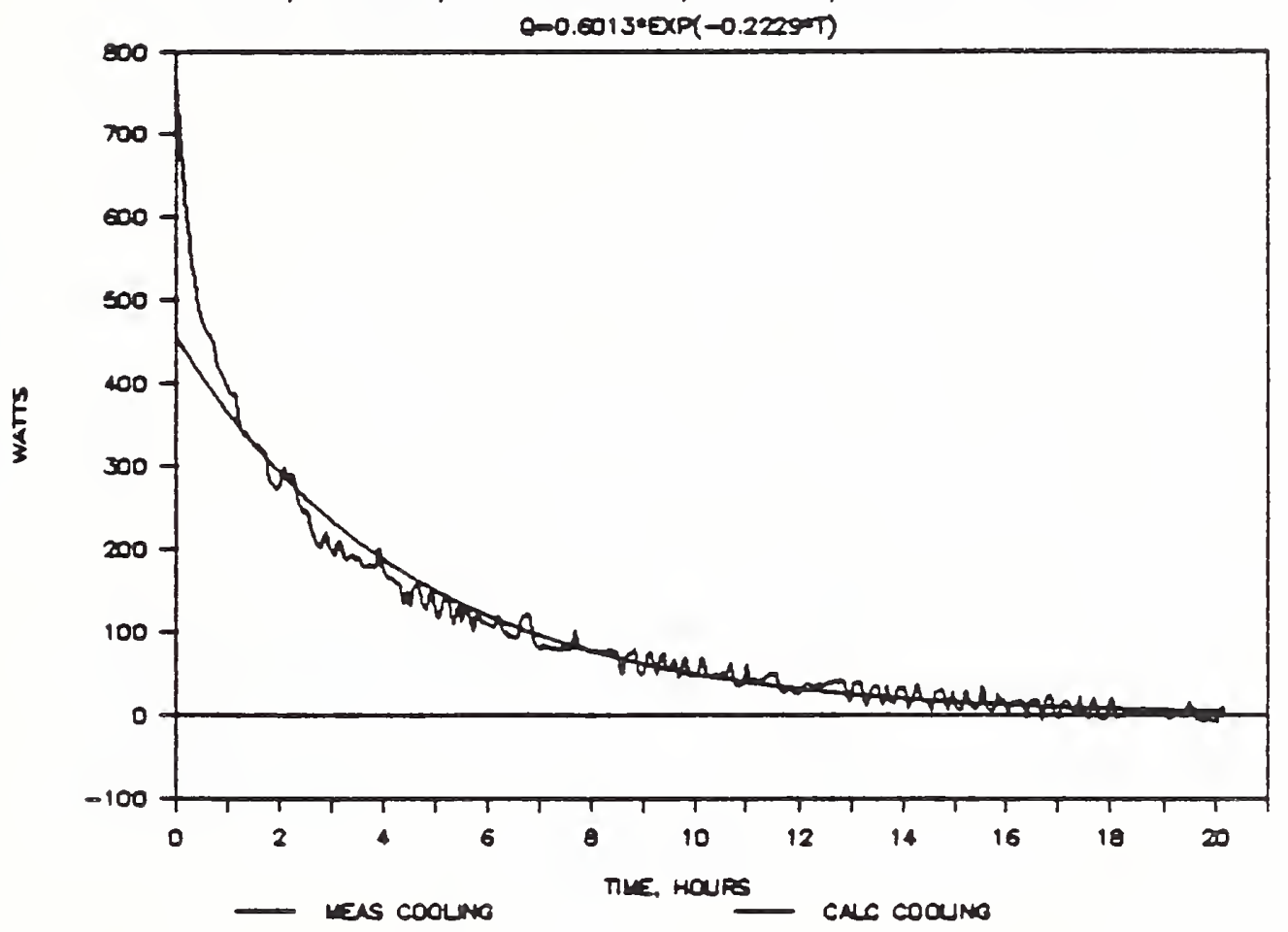

EN, PARA, 200 CFM, 75 F, LAMP COMP

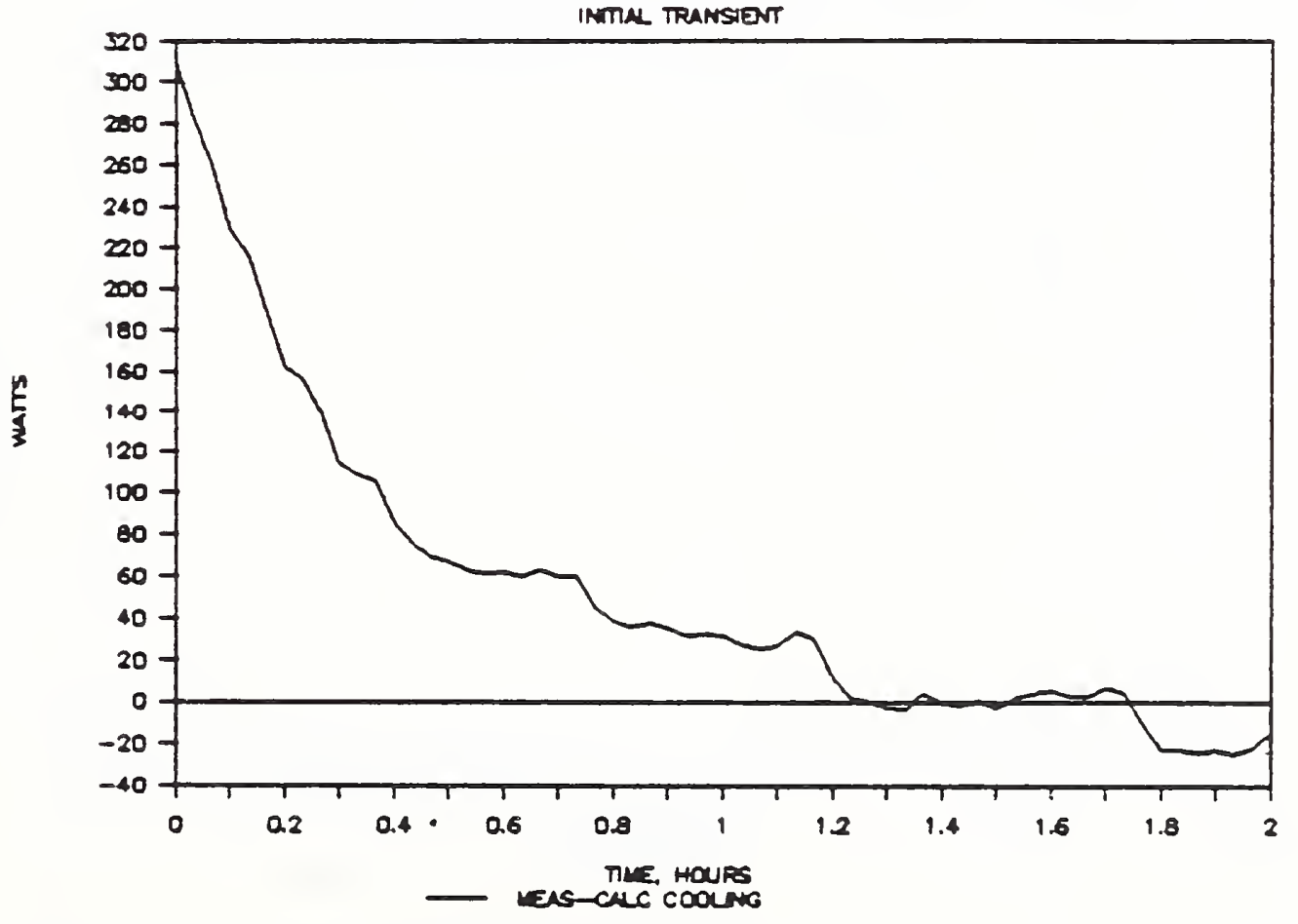

Figure 6.42 Initial Transient, LC200 off 
Figure 6.43 Measured Cooling Load Versus Double Exponential Regression Fit, LC200 off

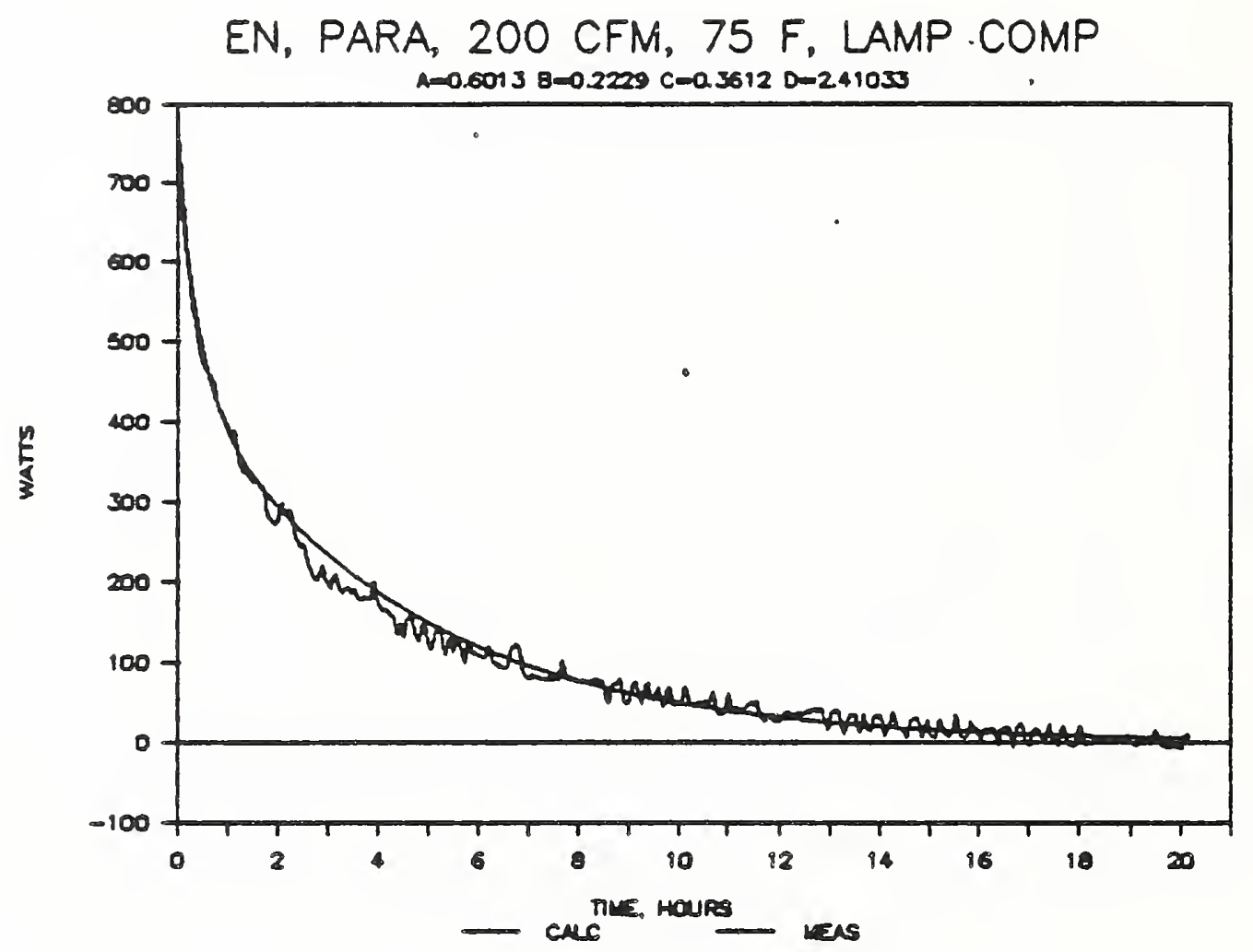

ES, ET LIGHTS ON VS OFF 200 CFM, 75 F, STOE SLOTS

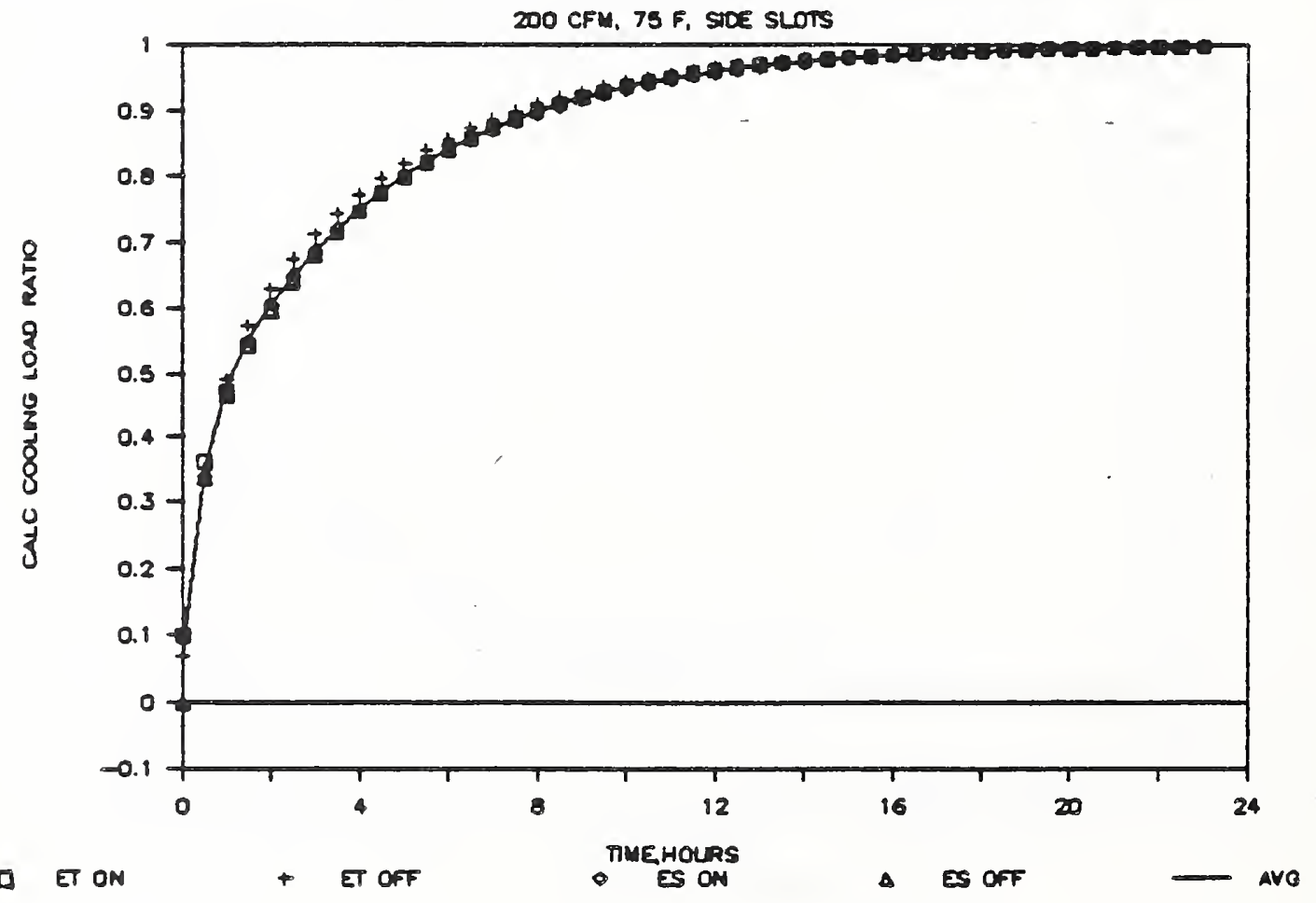

Figure 6.44 Comparison of Cooling Load Profiles From Different Tests with Same Conditions 
Figure 6.45 Regression Coefficients Versus Airflow Rate
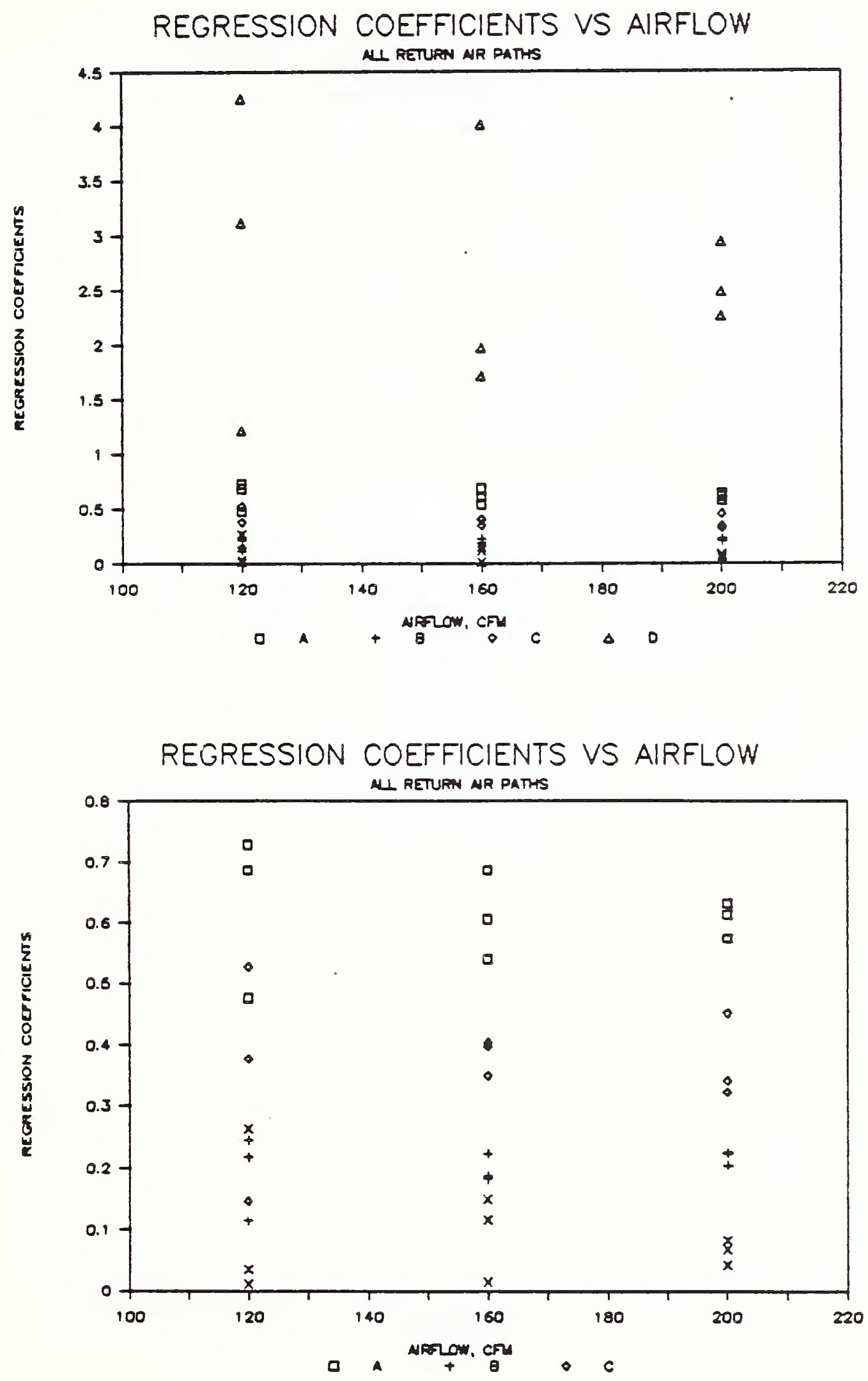

Figure 6.46 Regression Coefficients A, B and C Versus Airflow 
Figure 6.47 Regression Coefficient A Versus Airflow
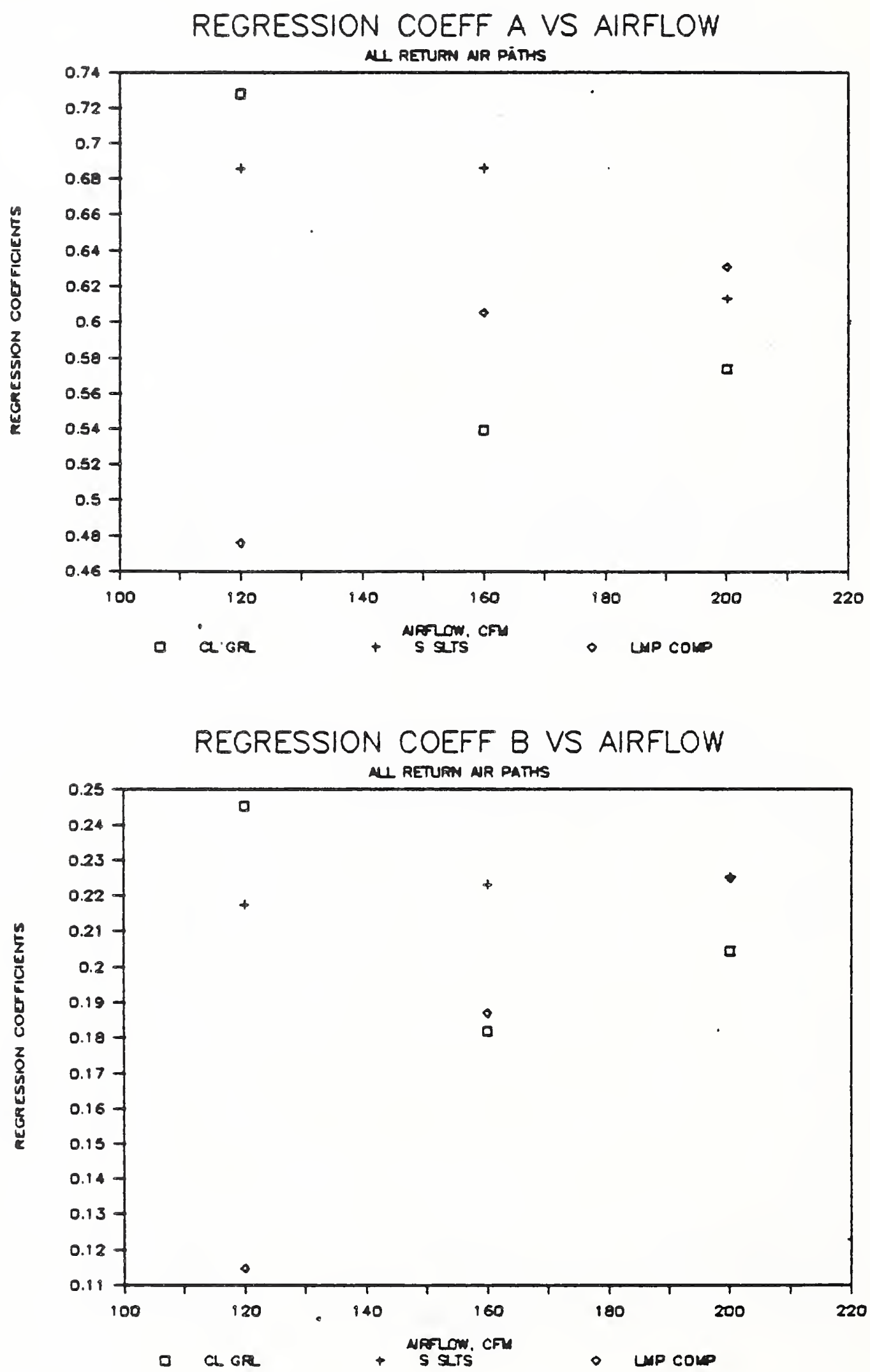

Figure 6.48 Regression Coefficient B Versus Airflow 
Figure 6.49 Regression Coefficient C Versus Airflow
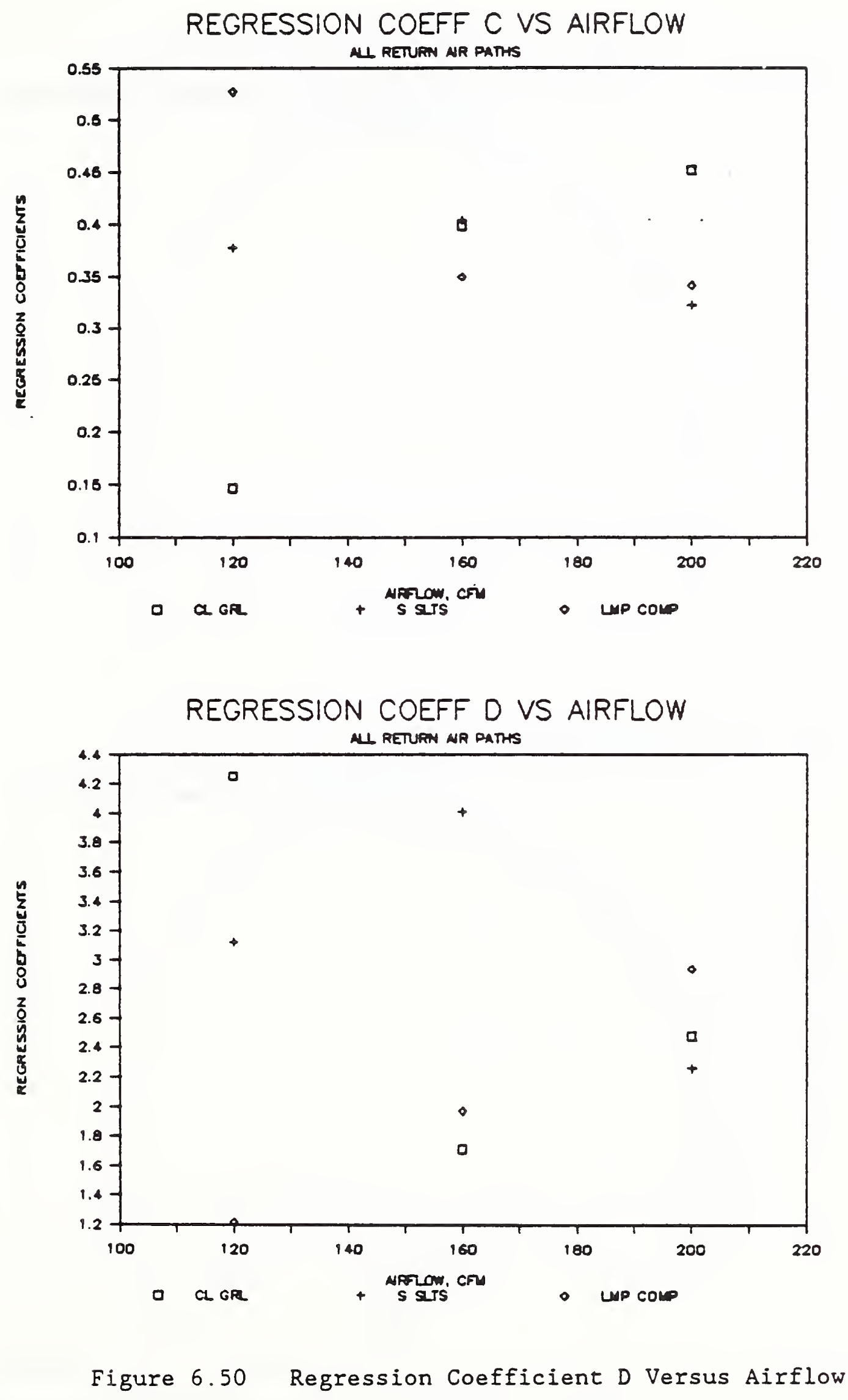
Figure 6.51 Cooling Load Profiles for Ceiling Grill Return
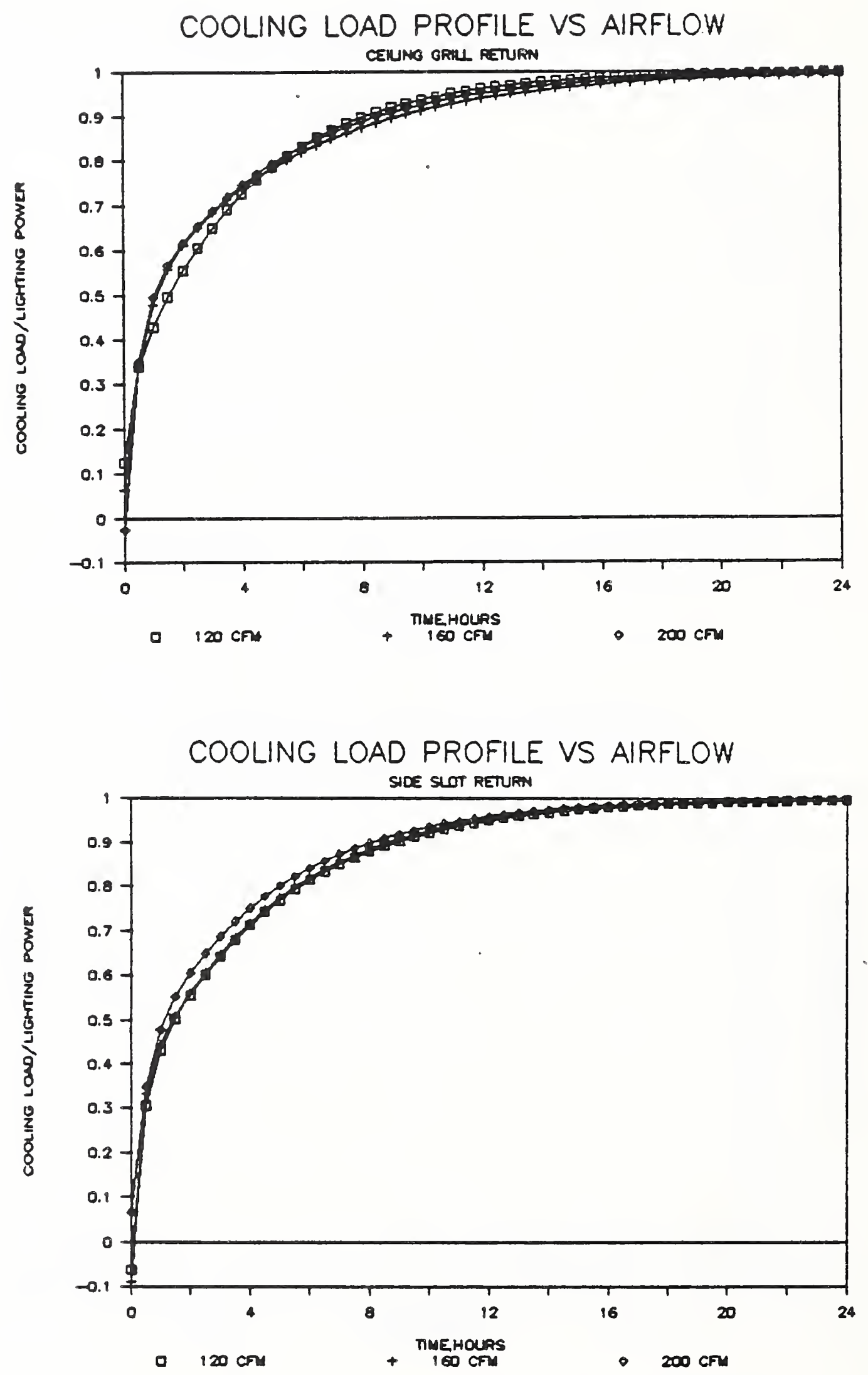

Figure 6.52 Cooling Load Profiles for Ceiling Side Slot Return 
Figure 6.53 Cooling Load Profiles for Ceiling Lamp Compartment Return
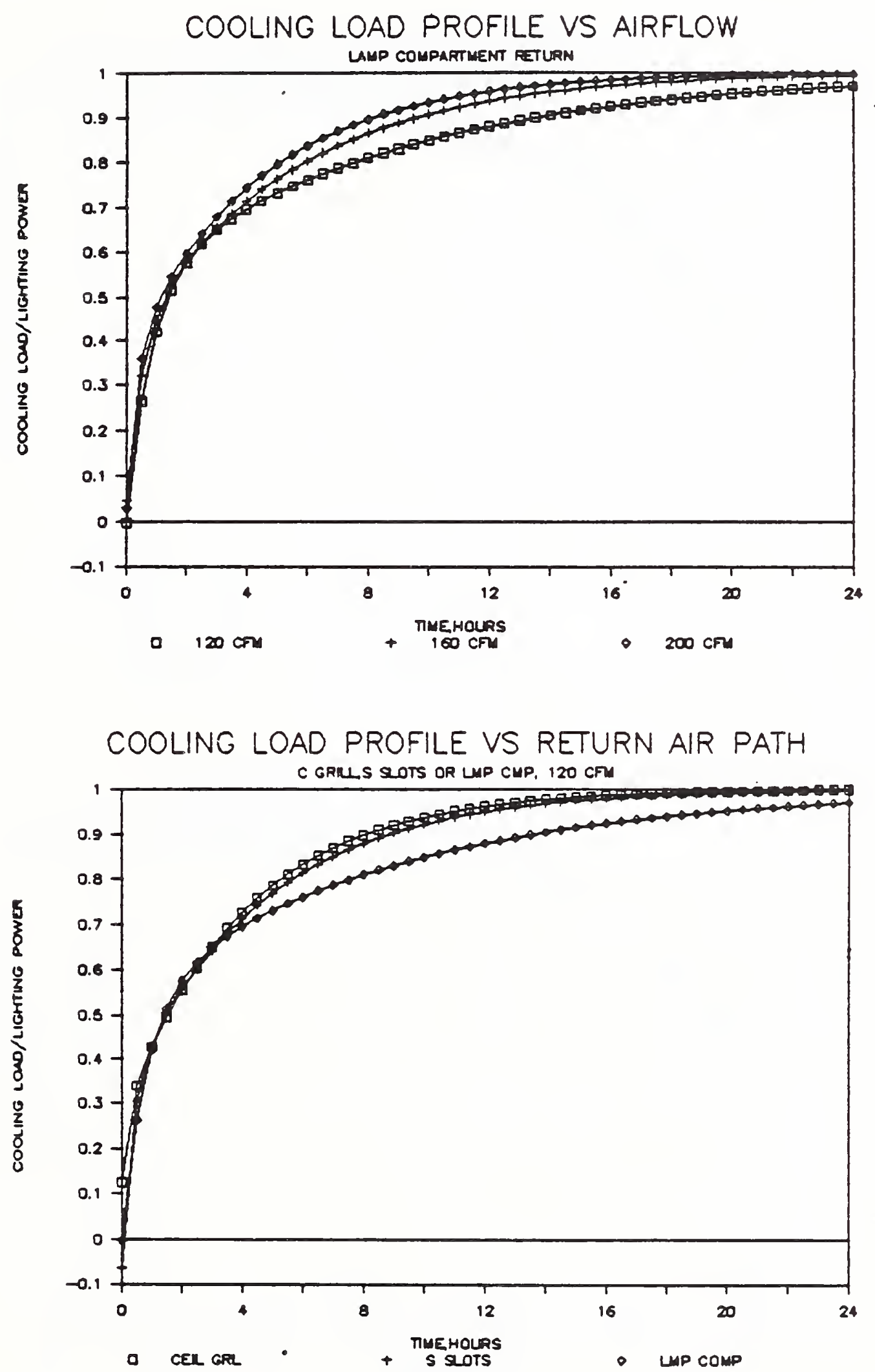

Figure 6.54 Cooling Load Profiles for Ceiling 120 cfm Airflow 
Figure 6.55 Cooling Load Profiles for Ceiling 160 cfm Airflow
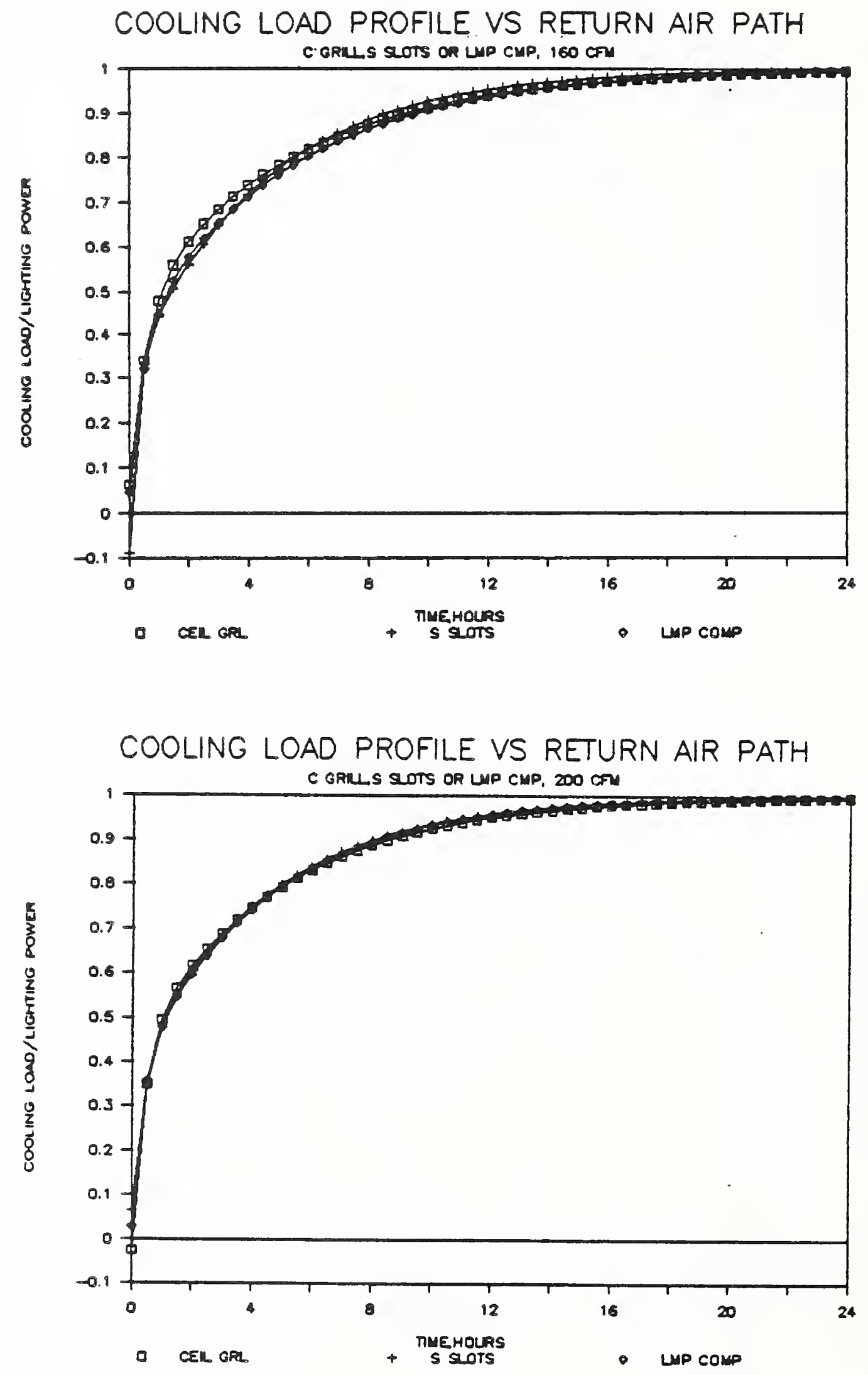

Figure 6.56 Cooling Load Profiles for Ceiling 200 cfm Airflow 
Figure 6.57 Cooling Load One Hour After Lights are Energized
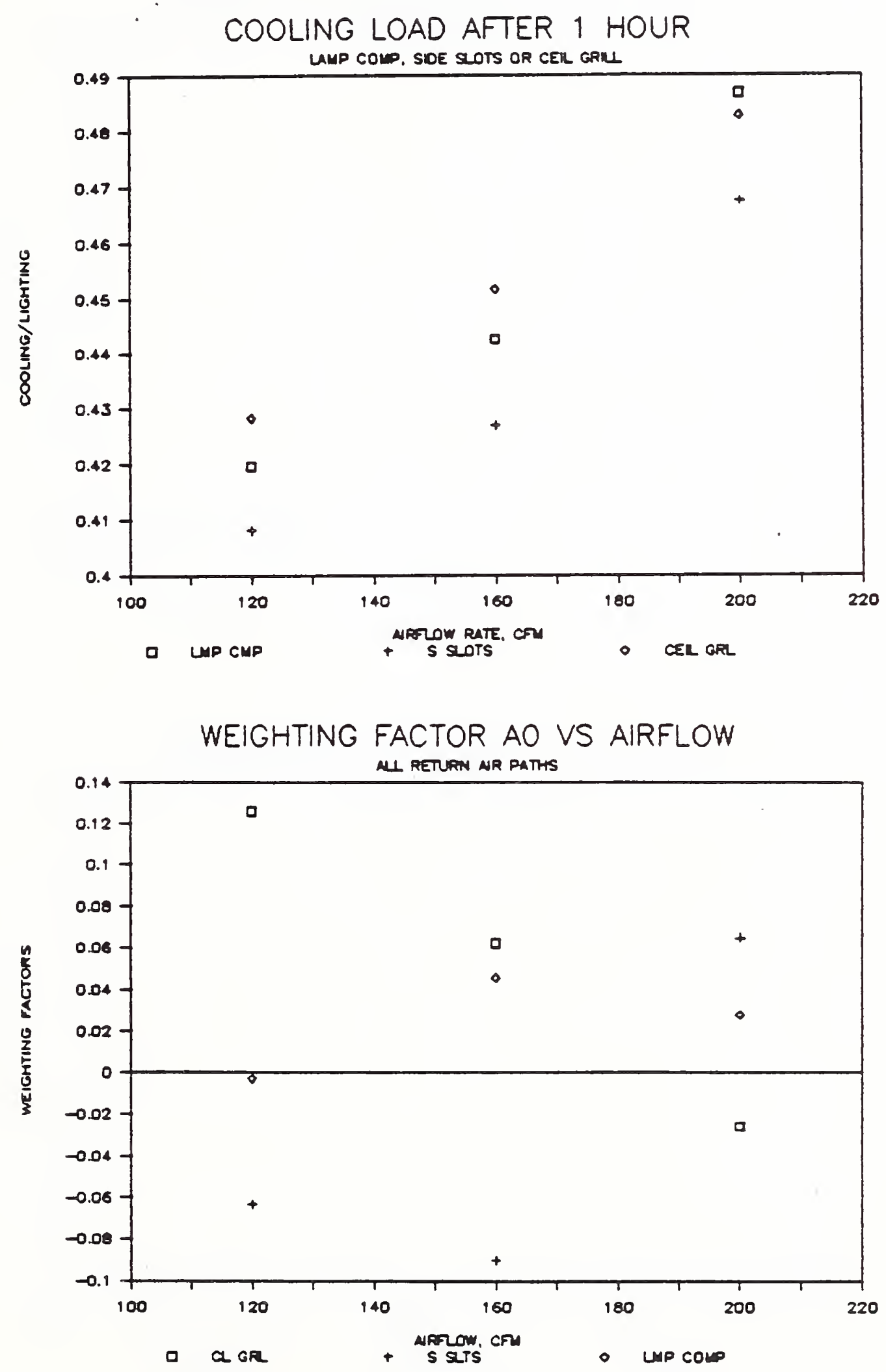

Figure 6.58 Weighting Factor $a_{0}$, Versus Airflow 
Figure 6.59 Weighting Factor a Versus Airflow

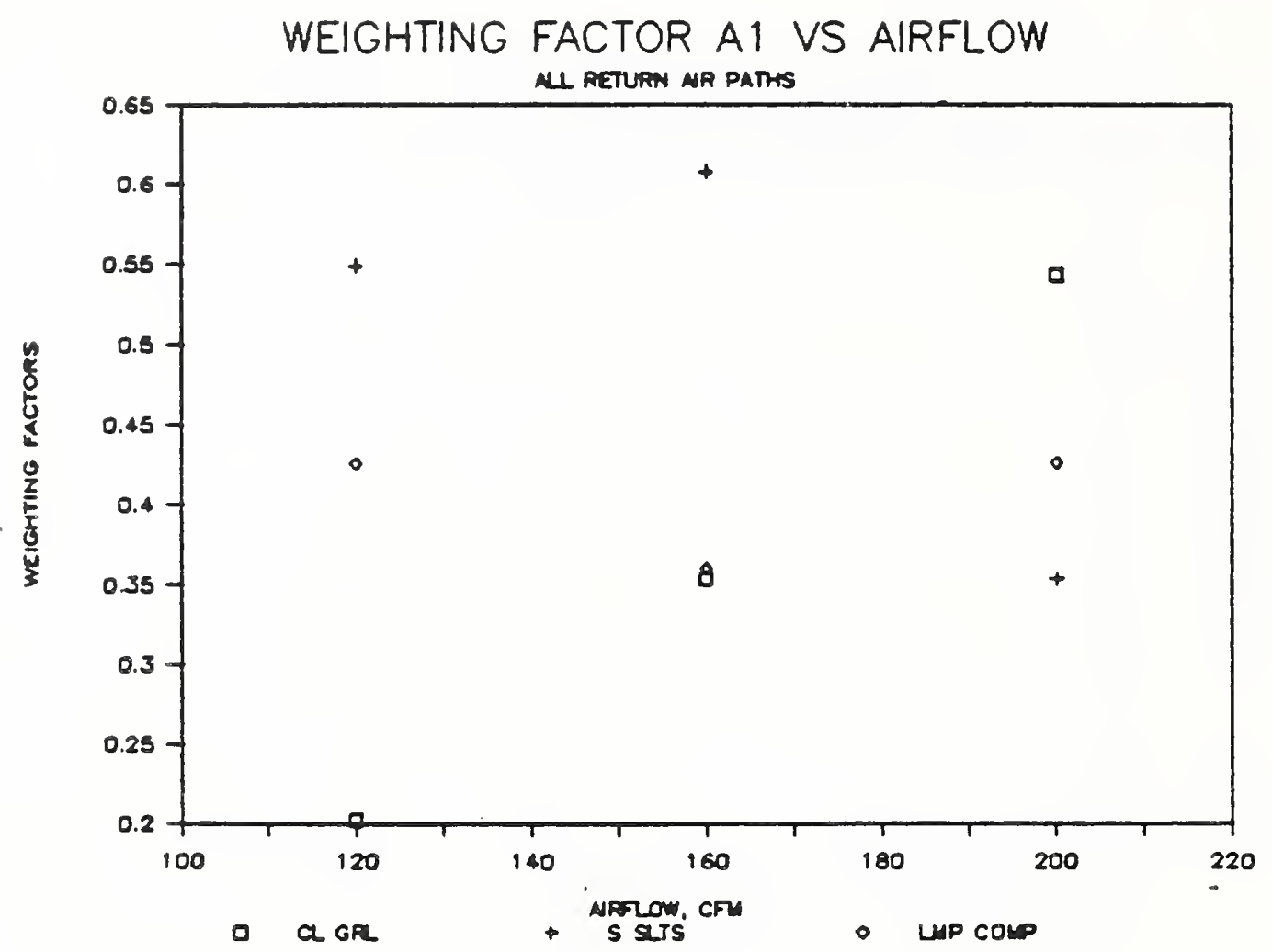

WEIGHTING FACTOR A2 VS AIRFLOW NL RETUAN NR PATHS

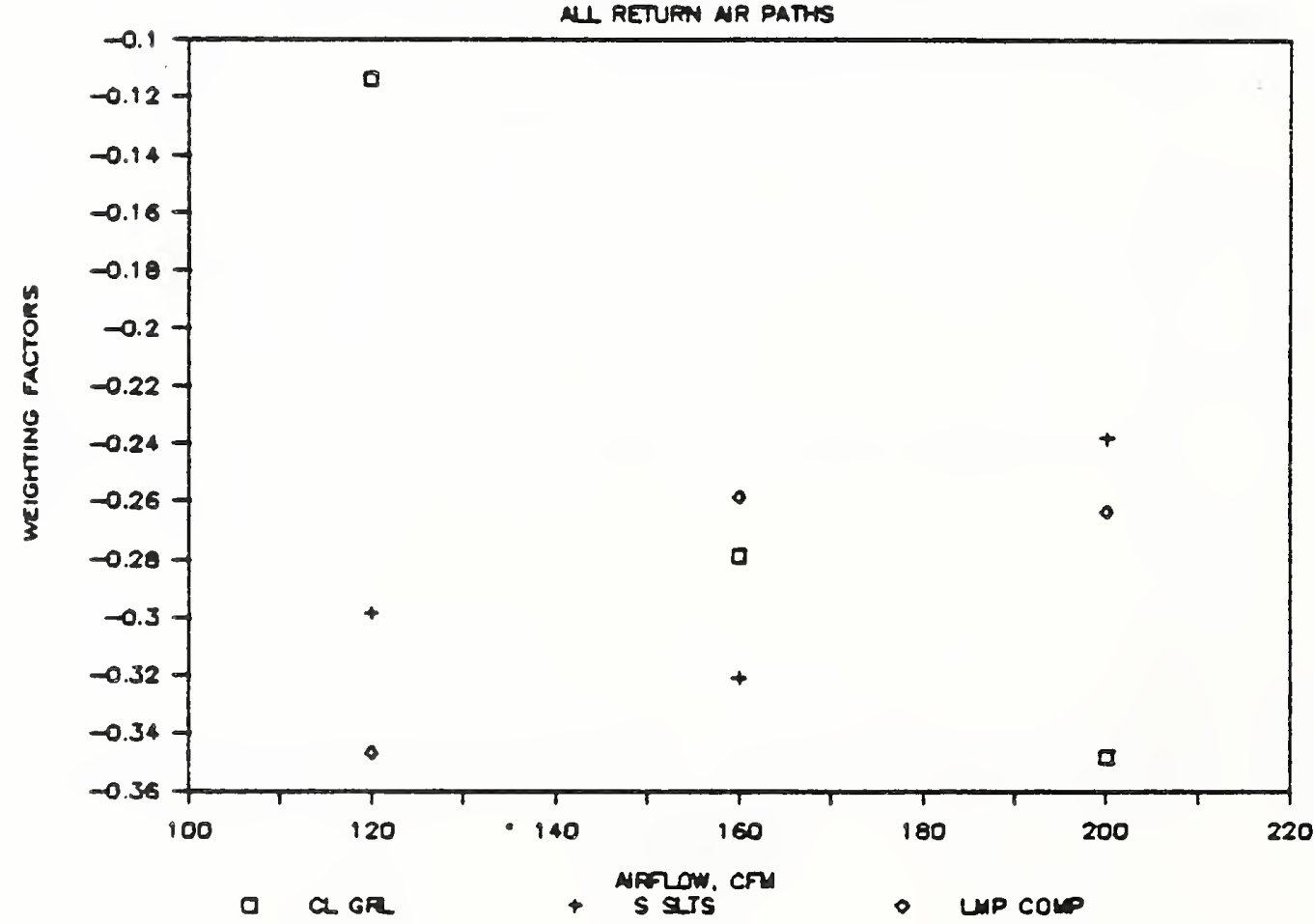

Figure 6.60 Weighting Factor a2 Versus Airflow 
Figure 6.61 Weighting Factor $b_{1}$ Versus Airflow
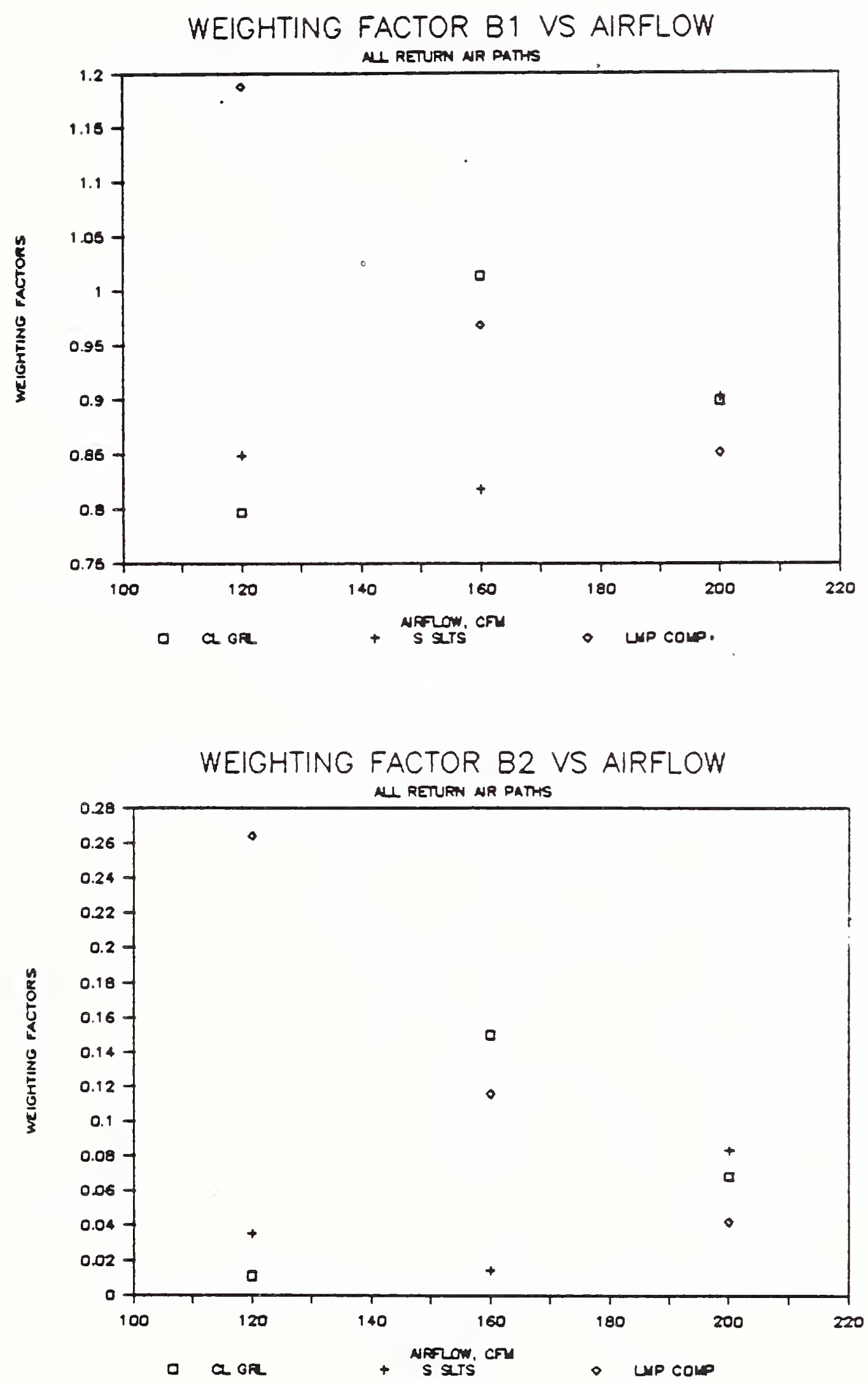

Figure 6.62 Weighting Factor b2 Versus Airflow 
Figure 6.63 Hourly Cooling Load Fractions for Four Days
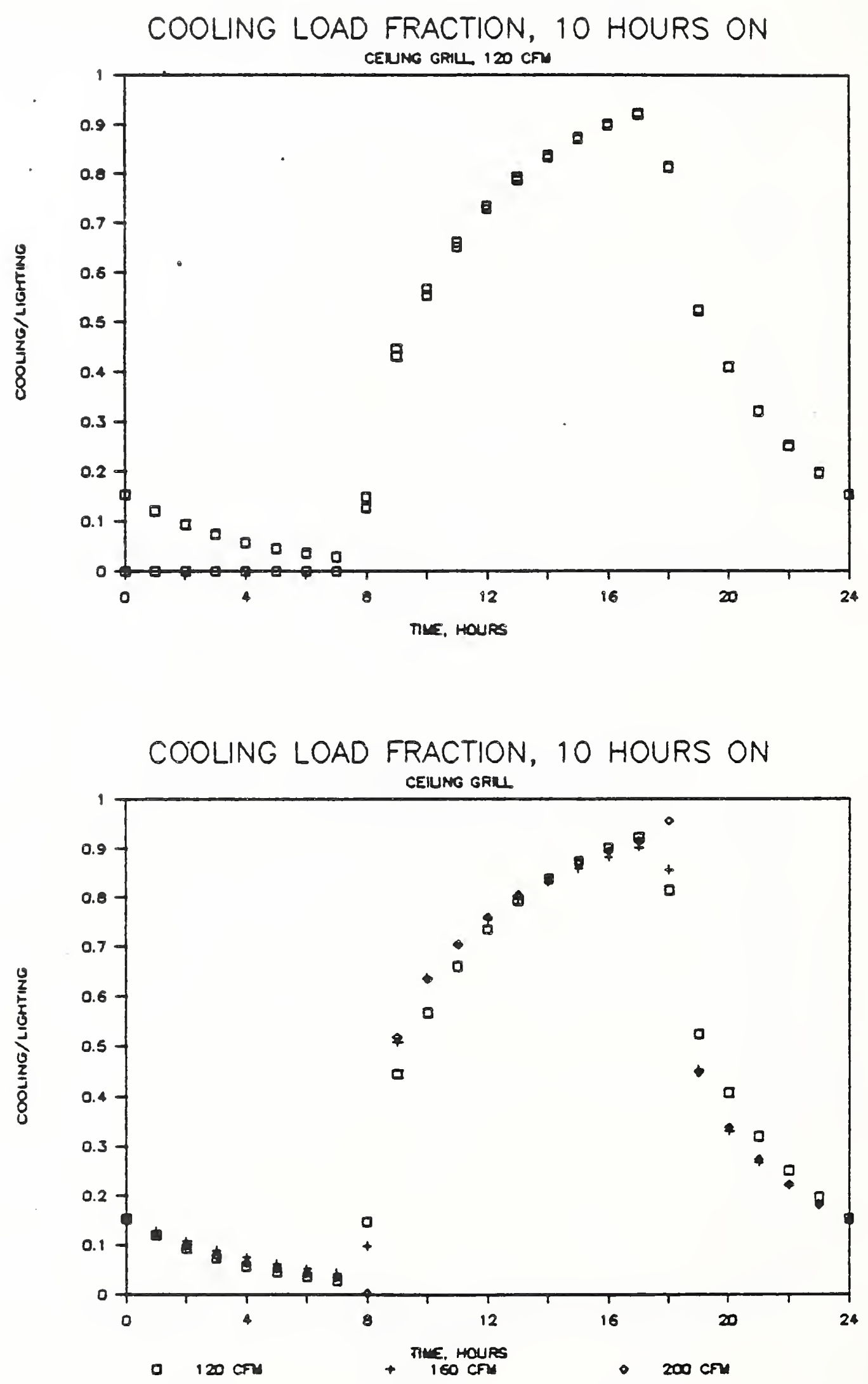

Figure 6.64 Hourly Cooling Load Fractions Versus Airflow Rate for Ceiling Grill 
Figure 6.65 Hourly Cooling Load Fractions Versus Airflow Rate for Side Slots
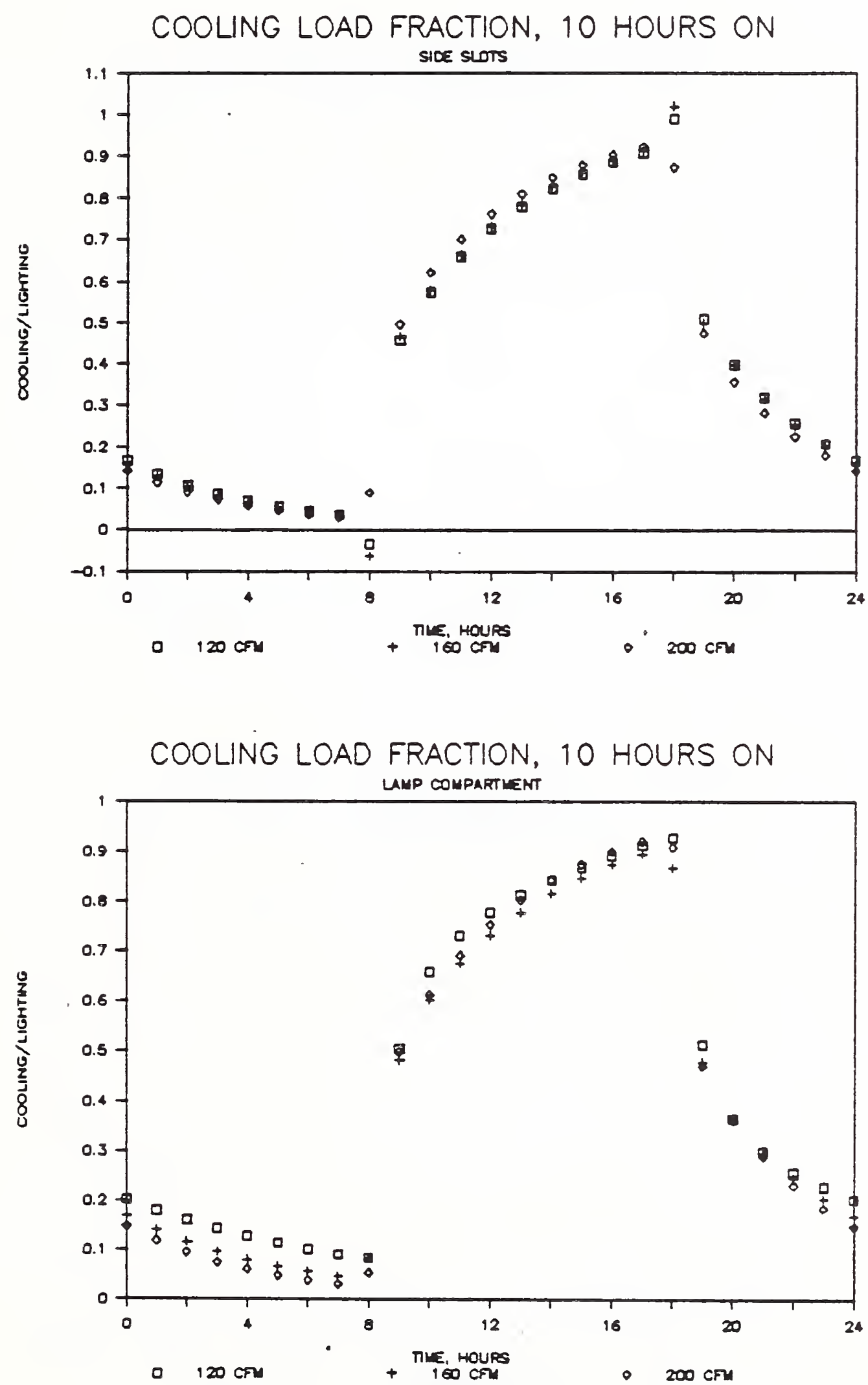

Figure 6.66 Hourly Cooling Load Fractions Versus Airflow Rate for Lamp Compartment 
Figure 6.67 Hourly Cooling Load Fractions Versus Airflow Rate for Average Conditions
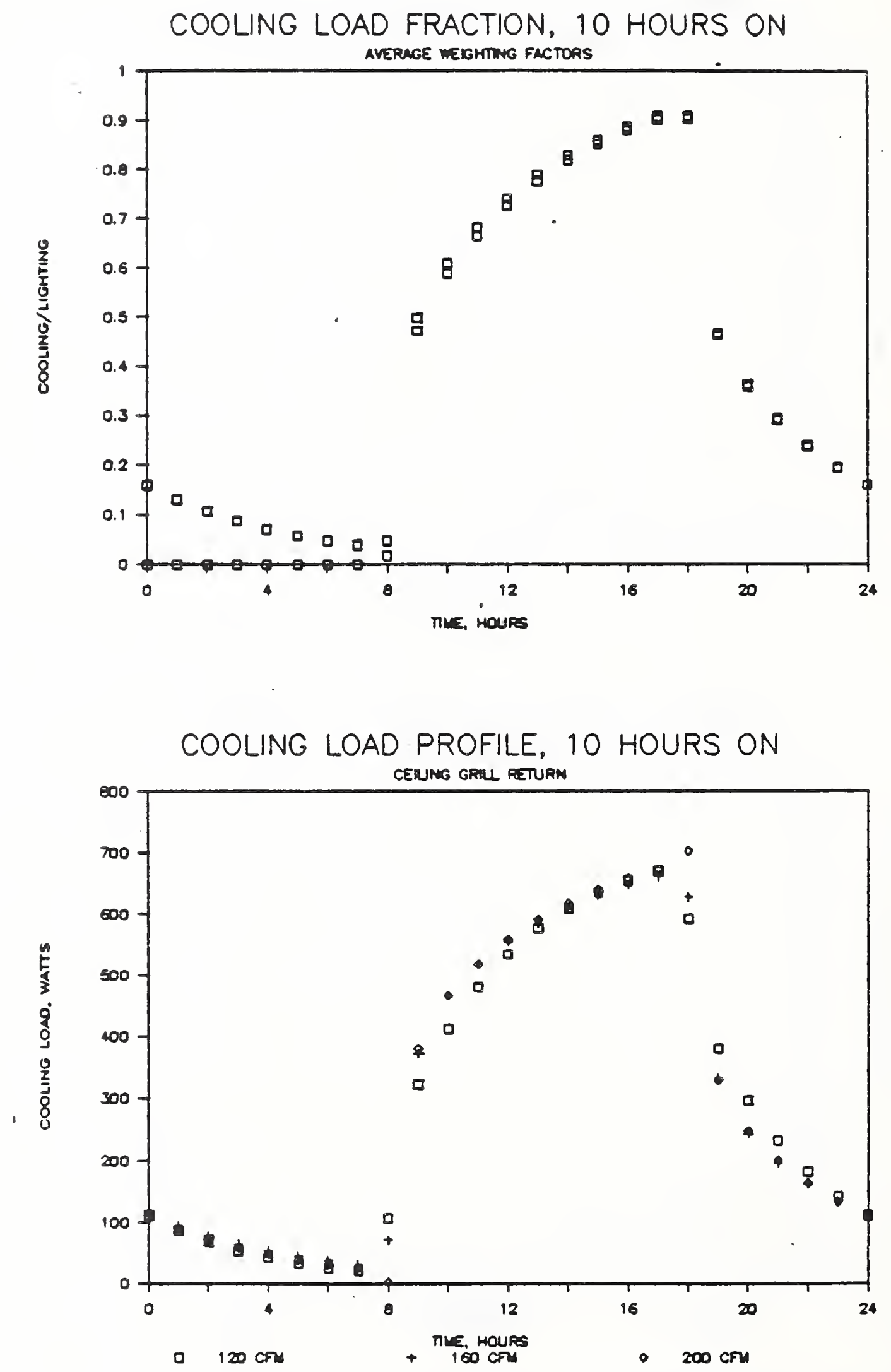

Figure 6.68 Cooling Load Profiles Versus Airflow for Ceiling Grill 
Figure 6.69 Cooling Load Profiles Versus Airflow for Side Slots
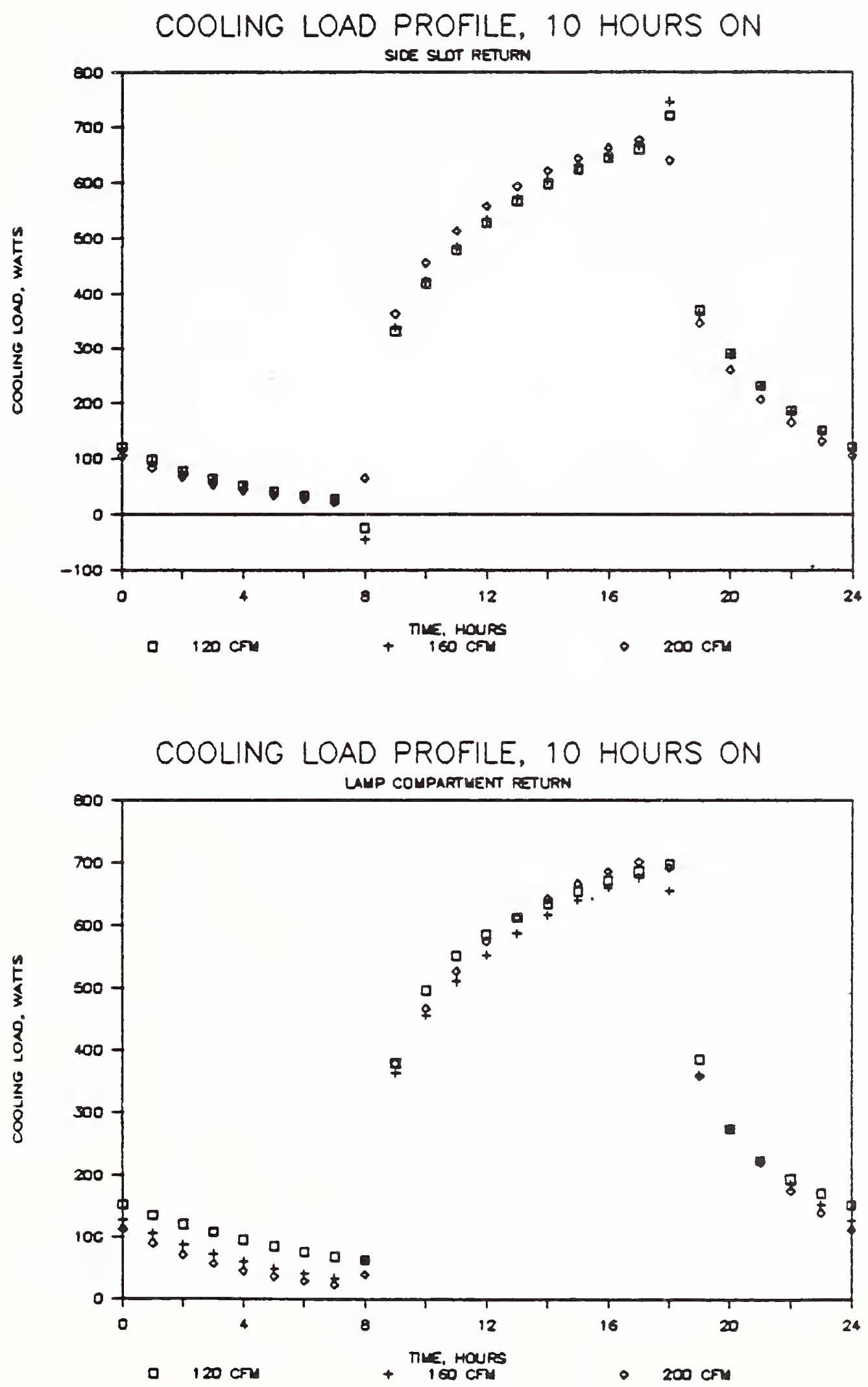

Figure 6.70 Cooling Load Profiles Versus Airflow for Lamp Compartment 
Figure 6.71 Cooling Load Fractions with Original and Adjusted Weighting Factors, CG200
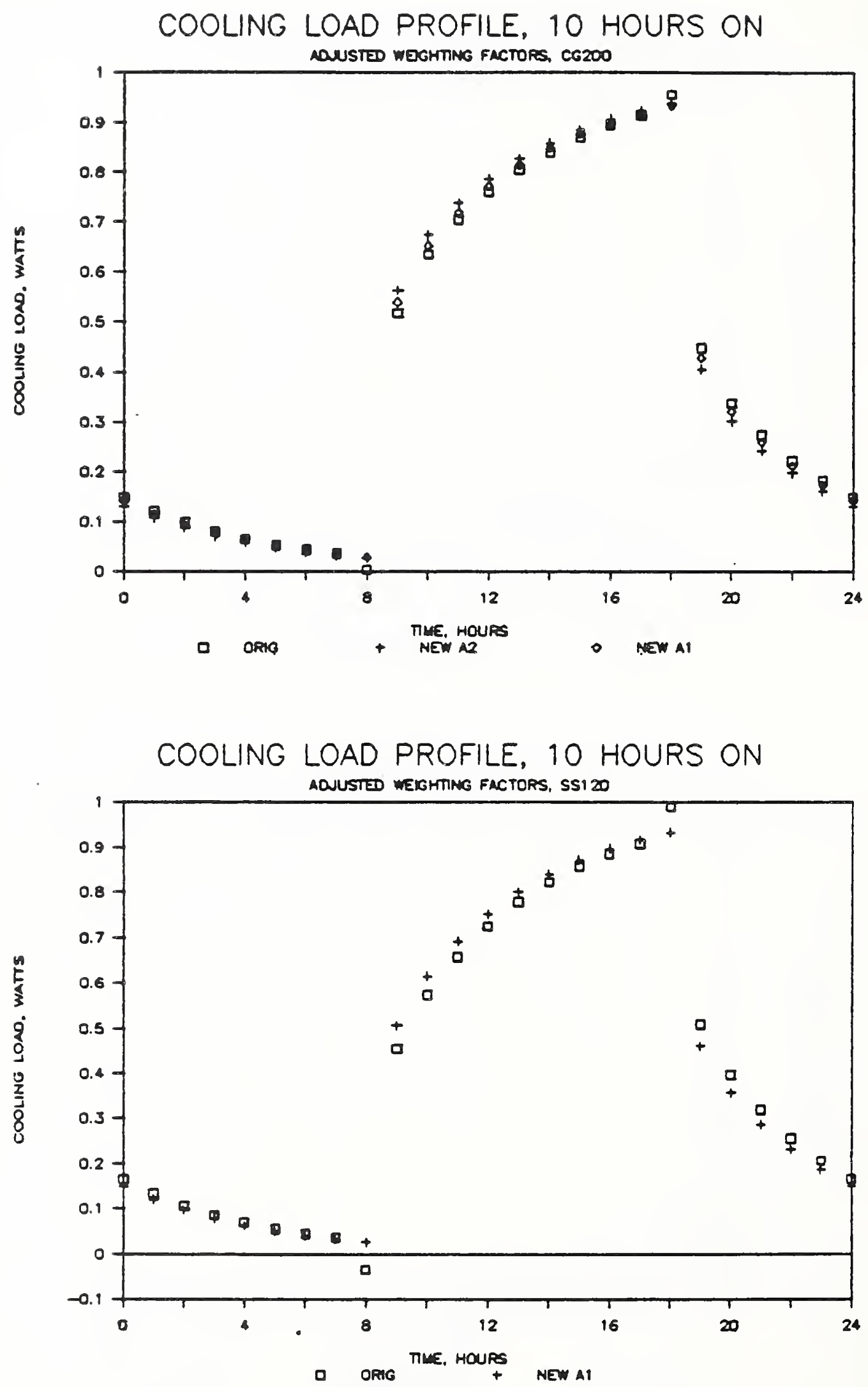

Figure 6.72 Cooling Load Fractions with Original and Adjusted Weighting Factors, SS160 
Figure 6.73 looling Load fractions with Original and Adjusted Weighting Factors, SS160
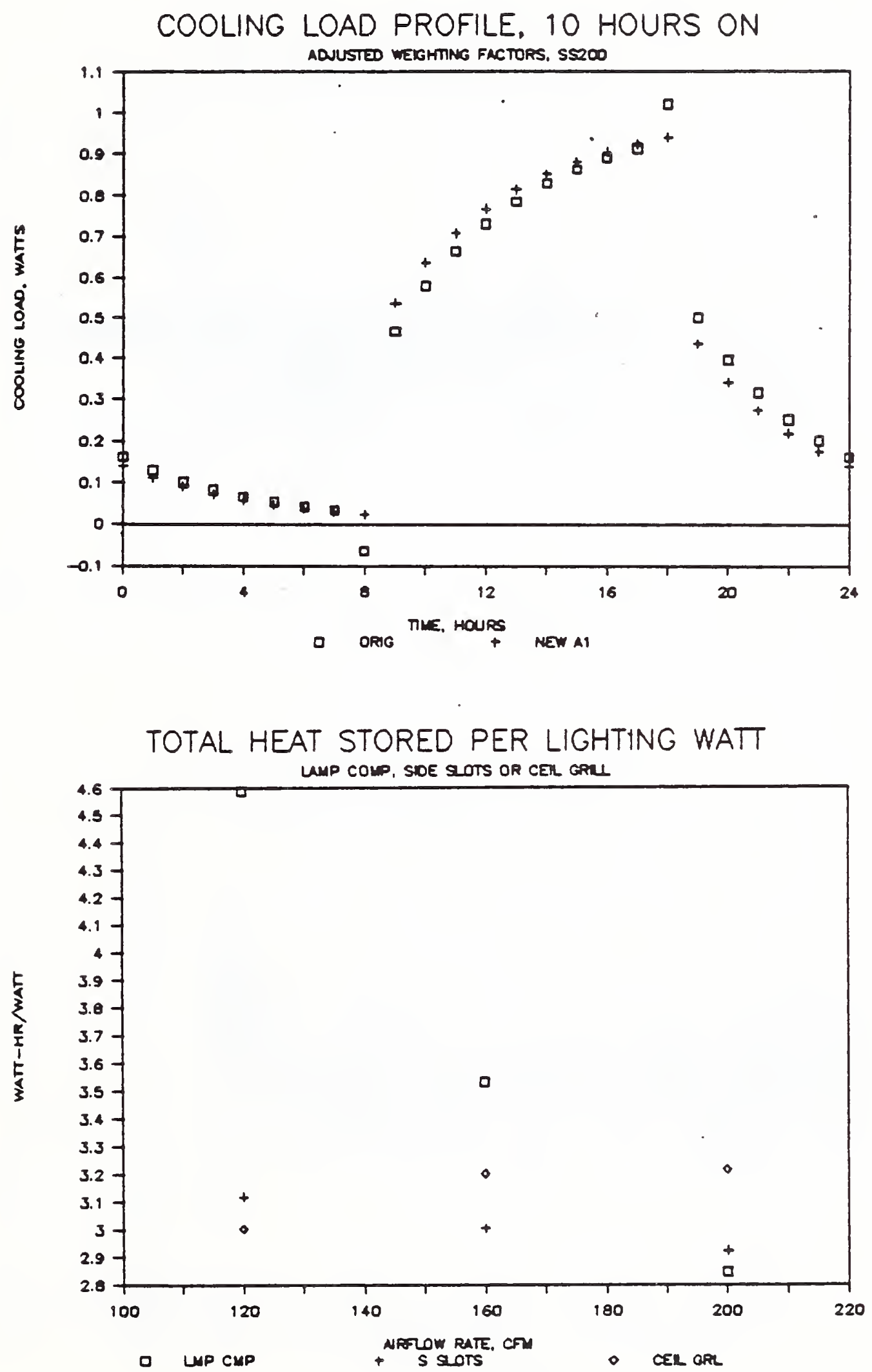

Figure 6.74 $\begin{aligned} & \text { Total Heat Storage Versus Airflow Rate and Return } \\ & \text { Configuration }\end{aligned}$ 
Figure 6.75 Heat Flow Sensor Readings for Floor and Walls During Backto-Back Lights on and Lights off Tests
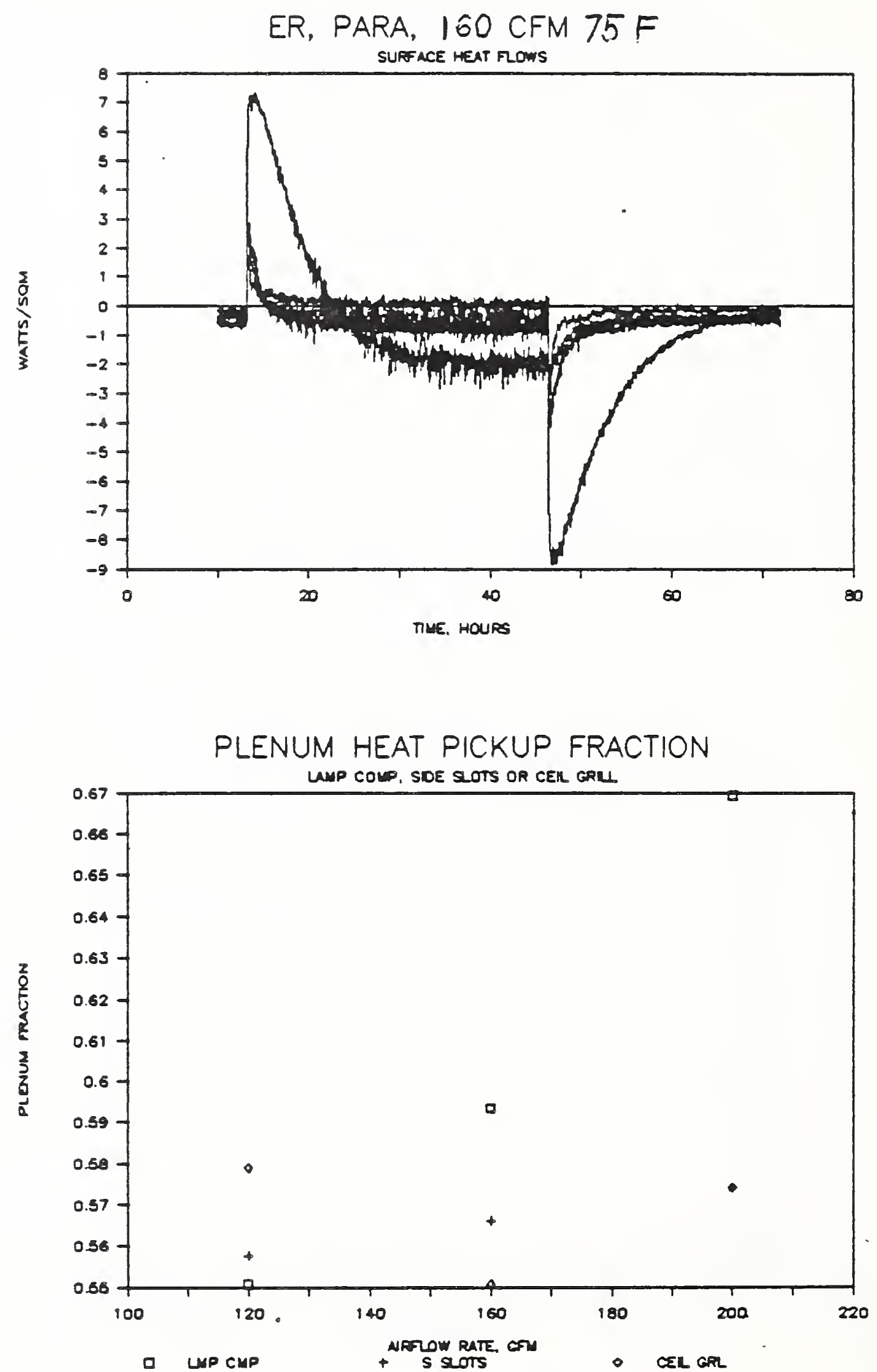

Figure 6.76 Plenum Heat Pickup Fraction Versus Airflow Rate and Return Air Configuration 
Figure 6.77 $\begin{aligned} & \text { Plenum Fraction Versus Time for } 160 \mathrm{cfm} \text {, Ceiling Grill. } \\ & \text { Return }\end{aligned}$
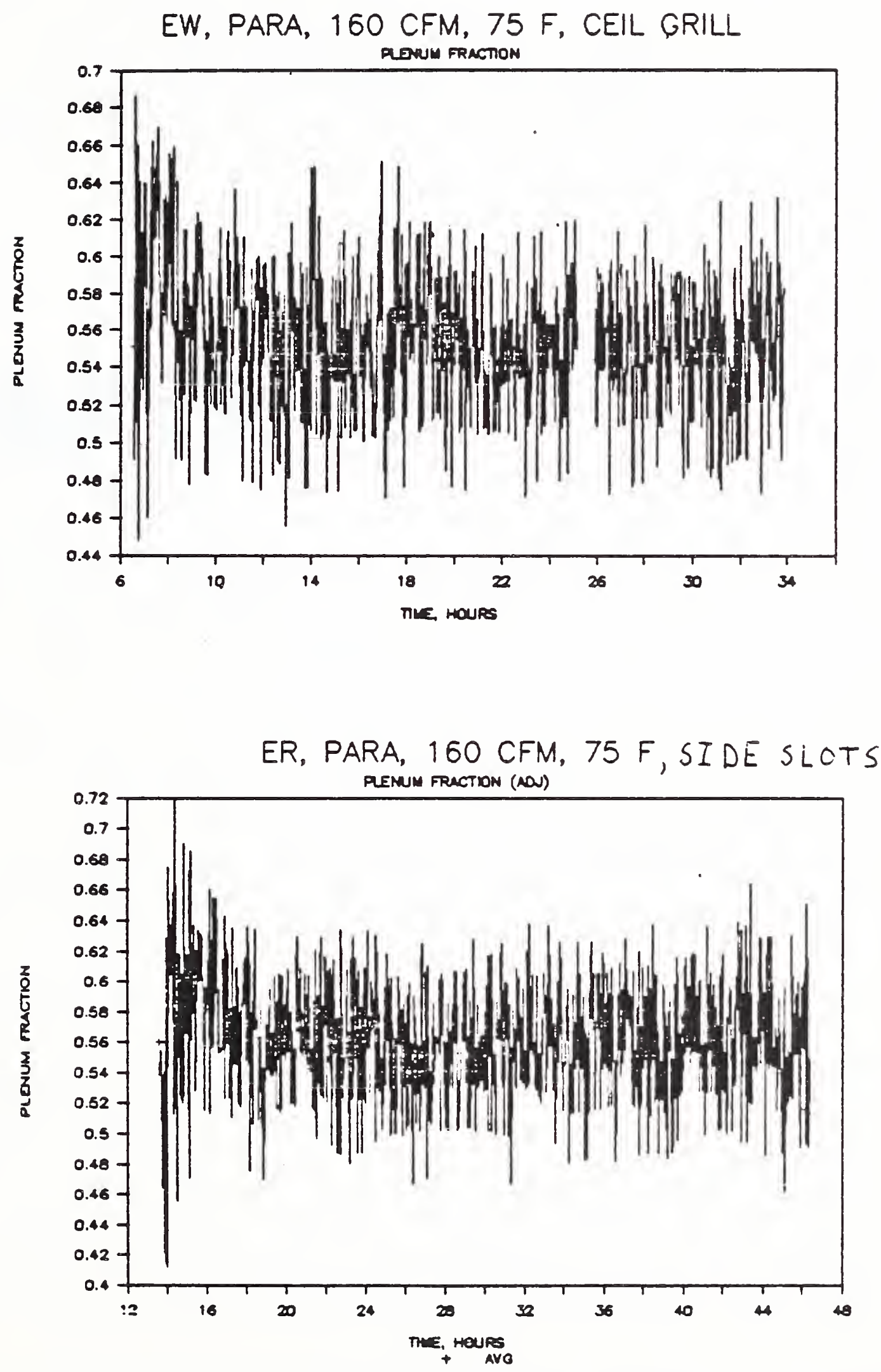

Figure 6.78 Plenum Fraction Versus Time for $160 \mathrm{cfm}$, Side Slot Return 
Figure 6.79 Plenum Fraction Versus Time for $160 \mathrm{cfm}$, Lamp Compartment Return

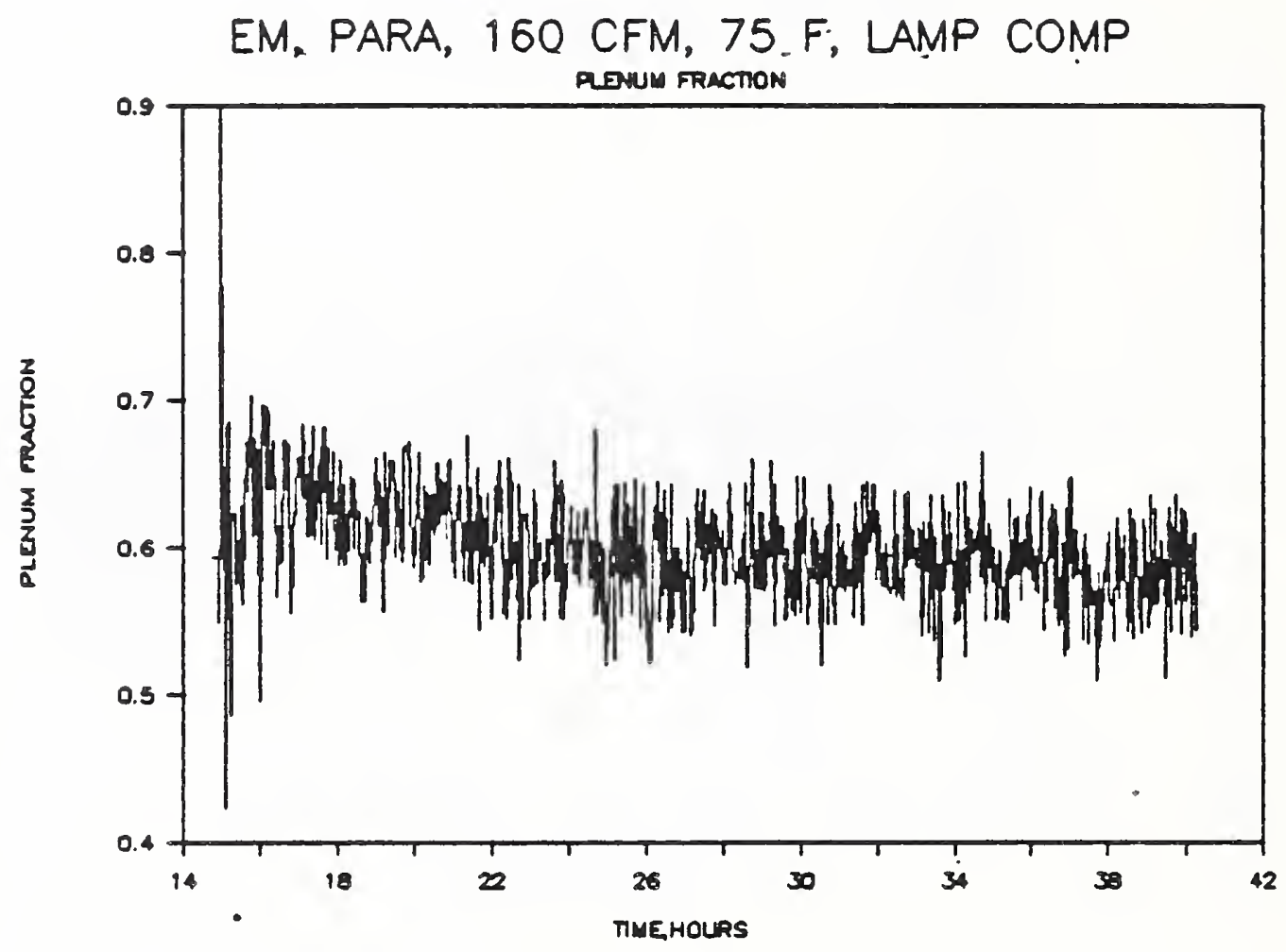




\section{Lighting Energy Distribution Fractions}

The distribution of the energy supplied to the lighting system by the various energy transfer mechanisms was determined from computer simulations of the test facility. The simulation results were compared to the corresponding measured data, and the computer model adjusted until cooling loads and temperatures matched. The lighting energy distribution fractions were determined from the corresponding values calculated by the computer model.

of the nine lighting energy distribution fractions listed earlier, one is a constant, the ballast fraction, and two are zero for the luminaires tested. These two are visible light up and convection to return air. All of the visible light is directed downward, so the upward visible fraction is zero. The return air is not ducted at the luminaire, so the convection to return air fraction is zero.

The visible light down fraction is determined from the ratio of lighting visible watts to lighting power, which are functions of lamp temperature. The infrared upward and downward fractions were determined by summing the net radiation exchange between the luminaire nodes and the room nodes, and plenum nodes respectively. The convection downward and upward fractions were determined by summing the convective exchange between the luminaire nodes and the room nodes, and plenum nodes, respectively. The heat stored fraction is determined from the difference between the lighting power input and the sum of the other energy distribution amounts.

Simulations were run for two return air configurations, either lamp compartment or ceiling return. The ceiling return corresponds to either the ceiling grill or side slot return, which the measurement results showed performed similarly. For the ceiling return, convective heat transfer from the lower luminaire housing surface and the lamps was assigned to the room air. For the lamp compartment return all convection from the luminaire was directed into the plenum air. Two airflow rates were simulated for each return configuration, 120 and 200 cfm. Also, the effects of a different room air temperature and double the amount of floor slab thermal mass were simulated.

\subsection{Calibration and Validation of Computer Model}

The calibration of the computer model involved adjusting the convective heat transfer coefficients so that the calculated surface and air temperatures matched the measured values. The initial assumption was free convection for each surface node. The calculated surface temperatures were then compared to the corresponding average measured values. If the calculated surface temperature for a node was too high, the convection coefficient was increased until the calculated and measured temperatures matched. The computer model was individually calibrated versus measured results for each simulation configuration.

The calculated cooling load profile was compared to the measured profile. Figure 7.1 shows a comparison of the measured and calculated cooling load profiles for a lights-on step response test, for ceiling return at $120 \mathrm{cfm}$ airflow rate. In general, simulated and measured 
values are in good agreement although, the simulated cooling load exceeds the measured during the first four hours after lights on.

Figure 7.2 presents a similar comparison of measured to simulated cooling load for the ceiling return, $200 \mathrm{cfm}$ condition. Very good agreement is seen between the measured and simulated values.

For the lamp compartment return configuration simulations, the measured and simulated cooling loads are compared in figures 7.3 and 7.4 for 120 cfm and $200 \mathrm{cfm}$ airflow rates, respectively. The agreement between measured and simulated cooling loads is poorest for the $120 \mathrm{cfm}$ condition, but best for the $200 \mathrm{cfm}$ condition.

\subsection{Computer Simulation Results}

The lighting energy distribution fractions are shown as a function of time in figure 7.5 , for the ceiling return, $120 \mathrm{cfm}$ condition. The visible down fraction is nearly constant at 18 percent. The greatest heat transfer from the luminaire is by convection to the room air, about 42 percent. The downward convection fraction starts out at about 35 percent and increases over the first four hours. The downward infrared heat transfer constitutes 26 percent of the lighting energy input. This quantity, and the upward infrared heat transfer of about 9 percent, start out at their maximum values and gradually decreases until they reach steady state values. The smallest lighting energy distribution fraction is the upward convection, which barely exceeds 5 percent.

The distribution fractions are quite a bit different for the lamp compartment return configuration, as shown in figure 7.6. Heat transfer to the plenum air by convection becomes the dominant mode of luminaire heat dissipation, topping 60 percent. Downward infrared heat exchange drops to 16 percent, just below downward visible light at 18 percent. Upward infrared heat transfer is cut in half to four percent.

Similar lighting energy fractions were determined for airflow rates of $200 \mathrm{cfm}$, room air temperature of $80^{\circ} \mathrm{F}$, and double the thermal mass in the slabs. Figure 7.7 shows the lighting energy distribution fractions for the ceiling return, $120 \mathrm{cfm}$ airflow rate with a room air temperature of $80^{\circ} \mathrm{F}$. These results are very similar to the same configurations at $75^{\circ} \mathrm{F}$, except downward infrared radiation is greater by two percent. This indicates that room air temperature set - point may not influence the lighting energy distribution fractions, for room temperatures typically encountered.

Figure 7.8 shows the simulated cooling load profile for the test room if the mass of the floor and ceiling slabs were doubled. Also plotted, for comparison, are the measured cooling load profiles for the ceiling grill return and airflow rates of 120 and $200 \mathrm{cfm}$. The additional thermal mass provides for much greater heat storage, and the potential for much lower peak cooling loads. After the lights have been on for 10 hours, cooling loads would only be 75 percent of lighting power for the heavy mass room, versus 90 percent of lighting power for the baseline room, a peak cooling load reduction of 17 percent. Figure 7.9 shows the lighting energy distribution fractions for the heavy thermal mass condition, with ceiling return and $120 \mathrm{cfm}$ airflow. These values are very similar to those for the normal mass room. 
The values of the lighting energy distribution fractions at equilibrium conditions are summarized in table 7.1 for the two airflow rates and return air configurations, the double mass configuration and the $80^{\circ} \mathrm{F}$ condition.

Table 7.1 Lighting Energy Distribution Fractions

\begin{tabular}{lllllll}
$\begin{array}{l}\text { Energy } \\
\text { Distribution }\end{array}$ & \multicolumn{1}{c}{ Ceiling Return } & \multicolumn{2}{c}{$\begin{array}{c}\text { Lampartment } \\
\text { Return }\end{array}$} & $\begin{array}{c}\text { Heavy } \\
\text { Thermal }\end{array}$ \\
\hline Mechanism & 120cfm & 200cfm & 120cfm & 200cfm & Mass & $80^{\circ} \mathrm{F}$ \\
Visible down & 0.1783 & 0.1782 & 0.1778 & 0.1777 & 0.1783 & 0.1786 \\
Visible up & 0 & 0 & 0 & 0 & 0 & 0 \\
Infrared down & 0.2568 & 0.2455 & 0.1656 & 0.1511 & 0.2576 & 0.2608 \\
Infrared up & 0.0944 & 0.0903 & 0.0427 & 0.0454 & 0.0944 & 0.0962 \\
Convection down & 0.4160 & 0.4269 & 0 & 0 & 0.4133 & 0.4105 \\
Convection up & 0.0545 & 0.0591 & 0.6139 & 0.6260 & 0.0546 & 0.0539 \\
Convection return & 0 & 0 & 0 & 0 & 0 & 0
\end{tabular}

The visible down fraction remains nearly constant. As would be expected, the upward convective fraction increases with airflow rate, and is greater for the lamp compartment return. The increases in upward convection are at the expense of downward convection, and upward and downward infrared radiation exchange. Upward convection is less than six percent with the ceiling return, but exceeds 60 percent with for the lamp compartment return. The downward infrared fraction is lower by 36 percent and the upward infrared fraction lower by 50 percent, for the lamp compartment return than the ceiling return. 
Figure 7.1 Comparison of Measured and Simulated Cooling Loads, Celling Return, 120 cfm
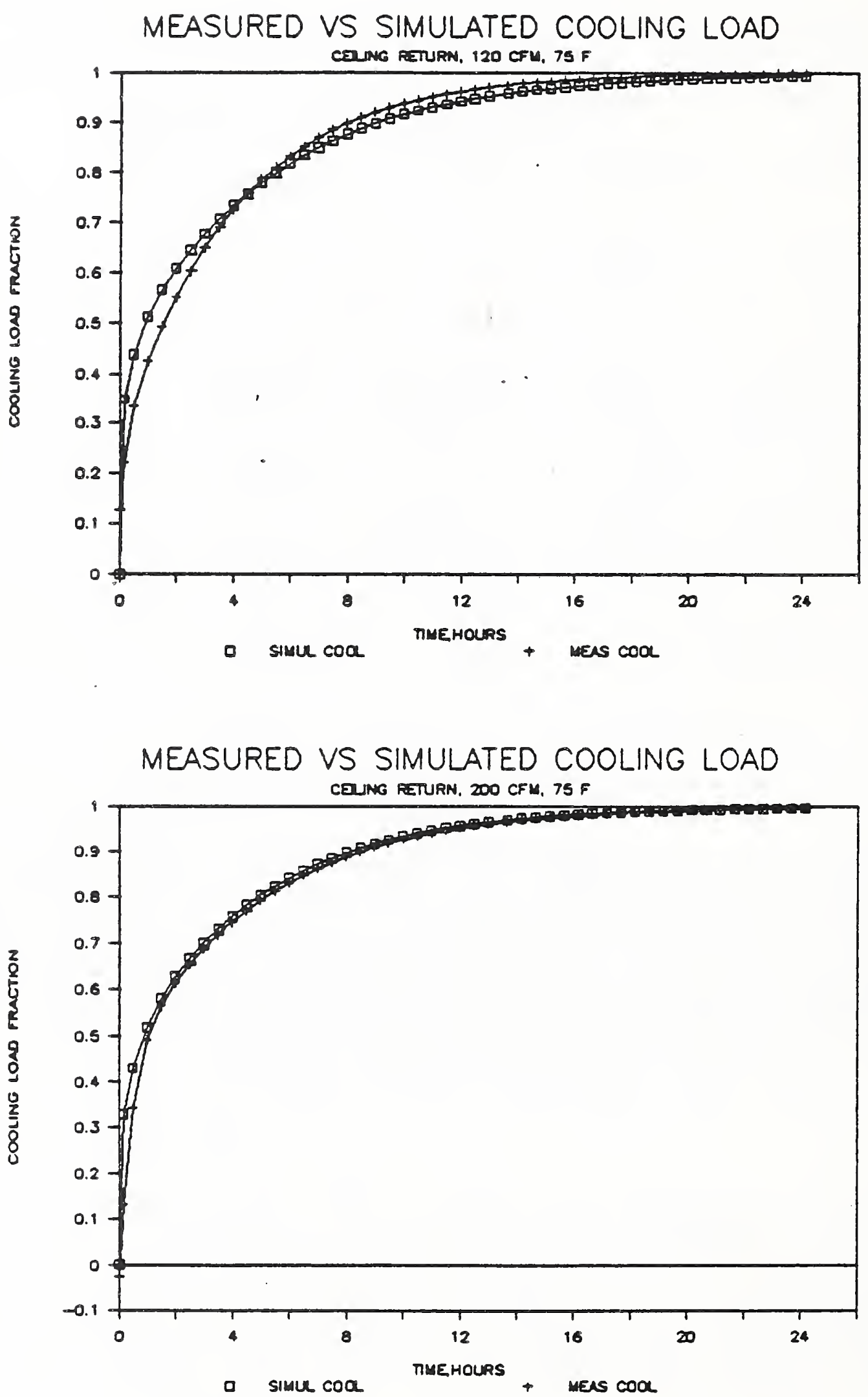

Figure 7.2 Comparison of Measured and Simulated Cooling Loads, Celling Return, 200 cfm 


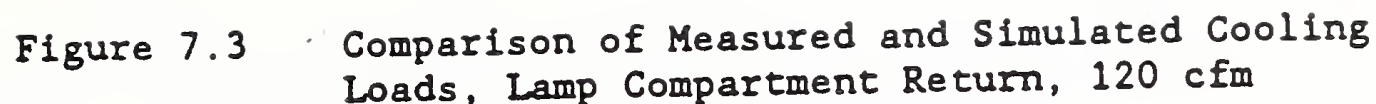
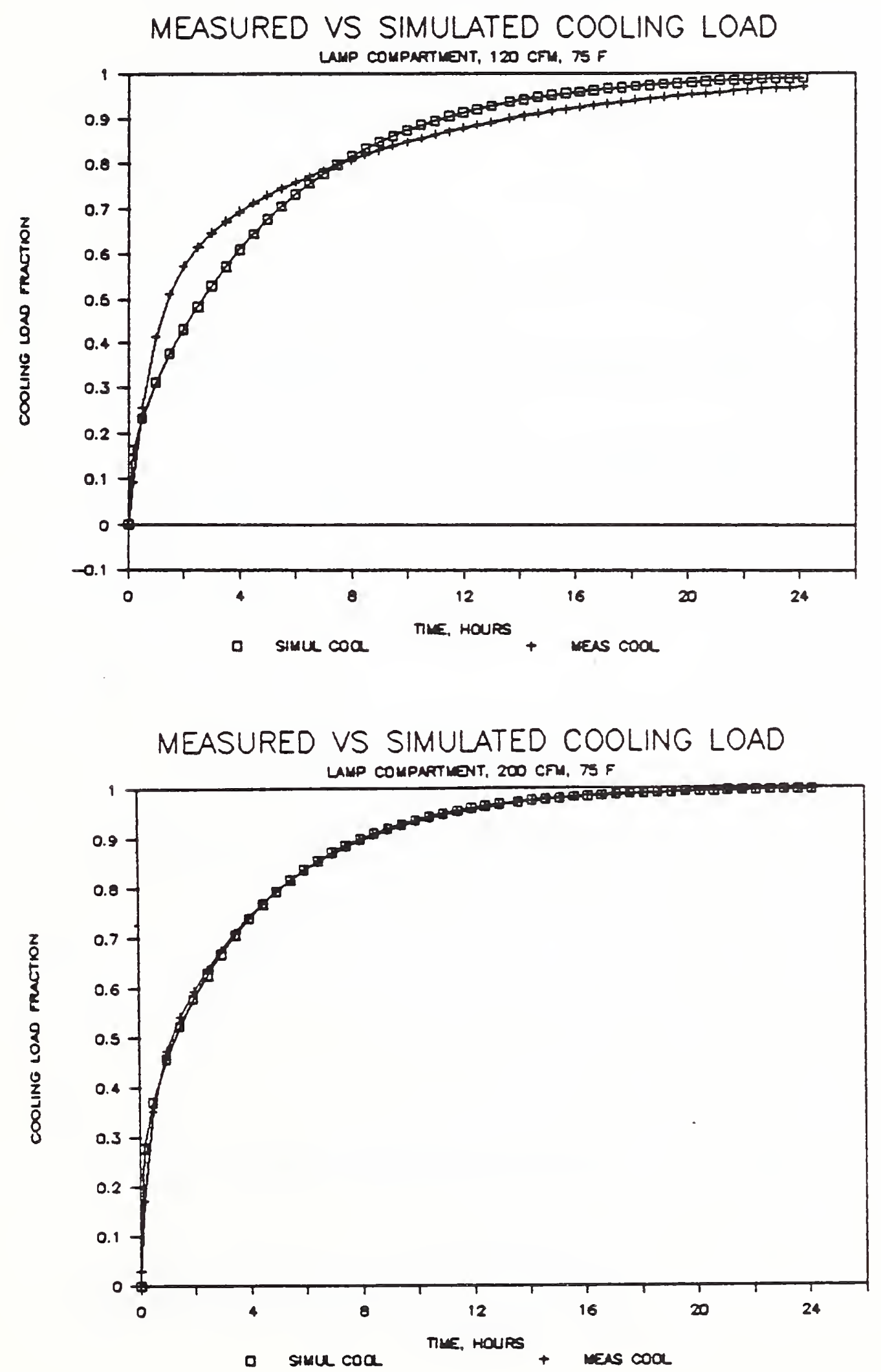

Figure 7.4 Comparison of Measured and Simulated Cooling Loads, Lamp Compartment Return 200 cfm 
Figure 7.5 Lighting Energy Distribution Fractions Versus Time, Ceiling Return, 120 cfm

LIGHTING ENERGY FRACTIONS CEUNG RETURN, 120 CFM

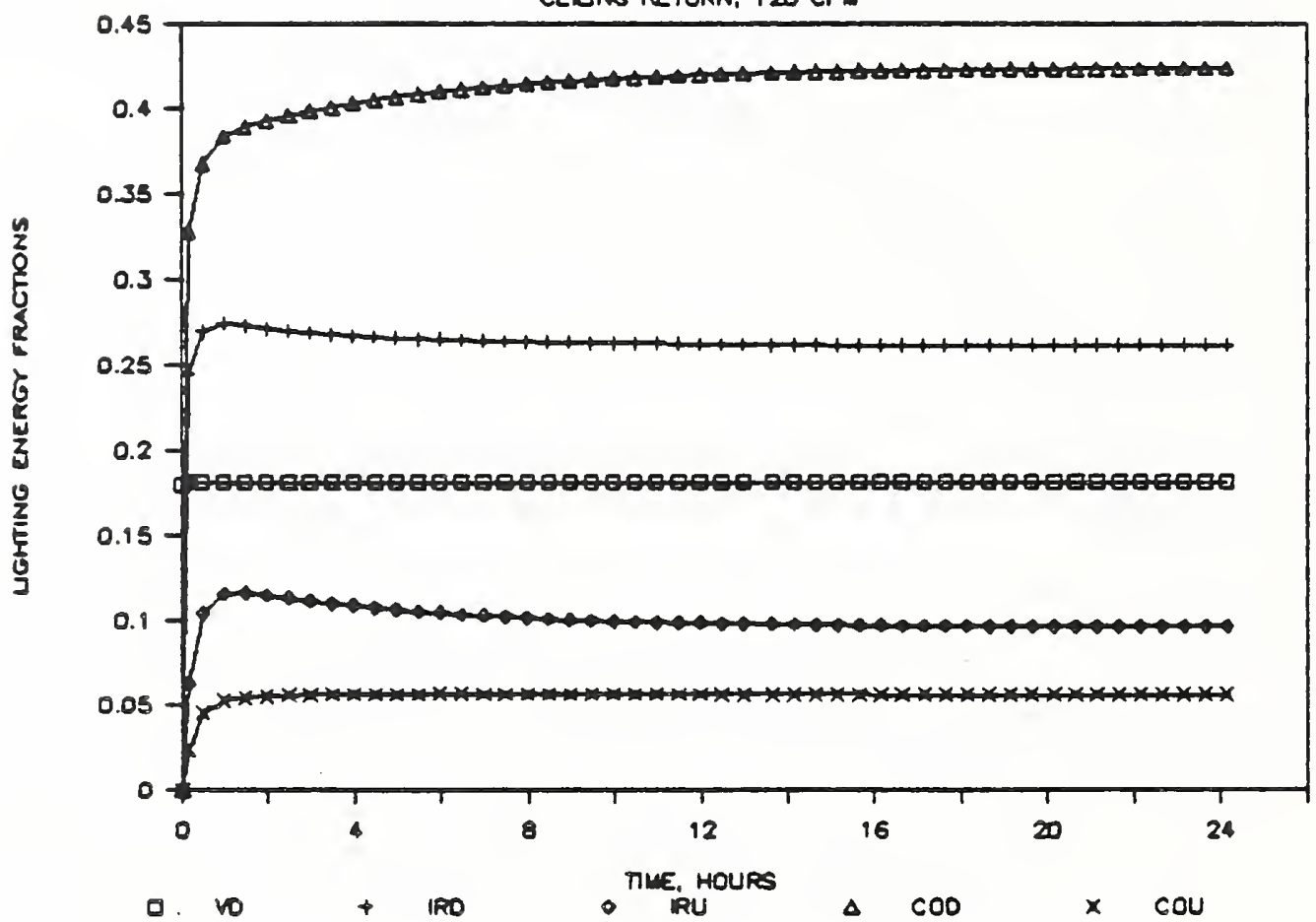

LIGHTING ENERGY FRACTIONS UMP COMPAPTIONT, $120 \mathrm{CFM}$, TSF

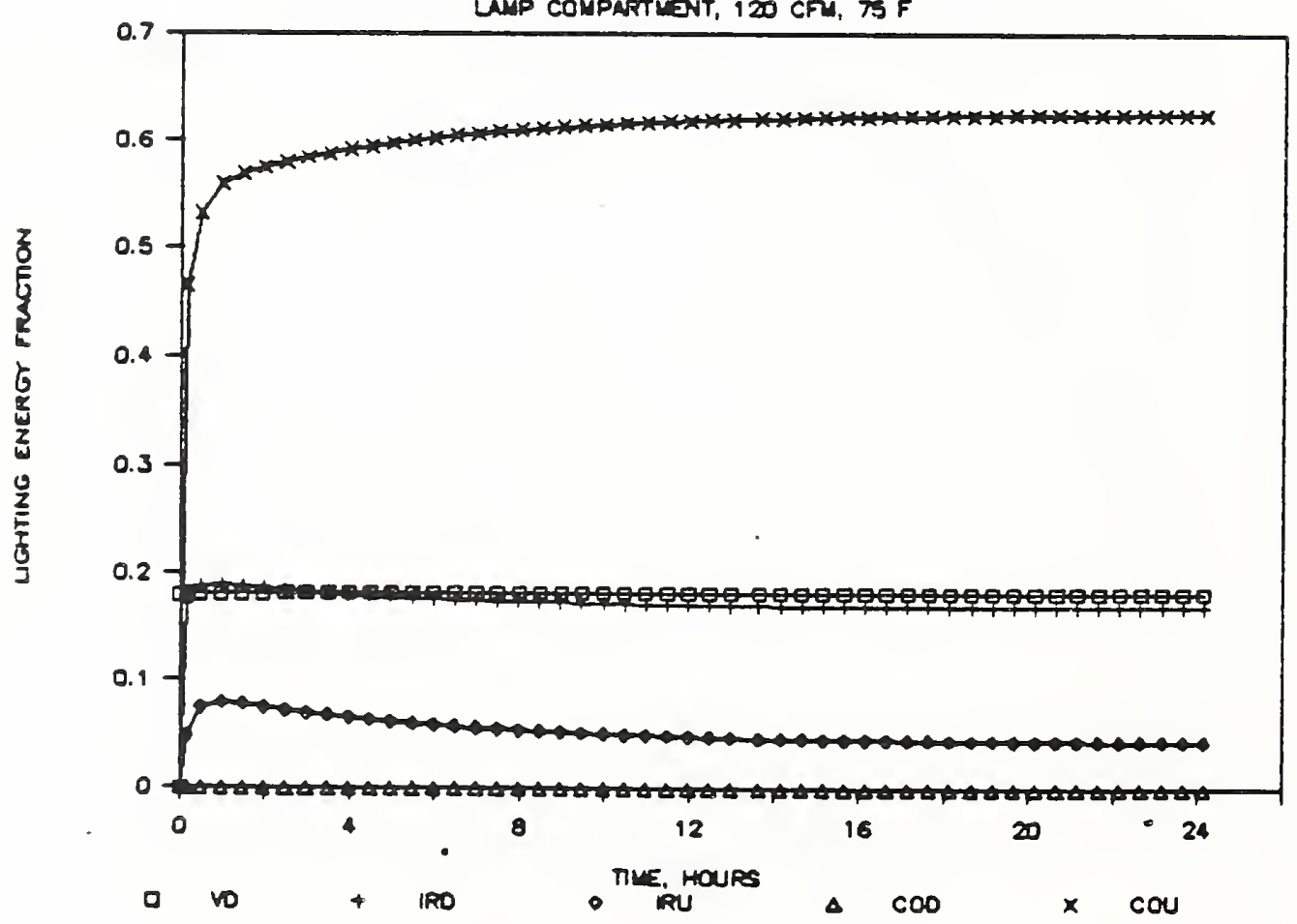

Figure 7.6 Lighting Energy Distribution Fractions Versus Time, Lamp Compartment Return, 120 cfm 
Figure 7.7 Lighting Energy Distribution Fractions Versus Time, Ceiling Return, $120 \mathrm{cfm}, 80^{\circ} \mathrm{F}$

LIGHTING ENERGY FRACTIONS, $80 \mathrm{~F}$ CELNG RETURN, $120 \mathrm{cFM}$

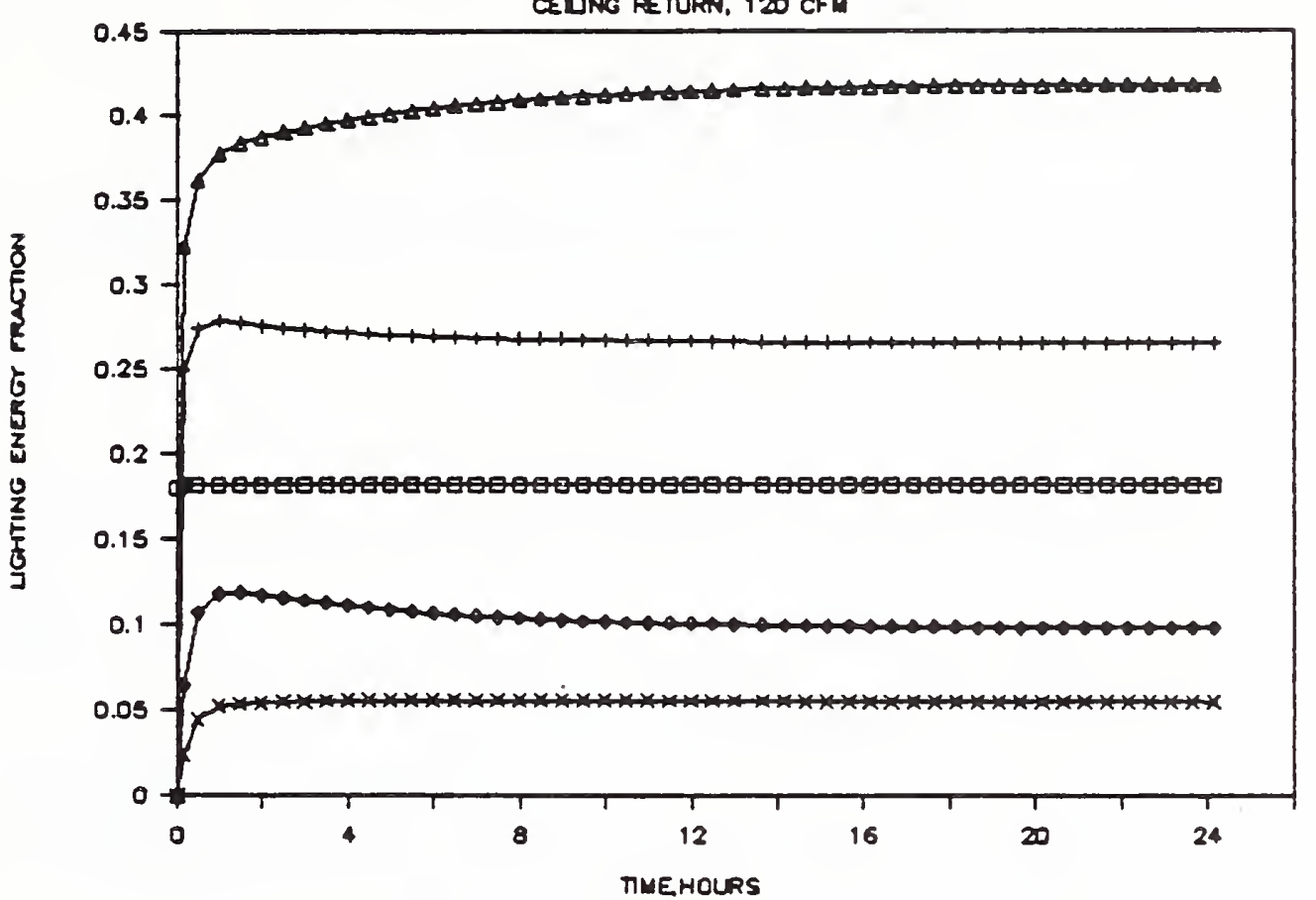
a 10
$+\quad$ IRO
- TME,HOLRS
$\triangle \quad 600$
$\times \quad \operatorname{COU}$

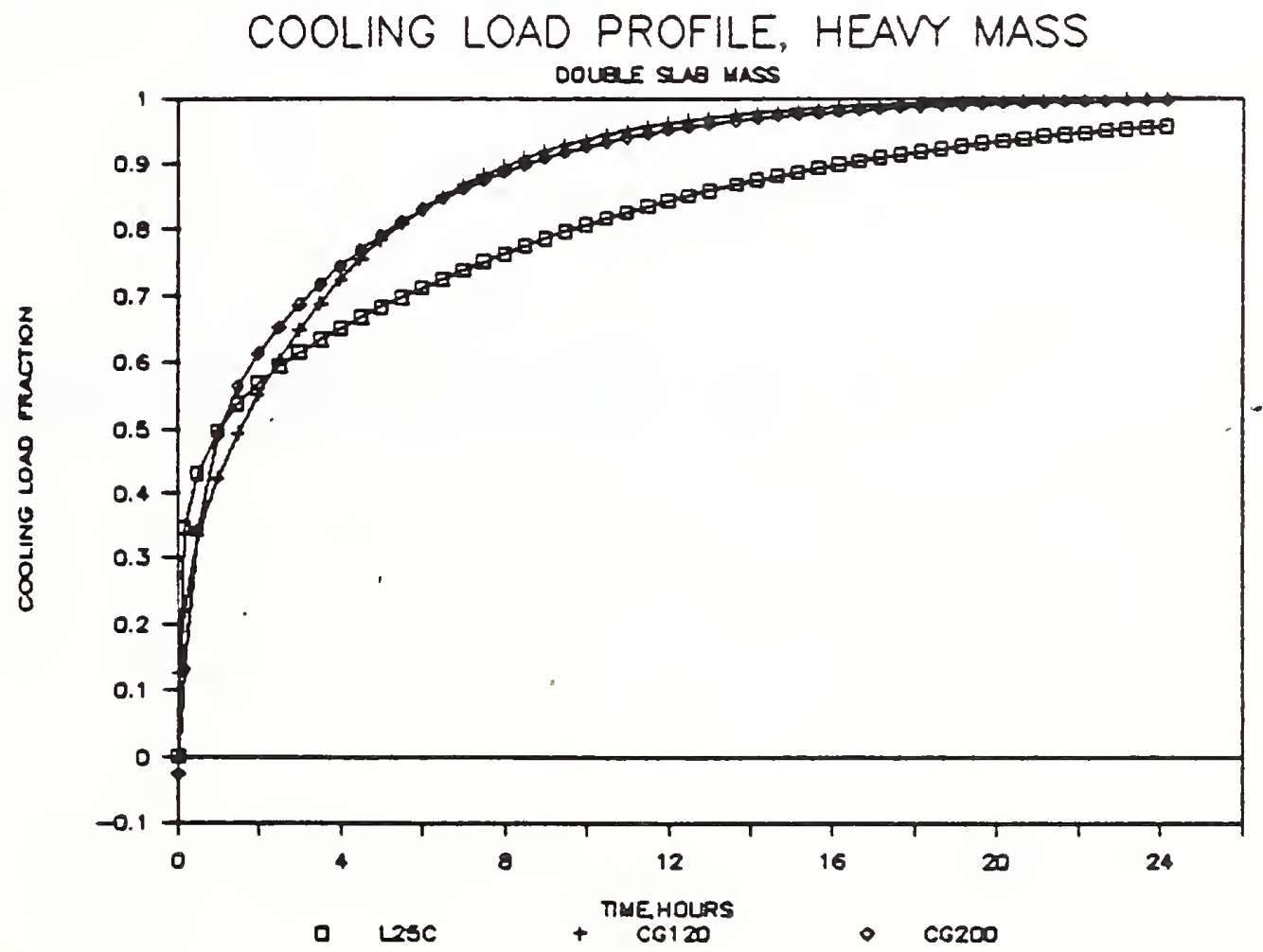

Figure 7.8 Cooling Load Profile for Heavy Thermal Mass Room, Celling Return, 120 cfm 


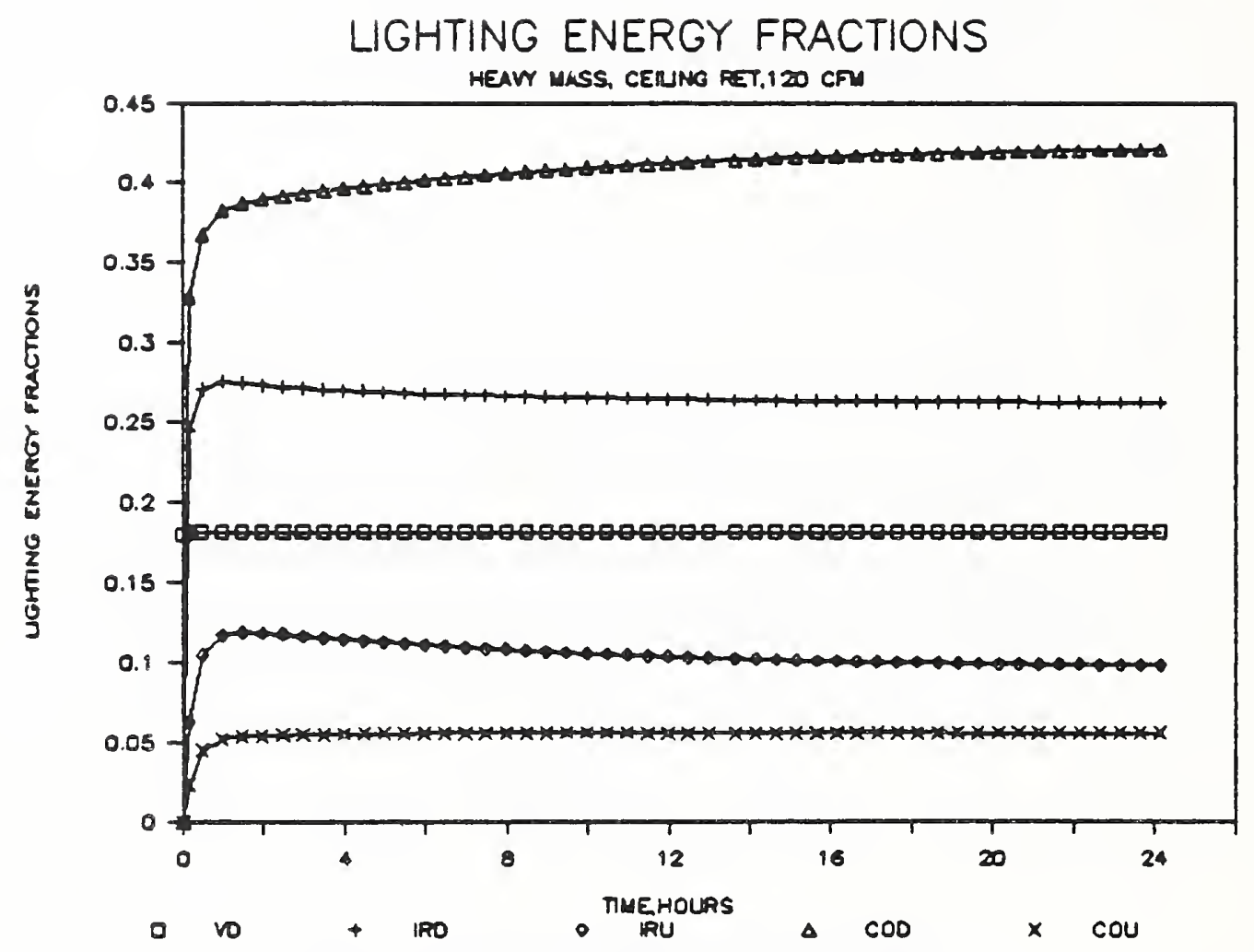

Figure 7.9 Lighting Energy Distribution Fractions Versus Time, Heavy Thermal Mass Room, Ceiling Return, 120 cfm 
Examination of the measurement and simulation results completed thus far reveals a series of preliminary general results related to the interaction of the lighting and HVAC system, and the room. The similarities and differences between the results for the different test conditions help to illuminate the factors which contribute to the energy and thermal performance of lighting systems in actual room environments. This information, in turn, will have potential impact on design considerations for lighting and HVAC systems.

One point is that although massive room components such as the floor slab may respond slowly to the effects of the lighting system, the luminaires themselves reach equilibrium relatively quickly, in two to three hours. Thus, the airflow conditions in the room should be selected so that the luminaires are at their most efficient operating point. For the type and size of the luminaire tested, lamp compartment return was required to achieve this. For 2-tube luminaires instead of 4-tube, the side slot or ceiling grill return may have been sufficient at high enough airflow rates. Two-tube luminaires are scheduled for future testing.

Lamp compartment return cools the lamps significantly more than the side slot or ceiling grill return. The performance with the side slots and ceiling grill were very similar. It may be adequate to lump these two return configurations into a single category for design considerations.

Most of the heat storage, about 60 percent was in the floor slabs. The portions of the sidewalls above the suspended ceiling stored about the same amount of heat as the room walls, their smaller volumes being compensated by higher equilibrium temperatures with the lights on. The room walls do not store much heat, due to relatively low thermal mass and small elevations in temperature above room air temperature. Convection at the room walls must be sufficiently high to keep the walls cool. If wall convective heat transfer could be reduced at the walls, more heat storage could occur. This could be accomplished by keeping the supply and return air registers away from the walls, where possible. Lowering airflow rates would also allow more heat storage.

From the point-of-view of controlling peak cooling load, the optimum cooling load profile due to cyclic operation of the lights would be a horizontal line. The height of the line would equal the product of the lighting power and the fraction of the day the lights are on. This minimum peak cooling load to remove the heat from the lights is given by:

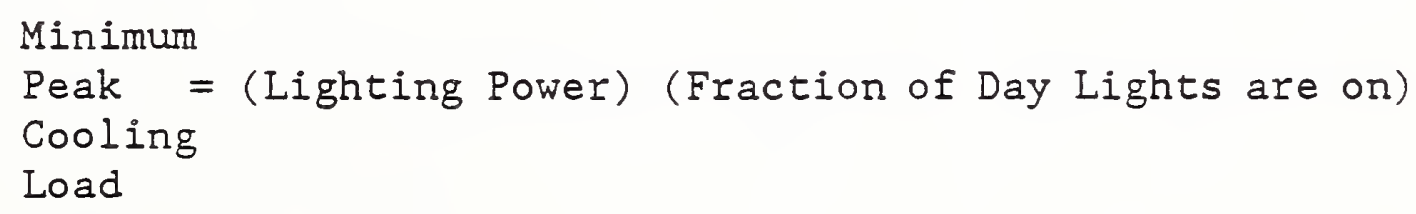

For these tests, lighting power averaged 750 watts. The minimum peak cooling load for 10 hour cyclic operation is 42 percent of the lighting power, or 313 watts. This is significantly less than the 90 percent values observed for the test conditions. 
In order to make the cooling load profiles for cyclic operation of the lights determined from these tests into a straight line with zero slope, the value for the regression coefficient $B$ would have to be smaller, and the $A$ values larger. Increasing $A$ corresponds to decreasing the initial cooling load by storing more heat. This must be accomplished while still cooling the lamps to an efficient operating point. Reducing $B$ corresponds to increasing long term heat storage, by adding more thermal mass. Adding furnishings would increase $B$.

Another way to look at this point would be to to cool the room at high airflow rates in the morning, then reduce airflow rates in the afternoon to force more of the lighting energy into storage. In this manner, the heat storage capacity is restored in the morning for use later in the day. A side benefit of reducing airflow rates in the afternoon is that lighting power could go down due to higher lamp temperatures. This is a double-edged sword though, because visible light output also goes down.

Of the heat storage in the room floor, more of the heat gain comes from the plenum below then from the room. There is a net flow of heat from the plenum into the slab above when the lights are turned on, then into the room when the lights are turned off. An equal amount of heat is lost through the ceiling slab above. Insulating the room from the plenum below could reduce the heat gain to the room. This could be accomplished by adding carpeting and padding. This would allow the floor and plenum to heat up more, thus storing more heat. Storing heat in the plenum is desirable since it is an unoccupied space with no comfort requirements. In contrast, as more heat is stored in the room, the impacts on thermal comfort should not be overlooked. As radiant temperatures increase, lower air temperatures or higher airflow rates are required to maintain equivalent comfort conditions [As77].

Topics for consideration for future research would include looking at the effects of carpet, and the effects of different supply air diffusers. Also, the effects of variable air volume operation on cooling load profiles would be of interest. The effects of different luminaire types and different lighting power densities on the steady state and transient performance of the lighting and cooling systems also are of interest. Other potential items for testing consideration include other lamp types and dimming controls. 


\section{Conclusions}

This interim report summarizes preliminary results regarding the effect of interactions between building lighting, heating and cooling systems on the energy performance of the lighting systems, and cooling loads due to lighting. The evaluation consisted of full-scale measurements and related computer simulations.

A unique test facility was designed, constructed and operated to emulate an office space with recessed fluorescent lighting system, surrounded by similar spaces on all six sides. The test facility was specially instrumented to record energy usage, cooling load, heat flows, temperatures and light levels. Measurements were made every twelve seconds and averaged over two minute intervals.

Steady state tests of lighting system performance demonstrated the temperature dependence of the light output and power consumption of the lighting system, which consisted of four luminaires with four lamps each. Temperature dependent correlations were derived for light output and lighting power, based on the measurements. Changes in room air temperature of $5^{\circ} \mathrm{F}$ produced 4 to $5{ }^{\circ} \mathrm{F}$ changes in room surface temperatures, and about $3^{\circ} \mathrm{F}$ change in minimum lamp temperature. Lighting power and light output varied about five percent for the range of conditions tested. The return plenum configuration provides some cooling for the luminaire even at the lowest airflow rate.

Airflow rate was observed to have a modest but predictable effect on lighting thermal performance, increasing convective transfer from the luminaire. Return air configuration had a much greater effect, particularly lamp compartment extract. Minimum lamp temperatures were an average of seven degrees less for the lamp compartment extract than either the ceiling grill or side slot returns, meaning greater light output and higher efficiency. The results for the ceiling grill and side slots were generally similar.

Results from transient measurements were generally similar for all test conditions, except for the lamp compartment return. More heat storage occurred under that configuration, especially at the lowest airflow rate. ASHRAE-type weighting factors were computed from measurements for all the test conditions.

A new double exponential curve fit was developed to improve the fit between the measured cooling load profile and the calculated profile. The weighting factors corresponding to the new curve fit were derived. Regression coefficients and extended weighting factors were determined from measurement data for each test condition. A set of regression coefficients and weighting factors was determined for the average of all the test conditions. Calculations using the weighting factors showed that for 10 hours-on daily cyclic lighting system usage, the steady periodic peak cooling load would be about 90 percent of lighting power for the conditions tested. The weighting factors can be used to determine cooling load due to any arbitrary lighting schedule. For the conditions tested, approximately 24 hours was required for the room to reach equilibrium. Doubling the floor mass reduced peak cooling load by 17 percent. 
Heat storage occurred mainly in the slabs, accounting for approximately 60 percent of total heat storage. The room walls and plenum walls stored equivalent amounts, as the plenum walls heated up about four times as much. More heat enters the floor slab from the lower plenum than the room, and more floor slab heat is discharged into the room than returns to the plenum below, leaving a net heat gain to the room. This is matched by a heat loss through the ceiling.

On average, about 57 percent of the total room cooling load was picked up in the plenum, leaving 43 percent due to room loads. The individual lighting energy distribution fractions were determined from computer simulations and tabulated. These values can be used as input values for building energy analysis computer programs.

The impact of the measurement results on design considerations was discussed. The lamp compartment return was seen to be very effective at keeping the lamps at a cool and efficient operating condition. Operating the fans at high speed in the morning and low speed in the afternoon was suggested as a way to reduce peak cooling loads. Reduction of convection at the room walls would allow for more heat storage in those elements. A carpeted floor would force more heat storage in the plenum. The plenum is the most desirable heat storage location, because it has minimal comfort effects. More mass in the floor or walls would reduce peak cooling loads, as would the addition of furnishings.

In closing, preliminary results from this research showed that lighting systems can be constrained to operate at their most efficient level, through manipulation of the thermal environment via the air temperature, airflow rate and return air configuration. A unique test facility was designed, built and operated, with a movel design to maintain thermal boundary conditions. The experimental plan, and test facility control system are original. A unique set of steady-state and transient measurements was collected and analyzed. A new regression correlation was developed to improve the fit between measured and calculated cooling load, and new weighting factors derived. . From analysis of the measurements, the energy distribution, and storage fractions were determined, both unique efforts. A detailed computer model was developed, calibrated and validated. Based on the measurements and modeling, design recommendations and considerations were developed. 


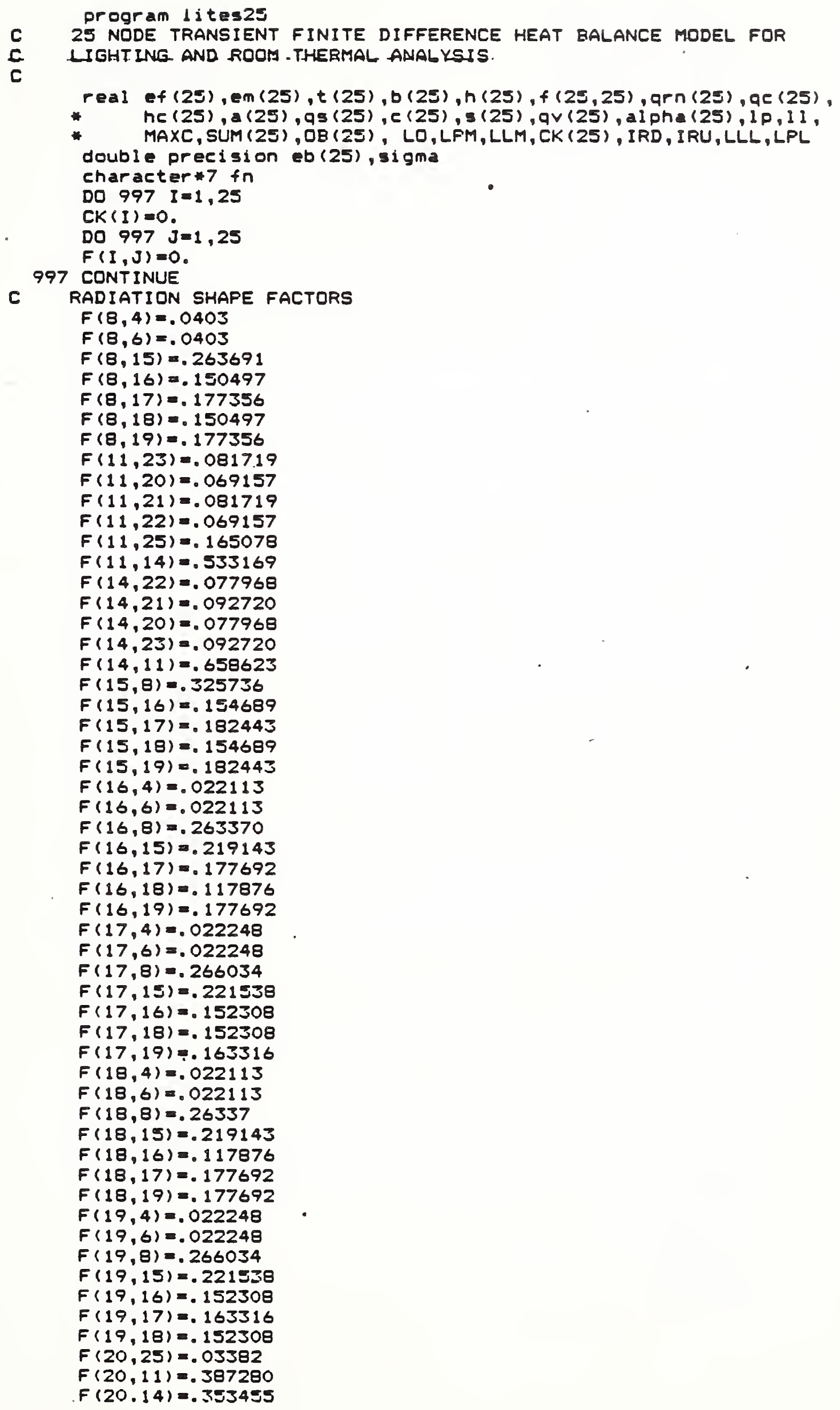




$$
\begin{aligned}
& F(20,21)=.092776 \\
& F(20,22)=.059893 \\
& F(20,23)=.092776 \\
& F(21,25)=.031964 \\
& F(21,11)=.39225 .3 \\
& F(21,14)=. \$ 60284 \\
& F(21,20)=.079522 \\
& F(21,22)=.079522 \\
& F(21,25)=.056455 \\
& F(22,25)=.03 .582 \\
& F(22,11)=. .387280 \\
& F(22,14)=.355455 \\
& F(22,20)=.03989 .3 \\
& F(22,21)=.002776 \\
& F(22,23)=.092776 \\
& F(23,25)=.031964 \\
& F(23,11)=.592255 \\
& F(23,14)=.360284 \\
& F(25,20)=.079522 \\
& F(25,21)=.056455 \\
& F(23,22)=.079522 \\
& F(25,25)=.031964 \\
& F(4,6)=.5 \\
& F(4,8)=.2115825 \\
& F(4,16)=.066 .359 \\
& F(4,17)=.077868 \\
& F(4,18)=.066 .39 \\
& F(4,19)=.077868 \\
& F(6,4)=.5 \\
& F(6,8)=.2115825 \\
& F(6,16)=.0663 .39 \\
& F(6,17)=.077868 \\
& F(6,18)=.066 .5 .59 \\
& F(6,19)=.077868 \\
& F(25,11)=.866664 \\
& F(25,20)=.031707 \\
& F(25,21)=.0 .54961 \\
& F(25,22)=.051707 \\
& F(25,25)=.034961
\end{aligned}
$$

C SUFFACE AFIEAS

$$
\begin{aligned}
& a(1)=0 . \\
& a(2)=0 .
\end{aligned}
$$$$
a(B)=0 \text {. }
$$

$a(4)=32$.

$A(5)=1.50$

$A(6)=52$.

$A(7)=52$.

$A(8)=168$.

$A(9)=168$.

$A(10)=168$.

$A(11)=168$.

$A(12)=168$.

$A(15)=158$.

$A(14)=1.56$.

$A(15)=1.56$.

$A(16)=96$.

$A(17)=112$.

$A(18)=96$.

$A(19)=112$.

$A(20)=30$.

$A(21)=35$.

$A(22)=20$

$A(25)=55$.

$A(24)=30$

$A(25)=.2$.

C STAFIING. IEMFEFGTURES 
DO $999 I=1,25$

$T(I)=75$.

999 CONTINUE

C

THERMAL CAPACITANCE

$C(1)=25.97$

$c(2)=8.11$

$c(3)=.155$

$c(4)=3.0$

$C(5)=6.0$

$C(6)=17.0$

$C(7)=1.44$

$C(8)=359.4$

$c(9)=359.4$

$C(10)=359.4$

$C(11)=359.4$

$C(12)=359.4$

$C(13)=359.4$

$C(14)=13.23$

$C(15)=13.23$

$C(16)=52$.

$C(17)=121.4$

$c(18)=52$.

$C(19)=60.7$

$C(20)=16.3$

$C(21)=37.7$

$C(22)=16.3$

$C(23)=14.6$

$C(24)=158.4$

$C(25)=8.49$

C CONDUCTANCES

$C K(5)=12$

$C K(6)=12$.

$C K(8)=870.91$

$C K(9)=870.91$

CK $(10)=870.91$

$C K(11)=870.91$

$C K(12)=870.91$

$C K(13)=870.91$

$C K(14)=89.04$

CK $(15)=89.04$

C SURFACE EMITTANCE

DO $998 \quad I=1,25$

$\operatorname{en}(I)=.9$

$S(I)=0$.

998 CONTINUE

$E M(7)=0$.

$E M(5)=0$.

$E M(9)=0$

$E M(10)=0$

$E M(12)=0$

$E M(13)=0$.

$E M(24)=0$.

C LIGHTING POWER

$1 \mathrm{pm}=2628$.

C BALLAST FRACTION

$B A L F=0.15$

C SHORT WAVE FRACTIONS

$s(1)=0$.

$s(2)=0.0$

$s(3)=0$.

$s(4)=0.0296$

$S(6)=0.0734$

$S(7)=0.0$

$S(8)=.4930$

$S(15)=0.0269$. 


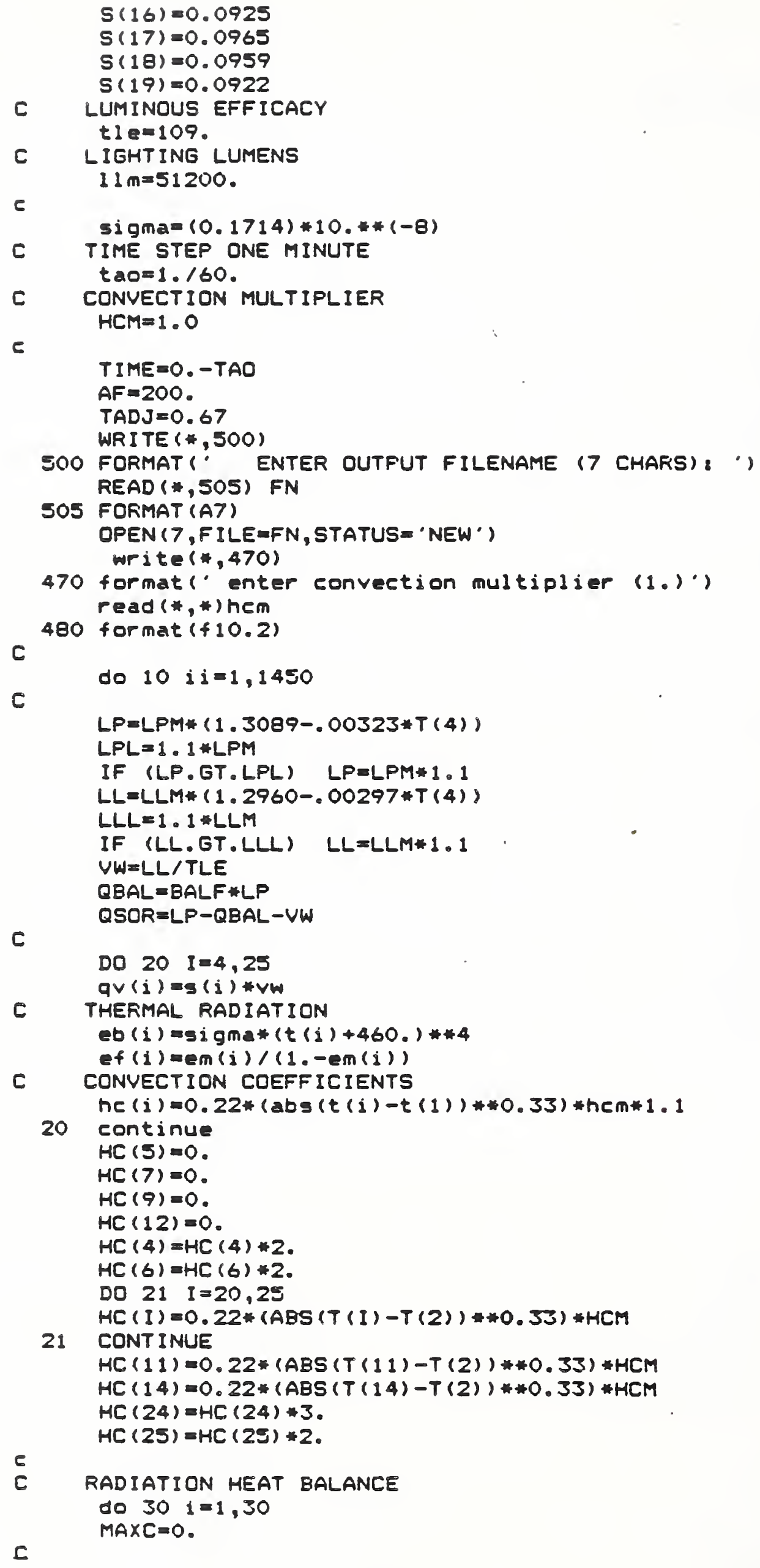




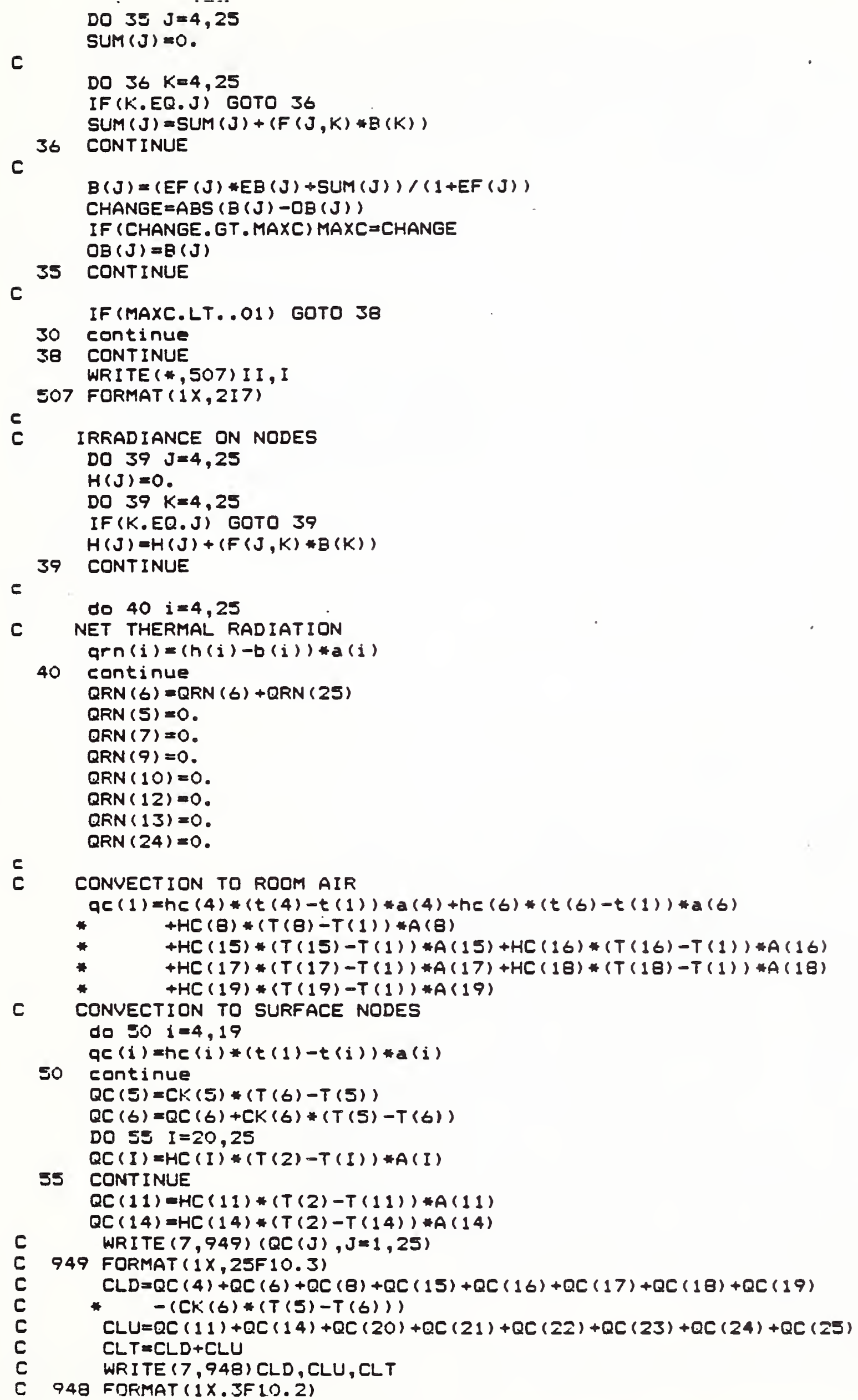


$Q C(14)=Q C(14)+C K(14) *(T(15)-T(14))$

$Q C(15)=Q C(15)+C K(15) *(T(14)-T(15))$

$Q C(8)=C K(8) *(T(9)-T(B))+Q C(B)$

$Q C(9)=C K(9) *(T(8)-T(9))+C K(9) *(T(11)-T(9))$

$Q C(11)=C K(11) *(T(12)-T(11))+Q C(11)$

$Q C(12)=C K(12) *(T(11)-T(12))+C K(12) *(T(8)-T(12))$

$Q C(6)=Q C(6)+Q C(25)$

C

HEAT STORAGE

QS $(1)=q C(1) *$ tao

do $60 \quad i=4,25$

c

$q s(i)=(q r n(i)+q c(i)+q v(i))=t a 0$

C

ADD LAMP SOURCE HEAT

$Q S(4)=Q S(4)+Q S O r$ tao

$Q S(5)=Q B A L * T A Q+Q S(5)$

QS $(2)=T A O *(H C(25) *(T(25)-T(2)) * A(25)+H C(11) *(T(11)-T(2)) * A(11)$

$* \quad+H C(14) *(T(14)-T(2)) * A(14)+H C(20) *(T(20)-T(2)) * A(20)$

* $+H C(21) *(T(21)-T(2)) * A(21)+H C(22) *(T(22)-T(2)) * A(22)$

$* \quad+H C(23) *(T(23)-T(2)) * A(23)+H C(24) *(T(24)-T(2)) * A(24)$

* $\quad-(A F * .0805 * .24 * 60 * T A D J *(T(2)-T(1))))$

$Q 41=H C(4) *(T(4)-T(1)) * A(4)$

Q61 $=H C(6) *(T(6)-T(1)) * A(6)$

$Q 71=H C(7) *(T(7)-T(1)) * A(7)$

$Q 62=H C(25) *(T(25)-T(2)) * A(25)$

$C L=Q S(1)+(A F * 60 . * T A D J * .0805 * .24 *(T(2)-T(1))) * T A O$

c

\section{COMPUTE TEMFERATURE CHANGES}

do $70 i=2,25$

$t(i)=t(i)+a s(i) / c(i)$

continue

$T(25)=T(6)$

$T(10)=T(11)$

$T(13)=T(8)$

Cl $f=c 1 /(1 D * T A Q)$

$T$ IME $=$ TIME + TAQ

$Q 48=A(4) * B(4) * F(4,8)-B(8) * A(8) * F(8,4)$

$Q 416=B(4) * A(4) * F(4,16)-B(16) * A(16) * F(16,4)$

$Q 417=B(4) * A(4) * F(4,17)-B(17) * A(17) * F(17,4)$

$Q 418=B(4) * A(4) * F(4,18)-B(18) * A(18) * F(18,4)$

$Q 419=B(4) * A(4) * F(4,19)-B(19) * A(19) * F(19,4)$

$Q 68=B(6) * A(6) * F(6,8)-B(8) * A(8) * F(8,6)$

$Q 616=B(6) * A(6) * F(6,16)-B(16) * A(16) * F(16,6)$

$Q 617=B(6) * A(6) * F(6,17)-B(17) * A(17) * F(17,6)$

$0618=B(6) * A(6) * F(6,18)-B(18) * A(18) * F(18,6)$

$Q 619=B(6) * A(6) * F(6,19)-B(19) * A(19) * F(19,6)$

$Q 78=B(7) * A(7) * F(7,8)-B(8) * A(8) * F(8,7)$

$Q 716=B(7) * A(7) * F(7,16)-B(16) * A(16) * F(16,7)$

$0717=B(7) * A(7) * F(7,17)-B(17) * A(17) * F(17,7)$

$Q 718=B(7) * A(7) * F(7,18)-B(18) * A(18) * F(18,7)$

$Q 719=B(7) * A(7) * F(7,19)-B(19) * A(19) * F(19,7)$

$Q 611=B(25) * A(25) * F(25,11)-B(11) * A(11) * F(11,25)$

$Q 620=B(25) * A(25) * F(25,20)-B(20) * A(20) * F(20,25)$

$Q 621=B(25) * A(25) * F(25,21)-B(21) * A(21) * F(21,25)$

$Q 622=B(25) * A(25) * F(25,22)-B(22) * A(22) * F(22,25)$

$Q 623=B(25) * A(25) * F(25,23)-B(23) * A(23) * F(23,25)$

$I R D=(Q 48+Q 416+Q 417+Q 418+Q 419+Q 68+Q 616+Q 617+Q 618+Q 619) / L P$ $I R U=(0611+Q 620+Q 621+0622+Q 623) / L P$

$C O D=(Q 41+Q 61) / L P$

$\mathrm{CQU}=Q 62 / L P$

$V D=V W / L P$

$V U=0$.

$C O R=0$.

$S T R=1 .-V D-V U-I R D-I R U-C O D-C O U-C O R$ 


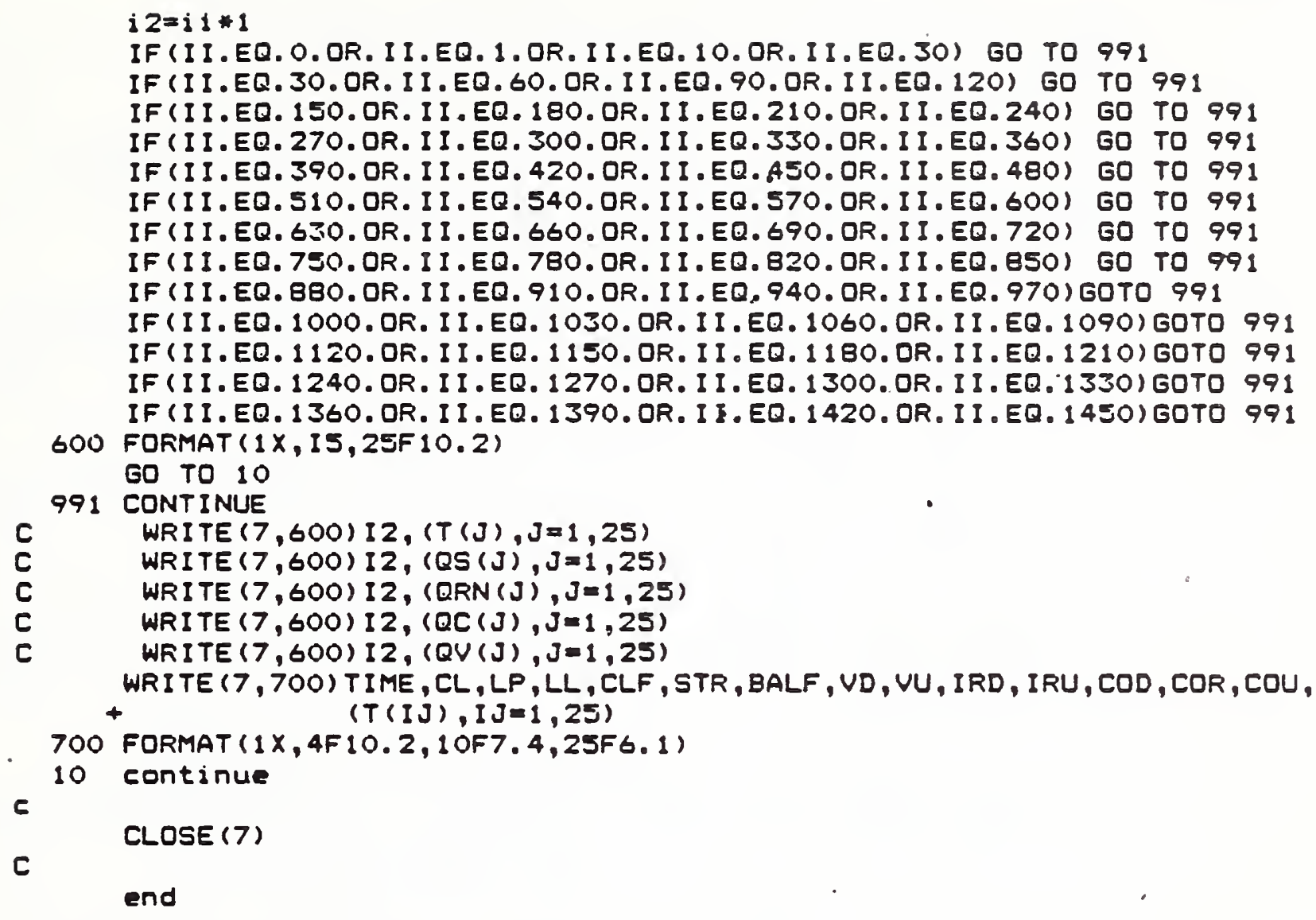


As77 American Society of Heating, Refrigerating and Air Conditioning Engineers, Handbook of Fundamentals, 1979.

Ba83a Ball, H.D., Green, D., The Impact of Lighting Fixtures on Heating and Cooling Loads - Mathematical Model, ASHRAE Transactions Vol. 89, Pt 2A and B, 1983.

Ba83b Ball, H.D., The Impact of. Lighting Fixtures on Heating and Cooling Loads - Application to Design, ASHRAE Transactions, Vol. 89, Pt 2A and B, 1983.

Ba64 Ballman, T.L., Bradley, R.D., Hoelscher, E.C., Calorimetry of Fluorescent Luminaires, Illuminating Engineering, Dec. 1964, pg. $779-785$.

Ba65 Ballman, T.L. Mueller, T., Fluorescent Luminaire Calorimetry: Principles and Procedures, ASHRAE Transactions Vol. 71, Pt 1 , 1965, pg. 51-60.

Be77 Bedocs, L., Godfrey, R.L., Sanford, T.P., Air-handling Luminaires and Plenum Exhaust Systems, Lighting Research and Technology, Vol. 9, No. 2, 1977, pg. 73-84.

Bo63 Bonvallet, G.G., Method of Determining Energy Distribution Characteristics of Fluorescent Luminaires, Illuminating Engineering, Feb., 1963, pg. 69-74.

Bo77 Boyce, P.R., Air-Handling Luminaires, Lighting and Environmental Design, Vol. 70, No. 6, Nov. 1977, pg. 243-276.

Bo66 Boyer, L.L., The Role of the Supply-Air Plenum in Interior zone Recessed Illumination Systems, Illuminating Engineering, Aug. 1966, pg. 528-533.

Bo67 Boyer, L.L., Thermal Environment in Perimeter Office Spaces Cooled with Ventilating Ceilings, ASHRAE Transactions, Vol. 71 , Pt 1, 1967.

Bo68a Boyer, L.L., Radiant Panel Effects of Floor-Ceiling Assemblies Incorporating Static, Return and Supply Plenums, ASHRAE Transactions, Vol. 74, Pt II, 1968, pg. 31-42.

Da40 Darley, W.G., Three in One-Light, Sound and Air Conditioning, Magazine of Light, Vol. 9, No. 2, Feb. 1940, pg. 27-29.

Do79 DoE-2 Users Guide, Lawrence Berkeley Laboratory and Los Alamos Scientific Laboratory, U.S. Dept. of Energy, Contract W-7405ENG-48. Feb. 1979.

Du64a Dunn, G.W., Gilleard, G,. Schmidt, R.D., Advanced Electrical Space Conditioning, Illuminating Engineering, Jan. 1964, pg. 43-51. 
Du64b Dunn, G.W., Gilleard, G., Schmidt, R.D., A Field Study of an Application of the Heat Transfer Lighting Fixture, ASHRAE Transactions, Vol. 70, 1964, pg. 347-353.

El33 Electrical World, Removing heat from High-Intensity Lighting, April 15, 1933, pg. 480-481.

Fi76 Finn, J.F., Efficient Application of Lighting Energy-a Luminaire Air Heat Transfer Evaluation, Lighting Design and Application, Jan. 1976, pg. 40-43.

Fi65 Fisher, W.S., Roehr, L. A., Smith, J.M., Some Factors Affecting Heat Transfer in Luminaires, Illuminating Engineering, Jan. 1965, pg. 51-60.

Fi66 Fisher, W.S., Stephens, W.R., Skerkoski, E.C., Electrical Space Conditioning in a Remodeled Office Building, Illuminating Engineering, March 1916, pg. 150-168.

Fi70 Fisher, W.S., Weinstein, S., Heat Transfer with Hegh Intensity Discharge Lamps and Luminaires, Illuminating Engineering, April 1970, pg. 185-192.

He41 Heating, Piping and Air Conditioning, Lighting and Air Conditioning Design Factors, Sept. 1941, pg. 605-608.

He66 Henderson, T.A., Heat Transfer from Ceiling Plenums, Air Condition, Heating and Ventilating, Nov. 1966, pg. 72-76.

Hi79 Hittle, D., The Building Loads Analysis and System Thermodynamics (BLAST) Program, Version 2.0, Users Mannual Vol. 1 and Vol. 2, Technical Report E-153/ADA072272 and ADA722730, U.S. Army Construction Engineering Research Laboratory, June 1979.

Ie56 Illuminating Engineering, Lighting and Air Conditioning, Sept. 1956, pg. 647-652.

Ie66 Illuminating Engineering, Lighting and Air Conditioning, March 1966, pg. 123-147.

Ie68 IES Transaction, Photometric and Thermal Testing of Air and Liquid Cooled Heat Transfer Luminaires, Sept. 1968, pg. 485497.

Ie72 IES Lighting Handbook, 5th Edition, Illuminating Engineering Society of North America, 1972.

Je73 Jewess, W., Pinniger, J.H., Thermal Effects in Lighting Equipment, Light and Lighting, Vol. 66, No. 9, Sept. 1973.

Ki68 Kimura, K., Stephenson, P.G., Theoretical Study of Cooling Load Caused by Lights, ASHRAE Transactions, Vol. 74, Pt II, 1968. 
Lu38 Luckiesh, M., Cooler Footcandles, Magazine of Light, Year End, 1938, pg. 23-38.

Ma71 Mathews, C.P., Ceiling Temperature Equations, Building Systems Design, April, 1971, pg. 37-38.

Ma84 Maya, J., Grossman, M.W., Lagushenko, R., Waymouth, J.F., Energy Conservation Through More Efficient Lighting, Science, Oct. 26, 1984, pg. 435-436.

Mc76 McIntyre, D.A., Radiant Heat from Lights and its Effect on Thermal Comfort, Lighting Research and Technology, Vol. 8, No. 3, 1976, pg. 121-128.

Mc83 Mckinley, A.D., Mitalas, G.P., Room Thermal Transfer Functions, - Computer Programs to Calculate z-Transfer Function Coefficients for Rooms, Computer Program No. 52, National Research Council Canada, De. 1983.

Me63 Meckler, G., Meckler, M., Design and Evaluation of Dynamically Integrated Lighting-Air Conditioning Systems, Illuminating Engineering, Feb. 1963, pg. 75-85.

Me64 Meckler, G., Pennington, C.W., Humphreville, T.N., Energy Integrated Lighting-Heating-Cooling System, ASHRAE Transactions, Vol. 70, 1964, pg. 335-346.

Mi71 Mitalas, G.P., Kimura, K., A Calorimeter to Determine Cooling Load Caused by Lights, ASHRAE Transactions, Vol. 77, Pt II, 1971, pg. 65-72.

Mi72 Mitalas, G.P., Transfer Function Method of Calculating Cooling Loads, Heat Extraction and Space Temperature, ASHRAE Journal, Vol. 14, No. 12, Dec. 1972 pg. 54-56.

Mi73 Mitalas, G.P., Calculating Cooling Load Caused by Lights, ASHRAE Journal, Vol. 15, No. 6, June 1973. pg. 37-40.

Mi74 Mitalas, G.P., Cooling Load Caused by Lights, Transactions Canadian Society for Mechanical Engineering, Vol. 2, No. 3, 1973-74, pg. 169-174.

Mi78 Mitalas, G.P., Comments on the z-Transfer Function Method for Calculating Heat Transfer in Buildings, ASHRAE Transactions, Vol. 84, Pt 1, 1978, pg. 667-674.

Mi83 Mitalas, G.P., Room Dynamic Thermal Response, DBR Paper No. 1189, National Research Council Canada, 1983.

Mo40 Mortensen, M.A., Continuous Trough Lighting, Magazine of Light, Vol. 9, No. 2, Feb. 25, 1940, pg. 30.

Mu62 Mueller, T., Benson, B.Sg., Testing and Performance of HeatRemoval Troffers, Illuminating Engineering, Dec. 1962, pg. 793802 . 
Mu85 Murdoch, J.E., Illuminating Engineering, Macmillan Publishing Co., New York, 1985.

Ne71 Nevins, R.G., Straub, H.E., Ball, H.D., Thermal Analysis of Heat Removal Troffers, ASHRAE Transactions, Vol. 77, Pt II, 1971, pg. 58-64.

No69 Nottage, H.B., Park, K.S., Performance of a Ventilated Luminaire, ASHRAE Transactions, Vol. 75, Pt I, 1969, pg. 50-70.

Ob70. O'Brien, P.F., Krumland, L.R., An Investigation of the Luminous and Thermal Radiative Transfer Characteristics of Luminaires, Illuminating Engineering, April 1970, pg. 218-230.

Qu62 Quin, M.L., Bradley, R.D., Corrective Transfer of Lighting Heat Loads, Illuminating Engineering, Jan. 1962, 45-56.

Ro78 Raven, F.H., Automatic Control Engineering, McGraw-Hill Book Co., 1978 .

Ro76 Rowe, G.D., Selecting Recessed Fluorescent Troffers for Optimum Efficiency and Visual Comfort, Lighting Design and Application, Feb. 1976, pg. 18-23.

Si84 Siminovitch, M.J., Rubinstein, F.M. Verderber, R.R., Determining Lamp/Ballast System Performance with a TemperatureControlled Integrating Chamber, Journal of IES, Oct. 1984 , pg. 364-378.

Si85 Siminovitch, M.J., Rubinstein, F.M., Clark, T.A., Verderber, R.R., A Luminaire/Plenum/HVAC Simulator, IEEE-IAS Conf. Paper, Oct. 1985 .

Si87 Siminovitch, M.J., Rubinstein, F.M., Clark, T.A., Verderber, R.R., Maintaining Optimum Fluorescent Lamp Performance Under Elevated Temperature Conditions, Lighting Design and Application, Sept. 1987, pg. 35-41.

So72 Sowell, E.F., Environmental Radiation from Fluorescent Ceiling Systems, Ph.D. Dissertation, University of California, Los Angeles, 1972 .

So73 Sowell, E.F., O'Brien, P.F., The Transport of Lighting Energy, ASHRAE Transactions, Vol. 79, Pt II, 1973, pg. 172-182.

So74 Sowell, E.F., A General Model for the Transport of Lighting Thermal Power, Second Symposium on the Use of Computers for Environmental Engineering, Paris, France, 1974, pg. 85-113.

Sp84 Spitler, J.D., An Experimental Study of Interior Convective heat Transfer in Buildings, Masters Thesis, University of Illinois at Urbana-Champaign, 1984. 
St69 Steck, B., European Practice in the Integration of Lighting, Air Conditioning and Acoustics in Offices, Lighting Research and Technology, Vol. I, No. 1, 1969.

Sy64 Sylvester, G.C., Performance of Heat-Removal Troffer with a Specific Building Design, ASHRAE Transactions, Vol. 70, 1964, pg. 328-334.

Un85 United States Department of Energy, Overview of Building Energy Use and Report of Analysis - 1985, Office of Building and Community Systems, Wash. DC, Oct. 1985.

Wa86 Walton, G.N., Algorithms for Calculating Radiation View Factors Between Plane Cover Polygons with Obstructions, NBSIR 86-3563, National Bureau of Standards, Oct. 1986. 
NBS.11AA IREV. 200C)

U.S. DEPT. OF COMM.

BIBLIOGRAPHIC DATA

SHEET (See instructions)

1. PUBLICATION OR REPORT NO.

NISTIR $88-3896$

DECEMBER 1988

4. TITLE AND SUBTITLE

The Interaction of Lighting, Heating and Cooling s stems in Buildings-Interim Report

\section{AUTHOR(S)}

Stephen I. Treado

6. PERFORMING ORGANIZATION (If joint or other than NBS, see instructions)

. ContracelGrant No.

\section{NATIONAL BUREAU OF STANDARDS \\ U.S. DEPARTMENT OF COMMERCE \\ GATTHERSBURG, MD 20899}

9. SPONSORING ORGANIZATION NAME AND COMPLETE ADDRESS (Street, City, Stote, ZIP)

8. Type of Repopt \& Period Covered

US DOE

10. SUPPLEMENTARY NOTES

Document describes a computer program; SF-185, FIPS Software Summary, is attached.

11. ABSTRACT (A 200-word or less foctual summary of most significont information. If document includes o significont bibliogrophy or literoture survey, mention it here)

The effect of interactions between building lighting, heating and cooling systems on the energy performance of the lighting system and cooling loads is examined, based on detailed full-scale measurements and supporting computer simulations. A test facility was designed, constructed and operated to emulate an office space with recessed fluorescent lighting. Special design features simulated adjacent building areas, providing realistic thermal boundary conditions for the test room. The test facility was extensively instrumented to monitor lighting power, cooling load, surface and air temperatures, heat flows and light levels. 398 measured parameters were averaged and recorded every two minutes during testing.

This interim report describes preliminary results from the research effort. The results showed that the lighting system can be constrained to operate at its most efficient level, if the fluorescent lamps are cooled sufficiently.

A two-term exponential relation with four regression coefficients was found to fit the measured data well. An extended set of weighting factors was derived based on the double exponential relation, and values computed from the measurements. Cooling load profiles due to cyclic operation of the lights were computed using the weighting factors Lighting energy distribution fractions were determined using a calibrated computer model Design considerations are discussed.

12. KEY WORDS (Six to twelve entries; olphobetical order; copitalize only proper names; and separate key words by semicolons) building energy, cooling, heat transfer, lighting, peakloads, weighting factors

13. AVAILABILITY

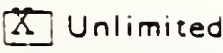

For Official Distribution. Do Not Release to NTIS

Order From Superintendent of Documents, U.S. Government Printing Office, Washington, D.C. 20402.

Order From National Technical Information Service (NTIS), Springfield, VA. 2216I
14. NO. OF

PRINTED PAGES

$$
152
$$

15. Price 

- 
